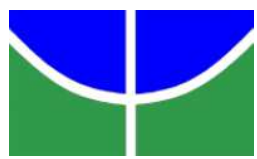

UNIVERSIDADE DE BRASÍLIA

FACULDADE DE CIÊNCIAS DA SAÚDE

PROGRAMA DE PÓS-GRADUAÇÃO EM NUTRIÇÃO HUMANA

CAFÉ DA MANHÃ: ASPECTOS NUTRICIONAIS E CULTURAIS ENTRE FREQUENTADORES ADULTOS DE RESTAURANTES POPULARES DO BRASIL

JANICE RAMOS DE SOUSA

BRASÍLIA - DF 2016 


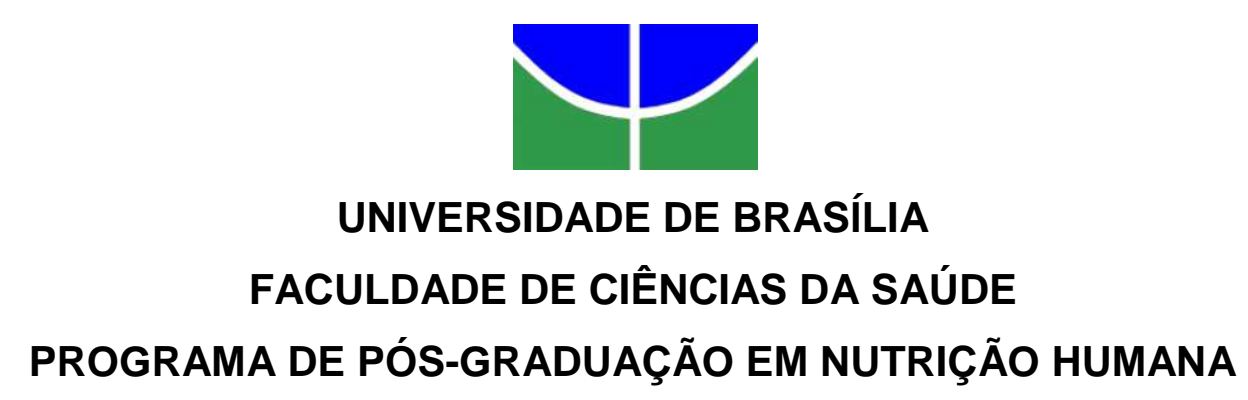

CAFÉ DA MANHÃ: ASPECTOS NUTRICIONAIS E CULTURAIS ENTRE FREQUENTADORES ADULTOS DE RESTAURANTES POPULARES DO BRASIL

Tese apresentada ao Programa de Pós-graduação em Nutrição Humana, da Faculdade de Ciências da Saúde, Universidade de Brasília, como parte das exigências para obtenção do título de doutora em Nutrição Humana.

Orientadora: Dr ${ }^{\mathrm{a}}$ Raquel Braz Assunção Botelho Coorientadora: Dra Rita de Cássia de A. Akutsu

JANICE RAMOS DE SOUSA

BRASÍLIA - DF 
Sousa, Janice Ramos de

CAFÉ DA MANHÃ: aspectos nutricionais e culturais entre frequentadores adultos de Restaurantes Populares do Brasil/ Janice Ramos de Sousa. Brasília, DF: 2016.

Tese (Doutorado) - Universidade de Brasília

Faculdade Ciências da Saúde, 2016.

Orientadora: Raquel Braz Assunção Botelho

Coorientadora: Drª Rita de Cássia de A. Akutsu 


\section{CAFÉ DA MANHÃ: ASPECTOS NUTRICIONAIS E CULTURAIS ENTRE FREQUENTADORES ADULTOS DE RESTAURANTES POPULARES DO BRASIL}

Tese apresentada ao Programa de Pós-graduação em Nutrição Humana como requisito para obtenção do título de doutora em Nutrição Humana.

10 Membro (Presidente): Drª . Raquel Braz Assunção Botelho Faculdade de Ciências da Saúde/ Departamento de Nutrição Universidade de Brasília

2ํㅡㄹ Membro: Drª Erika Barbosa Camargo Ministério da Saúde

3o Membro: Dra . Maria Natacha Toral

Faculdade de Ciências da Saúde/ Departamento de Nutrição Universidade de Brasília

4ํㅡㄹ Membro: Drª . Verônica Cortez Ginani

Faculdade de Ciências da Saúde/ Departamento de Nutrição Universidade de Brasília

5o Membro: Drª. Wilma Maria Coelho Araújo

Faculdade de Ciências da Saúde/ Departamento de Nutrição Universidade de Brasília

60 Membro (Suplente): Drª . Renata Puppin Zandonadi Faculdade de Ciências da Saúde/ Departamento de Nutrição Universidade de Brasília 
Data da aprovação:

\section{AGRADECIMENTOS}

Em primeiro lugar à divindade superior maior que me assiste em todos os momentos de desânimo e cansaço.

À prof ${ }^{a}$ Dra Raquel Braz de Assunção Botelho, minha orientadora, por ter acreditado em minha capacidade científica. Por ser um exemplo de mulher, de profissional, e de equilíbrio entre a vida pessoal e o excesso de trabalho próprio dos docentes. Todo o meu carinho e admiração!

À prof ${ }^{\text {a }}$ Dr ${ }^{\text {a }}$ Rita de Cássia de Almeida Akutsu, minha coorientadora, que me ensinou o caminho das pedras da metodologia científica e pelas orientações pertinentes a assuntos estatísticos. Sem saber, me foi exemplo de desprendimento.

À equipe de coleta de dados: Camila, Aline Lemos, Alinne Carrijo, Társia, Verônica, Carolina, Tiemmy, Katya e Simone. Um agradecimento especial à nutricionista Alinne de Paula Carrijo, que demonstrou disponibilidade em orientar e executar os dados no software de nutrição escolhido para o tratamento inicial dos dados.

À minha mãe pelo amor e pelo grande exemplo de luta e garra. À minha irmã Lúcia, pelo incentivo em minha carreira estudantil inicial, pelo amor de mãe dispensado a mim. À minha irmã Lucilene, pelo extremo exemplo de humildade.

Às minhas melhores amigas Débora e Rejânia pelo carinho e apoio direcionado a $\operatorname{mim}$.

Ao meu marido, Paulo César Peixoto, que mesmo achando que eu "forço a barra demais" com a minha forma exaustiva de estudar, sempre me apoiou com muita paciência, carinho e incentivo.

Ao meu filhote Fred Flintstones que se enroscava em meu pescoço ou pernas enquanto me debruçava ao computador. Ele ainda não sabe que é um lindo cachorrinho, pois se sente gente.

Ao meu saudoso pai que hoje habita no céu. Uma pessoa linda! Um exemplo de humildade jamais vista. Um anjo do Senhor! 
... Hoje me sinto mais forte, mais feliz quem sabe? Só levo a certeza de que muito pouco eu sei, que nada sei... ...Cada um de nós compõe a sua história e cada ser em si, carrega o dom de ser capaz e ser feliz ...

(Tocando em frente - Almir Sáter) 
SUMÁRIO

\section{RESUMO}

\section{ABSTRACT}

LISTA DE ILUSTRAÇÕES

\section{ESTRUTURA DA TESE}

1 INTRODUÇÃO

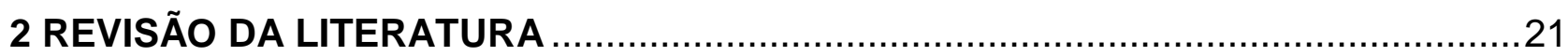

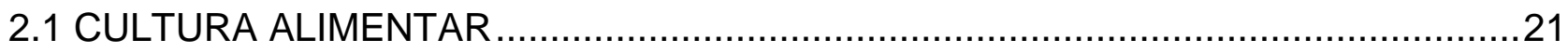

2.2 ALIMENTOS REGIONAIS, TRADICIONAIS OU TÍPICOS? ..................................27

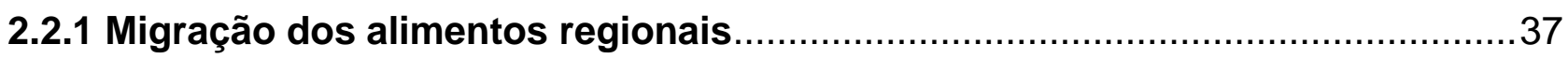

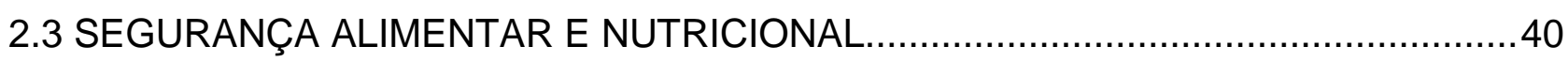

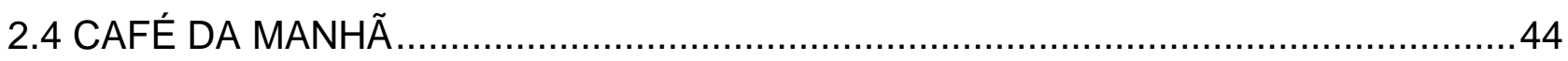

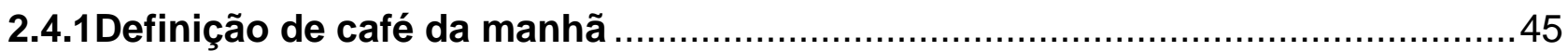

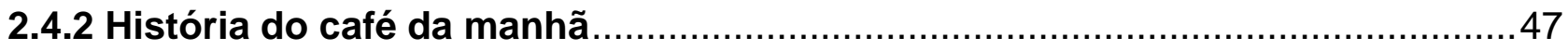

2.4.3 Variáveis relacionadas à supressão do café da manhã..................................49

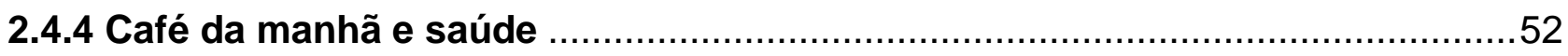

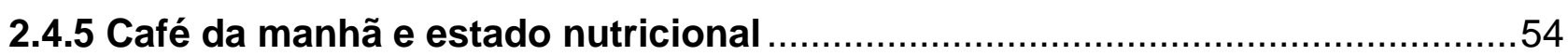

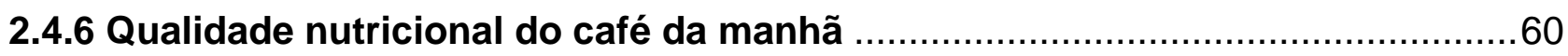

2.4.7 Contribuição energética do café da manhã no consumo de energia .................74

2.4.8 Alimentos do café da manhã brasileiro ............................................................

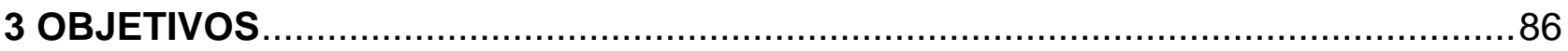

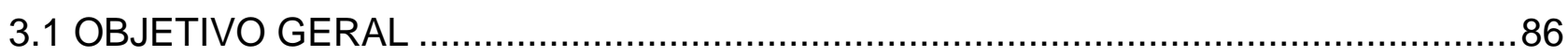

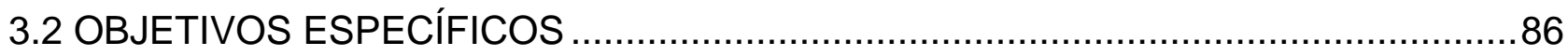

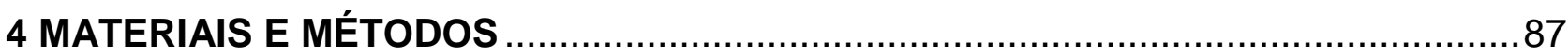

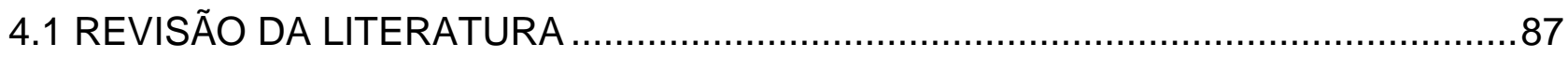

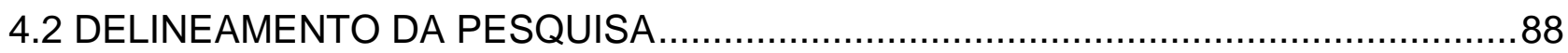

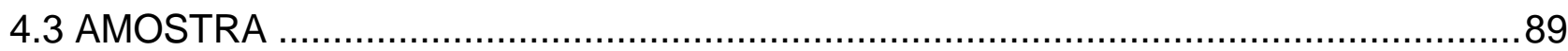

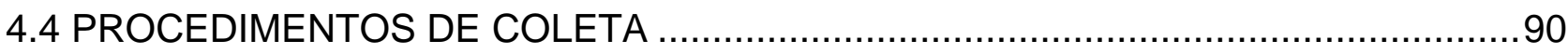

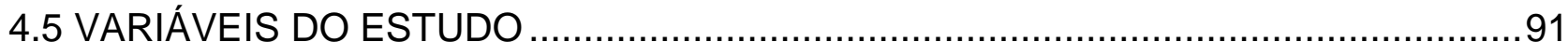

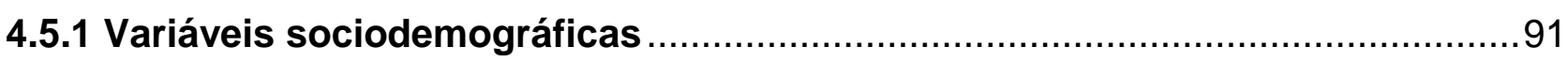


4.5.2 Análise do consumo alimentar 91

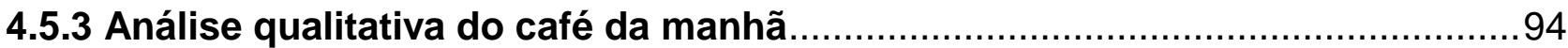

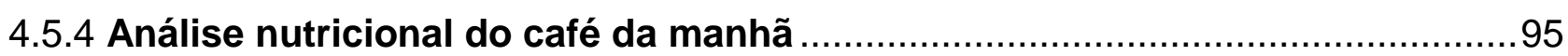

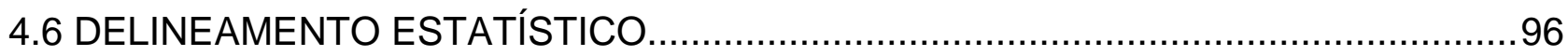

5 RESULTADOS

5.1 CAPÍTULO 1 - A regionalidade alimentar no café da manhã: uma revisão integrativa 99

5.2 CAPÍTULO 2 - A composição nutricional do café da manhã de usuários de Restaurantes Populares no Brasil.

5.3 CAPÍTULO 3 - Café da manhã: classificação, composição e regionalidade alimentar no Brasil..

6 CONCLUSÃO 192

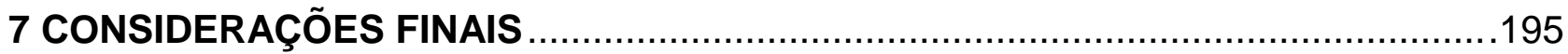

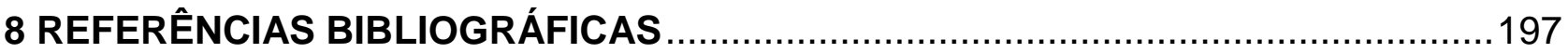

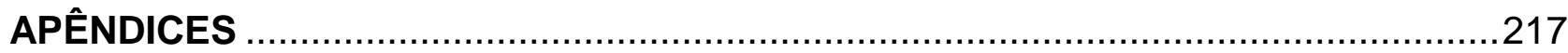




\section{RESUMO}

Diante do estilo de vida inadequado adotado no mundo moderno, o café da manhã (CM) é a refeição mais negligenciada. O baixo consumo de alimentos regionais nas principais refeições, sobretudo no $\mathrm{CM}$, pode indicar a não utilização de recursos alimentares locais de mais fácil acesso. Objetivo: Analisar a frequência de realização do café da manhã, sua composição nutricional e o hábito de consumo de alimentos regionais nessa refeição entre usuários adultos do Programa de Restaurantes Populares no Brasil. Materiais e Métodos: A primeira parte da pesquisa constitui-se de uma revisão bibliográfica do tipo integrativa, realizada no período de uma década nas bases de dados eletrônicas MEDLINE, LILACS e SciELO, com os seguintes descritores: "desjejum", "desjejum regional", "café da manhã" e "café da manhã regional". A segunda parte da pesquisa constitui-se de dois estudos transversais exploratórios com amostra total constituída por 1.872 indivíduos frequentadores de 36 restaurantes vinculados ao Programa Restaurantes Populares. Os indivíduos informaram três dias de recordatórios de 24 horas, cujos dados de consumo alimentar foram analisados por indivíduo, por unidade de restaurante e por região geográfica. $\mathrm{Na}$ análise da composição nutricional foram considerados os dados de 1.547 entrevistados, cujos foram analisados por sexo, faixa etária, renda per capita, escolaridade e região de consumo. Os grupos dos lácteos, cereais, frutas, raízes/tubérculos e carnes/ovos foram analisados pela frequência de consumo, independentemente do tamanho da porção ingerida. $O$ valor energético total, os macronutrientes, as fibras, os ácidos graxos monoinsaturados, saturados e trans foram analisados pelos valores de contribuição na recomendação de cada nutriente. O cálcio e o sódio foram avaliados em relação ao percentual de contribuição no dia de consumo. Para análise dos dados de consumo de alimentos regionais e classificação qualitativa do CM foi considerado o total da amostra de 1.872 usuários, cujos foram analisados por sexo, faixa etária, renda per capita, escolaridade, profissão, estado civil, participação em programas de governo e nacionalidade. Para a análise qualitativa do $\mathrm{CM}$ foi adotado um método que classifica a refeição de acordo com a presença/ausência dos alimentos: CM Padrão como a presença de alimentos fontes de cálcio e de energia; CM Completo como a presença de 
alimentos fontes de cálcio, energia, minerais, vitaminas e fibras; CM Incompleto como quaisquer outros alimentos que não contemplem as combinações do CM padrão ou CM completo; e CM Ausente ou supressão como a ausência total de consumo de alimento. Para análise dos marcadores de identidade alimentar do CM foram formados grupos de bebidas, cereais ou substitutos ricos em carboidratos complexos, complementos de cereais, frutas, açúcar, adoçante e alguns alimentos/preparações regionais. Resultados: na revisão integrativa, dos 242 artigos que atendiam aos critérios de inclusão, apenas 5 abordaram o tema regionalidade alimentar no CM. Tanto na análise da composição nutricional, como na análise qualitativa do CM houve predomínio de homens, de indivíduos na faixa etária entre 25 e 34 anos, com nível de escolaridade de ensino médio completo e faixa de renda per capita de 0,5 a um Salário Mínimo. Dos 4.641 CM previstos na análise da composição nutricional, 797 (17,2\%) não foram realizados sendo analisados 3.844 CM. A análise de grupos de alimentos mostrou alto consumo de lácteos e cereais, e baixos consumo de frutas, raízes/tubérculos e carnes/ovos. Os percentuais nacionais de contribuição energética dos macronutrientes no valor energético total foram adequados a uma dieta equilibrada. Os percentuais nacionais de contribuição dos ácidos graxos saturados e ácidos graxos trans se encontraram dentro da recomendação, sendo que a análise regional mostrou níveis de consumo elevados desses mesmos nutrientes na região Centro-oeste e de ácidos graxos saturados na região Nordeste. A média nacional da ingestão de fibras do CM foi baixa, concordando com o resultado encontrado de baixo consumo de frutas. $O$ consumo nacional de cálcio cobriu 73,49\% do esperado e o consumo de sódio foi adequado. Em relação à análise qualitativa e ao consumo de alimentos regionais, das 5.616 refeições previstas para os três dias de consumo, 17,3\% não foram realizadas, sendo analisados 4.642 CM. O CM do tipo padrão foi predominante em todas as regiões, e o $\mathrm{CM}$ completo foi pouco consumido entre os participantes. Os indivíduos que realizaram CM nos Restaurantes Populares consumiram mais alimentos regionais. A região com maior consumo de alimentos regionais foi a Centro-oeste $(46,6 \%)$ e a Sul $(45,9 \%)$, sendo os alimentos regionais mais consumidos em todas as regiões o presunto, o cuscuz e a laranja. Os alimentos mais consumidos no CM foram o café com leite (ou leite com café), açúcar, pão, margarina, indicando que esses são os marcadores de identidade alimentar do CM na amostra estudada. Conclusão: A revisão intregrativa realizada mostrou que o tema é pouco estudado 
no Brasil e no mundo e o enfoque no consumo de alimentos regionais é pouco frequente. Os indivíduos pesquisados consumiram um $\mathrm{CM}$ equilibrado em relação à composição de nutrientes, exceto em relação ao alto consumo de ácidos graxos saturados e trans na região Centro-oeste e ácidos graxos saturados da região Nordeste. Embora o consumo de lácteos tenha se apresentado como um dos grupos mais consumidos, o consumo de cálcio foi baixo, indicando a necessidade de maior consumo de alimentos fontes desse nutriente. Considerando que o percentual de CM do tipo padrão foi predominante e que o consumo de embutidos foi acentuado, são necessárias ações de estímulo ao consumo de frutas e de alimentos in natura em todas as refeições, sobretudo na primeira refeição do dia.

Palavras-chave - café da manhã, desjejum, alimentos regionais, Restaurantes Populares 


\section{ABSTRACT}

With the lifestyle adopted in the modern world, the breakfast $(B)$ is the most neglected meal. The low consumption of regional food in the main meals, especially in the $\mathrm{B}$, may indicate not using local food resources more easily accessible. Objective: To analyze the frequency of $B$, its nutritional composition and the consumption habits of regional food in this meal among adult users of Popular Restaurants program in Brazil. Materials and Methods: The first part of the research consists of a literature review of the integrative type, carried out from a decade in electronic databases MEDLINE, LILACS and SciELO, with the following descriptors: "breakfast", "regional breakfast", "breakfast" and "regional breakfast." The second part of the research consists of two exploratory cross-sectional studies with a total sample of 1,872 individuals members of 36 restaurants linked to the Program Popular Restaurants. Individuals reported three-day 24-hour recalls, whose food consumption data were analyzed by individual, restaurant unit and by geographic region. In the analysis of the nutritional composition data of 1,547 respondents were considered, which were analyzed by sex, age group, per capita income, education and consumption region. The dairy groups, cereals, fruits, roots/tubers and meat/eggs were analyzed by frequency of use, regardless of the size of the intake portion. The total energy, macronutrients, fiber, monounsaturated fatty acids, saturated and trans were analyzed by contribution amounts on the recommendation of each nutrient. Calcium and sodium were evaluated for percentage contribution on consumption. For analysis of consumption data of regional food and qualitative classification of $B$ was considered the total sample of 1,872 users, which were analyzed by sex, age group, per capita income, education, profession, marital status, participation in government programs and nationality. For the qualitative analysis of the $\mathrm{B}$ was adopted a method that classifies the meal according to the presence/absence of food: Standard B as the presence of food sources of calcium and energy; Complete B as the presence of food sources of calcium, energy, minerals, vitamins and fiber; Incomplete $B$ and any other foods that do not offer the Standard B combinations or Complete B; Missing B as the total absence of food 
intake. For analysis of the food identity of B markers were formed beverage groups, cereals or substitutes rich in complex carbohydrates, cereal supplements, fruit, sugar, sweetener and some food/regional preparations. Results: the integrative review of 242 articles that meet the inclusion criteria, only 5 addressed the issue food regionality in $\mathrm{B}$. Both in the analysis of the nutritional composition as in $\mathrm{B}$ qualitative analysis, predominated men, and individuals aged between 25 and 34 years with full high school education level and range of per capita income of 0.5 to a Salary Minimum. Of the 4,641 B provided in the analysis of the nutritional composition, 797 $(17.2 \%)$ were not carried out and analyzed 3,844 B. The analysis of food groups showed high consumption of dairy products and cereals, and low consumption of fruits, roots/tubers and meat/eggs. The national energy contribution percentages of macronutrients in the total energy intake were adequate for a balanced diet. The national contribution percentages of saturated fatty acids and trans fatty acids are found in the recommendation, and the regional analysis showed consumption levels high of those nutrients in the Midwest region and saturated fatty acids in the Northeast. The national average intake of $B$ fibers was low, according to the results found low consumption of fruit. The National calcium consumption covered $73.49 \%$ of the expected and sodium intake was adequate. Regarding the qualitative analysis and the consumption of regional foods of 5,616 meals planned for the three days of consumption, $17.3 \%$ were not performed and analyzed 4,642 B. The Standard B was prevalent in all regions, and the Complete $B$ was little consumed among the participants. Individuals who underwent B in Popular Restaurants consumed more regional foods. The region with greater consumption of regional food was the Midwest (46.6\%) and South (45.9\%), and regional foods consumed in all regions ham, couscous and orange. The most consumed foods in B were the latte with coffee (or coffee with milk), sugar, bread, margarine, indicating that these are the B food identity markers in the sample. Conclusion: An integrative review conducted showed that the topic is little studied in Brazil and in the world and focus on the consumption of regional food is uncommon. Individuals surveyed consumed a balanced $B$ in relation to the composition of nutrients, except for the high consumption of saturated and trans fatty acids in the Midwest region and saturated fatty acids in the Northeast. Although milk consumption has been presented as one of the most consumed groups, calcium intake was low, indicating a need for increased consumption of food sources of this nutrient. Whereas the B percentage of standard was prevalent and 
that consumption of embedded was pronounced, it is necessary actions that encourage consumption of fruits and fresh food at every meal, especially in the first meal of the day.

Keywords: breakfast, regional food, Popular Restaurants. 


\section{LISTA DE ILUSTRAÇÕES}

\section{REVISÃO DA LITERATURA}

Quadro 1. Distribuição dos estudos publicados com descrição dos alimentos consumidos no café da manhã, no período de 1994 a 2014. Brasil. .80

\section{CAPITULO 1}

Quadro 1. Descrição e avaliação dos artigos incluídos na revisão integrativa.......106

\section{CAPÍTULO 2}

Tabela 1. Distribuição das recomendações dos nutrientes sobre o VET de $400 \mathrm{kcal}$ do $\mathrm{CM}$ 125

Tabela 2. Distribuição da frequência de dados sociodemográficos do café da manhã de usuários de Restaurantes Populares, 2010/2011.

Tabela 3. Distribuição da frequência de três dias de consumo de grupos de alimentos por dados sociodemográficos do café da manhã de usuários de Restaurantes Populares, 2010/2011. 129

Tabela 4. Média e desvio padrão da ingestão de nutrientes por região geográfica do café da manhã de usuários de Restaurantes Populares, 2010/2011 135

\section{CAPITULO 3}


Tabela 1. Distribuição da frequência da classificação qualitativa do café da manhã dos usuários de Restaurantes Populares por região geográfica do Brasil, 2010/2011 155

Tabela 2. Distribuição da frequência de classificação qualitativa do $C M$ dos usuários de Restaurantes Populares por sexo e dia da semana, Brasil, 2010/2011 159

Tabela 3. Distribuição da frequência da supressão e do café da manhã regional, nos três dias de consumo dos usuários de Restaurantes Populares por região geográfica do Brasil, 2010/2011. 160

Tabela 4. Distribuição da frequência dos principais alimentos consumidos no café da manhã dos usuários de Restaurantes Populares por região geográfica, 2010/2011. 169 


\section{ESTRUTURA DA TESE}

Esta tese está estruturada em três partes: a primeira é composta por introdução, revisão bibliográfica, objetivos e materiais e métodos; a segunda contém os resultados da pesquisa composta por três artigos originais. $O$ primeiro o artigo é intitulado "A regionalidade alimentar no café da manhã: uma revisão integrativa"; o segundo artigo é intitulado " $A$ composição nutricional do café da manhã de usuários de Restaurantes Populares no Brasil" e o terceiro intitula-se "Café da manhã: classificação, composição e regionalidade alimentar no Brasil'. A terceira parte é composta pela conclusão geral e as considerações finais da tese. 


\section{INTRODUÇÃO}

No Brasil, as doenças crônicas não transmissíveis têm gerado elevado número de mortes prematuras, perda de qualidade de vida e ocasionado impactos econômicos negativos para a população. Tais doenças são hoje responsáveis por $72 \%$ da mortalidade no Brasil (WHO, 2014), sendo mais prevalentes entre as pessoas de baixa renda, por estarem mais expostas aos fatores de risco, como o fumo, a inatividade física, a alimentação inadequada e o uso de álcool (DUNCAN et al., 2012; SZWARCWALD et al., 2014).

A última Pesquisa de Orçamentos Familiares (POF) realizada no Brasil em 2008-2009 indicou que a desnutrição, nos primeiros anos de vida, e o excesso de peso ou obesidade, em todas as demais idades, são problemas de grande relevância para a saúde pública no Brasil (BRASIL, 2010a). O crescimento do excesso de peso e das doenças crônicas no Brasil é considerado face da insegurança alimentar (AÇÃO BRASILEIRA PELA NUTRIÇÃO E DIREITOS HUMANOS, 2013) e reflete os efeitos negativos da globalização, da urbanização rápida, da vida sedentária, da alimentação inadequada e do marketing, que estimula hábitos de vida não saudáveis (MALTA et al., 2014).

Há varias décadas, tem sido registrada no mundo uma tendência de comportamento alimentar que revela uma crescente substituição de alimentos saudáveis por alimentos industrializados. E no Brasil não é diferente, pois alimentos básicos e tradicionais da dieta brasileira (como arroz, feijão e hortaliças) estam sendo substituídos por bebidas e alimentos industrializados (como refrigerantes, biscoitos, carnes processadas e comida pronta), implicando aumento na densidade energética das refeições e padrões de alimentação capazes de comprometer o equilíbrio entre ingestão e utilização de calorias pelo organismo humano (BRASIL, 2010a).

O resultado dos esforços do Governo Federal em relação à superação da pobreza e da extrema pobreza empreendidos nos últimos anos, desde a estratégia Fome Zero ao Plano Brasil sem Miséria, demonstram que o acesso aos alimentos é um tema que ainda precisa ser expandido. A discussão sobre o acesso à 
alimentação, no contexto da Política Nacional de Segurança Alimentar e NutricionalPNSAN é marcada pelo pressuposto de que o problema da fome não é uma questão de indisponibilidade de alimentos. O Brasil produz o suficiente para alimentar toda sua população, porém milhões de pessoas não têm o acesso garantido, porque não têm poder aquisitivo suficiente para comprar os alimentos de que precisam ou porque não têm disponíveis os meios de produção dos alimentos (MENEZES; BRAIT-POPLAWSKI; ROVERSI, 2012), ou ainda, porque faltam informações sobre a qualidade nutricional de alguns alimentos locais mais disponíveis.

Nesse contexto, o Programa Restaurante Popular foi instituído pelo Ministério do Desenvolvimento Social e Combate à Fome - MDS em 2003 com a função de ampliar a oferta de refeições saudáveis a preços acessíveis, reduzindo assim o número de pessoas em situação de insegurança alimentar e vulnerabilidade nutricional (MACHADO et al., 2014).

O Restaurante Popular (RP) é um equipamento de múltiplo uso que deve procurar auxiliar a sociedade no combate à fome e estimular a adoção de hábitos alimentares saudáveis, promovendo a saúde e contribuindo para o enfrentamento de doenças e agravos não transmissíveis (SOBRINHO et al., 2014).

A parcela da população brasileira atendida pelos RP tem sido estudada por alguns pesquisadores que enfocam temas como o perfil nutricional da clientela atendida em restaurantes comunitários do Distrito Federal (SILVA, 2010); a avaliação da qualidade nutricional, sensorial e cultural de cardápios populares (GINANI, 2011); o estado nutricional dos usuários dos RP e o diagnóstico da insegurança alimentar (GODOY et al., 2014); o perfil sociodemográfico, nutricional e psicossocial dos usuários dos RP de Belo Horizonte - MG (BENTO, 2012); a insegurança alimentar em idosos (SOUZA; MARIN-LEON, 2013); o consumo alimentar dos usuários dos RP no almoço (CARRIJO, 2013); a avaliação da oferta de alimentos e preparações de alimentos regionais nos RP (VILLAS BOAS, 2013); os fatores associados ao excesso de peso em adultos usuários de RP em Belo Horizonte, Brasil (MACHADO et al., 2014); e os fatores determinantes da insegurança alimentar e nutricional: estudo realizado em Restaurantes Populares de Belo Horizonte, Minas Gerais, Brasil (SOBRINHO et al., 2014).

Dentre os diversos aspectos estudados em RP, GINANI (2011) e VILLAS BÔAS (2013) pesquisaram sobre a oferta de alimentos regionais em tais restaurantes, demonstrando que a presença de alimentos regionais em RP é uma 
ação importante por representar uma forma sustentável de promoção de saúde, além da utilização de alimentos de fácil acesso, baixo custo e quase sempre de alto valor nutritivo. Pessoas de baixa renda, quando beneficiárias de RP, possivelmente têm nesses serviços sua principal refeição do dia (GINANI, 2011).

São várias as terminologias utilizadas como sinônimas da expressão "alimento regional". Os termos mais encontrados na literatura são: alimentos locais, tradicionais, caseiros, de qualidade ímpar, da fazenda, produtos da terra, rurais e artesanais (ZUIN; ZUIN, 2009), entre outros.

Neste estudo será utilizada a terminologia alimentos regionais por ser a nomenclatura utilizada na definição oficial brasileira de alimentação saudável (BRASIL, 2007a) e nas publicações do Ministério da Saúde (BRASIL, 2002; BRASIL, 2010b; BRASIL, 2014; BRASIL, 2015a).

É importante destacar que são poucos os registros sobre o regionalismo e os alimentos regionais no Brasil, o que traz dificuldades para a realização de comparação dos resultados de estudos relativos ao tema. Em virtude dessa escassez de publicações no âmbito dos alimentos regionais, há a necessidade de realização de estudos multicêntricos (MARTINS, 2010) e de estudos com amostras representativas da população brasileira, uma vez que o consumo dos alimentos regionais pode representar uma alternativa para a resolução dos problemas de alimentação e nutrição, por meio da reorientação de programas governamentais (CUNHA et al., 2014; MARTINS, 2010; MARTINS et al., 2012; SILVEIRA et al., 2014; VILLAS BÔAS, 2013).

Diversos autores (BEZERRA; MANCUSO; HEITZ, 2014; CARDOSO; MONTEIRO, 2011; CARÚS; FRANÇA; BARROS, 2014; MONTEIRO et al., 2010; PROENÇA, 2010; REJMAN; KASPERSKA, 2011; SOUZA et al., 2013) têm apontado algumas tendências referentes ao comportamento alimentar das pessoas em sociedades industrializadas, tais como a busca por diversidade, a valorização da alimentação fora de casa, o aumento do consumo de alimentos processados, a substituição das refeições e das preparações tradicionais por lanches com elevada concentração de energia, de gorduras, de açúcar e de sódio. Todas essas situações proporcionam a desestruturação das refeições, onde o café da manhã (CM) é a refeição mais negligenciada (AFFINITA et al., 2013; FREITAS; MENDONÇA; LOPES, 2013; HALLSTROM et al., 2011; HUANG et al., 2014; MIN et al. 2012; NURUL-FADHILAH et al., 2013; TRANCOSO, CAVALLI, PROENÇA, 2010). 
Dentre os estudos realizados em RP ou restaurantes comunitários no Brasil, citados anteriormente, alguns estudaram as refeições servidas no almoço e no jantar (BENTO, 2012; CARRIJO, 2013; GODOY et al., 2014; GINANI, 2011; SILVA, 2010; VILLAS BOAS, 2013), mas nenhum enfocou o consumo de alimentos regionais no $\mathrm{CM}$.

A prática prejudicial de não realização do CM aumenta progressivamente a partir da infância até a fase adulta, fase em que, devido à falta de tempo e outros fatores cotidianos (HÖFELMANN; MOMM, 2014; MARANGONI et al., 2009; RIVES et al., 2015 SUGIYAMA et al., 2012; WIJTZES et al., 2016), a refeição é frequentemente suprimida ou é realizada fora de casa e com pouca atenção quanto à composição nutricional, o que tem garantido à população a presença de situações nutricionais de desequilíbrio.

A taxa do hábito de não realização do CM aumentou em todo o mundo e faz parte de um estilo de vida contemporâneo (KURODA et al., 2013; PURSLOW et al., 2008). Affinita et al. (2013) acrescentam que o CM mudou ao longo do tempo, sendo em grande parte dependente da cultura e da disponibilidade de alimentos tradicionais em diferentes países. Corroborando com esses últimos autores, Hallstrom et al., (2011) comentam que o hábito de consumo do CM está relacionado às características sociodemográficas e às regiões de consumo.

O CM tem sido considerado um dos indicadores mais importantes de comportamento saudável (BARUFALDI, 2014; RIVES et al., 2015). É consenso científico que o consumo do CM está associado ao melhor estado de saúde em todas as idades (AFFINITA et al., 2013; HALLSTROM et al., 2011; HUANG et al., 2014, MIN et al., 2012; MIRZAEI et al., 2016). Há evidências consideráveis de apoio ao pressuposto de que o consumo do CM por crianças e adultos está associado a uma maior ingestão de nutrientes, principalmente de vitaminas, minerais e fibras, e menor ingestão de gordura, inclusive de colesterol (CECATO, 2015; HOLMES et al., 2012; MIN et al., 2011; SHAFIEE et al., 2013). Alguns autores (BERTA et al., 2015; GRIEGER, COBIAC, 2012; LAZZERI et al., 2013; MARLATT et al., 2016; SONG et al., 2006) correlacionam o ato de realizar CM ao menor Indice de Massa Corporal (IMC), afirmando que o hábito de consumo do CM durante a infância geralmente permanece na idade adulta.

Apesar da existência de algumas pesquisas sobre a refeição $\mathrm{CM}$, Trancoso, Cavalli e Proença (2010), HÖFELMANN e MOMM (2014) consideram que 
há uma carência de informações científicas sobre esta refeição no Brasil e estudos envolvendo o consumo de CM em adultos são ainda mais raros (CECATO, 2015; CHAPLIN; SMITH, 2011; MILLA; JONHS; AGUERO, 2014; REEVES et al., 2013). Considerando que o tipo de alimentos consumidos no $\mathrm{CM}$ varia de acordo com as diferentes culturas (DI GIUSEPPE et al., 2012), faz-se necessário a realização de estudos sobre esta refeição nas diversas partes do mundo.

Portanto, considerando a existência de poucas informações sobre o consumo de alimentos regionais no Brasil, sobretudo na primeira refeição do dia, é que foi proposto o presente estudo. Assim, esta pesquisa pode contribuir com 0 direito à preservação de práticas alimentares tradicionais previsto no conceito atual de Segurança Alimentar e Nutricional (BRASIL, 2006a) na medida em que fornecer o diagnóstico atual do perfil de consumo da refeição $\mathrm{CM}$ e do consumo de alimentos regionais nesta refeição. Este estudo poderá ser uma forma de embasamento de novas propostas de ações de estímulo ao consumo de alimentos regionais dentro dos eixos de atividades do governo federal. 


\section{REVISÃO DA LITERATURA}

\subsection{CULTURA ALIMENTAR}

O homem tem como condição primordial para sua sobrevivência a necessidade de nutrientes, que ingere e incorpora na forma de alimentos. Mas esses são também produtos naturais culturalmente construídos e valorizados, transformados e consumidos sob a influência dos conceitos da sociedade (POULAIN, 2004).

Considerando o exposto acima, é essencial aos estudos sobre hábitos e consumo alimentar a abordagem integral de todos os fatores que influenciam 0 ato alimentar do ser humano, pois a alimentação e a nutrição vão além da ingestão de substâncias físico-químicas. Ao se nutrir, o ser humano também se alimenta de histórias, de cultura, de signos, de rituais e de tradição (ZUIN; ZUIN, 2009). A amplitude do tema alimentação demonstra que o assunto vai além dos aspectos nutricionais e envolve aspectos fisiológicos, políticos, econômicos, sociais, ambientais, psicológicos e culturais (CHEMIN, 2007). Desta forma, em estudos sobre o CM é também necessário considerar o aspecto cultural, pois o tipo de alimento consumido nesta refeição é depende das concepções de cada cultura (RIVES et al., 2015) .

A própria escolha do alimento está ligada à cultura. Cascudo (2004) afirma que de todos os atos naturais, o "alimentar-se" foi transformado em expressão de sociabilidade. Assim, a alimentação não pode ser tratada apenas do ponto de vista biológico, pois o aspecto cultural faz a passagem de uma geração à outra por meio de técnicas agrícolas, de produtos e de formas de beneficiamento e processamento para torná-los prontos e comestíveis. Comer é um ato social, enquanto se nutrir é uma atividade biológica. Por isso, o consumo de alimentos não se prende apenas à necessidade, mas à sociabilidade, à cultura, às crenças e aos tabus, à tecnologia e aos hábitos construídos por um grupo social (CARVALHO, 2008).

Assim, o indivíduo está inserido em uma cultura global constituída por diversas culturas, dentre elas a alimentar. Por definição, cultura alimentar é "o 
conjunto de representações, de crenças, de conhecimentos e de práticas herdadas e/ou aprendidas que estão associadas à alimentação e que são compartilhadas por indivíduos de uma determinada cultura ou grupo social" (HERNANDEZ; ARNÁIZ, 2005).

É um sistema simbólico, formado pelo conjunto de diversas influências (históricas, ambientais e regionais), nas quais cada sociedade estabelece um conjunto de práticas alimentares consolidadas ao longo do tempo (MACIEL, 2005; SANTOS; PASCOAL, 2013). Hernandez (2005) corrobora com essa definição quando comenta que a cultura alimentar é o resultado de um longo processo de aprendizagem que se inicia no momento do nascimento e se consolida no contexto familiar, social e ambiental.

Dessa forma, entende-se que cultura alimentar está relacionada com fatores como o local de origem da população, os recursos naturais, as crenças, a educação, a etnia, a tecnologia, a colonização e os cuidados de saúde (FABRI, 2013). A cultura alimentar de um povo, segundo Levi-Strauss, é uma das expressões mais características da organização social, religiosa, econômica e cultural de agrupamentos humanos (ALMEIDA, 2006).

Dentro desse contexto, é essencial definir o elemento cultural chave, a comida, que se diferencia conceitualmente do termo alimento. O termo comida transcende 0 ato alimentar e sinaliza uma aquisição da cultura. Mais que a manutenção do corpo, a comida é uma materialização emblemática da condição social, da identidade do ser, além de ser uma sinalização das diferenças sociais. Há, portanto, uma clara distinção entre comida e alimento, em que o primeiro termo não é apenas uma matéria que alimenta, mas antes, um modo, um estilo de se alimentar (SILVA; FREITAS; SOUSA, 2014).

Comer é mais que ingerir um alimento, significa também as relações pessoais, sociais e culturais que estão envolvidas nesse ato. As formas de escolher, preparar e consumir os alimentos estão intimamente ligadas à expressão cultural e social de um povo (LEONARDO, 2009), em que comer constitui um marcador de pertencimento, que pode incluir ou excluir os indivíduos socialmente (HERNANDEZ; ARNÁIZ, 2005). DAMATTA (1986) ratifica essa ideia quando comenta que a comida é uma das expressões culturais mais significativas, pois envolve os gostos e desejos das pessoas. Sendo assim, a comida nem sempre alimenta, mas pode saciar e estabelecer identidade social. 
Assim sendo, abordar o tema "comida" requer direta ou indiretamente falar sobre a questão da identidade, pois o ato alimentar marca as fronteiras de identidade entre os grupos humanos de uma cultura e de outra, assim como, no interior de uma mesma cultura, entre os membros que a constituem (POULAIN; PROENÇA, 2003). Comer cristaliza estados emocionais e identidades sociais, fazendo com que muitos processos de construção e afirmação identitária de determinados grupos sociais busquem apoio nas práticas alimentares (CHEMIN, 2007; GIMENES, 2008). Por isso, a cultura alimentar representa uma das maiores expressões da identidade de povos e tem sido considerada como patrimônio imaterial (SANTOS; PASCOAL, 2013).

O Guia Alimentar para a População Brasileira (BRASIL, 2014) considera que alimentos e preparações culinárias que resultam de modos de comer particulares constituem parte importante da cultura de uma sociedade e estão fortemente relacionados com a identidade e o sentimento de pertencimento social das pessoas. O sentimento de pertencer a uma dada identidade promove a sensação de autonomia, de prazer promovido pela alimentação e, consequentemente, um estado de bem-estar. O Guia reforça a premissa de que a alimentação vai além da ingestão de nutrientes, envolvendo também as características do modo de comer e as dimensões culturais e sociais das práticas alimentares.

Neste contexto, a alimentação tem uma função estruturante na organização social de cada grupo humano, em especial com relação às atividades de produção, distribuição, preparação e consumo, sendo um objeto do saber socioantropológico (POULAIN, 2004) que adentra a seara das práticas movidas por tradições. As disposições da cultura alimentar geram representações sociais que funcionam como um capital simbólico particularizado em cada região e em cada grupo social. Nesse sentido, os hábitos alimentares são inscrições emblemáticas ou referenciais de um modo de ver e sentir o mundo (BOURDIEU, 1979). A alimentação é uma instância cultural que preserva costumes, é um pilar da identidade cultural e traduz a estabilidade de um grupo social (GARCIA, 2003).

"Somente por meio das relações sociais, adquire-se o sentido de pertencimento e identidade. O consumo de alimentos regionais está em nossa história pessoal e social, em nossa comensalidade inevitavelmente territorializada. Assim, ao consumir alimentos "regionais", expressamos o habitus como linguagem 
polissêmica, que se mistura a outros valores e transcende fronteiras físicas e geográficas" (BRASIL, 2015a).

Os termos cultura alimentar regional e alimentos regionais referem-se ao sistema alimentar que considera as características que se ligam à história e ao contexto cultural de um determinado grupo, relacionado com a escolha, a preparação e o consumo de alimentos e constituindo-se em uma tradição que se torna símbolo de sua identidade (GIMENES, 2008). Acredita-se que as comidas regionais tenham ligação com tradições e hereditariedade ou origens de uma determinada região e suas pessoas. A tradição, a história, os sabores, as técnicas e as práticas culinárias somadas são geradores da formação das culturas regionais (UGGIONI, 2006).

A cultura alimentar brasileira foi formada, basicamente, pela chegada dos portugueses ao Brasil, pela revolução industrial, pela imigração de colonos (italianos, alemães, poloneses, japoneses, entre outros) e pelos indígenas. O resultado dessa miscigenação é uma herança cultural riquíssima, em que se fundamentam as preferências alimentares atuais. A grande variação da cultura alimentar observada entre as regiões geográficas do Brasil é consequência das dimensões continentais do país, que proporcionam "cozinhas regionais" peculiares e bem caracterizadas (SANTOS; PASCOAL, 2013).

No Brasil, a dimensão sociocultural tem sido negligenciada em inúmeras recomendações institucionais de promoção da alimentação saudável. E quando há alguma referência, menciona-se a necessidade de respeitar os "hábitos alimentares regionais", o que parece ser entendido pelos elaboradores de políticas públicas apenas como a condição moral do respeito ao desejo do outro, que é supostamente suficiente para ocupar a dimensão representacional e simbólica da alimentação humana. Nesse âmbito, a ordem sobre a nutrição, em geral, não dá lugar para a compreensão de significados sobre dieta, corpo, alimentação regional, alimentação saudável, etc. (SILVA; FREITAS; SOUSA, 2014) e outros aspectos da cultura alimentar.

Parece que esse panorama de desconsideração do aspecto cultural começa a ser alterado positivamente para uma questão discutida politicamente. Pelo menos é o que consta no artigo recentemente publicado por Castro (2015), onde o autor comenta que têm se ampliado e diversificado as iniciativas de resgate da alimentação como um dos eixos estruturantes da identidade coletiva (cultura) e de 
valorização do consumo como ação política, aqui entendida como a percepção e o uso das práticas e escolhas de consumo como uma forma de participação na esfera pública. Ou seja, na atualidade, existe maior consciência da dimensão política da alimentação vista em conjunto com as implicações nutricionais, ambientais, sociais e econômicas.

Os precursores nos estudos sobre as tradições alimentares do povo brasileiro foram Gilberto Freyre e Luís da Câmara Cascudo, que se destacaram pela elaboração de reflexões acerca da cultura e da identidade regional, legando importantes contribuições para a compreensão histórica das manifestações culturais locais. A alimentação (ou mais exatamente a comida, a refeição, o gosto ou o paladar) foi vista por eles como uma das constantes informadoras da identidade regional e nacional (CAVIGNAC; OLIVEIRA, 2010).

Esses estudiosos enfatizaram a autenticidade e a busca das raízes frente ao progresso e à urbanização, ressaltando a cozinha como patrimônio cultural a ser valorizado (UGGIONI, 2006).

Considerando que a globalização propicia a mundialização de produtos, sistemas e práticas, é fácil concordar que ocorre igualmente a mundialização da cultura. Ortiz (1994) considera como parte da mundialização da cultura o significado de "tradição", que pode ter dois sentidos distintos: a tradição como permanência do passado distante e com uma forma de organização social contrária à modernização, e a "tradição da modernidade" como uma tradição reinventada, a qual recria elementos da memória internacional popular, redesenhando e atualizando elementos do passado que se misturam com o presente.

Essa concepção de "tradição da modernidade" é importante para a compreensão de como a cozinha tradicional se reinstala na cultura mundializada. A existência de uma cultura mundializada no padrão alimentar é fácil de ser identificada pela existência de milhares de produtos industrializados e pela abertura de diversos restaurantes e lanchonetes de rede. Assim, estabeleceu-se uma nova cultura relacionada à tradicionalidade alimentar, em que a noção de "tradição da modernidade" explica as mudanças que ocorrem na estrutura alimentar contemporânea, onde o preparo de pratos tradicionais ou típicos é transferido para os restaurantes e instituições e, no âmbito doméstico, esses pratos são feitos, encomendados ou comprados apenas em ocasiões especiais, como festividades e comemorações (GARCIA, 2003). 
Com a modernidade, mudanças sociais e econômicas alteraram as formas de produção e de consumo dos alimentos (ZUIN; ZUIN, 2009). Tais mudanças no perfil de consumo alimentar da população brasileira, caracterizadas pelo aumento do consumo de alimentos fora do domićlio e de alimentos processados, pela diminuição do consumo de alimentos tradicionais e pelo consumo insuficiente de frutas e hortaliças, têm sido vistas como fatores importantes no aumento dos problemas de saúde revelados por meio da obesidade crescente e de casos de diabetes e de hipertensão na população. Esses novos padrões de consumo trazem grandes desafios à saúde pública, particularmente no âmbito das doenças crônicas, sendo essa preocupação reforçada no texto da Política Nacional de Alimentação e Nutrição e em instrumentos internacionais e nacionais (NILSON; JAIME; RESENDE, 2012).

Tal fenômeno é agravado pelo fato de o Brasil e de diversas outras nações serem muito permeáveis às novas práticas advindas de outras culturas. As heranças da colonização propiciaram a formação de uma identidade de país subalterno e dependente. Enquanto outras nações se perguntam para onde irão, nós nos perguntamos quem somos, o que faz do brasileiro um ser que absorve com muita rapidez itens das culturas americana e européia, por serem consideradas modos de vida "superiores" pelos que se julgam "inferiores" (GARCIA, 2003).

Percebe-se que países menos desenvolvidos como o Brasil são cada vez mais influenciados pelas culturas de países desenvolvidos. O próprio nível de desenvolvimento, mais tímido em relação às nações mais desenvolvidas, fragiliza a cultura do país, causando marcas que descaracterizam a própria identidade em favor de modos de vida que afetam negativamente os hábitos alimentares da população. Esse ciclo em cascata que ocorre entre a cultura global, a cultura alimentar e a identidade de uma população é parte formadora do que chamamos de hábitos alimentares, fator tão decisivo na determinação do estado nutricional dos indivíduos de uma sociedade. 


\subsection{ALIMENTOS REGIONAIS, TRADICIONAIS OU TÍPICOS?}

Diversos fatores influenciam na determinação do estado de saúde do indivíduo, sendo a alimentação saudável um dos mais importantes. No entanto, ter uma alimentação saudável é cada vez mais desafiador, diante dos hábitos de consumo da sociedade urbanizada. As altas taxas de incidências de doenças crônicas no Brasil (COUTINHO; GENTIL; TORAL, 2008; SOUZA et al., 2013; VASCONCELOS, 2008) indicam que é necessário adquirir novos hábitos alimentares que auxiliem o alcance do restabelecimento do estado de saúde da população brasileira.

Diante das consequências do mundo globalizado na saúde e no estado nutricional, considera-se importante o conhecimento e a valorização de práticas alimentares saudáveis que, quando associados ao estímulo da produção local de alimentos, da agricultura familiar e do consumo de alimentos regionais, podem auxiliar na promoção da saúde (BOTELHO, 2006; GINANI, 2011), favorecendo a geração de renda e o aumento da oferta de empregos.

São várias as terminologias utilizadas como sinônimas da expressão "alimento regional". Os autores ZUIN e ZUIN (2009), por exemplo, preferem designá-los como "produtos com história", pois constituem e fazem parte da história social de uma determinada cultura, podendo ser designados também como alimentos locais, tradicionais, caseiros, de qualidade ímpar, da fazenda, produtos da terra, rurais e artesanais. Além desses, HERNANDEZ (2005) também considera como sinônimo o termo colonial. Já Fouillé (2005) designa os alimentos tradicionais como autênticos ou legítimos, e Fisberg, Wehba e Cozzolino (2002) ainda utiliza o termo "sertanejo" para se referir a alimentos tradicionais.

Costa (2009) arrisca fazer uma diferenciação entre culinária típica e culinária tradicional. Para o autor, culinária tradicional é aquela em que o preparo dos pratos é feito segundo a tradição secular, utilizando ingredientes nativos e equipamentos artesanais, e que a produção em grande escala é inviabilizada por questões operacionais e econômicas. A culinária típica tem um caráter simbólico e alegórico, de forma que não tem obrigações pelo cumprimento dos mesmos rigores quanto aos ingredientes, equipamentos usados e formas de preparo, podendo ser produzidos de forma massificada. 
Nesses termos, o autor quis inferir que a comida tradicional somente pode ser feita na região onde os ingredientes são nativos. Na comida típica, tendo em vista a viabilidade comercial, os ingredientes artesanais podem ser substituídos por similares industrializados, assim como os equipamentos artesanais cedem lugar a equipamentos industriais. Um bom exemplo de diferenciação entre os dois conceitos é o preparo de paçoca de carne seca, que na culinária tradicional necessitaria de carne seca desidratada nos moldes nordestinos e de pilão de madeira para ser degradada em pedaços pequenos. Mas, se preparada na região sul, por exemplo, com carne bovina assada ou frita e triturada em processador de alimentos, passa a ser uma preparação típica.

Diante do interesse comercial em atender ao consumidor apreciador de comida regional, acredita-se que essa diferenciação realizada por Costa (2009) estará cada dia mais imperceptível, devido ao avanço da tecnologia na produção agrícola e nos equipamentos destinados ao preparo de alimentos. Atualmente, os solos são adequadamente corrigidos para simular as características necessárias ao plantio de alimentos antes somente cultivados em regiões específicas; estufas climatizadas são construídas e monitoradas para o crescimento de plantas alimentares características de determinados climas; a inovação em equipamentos e maquinários acontece, hoje, em uma alta velocidade; e as formas de preparos tradicionais estão sendo cada vez mais aprendidas com o objetivo de melhor agradar o gosto do comensal. De forma que, com o passar do tempo, tal diferenciação de termos não poderá mais ser observada, como propôs Costa (2009).

Fabri (2013) faz uma observação interessante quando comenta que os documentos existentes no âmbito das políticas públicas e na literatura científica são vagos quanto à definição de termos relevantes, como o caso de alimentos regionais. O que demonstra ser esse um ponto que merece mais estudos para uma melhor orientação na elaboração das políticas públicas em alimentação e nutrição e na publicação de artigos científicos.

A partir da consideração de que a expressão alimentos tradicionais é sinônima de alimentos regionais, torna-se possível conceituar a expressão baseada em alguns autores. Para Garcia (2003), tradição é um conceito amplo que se refere a fatores que transmitem valores vinculados à natureza, à terra, à origem rural e sua suposta identificação com o autêntico ou puro. Também se refere a práticas 
executadas por um grupo ou valores de identidade coletiva e de costumes populares.

Parece que a definição de alimentos regionais no Brasil é diferente da empregada em outras partes do mundo. Na comunidade européia, "um alimento só é considerado tradicional se ele for remetido às receitas do ambiente rural, desde o seu cultivo até o modo de preparo" (ZUIN; ZUIN, 2009). Sheehy, Roache e Sharma (2013) realizaram um estudo em uma região do Canadá e consideraram como dieta tradicional aquela em que os habitantes sobreviveram por milênios, baseada na ampla variedade de alimentos obtidos do meio ambiente local, como caça selvagem, mamíferos marinhos, peixes, aves, raízes, caules, tubérculos, frutos silvestres e algas comestíveis. Os autores não fizeram nenhuma referência quanto ao modo de preparo de tais alimentos.

Song et al. (2005) utilizaram a expressão dieta tradicional para se referirem aos alimentos comumente consumidos por adolescentes na Coréia, como pizza, batatas fritas, hambúrgueres, biscoitos, etc. Trichopoulou et al. (2006) estudaram os alimentos tradicionais como parte integrante da dieta mediterrânea que são geralmente saudáveis, com o consumo proveniente da herança cultural da região grega, fazendo uma referência superficial à existência de receitas, sem maiores detalhes ao modo de preparo. Di Giuseppe et al. (2012) usaram o termo "típico" para se referir a alimentos de consumo popular ou de consumo comum no dia-a-dia das pessoas, não se referindo, dessa forma, a alimentos tradicionais, produzidos e consumidos por gerações anteriores.

No entanto, além da diversidade de conceitos sobre alimentos regionais no mundo, parece que o assunto não é muito claro para as populações carentes, pelo menos foi o que demonstrou a pesquisa realizada por Martins (2010). Essa pesquisa objetivou avaliar os efeitos de uma intervenção educativa sobre a utilização dos alimentos regionais com 200 familiares de crianças na faixa etária de três a seis anos, atendidas em uma Unidade Básica de Saúde em Fortaleza. No planejamento da pesquisa, foi prevista uma intervenção onde foi indagado aos participantes sobre o conhecimento da terminologia alimentos regionais. Os resultados mostraram que $74,5 \%(n=200)$ dos entrevistados afirmaram desconhecer essa terminologia, e quando questionados sobre a utilidade desses alimentos, 41,5\% das famílias mencionaram que os alimentos regionais só serviam para fazer suco. Somente $17 \%$ disseram servir para realizar uma alimentação variada, 17,5\% das famílias 
desconheciam alguma alimentação que poderia ser preparada com esses alimentos e $24 \%$ elencaram outras finalidades (MARTINS, 2010).

Silveira et al. (2014) utilizaram a mesma pergunta em uma pesquisa realizada por eles com o objetivo de verificar o conhecimento, a atitude e a prática de famílias de crianças na fase pré-escolar acerca do uso de alimentos regionais em zona rural brasileira. Dos 200 participantes, apenas 51 (25,5\%) afirmaram já ter ouvido falar nesses alimentos, e 149 (74,5\%) entrevistados nunca ouviram falar na terminologia alimentos regionais.

Além da diversidade de conceitos de alimentos tradicionais no mundo, ainda há a diversidade de enfoques, como por exemplo, os enfoques da gastronomia e turismo (COSTA, 2009; ERLICH, 2004; PORCINO et al. 2012; UGGIONI; PROENÇA; ZENI, 2010); das ciências sociais (CERDAN, 2009; CONSONI; CAGLIANI, 2010; COUTINHO, 2012; ELOY; REIS, 2012; GIMENES, 2008) e das ciências da saúde (AIRES, 2012; CARVALHO, 2008; CHAVES et al., 2009; CRUZ; SCHNEIDER, 2010; DIMENSTEIN et al., 2010; FABRI, 2013; GABRIEL et al., 2012).

Uma das relações que apresenta maior conexão atual quanto ao tema "alimentos regionais" é a verificada entre a gastronomia e o turismo. Segundo Gimenes (2008), a lógica desses dois setores defende que os pratos típicos podem ser convertidos em elementos diferenciadores e divulgadores de localidades turísticas, dando base para a criação de estratégias para o desenvolvimento regional. Além disso, a autora faz uma observação muito importante em relação ao fato de que esses pratos não necessariamente se caracterizam como tradições culinárias, porque são criações recentes, chamadas de "tradições inventadas".

Segundo Eric Hobsbawm (1997), citado por Gimenes (2008), por "tradição inventada" entende-se um conjunto de práticas de natureza ritual ou simbólica que visa inculcar certos valores e normas de comportamento por meio da repetição, o que implica, automaticamente, uma continuidade em relação ao passado. Tais práticas são normalmente reguladas por regras tácitas ou abertamente aceitas. Para Santos (2005), um bom exemplo de tradições inventadas são as festas gastronômicas realizadas com cunhos turísticos e culturais.

As tradições inventadas são apropriações do passado para refletir no presente a ideia de produtos que encarnam o lugar de origem. Nesse contexto, a identidade e/ou patrimônio são novos recursos da modernidade de usos 
polivalentes. Já não se trata de seu lugar de origem, mas de produtos que o encarnam. A intenção é que os produtos evoquem um território, uma paisagem, alguns costumes e uma referência de identidade (HERNANDEZ, 2005).

Gimenes (2008) ainda argumenta que, além do processo de tradicionalização de alimentos, atualmente ainda acontece a reinterpretação da tradição por meio da descontextualização de algumas preparações, fazendo com que uma mudança na posição estrutural de preparo do prato permita a construção de um novo significado. Segundo Santos (2010), está ocorrendo, na atualidade, uma reformulação na composição dos produtos, utilizando os de baixa caloria ou propondo mudanças de alguns ingredientes, como uma indicação cientifica das ciências nutricionais com o objetivo de tornar as preparações mais saudáveis, como, por exemplo, na substituição do processo de cocção da fritura para o grelhado, o que, certamente, também tem acontecido com as preparações regionais.

Ao se analisar as diversas palavras e expressões utilizadas para definir o assunto, observou-se que os termos regional, tradicional ou típico apresentam maior pertinência para a significação semântica a que se propõem, pois os alimentos existentes em uma região (termo regional) representam os tipos de alimentos locais (termo típico) que possuem uma história e, por isso, é uma tradição (termo tradicional). Sendo assim, mais por uma questão de homogeinização de abordagem e por considerar que as principais bibliografias brasileiras sobre o tema utilizam 0 termo regional, acredita-se que esse termo seja a melhor opção para ser utilizado na presente pesquisa.

Existe uma tendência mundial que busca a valorização de alimentos regionais que eram consumidos no passado e que, além de fazerem parte da memória familiar, remetem a hábitos alimentares constituídos por alimentos menos industrializados e, portanto, mais saudáveis.

ZUIN e ZUIN (2009) acreditam que existam diversas razões que estimulam a tendência de resgate do consumo de alimentos e preparações regionais, entre elas a crescente desconfiança do consumidor em relação aos produtos industrializados, devido à ocorrência de constantes fraudes. Outra razão para essa tendência é a relação existente entre os aspectos histórico-culturais do indivíduo com relação ao alimento consumido, ou seja, aspectos relacionados à dimensão afetiva por meio da memória gustativa. Barbosa (2007) ainda acrescenta que a busca dos hábitos alimentares tradicionais também ocorreu em virtude da 
existência de muitas denúncias acerca da indústria de alimentos e do desenvolvimento tecnológico, que nos fazem ingerir algo sem composição declarada.

Hernandez (2005) afirma que a revalorização da tradição culinária deve ser preservada não apenas como uma forma de resgate de sabores e de produtos tradicionais, mas por razões ecológicas e culturais. Visto assim, o resgate do consumo de alimentos regionais é uma questão bem mais abrangente que apenas a alimentação saudável. Há toda uma relação de conexão com o meio ambiente, que leva o homem a se atentar para técnicas de cultivo, fabricação de produtos e descarte de resíduos que sejam ecologicamente corretos, permitindo uma interação com o meio ambiente de forma respeitosa.

A abordagem sobre resgate dos hábitos alimentares tradicionais faz necessária a referência ao movimento Slow Food, cujo objetivo é resgatar antigos hábitos relacionados ao preparo e ao consumo dos alimentos tradicionais, bem como aos comportamentos e aos rituais que se estabelecem, com a finalidade de preservação da história da cultura de uma região. Esse movimento teve início em 1986 na Itália e está no Brasil desde o ano 2000, o qual possui um acordo assinado com o governo brasileiro em respeito aos direitos humanos, à biodiversidade e à redescoberta do patrimônio agroalimentar brasileiro (MADER, 2007).

O Slow Food é uma associação que se opõe aos efeitos degradantes da modernidade alimentar, da industrialização, da padronização e da distribuição em massa de alimentos provenientes da cultura do Fast Food. O Slow Food defende os efeitos benéficos do consumo de alimentos locais, estimula a promoção de programas de educação alimentar e trabalha para a salvaguarda da divulgação de uma consciência pública de tradições culinárias (CAPATTI, 2006; LIMA, 2012).

Outro termo relacionado à valorização de alimentos tradicionais e que merece ser comentado é terroir. É um termo de origem francesa que significa originalmente uma extensão limitada de terra considerada do ponto de vista de suas aptidões agrícolas, particularmente a produção vinícola. Esse termo não designa apenas a terra, mas um conjunto de fatores como a geologia, a topologia, o clima e o produtor de vinhos. É utilizado também para expressar um conjunto de terras sob a ação de uma coletividade social congregada por relações familiares e culturais e por tradições de defesa comum e de solidariedade da exploração de seus produtos (CAVICCHIOLI, 2006). 
Nos dias atuais, o termo terroir remete a uma conotação positiva em relação ao vinho, exprimindo a interação entre o meio natural (clima, solo, relevo) e os fatores humanos como a escolha das variedades, os aspectos agronômicos e os aspectos de elaboração dos produtos. Na verdade, ele está na base do conceito das denominações de origem, pois agregam diferenciação e originalidade dos produtos. Tem sido usado muitas vezes de forma imprópria, frequentemente sem aderência ou conhecimento em relação ao efetivo significado do termo. Pela associação positiva entre terroir e vinho, é freqüentemente utilizado com objetivos puramente comerciais, apropriando o termo ao marketing para sensibilizar consumidores, sem real fundamento (TONIETTO, 2007).

Terroir é uma concepção naturalista que predomina nos discursos sobre alimentação, especialmente na versão gourmet. O conceito moderno de terroir enfatiza a produção em pequena escala que resume as qualidades mobilizadas pelas estratégias de desenvolvimento sustentável. Contudo, corre-se o risco de se atribuir ao produto a mesma confiabilidade que é dispensada pelos laboratórios, dada à limpeza e à precisão verificadas nas grandes vinícolas, sendo que o mesmo não pode ser atestado nos produtos artesanais (DÓRIA, 2009).

Para Bessière (2006), a cozinha de terroir permite que a história do território seja contada, exibindo uma identidade. Como está muito associado ao turismo, possibilita que o turista se integre social e culturalmente ao território ao passo que viabiliza a divulgação de publicações sobre cozinhas regionais, inventários gourmet e diversas informações relacionadas ao tema.

O conhecimento do atual consumo de alimentos/preparações regionais no Brasil ainda é inexistente. Os estudos e inquéritos populacionais não têm focalizado de maneira mais específica o consumo de alimentos tradicionais, com exceção dos que compõem a cesta básica brasileira. Acredita-se que o resgate da utilização de alimentos locais disponíveis, associado ao estímulo da produção caseira de alimentos, como frutas e hortaliças, e o aproveitamento integral dos alimentos, possa contribuir para a melhoria do estado nutricional da população.

O Ministério da Saúde (MS) do Brasil lançou, em 2002, a primeira edição do livro Alimentos regionais brasileiros, cujo objetivo foi "divulgar a imensa variedade de frutas, hortaliças, tubérculos e leguminosas brasileiras", de forma a contribuir com a segurança alimentar e nutricional da população brasileira mais carente. Esse trabalho também teve outras finalidades, como auxiliar na orientação das 
comunidades no sentido de uma alimentação acessível que utilize recursos locais e despertar o interesse para o resgate do cultivo, a extração racional, a produção, e a transformação para consumo próprio ou geração de renda (BRASIL, 2002).

Posteriormente, o MS publicou o material intitulado "Receitas Regionais para crianças de 6 a 24 meses", cujo conteúdo constitui-se em receitas distribuídas por região do Brasil, com ingredientes característicos desses locais, visando à formação de hábitos alimentares saudáveis desde a infância (BRASIL, 2010b).

No ano de 2015, o MS publicou a segunda edição do livro Alimentos regionais brasileiros, cujo propósito é favorecer o conhecimento das mais variadas espécies de alimentos existentes no país, além de estimular o desenvolvimento e a troca de habilidades culinárias. Na ultima versão do livro, são disponibilizadas receitas culinárias, dicas de como cozinhar com mais saúde e uma lista de possíveis substituições para as preparações desenvolvidas, ressaltando nossa diversidade cultural (BRASIL, 2015a).

Essas três obras brasileiras merecem destaque por serem as publicações de maior expressão em relação à questão da regionalidade alimentar brasileira. Além de servirem como guias na capacitação de profissionais de saúde, também constituem instrumentos de estímulo à prática de alimentação saudável junto à população, previstos na promoção da SAN, buscando ao mesmo tempo a valorização dos alimentos existentes em cada região do Brasil e a promoção do desenvolvimento local.

A abordagem dos hábitos e padrões alimentares tradicionais dos brasileiros torna necessária a consideração de vários fatores, entre eles os de ordem geográfica e sociológica. Quanto ao aspecto geográfico, é importante destacar que o país se situa em terras de clima tropical e temperado, o que facilita o cultivo de diversos alimentos, e, pela grande extensão de área litorânea, há uma considerável oferta e consumo de produtos pesqueiros. Quanto ao aspecto sociológico, não há como negar as influências africanas, europeias e indígenas (CHEIN; LEMOS; ASSUNÇÃO, 2007; PHILIPPI, 2006; SONATI; VILARTA; SILVA, 2009). De forma que o Brasil não tem uma única cultura alimentar, mas culturas alimentares diversas em cada uma das cinco regiões, com pratos típicos que são reconhecidos como marcadores identitários (CHEMIN, 2007), pois, como dizem Sonati, Vilarta e Silva (2009), a identidade de um povo dá-se, principalmente, por sua língua e por sua cultura alimentar. 
Hernandez (2005) considera que, no âmbito da alimentação, existem marcadores de identidade que correspondem às formas de alimentação, e os produtos consumidos e as formas como são preparados relacionam-se com os recursos locais, as características do clima e do solo, a forma de produção, a agricultura, a pecuária, a forma de armazenamento e o comércio. Assim como se relacionam também com os conhecimentos e com as práticas culinárias inseridas em todo o contexto socioeconômico.

A multiplicidade de culturas existentes na cozinha brasileira fez com que em cada região geográfica fossem formados verdadeiros marcadores identitários culinários, onde o denominador comum encontrado para as grandes refeições, como o almoço e jantar, em todo o país e em todas as classes sociais é o feijão com arroz, acrescido da farinha de mandioca (CHEMIN, 2007; MACIEL, 2004). São poucas as pesquisas abordando a refeição CM (CHAPLIN; SMITH, 2011; REEVES et al., 2013; TRANCOSO; CAVALLI; PROENÇA, 2010), de maneira que ainda não foram encontrados estudos fazendo referência aos marcadores culinários no CM.

Há um movimento crescente no Brasil e no mundo de manifestações sociais em relação à valorização da cozinha regional e de produtos locais como patrimônio de saberes e práticas culinárias. Até o ano de 2013, a UNESCO reconheceu como Patrimônios Imateriais da Humanidade a culinária mexicana, a refeição gastronômica à moda francesa, a dieta mediterrânea e o pão de mel croata. No Brasil, até esse mesmo ano, entre os bens culturais relacionados à gastronomia registrados pelo Instituto do Patrimônio Histórico e Artístico Nacional (IPHAN), está o ofício das paneleiras de Goiabeiras e o ofício das baianas de acarajé. Está em processo de registro o modo artesanal de fazer queijo Minas, nas regiões do Serro e na Serra da Canastra e do Salitre. No estado de Minas Gerais, portanto no âmbito municipal, também foram registrados como patrimônio cultural imaterial o modo de fazer pastel de angu em Itabirito e os doces de São Bartolomeu em Ouro Preto (BUNOMO, 2013).

Ate o mês de junho de 2015, constava como inventários realizados no IPHAN o ofício da Farinha de Mandioca no Pará, o Oficio das Tacacazeiras do Norte, o Tabuleiro das Baianas em Salvador, o Acarajé em Salvador, a Produção dos Doces Tradicionais Pelotenses e os Cocos do Nordeste. O inventário do Queijo Kochkase, típico do vale do Itajaí, e os Modos de fazer tradicional da cajuína no Piauí encontravam-se em fase de andamento (BRASIL, 2015b). 
Esses são os patrimônios imateriais registrados atualmente em âmbito nacional no IPHAN, mas muitos são os registros que acontecem em âmbito municipal e estadual. O ideal é que esses procedimentos de patrimonialização se desenvolvam a ponto de o Brasil ter um inventário de produtos tradicionais que, a exemplo de alguns países da Europa, realize um censo dos modos de fazer e de produzir específicos a cada produto, descrevendo características como a identidade, a origem, a forma de elaboração, a forma de consumo, os principais locais de produção e outras informações pertinentes.

De um modo geral, o resgate das tradições ainda acontece de forma tímida no Brasil, mas algumas regiões ainda preservam os antigos costumes e os rituais das tradições passadas de geração em geração, como em algumas cidades do interior de Minas Gerais, do Rio Grande do Sul, da Bahia, do Amazonas e de Goiás (ZUIN; ZUIN, 2009).

Cruz e Scheiner (2010) levantam uma importante questão em relação ao controle de qualidade dos produtos regionais brasileiros. A Legislação Brasileira de Alimentos adota os padrões internacionais para a produção de alimentos, cujos requisitos são baseados na inocuidade integral dos alimentos, considerando como ferramentas as Boas Práticas de Fabricação (BPF) e a Análise de Perigos e Pontos Críticos de Controle (APPCC) - adotados pela Food and Drug Administration (FDA). Ou seja, a legislação sanitária atual está direcionada à qualidade do sistema industrial de alimentos produzidos e transportados em grande escala. No entanto, a produção tradicional de alimentos está embasada em métodos artesanais, que operam em escalas de processamento incomparavelmente menores que as utilizadas na indústria convencional, de forma que a legislação pertinente ao controle de qualidade de produção de alimentos existente no Brasil não se ajusta à produção tradicional de alimentos regionais.

Pode ser que, por iniciativa de alguns pequenos produtores de alimentos regionais, existam práticas e condutas que visem à qualidade sanitária dos mesmos. Mas o certo é que essa situação indica a urgente necessidade de maiores investimentos no setor, não somente no que se refere à elaboração de leis sanitárias, mas como forma de melhor explorar esse potencial natural existente no Brasil. Investimentos realizados nesse setor produtivo influenciam positivamente diversos outros aspectos da sociedade, como desenvolvimento sustentável, ecologia, agricultura familiar, geração de empregos, aumento da renda familiar, 
capacitação profissional, melhora da autoestima da comunidade, cultura, melhor qualidade de vida no que concerne à educação, moradia, lazer e principalmente a saúde.

\subsubsection{Migração dos alimentos regionais}

A difusão mundial de certos alimentos é muito mais antiga do que a chamada globalização. Há quinhentos anos, tem-se notícia de revoluções nos hábitos alimentares que acometiam todos os continentes: o milho, o tomate e o pimentão, no Mediterrâneo; a introdução do cultivo da batata na Europa; o rápido sucesso da pimenta-do-reino na África e na Índia; e a popularização do café, chá, açúcar e chocolate na Europa. Assim, a comida foi um capítulo vital na história do capitalismo (MINTZ, 2001).

Em virtude dos processos de colonização ocorridos no mundo, os alimentos viajaram por diversas regiões e países, produzindo transformações significativas em sistemas alimentares já estabelecidos e com tradições próprias. Ao se deslocarem, as populações levavam com elas todo o conjunto de práticas culturais alimentares (MACIEL, 2004), caracterizando assim o processo migratório dos alimentos que acontece de forma contínua e diferenciada, dependendo do contexto em que o alimento está envolvido.

Carvalho (2008) confirma esse fenômeno quando comenta que há variações na composição dos grupos de alimentos adquiridos nas regiões brasileiras. As peculiaridades revelam os gostos locais na escala regional, o que, entretanto, pode esconder padrões introduzidos mais recentemente como resultado de migrações de pessoas (e de hábitos alimentares) de outras regiões.

Graças às trocas culinárias provenientes da miscigenação cultural ocorrida na colonização do Brasil (ELOY; REIS, 2012) e ao fenômeno da globalização, a população brasileira atualmente tem acesso a uma enorme quantidade de produtos alimentares regionais, principalmente de frutas e de seus inúmeros derivados. A globalização, por meio do desenvolvimento tecnológico referente à mecanização, às técnicas de conservação, ao armazenamento e ao 
transporte, proporcionou a disseminação dos alimentos entre regiões e países diferentes, tambem promoveu o intercâmbio entre culturas e o acesso a grande diversidade de alimentos (FABRI, 2013; GARCIA, 2003; HERNANDEZ, 2005; MALUF, 2007; POULAIN, 2004).

A ampliação das possibilidades de comunicação, com a melhoria dos sistemas de transportes, resultou em diminuição das distâncias entres os diversos mercados das diversas regiões, que, aliados à possibilidade de industrialização, propiciaram aos consumidores a oportunidade de conhecerem alimentos provenientes de regiões distantes, ampliando as opções de escolha, de consumo e até mesmo a adoção de culturas alimentares de outras partes do Brasil e do mundo (CARVALHO, 2007; CHEMIM, 2007; POPKIN, 2006; POULAIN, 2004).

Se por um lado tal processo de globalização amplia a diversidade alimentar, por outro também a reduz, uma vez que circulam as mesmas opções alimentares próprias da globalização (GARCIA, 2003). Por outro lado, pode acarretar na desvalorização do conhecimento agrícola e culinário tradicional; no distanciamento do homem com a origem e territorialidade dos produtos; na padronização dos hábitos alimentares e no comprometimento do consumo de alimentos regionais frente à praticidade proporcionada pelos alimentos industrializados; na uniformização dos modos de vida rural e urbana e de produtos; e na perda da identidade cultural (FABRI, 2013).

É inegável a influência do processo de urbanização e da modernização da agricultura nas mudanças alimentares do brasileiro, que se iniciaram aproximadamente no ano de 1966. Desde aquela época, o comportamento dos complexos agroindustriais desempenha um papel importante nessas mudanças, não somente pela visualização dos dados estatísticos que podem desvendar um processo bastante complexo, mas também pela mudança de valores e significados atribuídos ao que se põe na mesa, além da disseminação de informações sobre alimentos e saúde (CARVALHO, 2008).

Assim, a produção de alimentos também influencia a cultura alimentar local, mas esses dois aspectos são flexíveis e sofrem alterações ao longo do tempo e influenciam-se entre si. Esse processo faz com que, na atualidade, as pessoas de classe média nas grandes cidades usufruam da gastronomia de quase todas as regiões do mundo (BRASIL, 2006b). 
A migração das cozinhas regionais é vista por alguns como uma ameaça às cozinhas tradicionais, no entanto, essas mudanças não apenas não as extinguiram como também contribuíram para a recuperação de conhecimentos e práticas alimentares tradicionais em muitos lugares, como uma forma de afirmação identitária. Esse processo diminuiu o desconhecimento de alguns pratos regionais em que os ingredientes necessários eram exclusivos do lugar de origem, permitindo a experimentação de novos sabores pela população de outras regiões (MACIEL, 2005).

Acredita-se que a tradição e a modernidade alimentar não se ameaçam, pois os hábitos alimentares constituem um domínio em que a tradição e a inovação têm a mesma importância, em que o presente e o passado se entrelaçam para satisfazer a necessidade do momento. Sendo assim, compreende-se que as práticas alimentares dos comensais contemporâneos são permeadas por hábitos e costumes da tradição (SOUZA; ALMEIDA, 2011; COSTA, 2009).

Para a autora Pons (2005), as migrações são uma das linhas de transformações alimentares produzidas também pela influência da publicidade de alimentos sobre o consumo, provocando mudanças reais e complexas e processos de readaptação segundo as trajetórias de inserção e de êxito do projeto migratório, com consequências diferenciadas de impacto nutricional.

Carvalho (2007) comenta que hoje o regionalismo é menos intenso, pois a nossa experiência é de acesso a uma enorme diversidade e multiplicidade de alimentos, muitas vezes a preços razoáveis. É possível comprar produtos agrícolas que não são produzidos na região advindos de regiões distantes, dentro de uma estrutura econômica e comercial globalizada. Para Dória (2009), é possível ser nordestino em São Paulo ou gaúcho em Rondônia, devido às viagens que os alimentos realizam por meio das migrações internas.

Com base nesse último autor, é possível concluir que o ritmo de migração constante e progressiva dos alimentos regionais tende a facilitar cada vez mais 0 consumo de tais alimentos. Tal processo propiciará maior consumo de alimentos in natura e pouco processados, e consequentemente mais saudáveis, desde que sejam observados os requisitos mínimos de segurança alimentar e nutricional. 


\subsection{SEGURANÇA ALIMENTAR E NUTRICIONAL}

Estudar o consumo alimentar de uma população envolve considerar diversos fatores, como o econômico, o social, o nutricional, o cultural, e sobretudo verificar se os indivíduos têm acesso a uma alimentação de qualidade e segura em todos os aspectos, desde a produção na agricultura até o consumo em condições adequadas.

O consumo de alimentos regionais e o resultado do processo migratório desses alimentos são uma situação que favorece a promoção da saúde, porque permite ao indivíduo acessar alimentos regionais em locais distantes de sua área de produção. Mas o acesso à alimentação saudável, sendo ela regional ou não, deve estar embutido em um contexto de segurança alimentar e nutricional, para garantir que a promoção e a manutenção da saúde sejam efetivas.

Em primeiro lugar, faz-se necessário realizar uma definição de termos no que diz respeito ao tema segurança alimentar e nutricional (SAN), para uma melhor compreensão do assunto. Burlandy (2011) resume a dimensão alimentar como os aspectos relativos à produção, à comercialização e ao consumo de alimentos, e a dimensão nutricional como os aspectos da utilização do alimento pelo organismo e sua relação com a saúde. Para Monteiro (2004), esses conceitos são distintos, embora estejam intimamente relacionados. Segundo ele, a relação que une segurança alimentar e nutricional é clara: os elementos constitutivos do conceito de segurança alimentar (oferta de alimentos saudáveis e acesso aos meios necessários para se identificar e adquirir esses alimentos) tomam parte direta e central na determinação do estado nutricional dos indivíduos.

De fato, a Ação Brasileira pela Nutrição e Direitos Humanos - ABRANDH considera essas duas dimensões bastante distintas dentro do conceito da Segurança Alimentar e Nutricional - SAN. Para a ABRANDH, a segurança alimentar é um importante mecanismo para a garantia da segurança nutricional, mas não é capaz de dar conta por si só de toda sua dimensão. A dimensão alimentar refere-se à produção e disponibilidade de alimentos, que sejam suficientes para atender à demanda; que sejam estáveis e continuadas para garantir a oferta permanente; autônomas para que se alcance a autossuficiência nacional nos alimentos básicos; 
equitativas para garantir o acesso universal às necessidades nutricionais adequadas nas etapas da vida e nos diferentes grupos da população, e sustentáveis do ponto de vista agroecológico, social, econômico e cultural, com vistas a assegurar a SAN das próximas gerações (AÇÃO BRASILEIRA PELA NUTRIÇÃO E DIREITOS HUMANOS, 2010; 2013).

A dimensão nutricional incorpora as relações entre o homem e o alimento, implicando a escolha de alimentos saudáveis; valoriza o preparo dos alimentos com técnicas que preservem o seu valor nutricional e sanitário e o consumo alimentar adequado e saudável, em boas condições de saúde, higiene e de vida para melhorar e garantir a adequada utilização biológica dos alimentos consumidos; valoriza a promoção dos cuidados com sua própria saúde, de sua família e comunidade; o acesso aos serviços de saúde de forma oportuna e com resolutividade das ações prestadas; e a promoção dos fatores ambientais que interferem na saúde e nutrição como as condições psicossociais, econômicas, culturais e ambientais (AÇÃO BRASILEIRA PELA NUTRIÇÃO E DIREITOS HUMANOS, 2010; 2013).

De acordo com documento aprovado na II Conferência Nacional de Segurança Alimentar e Nutricional (BRASIL, 2004), SAN é definida como "a realização do direito de todos ao acesso regular e permanente a alimentos de qualidade, em quantidade suficiente, sem comprometer 0 acesso a outras necessidades essenciais, tendo como base práticas alimentares promotoras de saúde, que respeitem a diversidade cultural e que sejam social,

econômica e ambientalmente sustentáveis". Para Keplle, Segal e Correa (2011), é um conceito bastante abrangente, por natureza interdisciplinar, que envolve questões de acesso a alimentos de qualidade, práticas alimentares saudáveis, práticas sustentáveis de produção, cidadania e direitos humanos. Para essas autoras, a proposta brasileira de SAN destaca-se por defini-la em termos de qualidade e de quantidade de alimentos adequadas para toda a população, de todas as classes sociais, sem excluir, do âmbito de ações requisitadas, as classes menos carentes.

Na década de 90, despontaram no cenário internacional e nacional novas concepções sobre a segurança alimentar que extrapolavam os aspectos da qualidade sanitária dos alimentos, na ótica da segurança dos alimentos, entendida fundamentalmente como inocuidade. As novas concepções chamavam a atenção para as dimensões do abastecimento, do acesso aos alimentos, da escassez e da 
fome como expressões mais graves desse processo. Além disso, começaram a ser consideradas questões que foram além da dimensão nutricional, como as referentes ao respeito e ao resgate da diversidade cultural alimentar, à promoção da saúde e às questões de sustentabilidade social, ambiental e política. A partir daí a SAN vem ocupando de forma crescente a agenda pública no Brasil, dentro de um necessário processo de reconstrução de valores, concepções e práticas político-institucionais, compartilhado pelos diversos setores do governo e pelas organizações sociais (BURLANDY, 2011).

Há várias décadas o Brasil tem desenvolvido ações de políticas públicas direcionadas a melhorar a SAN de sua população. Essas ações, entretanto, receberam novo impulso em 2003, quando o enfrentamento da pobreza foi definido como prioridade. Para tal, foi instituído o programa Fome Zero, que teve como objetivo a superação da fome e da miséria no Brasil, sendo proposto como a principal política de proteção social do governo (CABRAL et al., 2014; KEPLLE; SEGAL; CORREA, 2011). Assim, o programa Fome Zero foi uma forma de assegurar o DHAA, a promoção da SAN, a inclusão social e a conquista da cidadania por parte da população mais vulnerável à fome.

Dentre os programas com finalidade de assistir à população mais vulnerável às situações de pobreza e de fome, foi instituído em 2003 o Programa Restaurante Popular, que visa garantir à população carente um maior acesso aos alimentos. Essas Unidades de Alimentação e Nutrição são equipamentos públicos que possuem o objetivo de oferecer alimentação de qualidade nutricional e segura em termos microbiológicos, a preços acessíveis, às populações sob o risco de Insegurança Alimentar e Nutricional - ISAN (BRASIL, 2011a).

A SAN vem sendo discutida internacionalmente e, segundo a Food and agriculture Organization, ela ocorre quando todas as pessoas, ininterruptamente, têm acesso físico, social e econômico à alimentação suficiente, segura e nutritiva, que atenda às suas necessidades dietéticas e preferências alimentares para uma vida saudável e ativa. No Brasil, tornou-se lei em 2006 (Lei Orgânica de Segurança Alimentar e Nutricional - LOSAN) e agrega ao seu conceito o estabelecimento da alimentação como um direito e o enfoque da necessidade de práticas alimentares promotoras de saúde, que respeitem a diversidade cultural e que sejam ambiental, cultural, econômica e socialmente sustentáveis para a garantia da SAN. Em 2010, essa lei foi referendada com a instituição da Política Nacional de Segurança 
Alimentar e Nutricional (BRASIL, 2011b), que reafirma a garantia do acesso universal à alimentação adequada (VIEIRA et al., 2013).

A implementação da SAN implica ações articuladas envolvendo vários setores: política econômica, emprego e renda, políticas de produção agroalimentar (políticas agrária, de produção agrícola e agroindustrial), comercialização, distribuição, acesso e consumo de alimentos, com perspectivas de descentralização e diferenciação regional; ações emergenciais contra a fome; ações de controle de qualidade dos alimentos; diagnóstico e monitoramento do estado nutricional e de saúde de populações; estímulo a práticas alimentares saudáveis, além da valorização das culturas locais e regionais (PRADO et al., 2010).

Como é possível observar, o conceito de segurança alimentar e nutricional foi ampliado e construído de forma a ultrapassar o marco dos processos de carências nutricionais, em função da transição nutricional marcada pela dupla carga de doenças, ou seja, a coexistência das carenciais (desnutrição e deficiências de micronutrientes) e das relacionadas ao excesso de peso e associadas às crônicas não transmissíveis (MORAIS et al., 2014).

Um estudo realizado por Martins (2010), com o objetivo de avaliar os efeitos de uma intervenção educativa sobre a utilização dos alimentos regionais, investigou 200 familiares de crianças na faixa etária de três a seis anos. Aos familiares das crianças atendidas em uma Unidade Básica de Saúde da Família, localizada na zona rural de Ceará, foi aplicado, entre outros instrumentos, a Escala Brasileira de Insegurança Alimentar - EBIA, que mostrou os seguintes resultados: segurança alimentar (12\%), insegurança alimentar leve (35\%), insegurança alimentar moderada (28,5\%) e insegurança alimentar grave (24,5\%), sofrendo influência do consumo dos seguintes grupos de alimentos regionais: tubérculos e raízes, frutas e hortaliças. Esses alimentos, ricos em fibras, vitaminas e minerais, apresentaram uma relação inversamente proporcional ao nível de insegurança alimentar, ou seja, à medida que o nível de insegurança alimentar aumentou, o consumo de alimentos regionais diminuiu.

Os resultados da pesquisa acima podem sugerir que o consumo de tais alimentos regionais aumenta a segurança alimentar, e podem sugerir também que as pessoas consumidoras de alimentos regionais são pessoas com um perfil diferenciado em relação aos aspectos socioeconômicos, educacionais, culturais, etc, o que pode favorecer o estabelecimento da segurança alimentar. 
Para Magalhães (2014), a segurança alimentar e nutricional não é uma questão isolada ou um privilégio de alguns. Ao contrário, é um tema fortemente vinculado à saúde, ao ambiente e ao desenvolvimento sustentável global. Então, o consumo de alimentos regionais está intimamente relacionado à segurança alimentar, uma vez que a produção desses alimentos está também muito vinculada ao estímulo da produção local de alimentos e ao fortalecimento da agricultura familiar, que pode contribuir mutuamente com o ambiente e o desenvolvimento sustentável.

A abordagem sobre a SAN no presente trabalho mostrou que a inclusão dos aspectos culturais nos estudos sobre consumo alimentar é imprescindível, principalmente em se tratando do consumo de alimentos regionais, uma vez que usufruir a SAN prevista em lei (BRASIL, 2006a) prevê práticas alimentares que respeitem a diversidade cultural.

Países em desenvolvimento como o Brasil sofrem modificações constantes no estilo de vida, em consequência da urbanização e da industrialização crescentes, que são responsáveis por mudanças sensíveis nos hábitos alimentares da população. Assim, as discussões sobre segurança alimentar devem necessariamente acompanhar tais mudanças, a fim de garantir o direito humano à alimentação adequada.

\subsection{CAFÉ DA MANHÃ}

Apesar dos objetivos deste estudo estarem direcionados à população adulta, para esta revisão bibliográfica foram citados alguns estudos realizados com amostra de crianças e de adolescentes, devido ao fato de serem poucas as pesquisas que abordam o CM de pessoas adultas (CHAPLIN; SMITH, 2011; REEVES et al., 2013). 


\subsubsection{Definição de café da manhã}

A diversidade de conceitos em torno da refeição $\mathrm{CM}$ demonstra que não existe uma definição universal. Autores de pesquisas mais antigas, por exemplo, conceituam como toda refeição ingerida antes das 11 horas da manhã (MUR de FRENNE; FLETA; MORENO, 1994; ORTEGA et al., 1996). Kennedy e Davis (1998) consideram a refeição CM como a mais importante do dia, por melhorar a qualidade total da dieta e restabelecer as funções orgânicas. Pereira et al. (2011) definem o CM como a primeira refeição do dia, realizada antes ou no início de atividades diárias, dentro de 2 horas depois de acordar, normalmente até às 10:00 da manhã, e representando um nível de energia entre 20 e 35\% do total das calorias diárias consumidas.Trancoso, Cavalli e Proença (2010) consideram uma forma mais simples de definição de CM: a primeira refeição consumida pela manhã.

Rampersaud et al. (2005) consideram CM o consumo de pelo menos um item alimentar entre os horários de 5 às 9 horas da manhã. Já Barton et al. (2005) fazem a diferenciação da realização do CM nos dias de fim de semana, considerando ser a refeição realizada entre 5 e 11 horas da manhã.

Mullan e Singh (2010) consideram que a definição de CM deve considerar não somente o horário em que a refeição é realizada, mas também o tipo de alimento consumido. AZADBAKHT et al. (2013), por exemplo, definiram CM como o consumo de qualquer alimento sólido ou bebida, exceto água, consumida até as 10 horas da manhã. Na elaboração dos conceitos de CM pelos pesquisadores, é comum a falta de descrição do consumo de água com o fez esses últimos autores.

Outros autores (GIOVANNINI et al., 2008; MONTEAGUDO et al., 2012; MORALES et al., 2011; RIVES et al., 2015; VAN DEN BOOM et al., 2006) consideram CM a primeira refeição do dia realizada antes ou no início das atividades diárias, com um teor de energia que atenda a 20-25\% do total das necessidades energéticas diárias, e que inclui produtos lácteos, cereais, frutas e gorduras saudáveis.

Para HÖFELMANN e MOMM (2014), o CM é uma das três principais refeições diárias, frequentemente definida como a primeira refeição do dia, que rompe o jejum involuntário após o período de sono noturno. 
Recentemente, Rives et al. (2015) formularam uma definição para $C M$ saudável, como sendo uma dieta contendo todos os nutrientes equlibrados de forma qualitatita e quantitativa, podendo ser composta de alimentos diversos para garantir a ingestão de hidratos de carbono, lípidos, proteínas, vitaminas e minerais. A tríade de grupos preferencialmente aconselhados são o do leite e derivados, cereais e frutas ou sucos de frutas frescas, que pode ser complementado com outros alimentos fonte de proteína, como ovos, presunto, etc.

O CM, em termos simples, significa o consumo de alimentos no período da manhã para "quebrar" o jejum ocorrido durante a noite, e pode consistir em qualquer consumo de alimentos sólidos, pastosos ou líquidos. No entanto, o CM pode ter significados diversos para indivíduos diferentes. Por exemplo, indivíduos de algumas etnias (tais como mexicanos-americanos) consideram "brunch" (uma combinação de CM e almoço) como CM. Devido a isso, muitos estudos sobre o tema consideram a definição de CM como um "auto-relato" dado pelos indivíduos, em vez de considerar uma definição única estabelecida pelos pesquisadores (DESHMUKHTASKAR, 2010a).

Sivaramakrishnan e Kamath (2012) adotaram uma definição de CM diferente: qualquer alimento (sólido/líquido/ou ambos) consumido antes das 9 horas para adultos, adolescentes e crianças que frequentam a escola de manhã, ou antes das 11 horas para adolescentes e as crianças que frequentam a escola à tarde. Isso mostra que a melhor forma de definir CM para a realização de uma pesquisa é considerar o contexto de realização do estudo.

Rampersaud (2009) faz uma observação interessante quando ressalta que, na definição de $\mathrm{CM}$, é importante considerar quatro aspectos: a percepção que o indivíduo tem dessa refeição, o tipo de alimento frequentemente consumido, a realização da refeição em uma hora específica do dia e o fato de ser a primeira refeição consumida após o acordar.

O'Neil et al. (2014) fazem uma observação bastante assertiva ao comentar que definições de refeições, incluindo assim o CM, variam de acordo com a localização geográfica, o tempo e a cultura em que o individuo está inserido. Para além dessas observações, os autores acentuam que a definição pode sofrer influência de fatores como a frequência semanal, a hora do dia, o tempo em relação ao estado de vigília, as atividades diárias, os tipos de alimentos ou de bebida consumidos, ou ainda a quantidade de energia fornecida na refeição. 
O estudo realizado por Adolphus, Lawton e Dye (2015), cujo objetivo foi avaliar a associação entre o consumo habitual do CM com a perfomance cognitiva, construiu o conceito de "CM habitual" pela análise de questionários contendo o autorelato dos próprios participantes da pesquisa.

Marlatt et al. (2016) consideram que a falta de uma definição universal de $\mathrm{CM}$, bem como os diferentes métodos para medição da composição desta refeição, tem levado a resultados diferentes nos estudos sobre a relação CM e saúde.

Observa-se que a pluralidade de definições em torno da refeição CM não permite a padronização do termo. Talvez na realização de pesquisas com maior rigor metodológico e para produção de dados fidedignos seja adequado que o pesquisador colete essa informação na própria amostra a ser estudada, a exemplo do realizado no estudo de Adolphus, Lawton e Dye (2015), ou seja, a formulação dessa definição deve ser incluída como parte da metodologia de coleta de dados.

\subsubsection{História do café da manhã}

O papel do CM como uma parte essencial de uma dieta saudável está sendo foco de atenção da comunidade científica apenas há pouco tempo, mesmo considerando que as práticas de consumo do $\mathrm{CM}$ eram conhecidas desde a Idade Média. Essa refeição mudou ao longo do tempo, sendo largamente dependente da cultura e da disponibilidade de alimentos tradicionais em diferentes países (AFFINITA et al., 2013).

Segundo Cascudo (2004), as refeições dos seres humanos nasceram condicionadas ao horário natural. Assim, antes de deixar a casa, o homem de Neanderthal alimentava-se, depois fazia uma refeição ao meio dia, realizando outra refeição ao anoitecer, quando regressava à caverna. Essas informações mostram que nos tempos mais remotos, poderia até não ter um nome definido a primeira refeição do dia feita após o despertar, mas de fato o hábito de fazer o desjejum ou o CM sempre existiu entre os primitivos.

Nos séculos III, IV e V, o regime alimentar dos romanos era descontínuo, não era regulado por horário, uma vez que o alimento era consumido apenas quando os homens sentiam necessidade. Conheciam apenas dois tipos de 
refeições, a cena e o prandium, onde a primeira reunia homens deitados em um lugar coberto, com um grupo social bem definido, que gozavam os prazeres da mesa por ocasião de uma festa. No prandium, os homens comiam apenas o bastante para se restaurarem, não importando onde e quando, mas frequentemente realizavam as refeições de forma isolada, sem a presença de familiares e outros. Nesse tipo de refeição, comiam apenas alimentos frugais, e ela representava a única refeição dos romanos engajados na guerra, na atividade política ou em qualquer outro tipo de atividade que requeria esforço. Geralmente, o prandium era consumido no desjejum ou em uma refeição leve, ao meio dia, e poderia ser composto de frutas acompanhadas ou não de pão (DUPONT, 1998).

$\mathrm{Na}$ idade média, existiam apenas duas refeições chamadas disner ou souper, a refeição matinal, que sugere ser o almoço, e o jantar no final do dia. Supostamente, havia uma refeição ao despertar, mas como a primeira refeição do dia não implicava na reunião de todos os membros da família, não havia um termo específico para ela (DOLADER, 1998).

Por volta do século XI, o regime alimentar do clero, por exemplo, iniciavase com a oferta de um desjejum servido após as primeiras orações. Esse desjejum, chamado de mixtum, era composto por um pedaço de pão e um copo de vinho servido aos monges de serviço, aos doentes, aos que sofriam sangria, aos velhos, às crianças e a quem mais desejasse (RIERA-MELIS, 1998). Nesse contexto, o CM parecia assumir o caráter restaurador de pessoas mais vulneráveis ou debilitadas, não sendo um hábito comum entre as pessoas supostamente saudáveis.

Quanto às práticas brasileiras de realizar as refeições, foi herdado de Portugal o hábito de realizar o almoço, o jantar e a ceia. Foi no território brasileiro, por volta do século XVIII, que foi criada a primeira comida da manhã denominada de café, já que nos demais países essa refeição é chamada de pequeno almoço. Naquela época era uma obrigação expressa alimentar-se antes de sair de casa, e não realizá-la era considerado uma ameaça à saúde. Nas casas grandes das fazendas, essa refeição ligeira era composta por frutas, carnes frias e leite (CASCUDO, 2004). 


\subsubsection{Variáveis relacionadas à supressão do café da manhã}

Dentre todas as refeições diárias, o CM é a mais preterida. Em virtude dos compromissos que se assume no mundo globalizado, em que tudo precisa atender a eventos rigorosamente cronometrados, é muito comum a supressão dessa refeição ou a falta de destinação de um tempo e lugar adequado para a realização dela.

Existem várias situações que se relacionam com a supressão do CM, entre elas a falta de tempo para a preparação e o consumo de alimentos no começo da manhã e as preocupações com o excesso de peso (CHO et al., 2003; LEVITSKY; PACANOWSKI, 2013). O declínio no consumo de CM está normalmente relacionado a mudanças no estilo de vida contemporâneo da população, tais como o aumento do número de indivíduos que moram sozinhos ou realizam a refeição sozinhos, a falta de tempo para realizar as refeições e particularidades no consumo de pratos diferentes pelos membros da família (HÖFELMANN; MOMM, 2014; TRANCOSO; CAVALLI; PROENÇA, 2010). Affinita et al. (2013) acrescentam que os motivos que levam as pessoas a não realizarem o CM são variados e transitam entre fatores como idade, gênero, profissão, tipo de trabalho, costumes culturais, estado existencial de cada indivíduo, incluindo-se a falta de apetite matinal e a tentativa de controle do peso corporal.

Há uma relação importante entre o consumo de CM, a idade, o gênero e o nível socioeconômico. O consumo dessa refeição parece aumentar com a idade quando se consideram pessoas adultas entre 18 e 60 anos, e diminuir quando se trata de crianças e adolescentes, entre 4 e 18 anos, constatando-se ainda que 0 consumo de CM é predominantemente maior na idade adulta que em outras fases da vida. Quanto ao gênero, a supressão dessa refeição é encontrada principalmenteentre adolescentes do sexo feminino, motivada pela preocupação com a imagem corporal, com consequente realização de dietas restritivas sem orientação. A supressão do $\mathrm{CM}$ é mais comum nas pessoas de baixo nível socioeconômico (TRANCOSO; CAVALLI; PROENÇA, 2010).

Fisiologicamente, suprimir o CM está associado a comportamentos pouco saudáveis, tais como o consumo de uma dieta pobre nutricionalmente e a baixos níveis de atividade física. Esses comportamentos podem resultar em um alto IMC, em obesidade, em diabetes tipo 2 e em desenvolvimento de doenças 
cardiovasculares (CAYRES et al., 2016; HUANG et al., 2014; PURSLOW et al., 2008; POT; HARDY; STEPHEN, 2016; SMITH et al., 2010), pois os alimentos que compõem o CM pertencem a grupos de alimentos importantes (pães, cereais, laticínios e frutas), sendo pobres em gordura, tornando-o uma refeição tipicamente nutritiva (SMITH et al., 2010) e conferindo-lhe um caráter protetor em relação à saúde. Freitas, Mendonça e Lopes (2013) comentam que a supressão dessa refeição também tem sido associada ao tabagismo, ao consumo de bebidas alcoólicas, ao sedentarismo, ao baixo nível de escolaridade e predominando em indivíduos do sexo masculino.

Observa-se que as consequências da supressão do CM vão além do simples fato de se omitir uma refeição objetivando a redução de calorias diárias. Está envolta em um conjunto de variáveis que descrevem o contexto em que o indivduo está inserido, em que hábitos não saudáveis interagem com características individuais, produzindo patologias de diversas ordens.

Prova da importância de multifatores como consequência da supressão do CM é a pesquisa realizada por Sun et al. (2013), cujo objetivo foi determinar a prevalência de supressão da refeição $\mathrm{CM}$ e os fatores associados a ela entre estudantes de medicina na Mongólia, China. Os resultados mostraram que o consumo de CM foi associado a muitos fatores, sobretudo a variáveis como gênero, classe social, anos de educação, apetite, despesas mensais, qualidade do sono e qualidade no processo de aprendizagem.

Hulshof et al. (2003) estudaram as diferenças na ingestão alimentar entre adultos com diferentes níveis socioeconômicos. O estudo transversal consultou a base de dados de três anos de pesquisas de consumo alimentar nacional holandês e considerou como amostra 12.965 indivíduos adultos de ambos os sexos. Entre outros resultados, encontraram que a prevalência de obesidade e a supressão do CM foram maiores entre as pessoas com nível socioeconômico mais baixo.

Os autores Chung et al. (2015) estudaram a associação entre o tipo de CM e a ocorrência de síndrome metabólica em 11.801 coreanos adultos e encontraram um percentual de supressão de $21,61 \%$, sendo maior entre os homens e na faixa etária entre 20 e 29 anos de idade. O alto percentual nessa faixa etária provavelmente está relacionado com a fase de vida produtiva, em que os indivíduos possuem menos tempo para realizar todas as atividades diárias. 
Já o percentual de supressão comumente encontrado no Brasil é diversificado. Marchioni et al. (2015), por exemplo, ao caracterizaram os padrões de CM de 795 adolescentes encontraram uma supressão do CM de 38\%. Pereira et al. (2011), observaram que é comum um percentual que varie de 12 a 34\%. Leal et al. (2010) realizaram um estudo com 228 adolescentes no Estado de São Paulo, Brasil, cujo objetivo foi avaliar o consumo alimentar e o padrão de refeições de adolescentes. Na análise dos resultados, os autores concluíram que houve a supressão do CM em $21 \%$ dos adolescentes, sendo maior no sexo feminino. Frequentemente, as meninas são mais motivadas a suprimir o CM pelo desejo de perder peso, na tentativa de obter ou manter um corpo escultural, muito valorizado nos dias atuais.

Outros estudos realizados no Brasil encontraram valores diferentes para a supressão do CM em adolescentes, tais como 2,5\% (NUZZO, 1998); 8\% (ESTIMA et al., 2009); 11\% (VIEIRA et al., 2005); 16\% (FElJÓ et al., 1997); 13,6\% para meninos e $18,7 \%$ para meninas no estudo realizado por Fonseca e Sichieri(1998). Um estudo atual realizado por HÖFELMANN e MOMM (2014) em Santa Catarina, Brasil, com 533 escolares, encontrou a prevalência de supressão do CM igual a 25\% ( $n=128)$.

A Pesquisa Nacional de Saúde Escolar (PNSE), realizada em 2012 pelo Instituto Brasileiro de Geografia e Estatística (IBGE), mostra que 38,1\% dos estudantes brasileiros do $9^{\circ}$ ano do ensino fundamental não tomam CM. Os dados de supressão do CM por região geográfica brasileira estão distribuídos da seguinte forma: Centro-oeste $=44,5 \%$, Nordeste $=28,8 \%$, Norte $=29,8 \%$, Sudeste $=41,1 \%$ e Sul $=45,8 \%$ (BRASIL, 2009). O IBGE ainda não publicou dados sobre a realização do $\mathrm{CM}$ em pessoas adultas, mas considerando que os hábitos alimentares de crianças e adolescentes tendem a se repetir na vida adulta (GRIEGER, COBIAC, 2012; LAZZERI et al., 2013; MARANGONI et al., 2009; SONG et al., 2006), fica mais fácil realizar uma aproximação referente aos percentuais de supressão da população adulta brasileira.

Medeiros et al. (2007), estudando uma amostra de 600 adultos que foram acidentados no trabalho e posteriormente atendidos em uma instituição de assistência médica de Piracicaba, São Paulo, encontraram um percentual de supressão do CM de 24,16\% ( $n=600)$. Costa e Vasconcelos (2013) realizaram uma pesquisa com o objetivo de avaliar o perfil e os fatores associados ao estado nutricional de estudantes ingressantes em uma universidade pública de 
Florianópolis, SC. Dentre os diversos resultados, encontraram que o CM é a refeição mais omitida, com um percentual de supressão de 19,6\% $(n=220)$.

Observa-se que são muitas as variáveis que influenciam a supressão do $\mathrm{CM}$, mas todas têm em comum a influência do local ou da cultura em que a pessoa está inserida. Nesse contexto, deve estar incluído todo o arcabouço da vida moderna que altera diretamente e negativamente o estilo de vida das pessoas, com consequências marcantes no padrão alimentar de cada indivíduo.

A questão do contexto apresenta-se como a justificativa principal da supressão do CM, mas se acredita que o fator mais importante nesse hábito seja a falta de conscientização sobre a importância dessa refeição. É necessaria uma reflexão que tenha como base a indiscutível necessidade do organismo humano de se reabastecer de combustível alimentar para o início das atividades diárias.

\subsubsection{Café da manhã e saúde}

A refeição $\mathrm{CM}$ objetiva prover energia e permitir a realização das atividades da manhã e dos demais períodos, depois do longo tempo de jejum ocorrido naturalmente durante o sono (MARANGONI et al., 2009; YOO et al., 2014). Devido a isso, a realização dessa refeição tem sido associada a um efeito positivo na saúde humana.

Existem inúmeras pesquisas abordando a relação entre o consumo frequente de CM e o baixo risco de sobrepeso e obesidade (AFFENITO, 2007; ALEXANDER et al., 2009; CORDER et al., 2014; ENES; SLATER, 2010; KAHLEOVA et al., 2014; KUTSUMA; NAKAJIMA; SUWA, 2014; MORILLAS-RUIZ et al., 2014; NICKLAS et al., 2004; RAMPERSAUD et al., 2005). Essas pesquisas focalizam os benefícios da realização dessa refeição, como o aumento da saciedade, uma menor ingestão calórica diária, um melhor controle glicêmico, um menor risco de ganho de peso, um menor ganho da gordura visceral e menor risco de comorbidades relacionadas com o peso, como hipertensão, a diabetes mellitus, a sindrome metabólica e as doenças cardiovasculares (CARDOSO et al., 2009; CAYRES et al., 2016; CIMADON; GEREMIA; PELLANDA, 2010; FREITAS; 
MENDONÇA; LOPES, 2013; MARLATT et al., 2016; POT; HARDY; STEPHEN, 2016; SCHEMBRE et al., 2013; UEMURA et al., 2015; YOO et al., 2014), sugerindo que esse hábito é um claro fator protetor da saúde humana.

O CM tem sido amplamente pesquisado com relação à função cerebral que envolve a cognição, o desempenho acadêmico e a concentração, principalmente em crianças em idade escolar (MIRZAEI et al., 2016). Teoricamente, foram sugeridos dois mecanismos biológicos pelos quais o CM pode afetar a função cerebral e o desempenho cognitivo. O primeiro envolve alterações metabólicas associadas ao fornecimento de nutrientes essenciais e à disponibilidade de energia para o sistema nervoso central, após o longo período de jejum noturno. O outro envolve os efeitos benéficos a longo prazo que o CM pode propiciar pela ingestão de nutrientes, com reflexos positivos no estado nutricional (AFFINITA et al., 2013; HÖFELMANN; MOMM, 2014; MARANGONI et al., 2009; MULLAN; SINGH, 2010; REEVES et al., 2013).

Azadbakht et al. (2013) acrescentam que a supressão da refeição CM compromete a saúde comportamental do indivíduo adulto. Benton e Brock (2010) acreditam que os alimentos consumidos no $\mathrm{CM}$ influenciam no humor durante a manhã. Para Reeves et al., (2013), as pessoas que fazem o CM tendem a ser menos deprimidas.

A não realização do $\mathrm{CM}$ apresenta correlação com o aumento do consumo de lanches calóricos, que desencadeia uma maior ingestão energética total de carboidratos e gorduras (AFFENITA et al., 2013; AFFENITO, 2007; ENES; SLATER, 2010; KAHLEOVA et al., 2014; RAMPERSAUD et al., 2005; SONG et al., 2005). A supressão do CM também está associada à inviabilização da elevação da glicemia aos níveis necessários às atividades matinais e ao favorecimento de uma possível deficiência de cálcio (GAMBARDELLA; FRUTUOSO; FRANCHI, 1999; HÖFELMANN; MOMM, 2014; TRANCOSO; CAVALLI; PROENÇA, 2010).

As observações elencadas acima confirmam a proposição máxima de que a alimentação é a necessidade primordial da vida humana. A alimentação saudável envolve diversos fatores, como os biológicos, os fisiológicos, os culturais, os psicológicos e até os fatores afetivos. De forma que a inanição, de um modo geral, pode representar, entre outros significados, a sensação de falta de poder na vida e um sentimento de renegação e de falta de pertencimento, por não ter o indivíduo acesso a uma condição básica de vida humana, a alimentação. Esse processo, 
quando ocorrido nas primeiras horas do dia, fatalmente irá afetar o humor e todo o estado psicológico do indivíduo durante o resto do dia.

Considerando todas as informações sobre o hábito de realizar o CM e o maior número de refeições durante o dia, Enes e Slater (2010) estão certos em afirmar que tais hábitos estão diretamente associados a um padrão mais regular e definido de realização de refeições, o que somente vem favorecer a promoção e a manutenção da saúde.

\subsubsection{Café da manhã e estado nutricional}

Existe uma polêmica ao redor da verdadeira relação entre a realização do $\mathrm{CM}$ e o controle do peso corporal. No entanto, o que mais preocupa é a prática não saudável da supressão de refeições para redução de calorias ingeridas, e entre elas o CM é a mais escolhida.

Tem sido proposta a afirmação de que a supressão do CM está associada a uma diminuição da capacidade de perder peso. Esse pressuposto se baseia na idéia de que a supressão dessa refeição pode levar ao desejo de maior consumo de alimentos no final do dia (RAMPERSAUD et al., 2005; REEVES et al., 2013). Isso parece bastante coerente se se considerar que a alimentação deve ser realizada de maneira saudável, em intervalos relativamente curtos. Se a alimentação não for fornecida ao organismo nessa periodicidade, é natural que a fome e o apetite fiquem exacerbados no final do dia.

São vários os enfoques dados aos estudos que pesquisam a relação do CM com o peso corporal. Jakubowicz et al. (2013), por exemplo, realizaram uma pesquisa com o objetivo de comparar o efeito de duas dietas para perda de peso de igual teor calórico diário (1400 kcal). Foi feita uma orientação quanto aos horários de realização das refeições: CM de 6 à 9 horas, lanche de 12 às 15 horas e jantar de 18 às 21 horas. Os participantes foram avaliados por 12 semanas e receberam dois tipos de dietas, sendo uma com alta ingestão calórica (aproximadamente $700 \mathrm{kcal}$, $50 \%$ ) durante o CM, médio valor calórico no lanche ( $500 \mathrm{kcal}, 36 \%)$ e jantar com baixa caloria ( 200 kcal, 14\%). A outra dieta foi o inverso da primeira, com CM pouco calórico e jantar hipercalórico. Os resultados mostraram que o CM com alto 
teor calórico e jantar com teor calórico reduzido é benéfico para o tratamento da obesidade, ou seja, auxilia na perda de peso.

Trabalhos como esse dizem respeito à associação da densidade energética da dieta com o consumo de energia e com o peso corporal. Foi com o objetivo de examinar as diferenças da densidade energética de dietas entre consumidores e não consumidores de CM, que Kant et al. (2008) analisaram os dados de três anos consecutivos da Pesquisa Nacional de Saúde e Nutrição dos Estados Unidos (1999-2004). Os resultados mostraram que a densidade energética de $24 \mathrm{~h}$ de ingestão foi menor nos consumidores de CM que entre os que omitiam a refeição. Esse achado confirma a idéia de que não realizar o $\mathrm{CM}$ regularmente estimula o consumo de alimentos com maior densidade energética nas demais refeições.

No estudo acima, mulheres consumidoras do CM tiveram menor IMC do que as não consumidoras da refeição. Com o aumento da ingestão energética no CM entre as não consumidoras da refeição, a densidade energética e a ingestão de gordura aumentaram, mas a ingestão de micronutrientes e a probabilidade de consumo de todos os cinco grupos de alimentos diminuíram. Esse comportamento alimentar demonstra que são necessárias intervenções que promovam melhores orientações nas escolhas alimentares para o CM (KANT et al., 2008).

Questionando a correlação inversa entre a frequência de realização do CM e a ingestão energética, Levitsky e Pacanowski (2013) investigaram se a supressão do CM induz ou não a mecanismos de compensação energética subsequente em indivíduos adultos. Para responder a esse questionamento, os autores realizaram duas pesquisas, sendo uma com o objetivo de examinar o efeito da supressão do $\mathrm{CM}$ na quantidade consumida no almoço. A segunda pesquisa examinou o efeito de comer o CM com maior quantidade sobre a quantidade consumida no almoço e durante o resto do dia. O protocolo para participar da pesquisa era não comer alimentos depois das 23 horas e fazer o CM entre 7:45 e 9:20 horas da manhã no Centro de Pesquisa de Metabologia Humana da Universidade de Cornell, Estados Unidos.

No primeiro estudo de Levitsky e Pacanowski (2013), os autores selecionaram randomicamente 24 participantes adultos que podiam optar por três condutas: (1) não realizar o CM, (2) alimentar-se com CM contendo alto teor de carboidrato, ou (3) alimentar-se com CM contendo alto teor de fibras. O segundo 
estudo seguiu o mesmo desenho de seleção que incluiu 18 participantes adultos, que poderiam optar por consumir um CM em maior quantidade ou com normal quantidade de carboidratos. No primeiro estudo, tanto o fato de não realizar CM como realizar o CM rico em carboidratos ou fibras alimentares não tiveram efeito sobre a quantidade de alimentos consumidos no almoço, apesar de os participantes apresentarem uma redução nos índices de fome. No segundo estudo, tanto a ingestão do almoço como a fome foram significativamente maiores após realizar o $\mathrm{CM}$ em maior quantidade ou normal.

Os dados relatados acima revelam que uma redução no tamanho da porção em uma refeição não resulta em um aumento do consumo durante o resto do dia, e que pular uma refeição não resulta em compensação de energia nas refeições subsequentes. Esses dados sugerem que a supressão do CM pode ser um meio eficaz para reduzir a ingestão diária de energia em alguns adultos (LEVITSKY; PACANOWSKI, 2013).

Os estudos realizados por esses últimos autores aparentemente contradizem a afirmação feita pelos autores Rampersaud et al. (2005) e Reeves et al. (2013) de que a supressão do CM ou a ingestão de menor quantidade de alimentos nessa refeição podem levar ao desejo de maior consumo de alimentos no final do dia. Algumas pesquisas podem indicar a possibilidade de supressão do CM como estratégia para redução da ingestão diária de energia em alguns adultos, mas apresentam algumas limitações, como o número pequeno da amostra estudada e a falta de acompanhamento do tratamento. Seriam necessários estudos de desenhos longitudinais para melhor avaliação da associação entre a causa e o efeito, detectando mudanças no indivíduo com o passar do tempo (PEREIRA, 2001), além de constatar a ocorrência de outros benefícios trazidos com o hábito de realização do CM.

Dessa forma, a pesquisa realizada por Levitsky e Pacanowski (2013) precisa ser analisada com cautela, antes de qualquer generalização de resultados, pois, além de sugerir que a supressão da refeição CM pode ser benéfica ao controle de peso corporal, o que seria contrário às recomendações mundiais de alimentação saudável, também apresenta algumas características metodológicas que impedem que os resultados sejam generalizáveis de forma segura. Se o tamanho das amostras das duas pesquisas não tivesse sido declaradamente pequeno, e tivesse ocorrido a aleatorização do tipo de dieta a ser consumida, poder-se-ia garantir que 
os resultados não sofreriam a influência de viéses, como a preferência alimentar por determinada opção de dieta.

Os pesquisadores Kant e Graubard (2015) realizaram um estudo com 2.132 indivíduos provenientes da Pesquisa Nacional de Saúde e Nutrição dos Estados Unidos, no periodo de 2005-2010, cujo objetivo foi comparar as diferenças nos comportamentos alimentares e de ingestão de energia de indivíduos em um dia que incluía a realização de $\mathrm{CM}$ e outro dia em que esta refeição foi suprimida. Os autores encontraram que não houve diferença no consumo de energia e de nutrientes entre as duas situações de consumo e não consumo de CM.

$\mathrm{Na}$ verdade, autores (MARLATT et al., 2016; SCHEMBRE et al.,2013) comentam que existe uma falta de consistência na literatura referente ao entendimento sobre a associação do balanço energético e o consumo de CM. Os autores Kant e Graubard (2015) consideram que os poucos estudos existentes nesta temática não utilizam estratégias analíticas ajustadas estatisticamente quanto às características demográficas, de estilo de vida, e de saúde, permintindo a ocorrência considerável de vieses de confundimento.

Será necessária a realização de diversas pesquisas com alto rigor metodológico para que haja um consenso em relação à associação do CM com o controle do peso corporal de forma estritamente saudável.

Além da relação do CM com o controle do peso corporal, existem outras associações que também estão sendo correlacionadas com a primeira refeição do dia, como as diversas medidas de avaliação do estado nutricional. Affinita et al. (2013), por exemplo, afirmam que as pessoas que fazem CM durante a idade adulta têm menores valores de circunferência abdominal, além de apresentarem menor vazio estomacal que afeta o apetite e a saciedade da fome. Indivíduos que não realizam essa refeição com frequência apresentam maior IMC ou excesso de peso corporal e podem apresentar alteração na densidade mineral óssea (BERTA et al., 2015; KURODA et al., 2013; MORILLAS-RUIZ et al., 2014; MULLAN; SINGH, 2010).

Um estudo (CECATO, 2015) recente que objetivou esclarecer, através de uma revisão bibliográfica, o efeito do consumo do CM para a saúde na manutenção e redução de peso, concluiu que o consumo diário do $\mathrm{CM}$ é benéfico em vários aspectos, tanto para a manutenção e equilíbrio do organismo quanto na perda de peso. Além disso, a autora cosiderou que há alguns tipos de alimentos que, quando 
consumidos no CM, auxiliam na perda e manutenção do peso devido ao poder de saciedade específico a cada tipo de alimento.

Assim sendo, o poder de saciedade dos alimentos ingeridos numa refeição influencia o peso corporal, por estimular o maior ou menor consumo de alimentos nas refeições posteriores, processo esse baseado na concepção de que há uma hierarquia em relação ao poder de saciedade dos macronutrientes. $O$ consumo de alimentos considerados de maior saciedade está associado à diminuição da ingestão de alimentos nas refeições seguintes, bem como a redução da ingestão em curto prazo.

Os alimentos com maior teor de proteína, fibra e água têm maiores efeitos sobre a saciedade do que os alimentos ricos em gordura e carboidratos (CHUNG et al., 2015; O'NEIL et al, 2014; RAINS et al., 2015). Assim, o aumento do consumo de gordura no início do dia tende a aumentar o consumo geral de nutrientes durante o resto do dia (ALFENAS; BRESSAN; PAIVA, 2010; CLEGG; SHAFAT, 2010; RUEDA; KHOSLA, 2013). Nicklas et al. (2001) foram ainda mais claros quando afirmam que o hábito de tomar CM pode contribuir para o controle do peso corporal, na medida em que reduz o consumo de gorduras na dieta.

Ao comparar três tipos de CM, sendo um rico em gordura, outro rico em proteínas e outro rico em carboidratos, observou-se que a dieta de alto teor de gordura resultou em maior fome no período que antecede o almoço, quando comparado com os cafés da manhã ricos em proteínas ou carboidratos (RUEDA; KHOSLA, 2013).

Dove et al. (2009) realizaram um estudo controlado com o objetivo de avaliar a saciedade pós-prandial e o consumo de energia na próxima refeição (quatro horas depois) de 34 indivíduos acima do peso. Os indivíduos selecionados comeram duas diferentes combinações de CM que deveria ser consumido entre 7 e 8:30 horas, de igual teor calórico em dois momentos diferentes, um com $600 \mathrm{ml}$ de leite desnatado e outro com a mesma quantidade de suco de fruta, acompanhados de duas fatias de torrada com margarina ou geléia. Os indivíduos que se alimentaram de leite, portanto de maior quantidade de proteína, sentiram saciedade depois de 4 horas de consumo quando comparado aos que consumiram o suco de fruta, o que possibilitou menor consumo de energia no momento do almoço.

Blom et al. (2006) realizaram um estudo duplo cego com 15 indivíduos saudáveis do sexo masculino, que foram divididos em 2 grupos a receber dietas 
diferentes. A primeira dieta com 58,1\% da energia proveniente de proteínas, e $14,1 \%$, de carboidratos. A segunda dieta foi constituída por $19,3 \%$ da energia de origem protéica e 47,3\%, de carboidratos. Foram realizados exames periódicos de sangue, e o nível de saciedade foi testado várias vezes num período de três horas logo após a ingestão para descobrir quanto tempo levava até que o sujeito tivesse fome novamente. A conclusão foi que o CM proteico reduziu as concentrações de grelina, um hormônio que causa a fome, liberadas no decorrer do dia. Além disso, reduziu o ritmo de esvaziamento gástrico e consequentemente da sensação de fome.

Outro estudo que comprovou a influência do consumo de proteínas no CM como coadjuvante no controle de perda de peso foi o relalizado por Hoertel, Will e Leidy (2014). Os pesquisadores estudaram, por uma semana, 20 mulheres jovens que foram divididas em três grupos. O primeiro grupo não realizou o $\mathrm{CM}$, o segundo grupo alimentou-se de um CM com $13 \%$ da energia proveniente de proteína, e 0 terceiro grupo com $\mathrm{CM}$ em que $35 \%$ da energia eram provenientes de proteína. A análise dos resultados mostrou que a ingestão de maior quantidade de proteína reduz a vontade de comer alimentos salgados e doces durante o dia. Além disso, aumenta o nível de ácido homovanílico, que libera a dopamina no cérebro, responsável pela sensação de saciedade.

Os dois últimos estudos citados acima mostram que as proteínas provocam a sensação de saciedade no cérebro de forma mais rápida e por tempo mais prolongado, promovendo menor fome na refeição seguinte.

Os resultados sobre a questão do poder de saciedade dos nutrientes demonstram que o conteúdo alimentar da refeição é de extrema importância no controle do peso corporal. Sendo assim, o conteúdo nutricional da refeição merece atenção redobrada durante o planejamento da dieta, pois é uma estratégia que pode contribuir para o bom estado nutricional do indivíduo.

Outros estudos realizados com crianças e adolescentes no Brasil (BRANCO et al., 2007; RECH et al., 2010) demonstraram uma associação direta entre o estado nutricional e a realização do CM. Os autores Bertin et al. (2010) realizaram um estudo para verificar a associação do estado nutricional com os hábitos alimentares de 259 escolares de Santa Catarina, Brasil. Na análise dos dados, encontraram uma associação entre obesidade e hábitos alimentares específicos, como o hábito de comer guloseimas. Verificaram uma associação entre 
o hábito de consumo do $\mathrm{CM}$ e o consumo de guloseimas com o estado nutricional, demonstrando que crianças com hábito infrequente de tomar o CM têm duas vezes mais chances de serem obesas do que os escolares que têm esse hábito.

\subsubsection{Qualidade nutricional do café da manhã}

São muitos os benefícios da realização do CM na saúde humana, garantindo um menor risco de comorbidades relacionadas ao peso, tais como a obesidade, a hipertensão, a diabetes mellitus, a síndrome metabólica e as doenças cardiovasculares, além dos benefícios referentes ao funcionamento cognitivo (CARDOSO et al., 2009; CAYRES et al., 2016; CIMADON; GEREMIA; PELLANDA, 2010; FREITAS; MENDONÇA; LOPES, 2013; SCHEMBRE et al., 2013; YOO et al., 2014). Sendo assim, é de suma importância aprofundar os conhecimentos sobre a qualidade nutricional de um CM saudável.

A expressão "qualidade em um alimento" pode ser analisada sob múltiplas dimensões. Considerando que a qualidade com relação aos alimentos deve ser um processo centrado no ser humano, ela pode ser percebida sob uma diversidade de óticas, como por exemplo, a nutricional, a sensorial, a higiênicossanitária, a de serviço, a regulamentar, a simbólica, a social (PROENÇA et al., 2005) e outras. A abordagem de qualidade em foco neste estudo será a nutricional, que diz repeito às características e benefícios dos nutrientes encontrados nos alimentos consumidos no CM.

Existem evidências que sugerem que o consumo diário do CM está associado à escolha de alimentos mais ricos nutricionalmente, como frutas, hortaliças, produtos lácteos e grãos (ENES; SLATER, 2010; NURUL-FADHILAR et al., 2013). Dessa forma, a realização do CM representa uma oportunidade para o consumo de alimentos ricos em nutrientes como proteínas, cálcio, vitaminas, minerais e fibras (HÖFELMANN; MOMM, 2014; TRANCOSO; CAVALLI; PROENÇA, 2010).

Travé (2013) realizou um estudo para analisar nutricionalmente o consumo do $\mathrm{CM}$ e do almoço com 740 estudantes universitários espanhóis, e o resultado mostrou que o percentual de ingestão de vitaminas e minerais foi 
significativamente superior no CM que o consumido no almoço. Os grupos de alimentos mais consumidos no $\mathrm{CM}$ dos participantes desse estudo foram os lácteos $(92,6 \%)$, os cereais $(58,8 \%)$ e o grupo de doces, bolos e produtos de panificação adocicados $(57,9 \%)$, como marmeladas, produtos com chocolates, biscoitos, croissants, muffins, etc. O resultado do estudo espanhol mostra claramente a influência cultural nos hábitos alimentares de consumo de alimentos adocicados na primeira refeição do dia.

Para Mirzaei et al. (2016), o CM deve conter, preferencialmente, os alimentos provenientes de cinco grupos: frutas/suco de frutas, cereais, laticínios (leite e derivados, ovos), gorduras e líquidos (água, chá ou café). Importante observar que os autores agruparam de forma conjunta os laticínios e o ovos, provavelmente baseados na argumentação de que ambos são fontes de proteínas de origem animal. Também estes autores se destacaram dos demais pesquisadores da refeição $\mathrm{CM}$ por nao se esquecerem de citar a importância dos líquidos na primeira refeição do dia.

Azadbakht et al. (2013) realizaram uma pesquisa para avaliar a associação entre o consumo do $\mathrm{CM}$ e a qualidade alimentar. Utilizando-se da aplicação do Índice de Alimentação Saudável, a Pontuação da Diversidade Alimentar e as medidas antropométricas, estudaram 411 mulheres universitárias, entre 18 e 29 anos. Os resultados mostraram que o consumo do CM foi associado a uma maior qualidade da dieta e a valores baixos de IMC.

Soares e Ping-Delfos (2008) concordam com os resultados das pesquisas acima ao afirmar que existe um pressuposto entre os pesquisadores do tema, sugerindo que a composição nutricional da primeira refeição do dia pode ter implicações no metabolismo energético do restante do dia.

O tipo de alimento consumido no CM é muito importante porque define diferentes padrões de ingestão de nutrientes (MIN et al., 2012), que variam de acordo com a cultura (DI GIUSEPPE et al., 2012). O CM dos japoneses, por exemplo, é constituído de peixes, soja, ovos, algas, tofu e hortaliças, sendo todos eles alimentos ricos em proteínas, vitaminas, minerais e pobres em gordura, bem diferente do CM do ocidente, que consome pães, ovos, produtos lácteos, cereais e carnes (HÖFELMANN; MOMM, 2014; MELBY; TAKEDA, 2014). A população dos Estados Unidos geralmente consome pães, ovos, frutas, cereal pronto para consumo e bebidas do tipo leite, café, suco e refrigerantes (DESHMUKH-TASKAR, 
2010a). O consumo de hortaliças no CM é mais realizado por hispano-americanos, alimentos que são fontes ricas em fibra dietética, folato, zinco, ferro e magnésio (O’NEIL et al., 2014).

Pedersen et al. (2012) investigaram a associação entre o consumo irregular do CM e o consumo de frutas e hortaliças em 3.913 adolescentes da Dinamarca. Os resultados mostraram que o CM irregular foi associado a uma baixa frequência de consumo de frutas e hortaliças, e que o sexo e a idade podem desempenhar um papel modificadordesse comportamento. Esses resultados destacam a importância do incentivo à realização do $\mathrm{CM}$ diariamente entre os adolescentes, uma vez que a tendência é esse comportamento ser mantido na idade adulta.

Herrera (2007) estudou 121 estudantes venezuelanos de nível superior com o objetivo de conhecer o consumo de grupos de alimentos básicos de acordo com diversas variáveis, entre elas o sexo. Os resultados do estudo, que teve duração de um ano, mostraram uma clara escassez na ingestão de hortaliças e frutas, principalmente no $\mathrm{CM}$ e no jantar. Estudantes do sexo masculino comeram menos hortaliças e frutas no almoço e no jantar, enquanto as mulheres comeram menos esses alimentos no CM. Em suma, o consumo de frutas mostrou ser deficitário no $\mathrm{CM}$, sendo essa tendência mais evidente no sexo feminino.

Kant et al. (2008) analisaram dados de 12.316 entrevistados provenientes de três anos de pesquisa do National Health and Nutrition Examination Surveys (NHANES), nos Estados Unidos. O resultado mostrou, entre outros fatores, que os cinco grupos de alimentos mais consumidos no CM foram a combinação de produtos lácteos e cereais; produtos lácteos, frutas e cereais; cereais e carne ou derivados; frutas e cereais; e somente cereais.

Souza et al. (2007) estudaram 400 pacientes adultos atendidos em um consultório de nutrição da zona sul da cidade de São Paulo, Brasil. Os dados foram coletados pela aplicação de um recordatório alimentar de 24 horas, que se limitaram às quantidades caseiras dos alimentos e das bebidas referidas pelos pacientes durante o desjejum. Os autores definiram CM como qualquer bebida ou alimento ingerido na refeição denominada pelo paciente como $\mathrm{CM}$. Os indivíduos que não comeram ou beberam, excluindo água, foram categorizados como "sem desjejum".

A análise do consumo alimentar do estudo acima mostrou que as categorias de alimentos mais consumidos foram gorduras e doces (margarina, 
manteiga, achocolatado em pó, açúcar, achocolatado pronto para beber, sucos industrializados, chocolate, pizza e refrigerantes); leites e derivados (leite desnatado, semi-desnatado ou integral, iogurte desnatado ou integral, queijos, queijo cremoso, leite fermentado, leite de soja); carnes e ovos (omelete, atum, salame, carne bovina); frutas e vegetais (laranja, cenoura, mamão, manga, sucos naturais, caqui e frutas secas); cereais (granola, aveia em flocos, flocos de milho e barras de cereais); pães (branco, integral, bisnaguinha, bolacha de água e sal, torradas, milho, pão de queijo, fubá, pão de batata, croissant); bolos e bolachas doces (bolachas recheadas, panetone e tortas doces); e bebidas (chá, café, cappuccino).

As categorias de alimentos na pesquisa de Souza et al. (2007) foram definidas de acordo com os alimentos mais consumidos pelos pacientes, diferentemente da forma de classificação dos grupos alimentares prescritos na Guia Alimentar para a População Brasileira (2006b), o que dificulta qualquer tipo de análise comparativa entre os dados encontrados e o guia alimentar elaborado pelo Ministério da Saúde do Brasil. Além disso, os autores não esclareceram o motivo pelo qual o achocolatado em pó, o achocolatado pronto para beber, o chocolate, o suco industrializado e o refrigerante foram alocados na categoria gorduras e doces. E ainda, porque o leite de soja constou na categoria leite e derivados. Também poderiam ter explicado melhor que tipos de doces estavam sendo considerados, uma vez que somente alguns tipos de doces são consumidos no CM, como as geleias de frutas e o doce de leite em algumas regiões brasileiras. A categoria frutas e vegetais poderia receber a nomenclatura frutas e hortaliças para melhor caracterização dos itens que a compõem.

Considerando a diversidade de alimentos consumidos no CM no mundo, é queTravé (2013) e os autores O'Neil et al. (2014) comentam que o CM deve incluir pelo menos três grupos básicos: lácteos, cereais e frutas, pois o tipo de alimento consumido no CM tem efeitos específicos sobre o estado nutricional. Por exemplo, comer cereais ou pães no CM demonstrou estar associado a um IMC significativamente menor quando comparado com aqueles que omitiam o $\mathrm{CM}$ ou consumiam carne e/ou ovos nessa refeição (CHO et al., 2003).

Os alimentos mais ricos em micronutrientes essenciais consumidos no CM em todo o mundo são o leite e derivados. Por isso, devem estar sempre presentes no cardápio do $\mathrm{CM}$ e devem preferencialmente ser combinados com hidratos de carbono complexos como fonte de energia. Além disso, o leite é fonte de 
proteína de alta qualidade nutricional e importante fonte de cálcio, fósforo e aminoácidos essenciais (AFFINITTA et al., 2013; BONJOUR et al., 2013). Mas atualmente existe uma tendência de substituição desses alimentos devido ao fato de a proteína do leite de vaca ser o mais frequente componente causador de alergias alimentares (AGUIAR et al., 2013).

Um dos nutrientes considerados essenciais em um CM equilibrado é a fibra, fornecida principalmente pelas frutas, hortaliças e cereais integrais. Ela age positivamente no metabolismo da glicose e na resposta à insulina (MARANGONI et al., 2009), reduzindo assim o risco de desenvolvimento da diabetes tipo 2 e do excesso de peso. Pedersen et al. (2012) acrescentam que as dietas ricas em frutas e hortaliças reduzem o risco de doenças cardiovasculares e de algumas formas de câncer.

O cálcio é um nutriente essencial em diversas funções biológicas, como a contração muscular, a mitose, a coagulação sanguínea, a transmissão do impulso nervoso ou sináptico e na estrutura óssea. Assim, o consumo de cálcio previne doenças como a osteoporose, a hipertensão arterial, o câncer de cólon e a obesidade (AHMED et al., 2012). Surpreendentemente, o aumento da ingestão de cálcio levaria à redução da massa gorda (PEREIRA et al., 2009) por influenciar a atividade das enzimas envolvidas na síntese de gordura e na lipólise (SOARES; PING-DELFOS, 2008).

Galas, Augustyniak e Sochacka-Tatara (2013) realizaram um estudo com o objetivo de avaliar o efeito da ingestão de maiores níveis de cálcio na dieta sobre o risco de desenvolvimento de câncer colorretal. O resultado do estudo confirmou o efeito protetor de doses mais elevadas de cálcio na dieta contra o risco de câncer de cólon. Os resultados apoiam a evidência para a potencial vantagem de um aumento do consumo de alimentos na mesma refeição que sejam fontes de cálcio e fibras, o que é perfeitamente recomendável para o CM.

A única fonte de cálcio disponível para o organismo humano é aquela proveniente da dieta, sendo essencial garantir uma ingestão mínima do mineral para permitir o crescimento e a manutenção ósseos (BUENO; CZEPIELEWSKI, 2008; LUZ, 2007). O'Neil et al. (2014) sugerem que o consumo apropriado de cálcio no CM seja entre 200 e 300 mg. Esse valor de ingestão de cálcio no CM deve-se ao fato de esse mineral serperdido diariamente pelo corpo em quantidades consideráveis. Se essa perda não for compensada por uma quantidade correspondente, consumida via 
alimentação, o corpo rompe unidades da estrutura óssea no intuito de prover cálcio para circulação (BEDANI; ROSSI, 2005). No Brasil, alguns estudos (LEAL et al., 2010; TRICHES; GIUGLIANI, 2005; VIEIRA; DEL CIAMPO; DEL CIAMPO, 2014) têm focalizado o hábito de tomar $\mathrm{CM}$ e sua relação com o consumo de cálcio em crianças e adolescentes, mas estudos com adultos são raros.

Um estudo que avaliou a associação da obesidade com as práticas alimentares em 573 escolares do Rio Grande do Sul, Brasil, encontrou que o hábito de não tomar CM está significativamente associado com o baixo consumo de leite e com a obesidade (TRICHES; GIUGLIANI, 2005). Esse dado demonstra que a supressão dessa refeição afeta negativamente o aporte de proteínas e de minerais como o cálcio, que deveria ser suprido pelo consumo de alimentos que compõem a dieta de crianças, adolescentes e adultos.

Ao avaliar os hábitos e o consumo alimentar de 130 adolescentes matriculados em duas escolas públicas de Ribeirão Preto (SP), os autores VIEIRA, DEL CIAMPO e DEL CIAMPO (2014) levantaram a hipótese de que a supressão do CM, que nesse caso foi de $14 \%$, assim como dos lanches da manhã $(54,8 \%)$ e da tarde $(16,1 \%)$, auxiliou na baixa ingestão dos grupos das frutas e de leite e derivados, contribuindo para o baixo consumo de fibras, vitaminas e minerais, entre eles o cálcio.

Leal et al. (2010) realizaram um estudo com 228 adolescentes no Estado de São Paulo, Brasil, cujo objetivo foi avaliar o consumo alimentar e o padrão de refeições de adolescentes. A análise dos resultados indicou que $96 \%$ das meninas e $90 \%$ dos meninos apresentaram ingestão de cálcio inferior à recomendação. O baixo consumo de cálcio apresentou uma correlação direta com os $21 \%$ de supressão do CM entre os adolescentes, sendo esse índice superior entre as meninas (29\%) em relação aos meninos (13\%), verificando-se associação positiva entre o gênero feminino e a não realização dessa refeição.

As hortaliças verdes-escuras, como brócolis e couve, são fontes alternativas de cálcio, porém a quantidade e biodisponibilidade do cálcio nesses alimentos são menores quando comparadas ao leite e seus derivados (BUENO; CZEPIELEWSKI, 2008; WEAVER; HEANEY, 2006), mas se acredita que elas não sejam comumente consumidas no CM dos brasileiros.

Em casos de substituição do leite por bebidas com baixo teor de cálcio, como chá, café, sucos e refrigerantes, o consumo de cálcio é diretamente afetado. 
Nos casos de substituição do leite pelo chá, é importante acentuar que os taninos, presentes neste último alimento, podem formar complexos insolúveis com o cálcio, reduzindo a sua absorção, embora esses componentes pareçam afetar a absorção do cálcio apenas quando a dieta não é balanceada (PEREIRA et al., 2009).

A substituição frequente de leite por café também não é adequada, devido ao efeito deletério da cafeína na densidade mineral óssea (LUZ, 2007). O consumo de cafeína com a absorção de cálcio têm sido muito discutidos, mas o consumo moderado dessa substância não prejudica a saúde óssea. No entanto, doses excessivas de cafeína podem resultar em maior excreção de cálcio, aumentando, assim, o risco de osteoporose. Os efeitos da cafeína sobre o tecido ósseo têm sido correlacionados ao aumento da calciúria e à diminuição da eficiência da absorção intestinal de cálcio. Esses mecanismos podem promover um saldo negativo no metabolismo do cálcio, apresentando assim um impacto negativo sobre o metabolismo ósseo e levando a uma redução significativamente maior da massa óssea (HARTER et al., 2013). Higdon e Frei (2006) afirmam que uma dieta equilibrada, com um consumo moderado de café, limitado a três xícaras (equivalente a $710 \mathrm{ml}$ ) por dia (300 mg/dia de cafeína), não é prejudicial à absorção de cálcio.

Quando a substituição do leite é feita por refrigerantes, a troca é ainda mais prejudicial à saúde, pois se trata de alimentos de baixa qualidade nutritiva. As bebidas à base de colas possuem uma agravante maior, pois contêm cafeína e ácido fosfórico, podendo afetar negativamente a biodisponibilidade de cálcio, por meio da geração de carga ácida no organismo causada pelo ácido fosfórico usado como acidulante nessas bebidas (MORAIS; BURGOS, 2007). Essa tendência observada em crianças, em adolescentes e em adultos jovens reflete negativamente sobre a saúde óssea de duas formas: em primeiro, a disponibilidade de cálcio nas fases de crescimento e de desenvolvimento pode ser comprometida; em segundo, as substâncias contidas nos refrigerantes impedem a fixação do cálcio na matriz óssea (BRASIL, 2006b).

$A$ vitamina $D$ é outro nutriente intrinsecamente relacionado com o consumo do CM, por estar intimamente conectada ao metabolismo do cálcio no organismo. Quando o consumo de alimentos-fonte de vitamina D é insuficiente, pode interferir na absorção do cálcio (MAEDA et al., 2014; MORAIS; BURGOS, 2007).

Apesar de a dieta no Brasil ser geralmente pobre em vitamina D (CORREIA et al., 2014), o país conta com um fator protetor à hipovitaminose D. O 
território de clima ensolarado afasta a necessidade compulsória de adição dessa vitamina no consumo diário dos indivíduos (AVELAR; PINHEIRO-SANT'ANA; LIBERATO, 2001). Cirino (2013) afirma que não há nenhuma evidência da necessidade de fortificação de alimentos com a vitamina $D$ no Brasil.

Outro fator que pode influenciar a biodisponibilidade do cálcio é o sódio, uma vez que a ingestão elevada desse nutriente acarreta aumento da excreção renal de cálcio (MORAIS; BURGOS, 2007; PEREIRA et al., 2009). Pereira et al. (2009) consideram que o aumento da ingestão de cálcio atenua a sensibilidade ao sal e reduz a pressão sanguínea, principalmente em indivíduos hipertensos. Esse é mais um fator que realça a importância do consumo de alimentos fontes de cálcio no CM.

O sódio tem sido relacionado com a refeição $\mathrm{CM}$ em todo o mundo, pois o pão é um dos principais contribuintes para a ingestão elevada desse mineral, por trazer alta concentração dele em sua composição (BOLHUIS et al., 2011). $\mathrm{Na}$ análise de uma refeição simples de CM composta de pão com manteiga/margarina e leite com café (ou café com leite), um dos principais nutrientes merecedor de preocupação é o possível excesso de ingestão de sódio, por ser fator de risco para o desenvolvimento de doenças cardiovasculares. Considerando que o leite é fonte natural de sódio, que normalmente a população saudável consome manteiga/margarina com sal e que o pão francês recebe sal em sua receita, o consumo desse mineral pode facilmente ultrapassar a quantidade média diária recomendada, depois de considerado seu consumo em todas as refeições do dia.

Desta forma, o consumo elevado de sódio em todas as refeições e inclusive no $\mathrm{CM}$, pelo consumo de pães, está diretamente relacionado à pressão arterial elevada e a um fator de risco aumentado para a ocorrência de doenças cardiovasculares, principal causa de mortalidade no mundo. Uma evidência crescente sugere que a alta ingestão de sódio também está relacionada à doença renal e tem sido apontada como uma das principais causas de câncer de estômago. O consumo de alimentos como os embutidos e alguns queijos, também influencia a ingestão de sódio e deve receber atenção redobrada quanto à sua presença no cardápio diário, principalmente para pessoas com tais patologias (BOLHUIS et al., 2011; BRASIL, 2006b; IGNÁCIO et al., 2013; SARNO et al., 2009).

Alimentos processados são aqueles que passam por "métodos utilizados pelos fabricantes para transformar a matéria-prima ou os produtos primários em 
alimentos e bebidas para venda no comércio" (BRASIL, 2006b, p. 205). Dentre os diferentes métodos de processamento de alimentos existentes, alguns preservam ou aumentam a qualidade dos alimentos, mas outros degradam ou acrescentam elementos prejudiciais à saúde, como é o caso da introdução de sal usado com a finalidade de conservar os alimentos (BRASIL, 2006b), como os embutidos, enlatados, conservas e outros produtos industrializados.

O advento de técnicas modernas de armazenamento tem, obviamente, reduzido a necessidade de usar o sal para esse fim, no entanto, a adição de sal ainda desempenha um papel multiuso em muitos alimentos e em bebidas fabricadas, sendo usado para o controle do crescimento do fermento e taxa de fermentação de pão e outros produtos de panificação, com o objetivo de auxiliar na preservação da textura dos alimentos (STRAZZULLO et al., 2012).

Para a Organização Mundial de Saúde - OMS (WHO, 2011), a necessidade nutricional de sódio para os seres humanos é de 500 miligramas, que corresponde a cerca de 1,2 grama de cloreto de sódio (sal de cozinha), tendo definido também que a quantidade considerada máxima saudável para ingestão alimentar diária é de $5 \mathrm{~g}$ de cloreto de sódio ou sal de cozinha (que corresponde a $2 \mathrm{~g}$ de sódio). Entretanto, apesar de esses limites para consumo de sódio já terem sido definidos pela OMS, o consumo médio da população brasileira corresponde aproximadamente ao dobro do recomendado (TINOCO et al., 2013).

Devido à composição do CM regularmente consumido no Brasil contar com a presença de alimentos fontes de sódio, como o leite, o pão e a manteiga, presume-se que o CM seja responsável por grande parte de seu consumo diário. Uma unidade de pão francês (50 g) pode conter $324 \mathrm{mg}$ de sódio, o que representa 15\% da ingestão diária recomendada (TACO, 2006). Esse dado contribui para entender a importância do controle de consumo do sal a partir da realização do CM pela população brasileira, visto ser comum uma única pessoa ingerir mais de um pão por dia.

É interessante observar que nem sempre os produtos com maior teor de sódio são aqueles que mais contribuem para a ingestão desse nutriente. Por exemplo, o macarrão instantâneo é um produto com alto teor de sódio, mas não participa da dieta diária das pessoas como o pão francês, que é consumido mais vezes ao dia, passando a ser uma fonte permanente de sódio (MARTINS, 2014). 
Sarno et al. (2009) fizeram uma estimativa de consumo de sódio pela população brasileira, baseada nos dados da Pesquisa de Orçamentos Familiares, realizada no Brasil entre julho de 2002 e junho de 2003 e verificaram que a quantidade diária de sódio disponível para consumo nos domicílios brasileiros foi de $4,5 \mathrm{~g}$ por pessoa (ou 4,7g para uma ingestão diária de $2.000 \mathrm{kcal}$ ), confirmando a proposição de que o brasileiro excede em mais de duas vezes o limite recomendado de ingestão desse nutriente.

Devido ao seu elevado teor de sódio e ao seu papel importante no consumo diário, o pão é um dos principais contribuintes para a ingestão de sódio na dieta de muitos países (BOLHUIS et al., 2011; CORREIA et al., 2012; MENETON et al., 2009; STRAZZULLO et al., 2012). No estudo realizado por Gibson e Ashwell (2011), cujo objetivo foi examinar os padrões dietéticos entre adultos britânicos e as associações do sódio com a ingestão de macronutrientes, o pão foi o maior contribuinte para a ingestão total de sódio, sendo responsável por $22 \%$ da ingestão de sódio para os homens e de $21 \%$ para mulheres.

Souza et al. (2013) analisaram os dados de um dos módulos da POF 2008-2009, considerando os indivíduos de ambos os sexos, acima de dez anos de idade. A análise dos dados mostrou que o pão de sal foi um dos cinco alimentos mais consumidos (63\%) e que a sua disponibilidade dentro do domicílio corresponde a $6 \%$ do total de calorias. A partir da análise realizada pelos autores com os dados das POF de 2002-03 e 2008-09, estimou-se que mais de $70 \%$ da população brasileira consumiam sódio em excesso (mais que $2000 \mathrm{mg}$ ao dia) e que mais de 90\% dos adultos e adolescentesde 14 a 18 anos de idade nas áreas urbanas ultrapassam esse limite diário.

Apesar da recomendação do Guia Alimentar para a População Brasileira (BRASIL, 2014) em relação à necessidade de redução da ingestão de sal no consumo dietético diário, o Brasil está aquém na execução de estratégias com esse objetivo quando comparado a outras nações, como a Finlândia, a Inglaterra e o Japão (NILSON; JAIME; REZENDE, 2012).

$\mathrm{Na}$ tentativa de iniciar uma série de ações para a redução de consumo de sal pela população brasileira, em 2009 foi realizado um pacto entre o governo e as indústrias de alimentos que incluiu metas de redução voluntária, gradual e sustentável dos teores máximos de sódio nos alimentos industrializados. Apartir de 2010, a redução dos teores de sódio foi incluída como nova pauta na agenda 
conjunta entre o Ministério da Saúde e a principal associação representativa do setor produtivo no Brasil, a Associação Brasileira das Indústrias de Alimentação (ABIA). O primeiro item trabalhado nesse sentido foi o pão francês, tendo em vista ser um dos alimentos mais consumidos pela população brasileira, e, por isso, um dos principais contribuintes para a ingestão de sódio (NILSON; JAIME; REZENDE, 2012).

Assim, para a regulamentação do pacto descrito acima, em 2011 foi publicado no Brasil o Plano de Ações Estratégicas para o Enfrentamento das Doenças Crônicas não Transmissíveis (DCNT) para o período de 2011-2022, que tem como uma das metas a redução do consumo médio de sal (BRASIL, 2011c).

Em 2014, foi realizada uma primeira análise do processo decisório e das principais discussões em torno da formulação dos acordos voluntários estabelecidos após esse plano. As análises identificaram alguns aspectos, como a baixa participação da sociedade civil; a ausência de parâmetros claros sobre os teores adequados de sódio nas diversas categorias de alimentos; e a dificuldade de monitoramento para verificação do cumprimento dos acordos por parte da ANVISA (Agência Nacional de Vigilância Sanitária). Tais constatações deixaram claro que as metas estabelecidas nos primeiros pactos e no Plano de Ações são bastante tímidas e insuficientes para acarretarem a redução do consumo de sódio pela população (MARTINS, 2014).

Segundo o Guia de Boas Práticas Nutricionais para Pão Francês da ANVISA (BRASIL, 2012a), acordou-se que a adição de sal ao produto seria progressivamente reduzida de $2 \%$ para $1,8 \%$ até o final de 2014 , o que representou uma redução de $10 \%$ na quantidade de sódio no produto. Assim, uma unidade de pão francês (50 g) que, em 2011, tinha em média 320 mg de sódio, teve 304 mg em 2012 e 289 mg em 2014 (IGNÁCIO et al., 2013).

A ação conjunta entre o governo federal e as indústrias de alimentos pode não resolver o problema do excesso de consumo de sal pela população brasileira, mas representa um grande passo, uma vez que envolvem outros atores da sociedade civil. Há que se considerar que projetos como esse são difíceis de executar, pelo fato de, inevitavelmente, entrar no espaço íntimo do consumidor em relação às preferências alimentares de cada indivíduo. Também é louvável perceber que o setor privado se comprometeu espontaneamente a realizar ações para o bem geral dos consumidores, visto que essa iniciativa de redução de sal não se trata de uma proibição, mas sim de redução voluntária e gradual. 
Além dos alimentos salgados, é importante atentar também para os produtos de sabor doce que podem apresentar alto teor de sódio. A indústria alimentícia utiliza o sódio com o propósito de melhorar as características sensoriais ou disfarçar o uso de outros aditivos empregados durante o seu processamento (IGNÁCIO et al., 2013).

Para avaliar os teores de sódio de produtos com sabor doce, Tinoco et al. (2013) verificaram essas informações presentes nos rótulos de 90 produtos alimentícios que apresentavam gosto doce. Dentre os alimentos avaliados, foram incluídos os seguintes: cereal matinal e em barra, leite e seus derivados, biscoito diversos, refrigerantes, chocolate em barra, achocolatado pronto para beber, bebida à base de soja, granola, bolo, mistura para bolo, etc. Os resultados mostraram que as amostras que apresentaram maiores teores de sódio foram a mistura para bolo $(10,46 \%)$ e o achocolatado pronto para beber (5,90\%), seguidos dos produtos: leite integral em pó (5,03\%), biscoito maisena (4,89\%), leite desnatado em pó $(4,50 \%)$, biscoito recheado (4,35\%), cereal matinal (4,24\%), bebida à basede soja $(3,93 \%) \mathrm{e}$ bolo $(3,22 \%)$ respectivamente. Importante ressaltar que todos os alimentos que apresentaram maior teor de sódio na pesquisa são potencialmente consumíveis no $\mathrm{CM}$, mostrando que a preocupação com esse nutriente merece atenção especial para atender aos critérios de uma alimentação saudável.

Preocupação semelhante à direcionada ao sódio deve ser dada à ingestão de gorduras saturadas, principalmente os ácidos graxos transhidrogenados, presentes em margarinas, cremes vegetais, bolachas, biscoitos, sorvetes, batatas fritas, pastéis e produtos de panificação consumidos no $\mathrm{CM}$, requerendo muita atenção devido aos seus efeitos desfavoráveis na saúde humana (MARANGONI et al., 2009). Eles têm sido negativamente associados às doenças cardiovasculares, às doenças crônicas degenerativas, ao crescimento intrauterino, à obesidade e às doenças inflamatórias (ANSORENA et al., 2013; BENATAR; STEWART, 2014; HISSANAGA; PROENÇA; BLOCK, 2012; WANG; PROCTOR, 2013).

Os ácidos graxos trans são os triglicerídeos que contêm ácidos graxos insaturados com uma ou mais dupla ligação trans, expressos como ácidos graxos livres (BRASIL, 2003a). Em outras palavras, os ácidos graxos trans são óleos vegetais, portanto líquidos, que passam por processo de hidrogenação parcial capaz de converter os óleos líquidos em substâncias pastosas. São raramente encontrados 
em estado natural, mas estão presentes no leite e nas carnes de animais ruminantes. Uma das principais fontes de ácidos graxos trans na dieta vem a partir de óleo vegetal parcialmente hidrogenado utilizado no processamento de alguns produtos bastante consumidos na dieta tipicamente ocidental (AUED-PIMENTEL et al., 2009; BERTOLINO et al., 2006; CASTRO et al., 2009; CORTÉS et al., 2013).

Os ácidos graxos trans não são essenciais nem oferecem benefício para a saúde. Por isso, as Dietary Reference Intakes (DRI), que é um sistema de recomendação nutricional considerada em quase todos os países do mundo, não apontam recomendações de consumo ou valor máximo tolerado para esse tipo de gordura (PROENÇA; SILVEIRA, 2012).

Por isso, ao publicar a Resolução da Diretoria Colegiada (RDC) nํ 359, de 23 de dezembro de 2003 (BRASIL, 2003b), o governo brasileiro contribuiu para o controle do consumo de gordura trans relativo à porção do produto, pois estabelece os tamanhos das porções dos alimentos embalados para fins de rotulagem nutricional. Mas a RDC no 360 (BRASIL, 2003a) da mesma data foi mais incisiva em relação à informação sobre a presença de gordura trans em produtos embalados, ao determinar que na rotulagem nutricional devam ser declarados vários nutrientes, entre eles, as gorduras trans. $O$ documento ainda faz uma ressalva ao citar que 0 produto pode ser considerado como "não contém trans" quando apresentar teor de gordura trans menor ou igual a 0,2g/porção, pois este é descrito como valor "não significativo".

Diante da importância do tema, em 2004 a Organização Mundial da Saúde (OMS) lançou a Estratégia Global para Promoção da Alimentação Saudável, Atividade Física e Saúde, estabelecendo, entre outros aspectos, a eliminação do consumo dos ácidos graxos trans como meta. Em 2007, a OMS demostrou manter preocupação quanto ao consumo de goduras trans ao recomendaruma revisão de seu limite tolerável, que era de até $1 \%$ do consumo energético diário, e que atualmente continua em vigor em muitos países, entre eles o Brasil (PROENÇA; SILVEIRA, 2012).

No Brasil, o Ministério da Saúde e ABIA estabeleceram em 2008 metas para reduzir o percentual de gorduras trans nos alimentos a um limite de $2 \%$ do total de gorduras até o final de 2010. As metas de redução desse tipo de gordura foram definidas a partir de recomendações da Organização Pan-Americana de Saúde, que estabelece o limite de $5 \%$ de presença de gordura trans do total de gorduras em 
alimentos processados, e $2 \%$ do total de gorduras em óleos e margarinas. Como resultado desse acordo, cerca de 230 mil toneladas de gordura trans deixaram de ir para as prateleiras em 2009, em comparação com 2008. Em 2010, e posteriormente em 2013, o acordo foi prorrogado para dar continuidade aos esforços em se atingir $100 \%$ das metas de redução de gorduras trans em todos os produtos industrializados, principalmente em categorias de alimentos que obtiveram resultados menos expressivos quanto à redução de gorduras trans, como margarinas e cremes vegetais, bolos e biscoitos (ESCOLA NACIONAL DE SAUDE PÚBLICA, 2010).

Nestel (2014) considera que as ações coordenadas entre nutricionistas, órgãos reguladores de alimentos e indústria de alimentos para reduzir ou eliminar os efeitos nocivos dos ácidos graxos trans em alimentos são uma das poucas histórias de sucesso na área de nutrição.

O interesse e o esforço conjunto de diversos atores do país, como o governo, a indústria e a sociedade, em reduzir a quantidade de gordura trans disponível no mercado é uma ação extremamente louvável, já que nos intercalços dos efeitos da globalização, muitos são os malefícios que surgiram com consequências profundas na alimentação humana. Para o maior atendimento à satisfação do sabor e da praticidade na alimentação, a indústria alimentícia investiu fortemente na oferta de novos produtos e na inserção da gordura trans nos preparos de vários gêneros alimentícios, principalmente nos produtos de panificação e confeitaria.

Observa-se que, como em toda refeição, é importante atentar para o tipo de alimento a ser consumido no CM, pois cada grupo de alimentos oferece um determinado tipo de nutriente essencial. A essência da alimentação equilibrada é harmonizar a presença de todos os grupos de alimentos de forma a garantir os constituintes necessários para a promoção e a manutenção da saúde humana. 


\subsubsection{Contribuição energética do café da manhã no consumo de energia}

O percentual de contribuição energética do CM no consumo diário de energia é uma informação que ainda diverge entre os autores. Para Pereira et al. (2011), deve representar um nível de energia entre 20 e 35\% do total das calorias diárias consumidas. Para outros autores, o CM deve ter um teor de energia que atenda a 20-25\% do total das necessidades energéticas diárias (CECATO, 2015; GIOVANNINI et al., 2008; MONTEAGUDO et al., 2012; MORALES et al., 2011; VAN DEN BOOM et al., 2006). Já para Marangoni et al. (2009), o consumo regular do CM deve fornecer de 15 a 20\% da ingestão calórica diária. Trancoso, Cavalli e Proença (2010) são mais categóricas ao informar que a recomendação brasileira é que o CM garanta em média $25 \%$ do total energético consumido durante o dia. Considerando as diversas informações dadas acima, pode-se adotar que existe uma faixa de contribuição de energia do CM que deve variar de 15 a 35\% do total calórico ingerido diariamente.

Em termos de medida em calorias, e considerando a primeira edição do Guia Alimentar para a População Brasileira (BRASIL, 2006b) sugere um consumo médio diário de $2000 \mathrm{kcal}$ totais divididas em três refeições, intercaladas por pequenos lanches (CM, colação, almoço, lanche, jantar e ceia), e a contribuição adequada do CM em $25 \%$ do valor calórico total segundo Trancoso, Cavalli e Proença (2010), o CM representaria um consumo médio de 500 kcal.

Araújo, Santos e Araújo (2011) realizaram uma pesquisa com o objetivo de analisar se o CM oferecido pelo Projeto Café do Trabalhador, na cidade de Natal, $\mathrm{RN}$, atendia aos aspectos dos conceitos de SAN: quantidade, qualidade e regularidade. Entre outros resultados, os autores descobriram que a contribuição energética média do CM na ingestão diária dos consumidores excedia levemente o valor recomendado pelo Programa de Alimentação do Trabalhador - PAT, que é de $20 \%$, enquanto que o valor médio encontrado foi de $24 \%$. Embora a contribuição energética da refeição CM oferecida pelo Projeto Café do Trabalhador tenha excedido ao do estabelecido pelo PAT, essa ainda continua dentro da faixa de limite sugerida pelos autores citados. Além disso, em se tratando de trabalhadores de baixo aporte econômico e que supostamente podem destinar pouco da sua renda mensal com alimentação, seria interessante oferecer mais calorias na primeira 
refeição do dia para compensar uma eventual impossibilidade de realização das demais refeições ou de um deficit calórico delas.

O trabalho realizado por Bispo (2006), cujo objetivo foi traçar o perfil alimentar do CM dos docentes da Universidade de Brasília, separou os participantes em três áreas do conhecimento: Ciências, Saúde e Humanas. Os 284 professores de ambos os sexos apresentaram uma contribuição percentual energética do CM no consumo total de energia que variou de $25 \%$ a $36 \%$.

Pinheiro (2006) realizou uma pesquisa semelhante ao estudo anterior, mas com uma amostra de estudantes dos cursos pertencentes à área de saúde da Universidade de Brasília. Foram incluídos 232 estudantes que realizaram a refeição CM com um percentual médio de contribuição energética no VET (valor energético total) de $19,4 \%$.

A autora Silva (2006) também avaliou o CM de 214 adolescentes estudantes do ensino médio em escolas particulares de Brasilia, DF. O resultado apontou para um consumo médio de contribuição energética no VET de 16,5\% $(n=214)$, entre os sexos feminino e masculino.

Analisando os resultados dos três estudos, observa-se que os valores relativos ao consumo pelos estudantes apresentaram menores percentuais de contribuição energética no VET $(19,4 \%, n=232$ e 16,5\%, n=214), demonstrando que possivelmente fatores como a idade, a escolaridade e o estilo vida influenciem neste valor.

O reflexo da contribuição energética do $\mathrm{CM}$ no valor calórico total diário é uma questão de debate. Existem atualmente duas vertentes de conhecimentos, sendo que uma acredita que omitir o CM (NICKLAS et al., 1998) ou realizar um CM hipercalórico (COTTON; BURLEY; BLUNDELL, 1992; 1993) não induz à compensação energética das calorias ausentes ou extras nas refeições posteriores, e a outra vertente defende que um CM de maior contribuição energética está associado a um menor consumo diário de energia, por meio de uma menor eficiência da utilização da energia (CASTRO, 2004; 2007).

Essa dupla concepção sobre a participação energética do CM no valor calórico total diário é que motivou a pesquisa de Schusdziarra et al. (2011). Esses autores analisaram o consumo de energia intraindividual de um grupo de 280 obesos e 100 indivíduos com peso normal. Em ambos os grupos, os dados foram analisados levando-se em consideração o consumo de energia no CM e a proporção 
da contribuição dessa refeição na ingestão total de energia. O estudo concluiu que a redução do consumo de energia do CM está associada a uma menor ingestão diária total. Dessa forma, a supressão do CM pode ser útil para diminuir a ingestão diária e melhorar o balanço energético durante 0 tratamento da obesidade (SCHUSDZIARRA et al., 2011).

Um estudo recente (CHOWDHURY et al., 2015) que investigou os efeitos da supressão do CM na ingestão energética das refeições posteriores em 24 adultos obesos, encontrou que a supressão desta refeição não causa ingestão compensatória e nem aumenta o apetite durante o restante do dia.

São muitos os estudos que têm pesquisado a relação entre o consumo ou a supressão do CM, a ingestão energética e/ou o IMC. Mas a análise dos resultados mostra que há uma diversidade de achados que são muitas vezes contraditórios. Isso sugere que há necessidade de mais pesquisas, com controle rigoroso das variáveis envolvidas. Estudos publicados abordando essa questão, com amostra de brasileiros, sejam eles crianças, adolescentes ou adultos, são muito raros.

\subsubsection{Alimentos do café da manhã brasileiro}

A recomendação de que toda refeição deve corresponder a uma alimentação saudável pode adquirir muitos significados, dependendo da região ou do país, da cultura e da época (BRASIL, 2006b). Sendo assim, a alimentação adequada e saudável é um direito humano básico que deve ser referenciada pela cultura alimentar local (BRASIL, 2014). Dessa forma, os alimentos que compõem o CM variam de acordo com a cultura (HÖFELMANN; MOMM, 2014).

A historiografia da alimentação brasileira descreve, em um primeiro lugar, entre os alimentos e preparações potencialmente consumidos no CM dos primeiros habitantes do Brasil, o consumo da mandioca acompanhada de muitas frutas. A mandioca era um alimento cotidiano comido em substituição ao pão e também usado para fazer farinha, bolo e carimã (raízes secas de mandioca que se transformam em beijus) (MACIEL, 2005). 
No Brasil republicano, por volta de 1890, o café, também chamado em São Paulo de "café-de-duas-mãos", era composto de leite com cuscuz ou cuscuz com leite de coco; macaxeira, batata doce e jerimum, esmagados na sopa de leite de gado; beijus de goma (tapioca); carne assada ou paçoca, com bananas, e broas de milho ou de goma de mandioca. O consumo de leite não era muito popular, sendo mais utilizado com algum alimento sólido. As pessoas mais ricas comiam esses alimentos acrescidos de ovos estrelados, mingaus, biscoitos, bolos, manteiga, mingau de carimã com gemas de ovos, milho cozido com leite de coco e mugunzá, e no inverno consumiam queijo geralmente assado. Nos sertões, era muito comum o consumo de coalhada fresca. Raramente consumiam frutas, e o mingau teria sido a comida mais amplamente consumida. O pão era consumido nas cidades, mas não era muito regular nas refeições modestas, pois a farinha de trigo era importada da Europa e por isso apresentava alto custo (CASCUDO, 2004).

Nos dias atuais, em grandes cidades é comum a existência de lanchonetes, panificadoras e até mesmo camelôs que abrem bem cedo para oferecer CM para os trabalhadores que saem de casa de madrugada e não disponibilizam de tempo para o preparo dessa refeição. O número de opções de alimentos e preparações varia de acordo com o poder aquisitivo da região, sendo que o "pingado" com pão na chapa é uma unanimidade. O "pingado" é uma bebida com pouco leite e muito café em infusão, tradicionalmente servido no copo americano, e o pão na chapa é o pão francês com muita manteiga ou margarina, prensado na chapa quente até ficar bem fino e dourado por fora (MASTROROSA, 2010).

As cafeterias de luxo já oferecem cappuccinos, cafés especiais, chocolates quentes e gelados, pães de queijo, croissants, broas, salgadinhos variados (como coxinhas, empadinhas, esfiras, enroladinhos, etc.), além de sanduíches do tipo misto-quente (pão de forma ou francês com queijo prato e presunto cozido), bauru (a mesma receita do misto-quente acrescido de tomate e orégano), americano (a mesma receita de bauru acrescido de alface e ovo frito), cheese burguer e outras guloseimas (MASTROROSA, 2010).

Com o passar do tempo, as panificadoras passaram a oferecer aos clientes uma grande variedade de produtos que vão além da simples oferta de pães e leite. É possível encontrar em todas elas cafés de váriados tipos, leites em diversas versões, açúcar, achocolatados, compotas, geleias, molhos, temperos, 
condimentos, vinhos, sucos, água, refrigerantes, produtos in natura, frios de todos os tipose refrigerados, como iogurtes, requeijões e margarinas (FEDERAÇÃO DAS INDÚSTRIAS DO ESTADO DE SÃO PAULO; INSTITUTO DE TECNOLOGIA DE ALIMENTOS, 2010).

Costa e Schor (2013) realizaram um estudo com o objetivo de analisar a relação entre transição dos hábitos alimentares, saúde, envelhecimento de mulheres e a rede urbana em uma cidade da Amazônia. Ao aplicar 15 formulários em cinco diferentes bairros da cidade, as autoras observaram que, entre outros achados, das refeições analisadas a que mais foi modificada no decorrer dos anos foi o CM. As entrevistadas comentaram que nos dias de hoje estão tendo um CM menos variado e mais próximo de uma "dieta de supermercado" (café, pão e manteiga).

No estudo acima, a população de menor poder aquisitivo apresentou menos ou nenhum acesso a frutas e um CM menos variado. As mulheres de melhor poder aquisitivo consumiam no $\mathrm{CM}$, além do trivial café, pão, manteiga, também frutas, como mamão, tucumã, além de queijo e tapioca. Algumas entrevistadas comentaram que era raro o consumo de alimentos tradicionais no $\mathrm{CM}$, como o cará, a macaxeira e os mingaus de diversos tipos. As entrevistadas realçaram também que o mingau de banana desapareceu por completo da mesa das famílias, o que, de acordo com a memória das idosas, era um alimento importante quando crianças (COSTA; SCHOR, 2013).

A composição alimentar mais frequente do CM do brasileiro tem sido café puro ou com leite, e pão acompanhado de manteiga ou margarina, mas o consumo de frutas e hortaliças é raro (BARBOSA, 2007; FREITAS; MENDONÇA; LOPES, 2013; MATTOS; MARTINS, 2000; PINEYRUA, 2006; SOUZA et al., 2013). Outros citam uma forma mais simples de cardápio de CM constituído apenas de café puro (GARCIA, 1997). A mandioca ainda é citada como substituto do pão em algumas regiões do país (MAZZILLI, 1975; SILVA, 2008). Santos et al. (2005), Hofelmann e Momm (2014) citam uma composição mais completa no CM do brasileiro: leite, café, pães, frios, biscoitos, bolos, frutas e suco de frutas, manteiga/margarina, mas provavelmente esse cardápio não representa o cardápio de CM da maioria dos brasileiros.

Embora sejam raros os registros de consumo de hortaliças no $\mathrm{CM}$ brasileiro (HOFELMANN; MONN, 2014), acredita-se que a cenoura, a beterraba e os folhosos verdes escuros sejam os mais comumente consumidos em forma de sucos 
com frutas. A mandioca, a batata doce, o cará e o inhame (grupo das raízes e tubérculos) são alimentos próprios do CM regional, não sendo consumidos pela grande maioria dos brasileiros (BRASIL, 2014). Levando-se em consideração essas constatações, acredita-se que as políticas públicas de alimentação e nutrição deveriam estimular mais o consumo de frutas e hortaliças na refeição $\mathrm{CM}$, pois o consumo de algumas hortaliças é perfeitamente viável nesta refeição em forma de sucos ou cozidas, garantindo assim um maior aporte de vitaminas, de minerais e de fibras a partir da primeira refeição diária.

Devido à existência de poucos estudos direcionados à refeição $\mathrm{CM}$ (HÖFELMANN; MOMM, 2014; TRANCOSO; CAVALLI; PROENÇA, 2010), realizouse neste trabalho uma busca em bases de dados eletrônicas por um período de 20 anos, de 1994 a 2014, cujo objetivo foi verificar quais alimentos foram consumidos nas pesquisas sobre o $\mathrm{CM}$. Também devido à carência de estudos envolvendo pessoas adultas (CHAPLIN; SMITH, 2011; MILLA; JONHS; AGUERO, 2014; REEVES et al., 2013), essa revisão considerou pesquisas realizadas com crianças, adolescentes, adultos saudáveis e aquelas direcionadas à análise de instrumentos como cardápios, índices e indicadores alimentares.

Foram identificados 163 artigos com descritores pré-definidos, sendo que 130 foram descartados pelo título, quatro eram repetidos e 29 atendiam aos critérios de inclusão. Dentre eles, 22 atendiam integralmente ao objetivo da pesquisa. A descrição dos artigos selecionados encontra-se no Quadro 1, organizados por ordem cronológica. 
Quadro 1. Distribuição dos estudos publicados com descrição dos alimentos consumidos no café da manhã, no período de 1994 a

2014. Brasil.

\begin{tabular}{|c|c|c|c|c|}
\hline $\begin{array}{l}\text { Autor(es)/ } \\
\text { Ano/ local }\end{array}$ & Objetivo & n da amostra & $\begin{array}{l}\text { Metodologia } \\
\text { de indicação } \\
\text { dos alimentos }\end{array}$ & Alimentos citados no café da manhã \\
\hline $\begin{array}{l}\text { Silva, A.C., } 1995 \\
\text { Rio de Janeiro }\end{array}$ & $\begin{array}{l}\text { Descrever políticas e programas de } \\
\text { alimentação e nutrição }\end{array}$ & 50 empresas & $\begin{array}{l}\text { Definido pelo } \\
\text { Programa de } \\
\text { Desjejum } \\
\text { Escolar }\end{array}$ & Leite, pão, frutas \\
\hline $\begin{array}{l}\text { Silva, M.V., } 1995 \\
\text { São Paulo }\end{array}$ & $\begin{array}{l}\text { Avaliar o consumo alimentar de } \\
\text { escolares de um Centro Integrado de } \\
\text { Educação Pública do município de } \\
\text { Americana,São Paulo }\end{array}$ & $\begin{array}{c}442 \\
\text { Crianças }\end{array}$ & $\begin{array}{l}\text { Definido pelo } \\
\text { programa de } \\
\text { alimentação } \\
\text { da instituição }\end{array}$ & Leite, café, pão, margarina ou biscoitos \\
\hline $\begin{array}{l}\text { Oliveira; Hébaud-Mony, } \\
1998 \\
\text { São Paulo }\end{array}$ & $\begin{array}{l}\text { Estudar o consumo alimentar em três } \\
\text { localidades na cidade de São Paulo. }\end{array}$ & $\begin{array}{c}32 \\
\text { Adultas }\end{array}$ & $\begin{array}{l}\text { Recordatório } \\
24 \text { horas }\end{array}$ & Leite, café, pão, margarina \\
\hline $\begin{array}{l}\text { Gambardella; Frutuoso; } \\
\text { Franch, 1999, São Paulo }\end{array}$ & $\begin{array}{l}\text { Conhecer a prática alimentar de } \\
\text { adolescentes }\end{array}$ & $\begin{array}{c}153 \\
\text { adolescentes }\end{array}$ & $\begin{array}{l}\text { Questionário } \\
\text { alimentar não } \\
\text { especificado }\end{array}$ & $\begin{array}{l}\text { Leite, leite com café/chocolate ou fruta } \\
(63 \%) \text {, queijo ( } 3 \%) \text {, pão/biscoito }(24 \%) \text {, } \\
\text { pão/biscoito com margarina (42\%), pães } \\
\text { e frios }(6 \%)\end{array}$ \\
\hline $\begin{array}{l}\text { Mattos; Martins, } 2000 \\
\text { São Paulo }\end{array}$ & $\begin{array}{l}\text { Estimar o consumo médio diário de } \\
\text { fibras nas refeições de indivíduos } \\
\text { adultos em população de São Paulo }\end{array}$ & $\begin{array}{c}559 \\
\text { Adultos }\end{array}$ & $\begin{array}{l}\text { História } \\
\text { alimentar }\end{array}$ & $\begin{array}{l}\text { Leite }(51,3 \%) \text {, café }(87,5 \%) \text {, pão } \\
\begin{array}{l}(70,8 \%), \quad \text { margarina }(50,8 \%), \text { frutas } \\
(11,3 \%)\end{array}\end{array}$ \\
\hline $\begin{array}{l}\text { Carvalho et al., } 2003 \\
\text { Piaui }\end{array}$ & $\begin{array}{l}\text { Avaliar a qualidade nutricional das } \\
\text { refeições de idosos residentes em três } \\
\text { instituições geriátricas de Teresina-PI }\end{array}$ & $\begin{array}{c}156 \\
\text { Idosos }\end{array}$ & $\begin{array}{l}\text { Cardápio da } \\
\text { instituição }\end{array}$ & $\begin{array}{l}\text { Leite, café, pão, margarina, bolacha, } \\
\text { cuscuz }\end{array}$ \\
\hline \multirow[t]{2}{*}{$\begin{array}{l}\text { Monteiro; Mendonça, } \\
2004 \\
\text { Rio de Janeiro }\end{array}$} & \multirow[t]{2}{*}{$\begin{array}{l}\text { Relatar a experiência de moradores do } \\
\text { loteamento Ana Gonzaga, periferia do } \\
\text { Rio de Janeiro }\end{array}$} & \multirow[t]{2}{*}{$\begin{array}{l}150 \\
\text { residências }\end{array}$} & \multirow[t]{2}{*}{$\begin{array}{l}\text { Entrevista } \\
\text { coletiva }\end{array}$} & Leite, café, pão, margarina \\
\hline & & & & leite $\quad(90,25 \%)$ \\
\hline
\end{tabular}


Mainard, 2005

São Paulo

Bispo, 2006

Distrito Federal

Pineyrua, 2006

Porto Alegre, São Paulo,

Goiânia e Recife

Pinheiro, 2006

Distrito Federal

Silva, 2006

Distrito Federal

Alves; Boog, 2007

São Paulo

Barbosa, 2007

Brasil

Souza et al., 2007

São Paulo
Analisar hábitos alimentares e opiniões de alunos concluintes do ensino fundamental

Traçar o perfil alimentar do desjejum dos professores da Universidade de Brasília de 3 áreas do conhecimento

Identificar o comportamento alimentar típico do brasileiro que valoriza a alimentação tradicional e prazerosa

Conhecer o perfil do consumo de CM de estudantes de cursos da área de saúde da Universidade de Brasília

Conhecer o perfil alimentar do desjejum de adolescentes de 3 escolas particulares de ensino médio

Descrever o comportamento alimentar de estudantes residentes em moradia universitária

Mapear os hábitos alimentares a partir das declarações dos consumidores

Verificar a relação entre o tipo de $\mathrm{CM}$ e o IMC de pacientes de um consultório de nutrição
1.414 adolescentes

Inquérito alimentar não especificado

284

adultos

1.545

adultos

232

adultos

214

adolescentes

100

adultos

2.536

adultos

400

adultos
Inquérito alimentar não especificado

Questionário estruturado

Questionário de freqüência alimentar

Questionário de freqüência alimentar

Recordatório 24 horas

Questionário estruturado

\section{Recordatório} 24 horas
$(73,58 \%)$ pão $(99,14 \%)$, manteiga $(63,09 \%)$, bolacha $(50,37 \%)$

Zona rural: leite $(86,09 \%)$, café $(65,22 \%)$ pão $(92,17 \%)$ bolacha $(66,96 \%)$, bolo $(58,26 \%)$

Leite integral, leite desnatado, café, pão francês, pão de forma integral,manteiga frutas, iogurte, geleia, açúcar, adoçante

Leite, café, pão, manteiga/margarina, fruta, queijo, requeijão

Leite, café, achocolatado, pão francês, margarina/manteiga, frutas, iogurte, queijo, requeijão

Leite com achocolatado (38,6\%), café $(12,3 \%)$, pão $(34 \%)$, margarina $(20,4 \%)$, frutas $(46,1 \%)$, iogurte $(11,8 \%)$, queijo $(21,9 \%)$, requeijão $(14,5 \%)$

Considerando $30 \%$ de supressão do $\mathrm{CM}$, a maioria consumiu leite, café, pão, manteiga/margarina (37\%)

Leite $(73 \%)$, café (85\%), pão francês (76\%)

Leite e derivados; $P$ ães (branco, integral, bisnaguinha, bolacha, torradas, pão de queijo, pão de batata, etc); Gorduras e doces (margarina, manteiga, açúcar, achocolatado, etc); Frutas e vegetais; Bolos e bolachas; Bebidas (café) 
Machado; Simões, 2008

São Paulo

Pinheiro et al., 2010

Rio Grande do Sul

Araújo; Santos; Araújo,

2011

Rio Grande do Norte

Valenga, 2011

Paraná

Longo-Silva et al., 2012,

São Paulo

Costa; Schor, 2013

Amazonas

Santos, 2014

São Paulo

Menezes et al., 2016

Brasil
Testar a metodologia de análise custoefetividade como instrumento de decisão na produção de refeições

Caracterizar as preferências

alimentares de funcionários do Hospital Santa Casa de Pelotas

Analisar se o CM oferecido pelo Projeto Café do Trabalhador atendia aos conceitos de segurança alimentar e nutricional

Analisar os hábitos alimentares de alunos do ensino fundamental

Avaliar o consumo energético e a adequação da dieta de crianças de creches públicas em São Paulo

Analisar a transição dos hábitos alimentares, saúde e envelhecimento de mulheres de uma cidade da Amazônia.

Identificar os padrões alimentares do $\mathrm{CM}$, do almoço e do jantar da população adulta e idosa do município de São Paulo

Avaliar o impacto da energia proveniente de fibras dietéticas no cálculo da caloria do alimento
5 cardápios de CM propostos pela instituição

26

adultos

1 Unidade de

Alimentação e Nutrição

40

Adolescentes

240 crianças entre 12 a 29 meses

\section{5}

Idosas

1.043 adultos e idosos

1753 alimentos

\section{Cardápio da \\ instituição}

Questionário

Cardápios propostos pelo projeto de oferta de CM

\section{Questionário}

\section{Recordatório 24 horas}

Banco de dados de composição de alimentos
Leite com café e açúcar, leite com achocolatado, pão com manteiga, pão com presunto, pão com queijo, pão com presunto e queijo, frutas

Leite, café, pão branco, manteiga/ margarina, açúcar refinado, frios/queijo, frutas

Leite e derivados: café com leite, queijo, achocolatado; Cereais: bolos, pães, aipim cozido, cuscuz, tapioca, biscoito, batata doce; Frutas; Carne ou ovos

Leite, café, achocolatado, pães, biscoitos

Leite, café, achocolatado, pão ou biscoito com margarina ou geleia, bolo, cereais matinais

Café com açúcar, pão, manteiga, frutas, queijo, tapioca

Leite integral/desnatado, café, achocolatado, pão/torrada, pão integral, manteiga/margarina, frutas, queijos, frios, biscoitos, açúcar

Região Sudeste: leite, café, açúcar, pão, manteiga,queijo. Região Centro-Oeste:

leite, café, açúcar, bolo de coco, queijo, papaia. Região Nordeste: leite, açúcar, tapioca e banana 
Embora não sejam muitas as pesquisas que abordaram essa temática especfica no período pesquisado, observou-se que os artigos selecionados constituíram-se, coincidentemente, de pesquisas realizadas em todas as regiões geográficas do país.

A presença de estudos com amostras constituídas por indivíduos de todas as faixas etárias foi outro aspecto que favoreceu a representatividade, pois possibilitou observar o que é proposto ou consumido em diversas faixas de idade. Algumas pesquisas (BARBOSA, 2007; MAINARD, 2005; PINEYRUA, 2006; SANTOS, 2014) foram realizadas com um número expressivo de participantes, de forma a aumentar a segurança na generalização dos resultados, ou seja, aumento de confiança na delimitação dos marcadores de alimentos identitários do CM.

A metodologia de indicação dos alimentos propostos ou consumidos no CM de cada estudo fez referência ao método de obtenção dos dados. Parte deles $(72,3 \%, n=16)$ correspondeu à forma de obtenção de consumo alimentar por algum tipo de questionário, embora outra parte das pesquisas não tenha apresentado maiores detalhes sobre o tipo de questionário utilizado, demonstrando a falta de rigor metodológico. Para além dessas observações, pressupõe-se que, nesse caso, as análises de dados provenientes da utilização de instrumentos como questionários sejam mais fidedignas que análises de instrumentos que avaliam cardápios ou projetos/programas propostos.

Um único estudo (MINARD, 2005) abordou as diferenças de consumo alimentar entre as áreas urbana e rural. Pelos percentuais de consumo de alimentos apresentados no estudo, o consumo de pão foi maior na área urbana, e o consumo de bolacha e bolo foi maior na área rural, provavelmente justificado por questões de acesso aos locais de venda de pães, que são mais numerosos na área urbana.

O estudo mais recente (MENEZES et al., 2016) que objetivou avaliar o impacto da energia proveniente de fibra dietética, criou três cardápios regionais simulando refeições típicas da população brasileira para o $\mathrm{CM}$, almoço, lanche e jantar. De forma interessante, os autores criaram cardápios que continham alimentos rotineiramente consumidos pelas regiões Sudeste, Centro oeste e Nordeste, o que fez deste estudo um possivel pioneiro em considerar diferenças regionais em estudos considerando o CM brasileiro.

Por meio da análise de alguns dos estudos selecionados (MATTOS, MARTINS, 2000; BARBOSA, 2007), acredita-se ser possível inferir que o leite com café (ou café com leite) e o pão com manteiga/margarina possam ser considerados marcadores de alimentos identitários da primeira refeição do dia. Embora outros autores (PINEYRUA, 2007; SOUZA 
et al., 2007) façam referência a uma maior frequência de um CM mais simples, constituído apenas de café e pão.

No caso dos estudos selecionados nessa pesquisa, pode-se observar que os alimentos citados no CM são agrupados de diversas formas e apresentam uma grande variedade. Alguns fazem referência a composições simples como as citadas pelos autores acima, outros expandem a outros alimentos.

A análise dos artigos selecionados nesta revisão mostrou que a maioria das pesquisas estuda a realização ou não do $\mathrm{CM}$, mas não exploram a quantidade e a qualidade dessa refeição, não permitindo assim verificar que tipos de alimentos estão sendo consumidos, assim como qual seriam os possíveis marcadores identitários alimentares.

A análise dos artigos que citaram o tipo de alimento consumido ou ofertado mostrou que os possíveis marcadores identitários alimentares da refeição CM são o leite, o café e o pão, sendo que este último não necessariamente seja do tipo Francês, talvez justificado pela falta de especificação do tipo de pão em cada pesquisa. Considerando as premissas existentes no Guia Alimentar para a População Brasileira, o CM dos brasileiros poderia ser constituído pelo consumo de mais alguns grupos alimentares, como o das frutas, do leite e derivados, o que significaria mais marcadores identitários alimentares que culturalmente representariam uma população mais saudável.

Santos et al. (2015) publicaram recentemente um estudo pioneiro sobre os tipos de padrões alimentares presentes na população brasileira. A pesquisa objetivou identificar a relação do padrão dietético das refeições CM, almoço e jantar de 1.102 indivíduos maiores que 20 anos, participantes do Inquérito de Saúde de São Paulo. A ingestão de alimentos foi estimada usando o Multiple Source Method (MSM), método de estimação do consumo alimentar usual, através da utilização de recordatórios de $24 \mathrm{~h}$. A correlação final dos dados indicou a existência de 3 tipos de padrões dietéticos para o CM: saudável, tradicional e snack. No padrão dietético saudável mostrou maior consumo de leite desnatado, pão integral, queijo branco e frutas. O padrão dietetico tradicional foi caracterizado pelo maior consumo de café, açúcar, manteiga/margarina e pão/torradas. Já no padrão dietético snack apresentou maior consumo de frios, pão/torrada e queijo amarelo. 
A falta de rigor metodológico nas pesquisas que estudam os alimentos consumidos no $\mathrm{CM}$ dos brasileiros é um fato indiscutível, o que não condiz com a importância da primeira refeição do dia na promoção da saúde humana. A promoção de ações públicas de incentivo à realização do $\mathrm{CM}$ mais saudável e a maior ênfase dos estudiosos no assunto podem influenciar na formação de marcadores identitários de uma alimentação mais saudável. 


\section{OBJETIVOS}

\subsection{OBJETIVO GERAL}

Analisar a frequência de realização do café da manhã, sua composição nutricional e o hábito de consumo de alimentos regionais nessa refeição entre usuários adultos do Programa de Restaurantes Populares no Brasil.

\subsection{OBJETIVOS ESPECÍFICOS}

- Realizar uma revisão bibliográfica sobre a refeição CM no mundo, com enfoque no consumo de alimentos regionais nessa refeição;

- Relacionar as diferenças existentes no consumo do CM quanto ao perfil sociodemográfico dos participantes da pesquisa;

- $\quad$ Analisar a composição nutricional do CM dos participantes da pesquisa;

- Verificar a frequência do consumo de alimentos regionais no CM;

- Realizar análise comparativa entre o consumo de alimentos regionais no CM dos participantes nas diversas regiões geográficas e entre os dias da semana;

- Avaliar o consumo de alimentos regionais nas unidades de Restaurantes Populares que fornecem CM;

- Realizar avaliação qualitativa do CM dos participantes da pesquisa;

- Efetuar análise comparativa da avaliação qualitativa entre o CM realizado em casa com o CM realizado no Restaurante Popular;

- Identificar os marcadores de identidade alimentar do CM. 


\section{MATERIAIS E MÉTODOS}

A metodologia deste trabalho está estruturada em duas partes. A primeira parte é composta pelos procedimentos adotados para conduzir uma revisão bibliográfica que forneceu suporte teórico à execução desta pesquisa, no que se refere à forma de abordagem das pesquisas existentes sobre o tema "consumo de alimentos regionais no CM no mundo". A segunda parte contém a descrição do delineamento, da execução e da análise dos dados da pesquisa com os usuários dos Restaurantes Populares.

\subsection{REVISÃO DA LITERATURA}

O tipo de revisão escolhida foi a integrativa, que articula dados da literatura teórica e empírica, além de agregar propósitos como definição de conceitos, revisão de teorias e evidências, e análise de problemas metodológicos de um tópico em particular. Possibilita assim, a inclusão de estudos experimentais e não-experimentais, e permite uma compreensão completa do fenômeno analisado (SOUZA; SILVA; CARVALHO, 2010).

Essa revisão integrativa teve como objetivo analisar estudos sobre o CM no mundo, com enfoque no consumo de alimentos regionais nessa refeição. A estratégia de busca de artigos dessa revisão compreendeu uma pesquisa em bases de dados eletrônicas na Biblioteca Virtual em Saúde (BIREME), utilizando-se as bases MEDLINE (National Library of Medicine, Estados Unidos), LILACS (Literatura Latino-americana e do Caribe em Ciências da Saúde) e SciELO (Scientific Eletronic Library on Line), no período de janeiro de 2003 a julho de 2013. A busca foi realizada separadamente nos idiomas português, inglês e espanhol, utilizando-se os descritores "desjejum", "desjejum regional", "café da manhã" e "café da manha regional" e os seus equivalentes nas demais línguas. Como a palavra "regional" em alimentação possui diversos sinônimos, também foram utilizados como descritores os substitutos "tradicional" e "típico".

Foram critérios de exclusão para essa seleção os artigos de revisão e editoriais; os artigos em línguas diferentes do português, inglês e espanhol; os artigos incompletos; as monografias, dissertações e teses; os capítulos de livros e os artigos que não tinham ligação com a temática em estudo. As referências dos artigos incluídos foram vistas com 
intenção de captar mais estudos com o tema em questão, mas nenhuma se adequou aos critérios de inclusão.

Após o resultado da busca, foi realizada uma seleção a partir do título e foram descartados os artigos que não apresentavam conexão com o tema estudado. O passo seguinte foi a leitura individual do resumo de cada artigo selecionado, verificando-se mais uma vez o atendimento ao tema de interesse. Cabe destacar que cinco artigos não apresentaram resumo e foram descartados. Todos os artigos que abordavam o tema "café da manhã" sob qualquer aspecto foram incluídos.

Cada artigo foi analisado de acordo com uma adaptação do sistema de classificação que dispõe os estudos de forma hierárquica, segundo a abordagem metodológica adotada por Souza, Silva e Carvalho (2010). Para este trabalho foi desconsiderado o nível 1 de evidências descrita pelos citados autores, em virtude da exclusão dos artigos de revisão. O objetivo desse sistema de classificação é auxiliar na escolha da melhor evidência possível, propondo uma hierarquia das evidências, segundo o delineamento das pesquisas. Segundo os autores, esse sistema de classificação está inserido na fase de análise crítica dos estudos incluídos, possibilitando uma abordagem organizada para ponderar o rigor e as características de cada estudo. Os níveis de evidências estabelecidos são:

- Nível 1: evidências obtidas em estudos individuais com delineamento experimental;

- Nível 2: evidências de estudos quase-experimentais;

- Nível 3: evidências de estudos descritivos ou com abordagem qualitativa

- Nível 4: evidências provenientes de relatos de caso ou de experiência;

- Nível 5: evidências baseadas em opiniões de especialistas.

\subsection{DELINEAMENTO DA PESQUISA}

Este estudo é parte integrante do projeto "Avaliação do Serviço de Alimentação Coletiva prestado pelos Restaurantes Populares: diagnóstico da qualidade e atenção dietética das refeições servidas", financiado pelo Ministério de Desenvolvimento Social e Combate à Fome - MDS e conduzido pelo Departamento de Nutrição da Faculdade de Ciências da Saúde da Universidade de Brasília-UnB (UNIVERSIDADE DE BRASILIA, 
2010). A referida pesquisa de intervenção foi aprovada pelo Comitê de Ética e Pesquisa da Faculdade de Saúde da UnB (no 0372/10).

Cada restaurante participante recebeu uma carta que correspondeu ao termo de consentimento da instituição, que foi assinado pelo Responsável Técnico da Unidade de Alimentação e Nutrição - UAN (APÊNDICE A). Os participantes da pesquisa receberam uma carta de apresentação do estudo e o Termo de Consentimento Livre e Esclarecido para a devida assinatura, sendo que uma cópia do documento assinado ficou arquivada com a equipe responsável pela pesquisa, e a outra foi entregue ao participante (APÊNDICE B).

Este estudo é do tipo exploratório de delineamento transversal (PEREIRA, 2001), pois compreende a análise e a descrição dos dados coletados no período de maio de 2010 a junho de 2011, referentes ao CM dos usuários entrevistados na pesquisa do MDS-UnB citada anteriormente.

\subsection{AMOSTRA}

Para o presente trabalho, foi considerado como unidade amostral o indivíduo frequentador dos Restaurantes Populares na refeição almoço, tendo em vista que nem todas as unidades de restaurantes ofereciam CM. Para determinação da amostra final, foram considerados os 65 restaurantes vinculados ao Programa Restaurantes Populares do MDS no momento da concepção do projeto em 2010. Dessa forma, calculou-se uma amostra aleatória simples, com base no total de usuários do Programa Restaurantes Populares no país (55.350 indivíduos), distribuídos nas cinco regiões geográficas do Brasil.

Com o objetivo de garantir a proporcionalidade de usuários para cada região, o levantamento foi feito em pelo menos $20 \%$ dos Restaurantes Populares de cada região, excetuando-se a Região Centro-oeste, onde foi realizada em apenas um restaurante, correspondendo a $25 \%$ da amostra regional. Apesar do restaurante sorteado para a região Centro-oeste corresponder a $25 \%$ da amostra, o erro amostral foi maior do que o estimado para as demais regiões (erro estimado em 15\%), portanto os dados da região Centro-oeste serão apresentados, mas é necessário acentuar que qualquer generalização de resultados pode não ser indicada. 
A amostra dos usuários foi calculada conforme Datallo (2008), obtendo-se um tamanho de amostra mínima de 41 usuários por cada um dos 36 restaurantes, ou seja, pelo menos 1.476 usuários no total. A amostra selecionada em cada RP foi de 80 indivíduos, valor superior ao calculado, pois, como os mesmos indivíduos foram acompanhados durante os três dias consecutivos (domingo, segunda e terça-feira), considerou-se uma margem de segurança durante o processo de coleta. Após a exclusão dos recordatórios inválidos, a amostra final desse estudo constituiu-se de 1.872 indivíduos usuários de 36 restaurantes vinculados ao Programa Restaurantes Populares do MDS no ano de 2010, cujo tamanho da amostra final foi obtido com base em parâmetros estatísticos com nível de significância (a) de 5\% e poder de teste de 80\% (COHEN, 1962).

A distribuição da quantidade de unidades selecionadas foi proporcional ao número de restaurantes existentes por região geográfica: Norte com quatro unidades, Nordeste com dez Unidades, Centro-oeste com uma unidade, Sudeste com 15 unidades e Sul com seis unidades. Todas as unidades selecionadas são de grande porte e servem almoço por, no mínimo, cinco dias por semana (BRASIL, 2007b). A maioria dos entrevistados fazia o CM em casa, excetuando-se os de Araraquara (SP), Bonsucesso $(R J)$, Campina Grande (PB), Campo Grande (RJ), Guarulhos (SP), Méier (RJ) e uma unidade de Belo Horizonte (MG), cujas unidades de Restaurantes Populares ofereciam o CM com cardápios elaborados por nutricionistas.

Os critérios para inclusão dos indivíduos no estudo foram a adesão do participante na realização da pesquisa, a realização do almoço no Restaurante Popular nos três dias de coleta e idade igual ou superior a 18 anos. Foram excluídos da pesquisa os indivíduos que não completaram o protocolo (realizar a refeição almoço), as gestantes e os menores de 18 anos.

\subsection{PROCEDIMENTOS DE COLETA}

Todos os pesquisadores foram devidamente treinados e compareceram a cada RP estudado três vezes por semana para aplicação do questionário elaborado especificamente para a pesquisa.

A seleção da amostra de indivíduos em cada unidade foi realizada de forma sistemática na fila de espera para entrada no Restaurante Popular, selecionando a partir 
do primeiro indivíduo da fila, o 15ำ e assim sucessivamente a cada 15 indivíduos. Caso não aceitassem participar seriam substituídos na própria fila pelo indivíduo subsequente

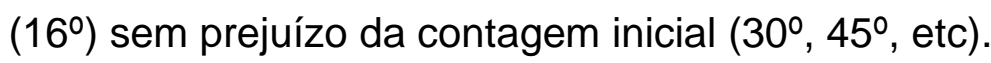

Todos os participantes foram informados sobre o objetivo, a duração e as etapas da pesquisa. Para evitar perdas de dados de consumo, os indivíduos selecionados para a pesquisa foram encaminhados a lugares específicos dentro do salão de cada RP. Cada cliente foi orientado a procurar a equipe de pesquisa durante os três dias seguintes à seleção. A equipe de pesquisa disponibilizou um integrante para o acolhimento dos indivíduos. Ao final, verificou-se que o percentual total de perdas foi de $33,1 \%$ dos indivíduos.

\subsection{VARIÁVEIS DO ESTUDO}

\subsubsection{Variáveis sociodemográficas}

Foram coletadas informações dos participantes relativas ao sexo, idade, escolaridade, tipo de atividade profissional, naturalidade, estado civil e participação em programas sociais do governo. A renda familiar e o número de pessoas da família foram coletados para obtenção da renda per capita (APÊNDICE C).

\subsubsection{Análise do consumo alimentar}

Para verificar o consumo alimentar dos usuários, foi utilizado um recordatório de 24 horas por três dias. Com o objetivo de captar diferenças de consumo de alimentos entre os dias da semana, aplicou-se o instrumento em um dia de domingo e em dois dias durante a semana (segunda e terça-feira). As informações de consumo registradas nos recordatórios foram relatadas pelos participantes da pesquisa e anotadas no formulário próprio por membros da equipe de pesquisa devidamente treinados. 
A definição de $\mathrm{CM}$ foi construída a partir da análise preliminar dos próprios questionários contendo o relato de consumo diário de alimentos de cada participante. Assim, a refeição CM ficou sendo definida como a primeira refeição do dia realizada a partir das quatro horas da manhã, podendo ser um único alimento/preparação ou vários alimentos/preparações, exceto água, consumidos até as 11h30min da manhã. Esse ponto de corte no horário foi estabelecido também em virtude da análise preliminar dos questionários, em que a primeira refeição de alguns participantes aconteceu até as11h30min, com posterior consumo de refeição característica de almoço e em virtude de a maioria dos restaurantes iniciarem a distribuição do almoço a partir das 11h30min.

Por se tratar de um estudo sobre hábitos alimentares regionais brasileiros e tendo em vista os hábitos característicos de algumas regiões em consumir no CM preparações mais elaboradas, características da refeição almoço, tais refeições também foram consideradas CM desde que esta fosse a primeira refeição do dia. Se a primeira refeição do dia foi o almoço do $\mathrm{RP}$, esta não foi considerada como $\mathrm{CM}$.

Embora não exista a recomendação de grupos de alimentos específicos para o CM no Guia Alimentar para a População Brasileira (BRASIL, 2014), foi analisada a presença de grupos de alimentos para a análise da composição nutricional do $\mathrm{CM}$, sendo eles os lácteos, os cereais, as frutas, as raízes/tubérculos, e as carnes/ovos.

A informação do local de realização do CM foi obtida pela análise dos questionários contendo o registro de consumo diário de alimentos, uma vez que os entrevistadores foram treinados para registrar o local de realização de cada refeição. Esse procedimento possibilitou a realização da análise comparativa entre a classificação qualitativa e o consumo de alimentos regionais no $\mathrm{CM}$ realizado em casa e o CM realizado nas sete unidades de RP que ofereciam essa refeição, levando-se em consideração apenas o consumo de alimentos regionais na segunda e terça-feira, pois aos domingos não havia funcionamento dos Restaurantes Populares. Da mesma forma foi avaliada a diferença de consumo do número de alimentos regionais entre domingo e os dias de meio de semana, assim como os quatros principais alimentos regionais consumidos em cada região.

Foi considerada refeição regional aquela que apresentou consumo de pelo menos um alimento/preparação (independente da região de consumo) contido na Lista de Alimentos Regionais do CM (APÊNDICE D). Essa lista foi elaborada a partir de Ginani (2011), adaptada para o CM, acrescida de outras publicações da área de alimentos (ABRIL COLEÇÕES, 2012; ARAÚJO et al., 2005; BRASIL, 2002a; CHAVES et al., 2009; 
FISBERG, WEHBA, COZZOLINO, 2002; PHILIPPI, 2006; WIKIPÉDIA, 2013). Como a lista criada por Ginani (2011) refere-se somente à refeição almoço, foi necessária a busca em novas referências para a seleção de alimentos regionais que poderiam ser consumidos nas refeições CM de todas as regiões brasileiras. No exame preliminar dos recordatórios, foram encontrados alguns nomes de alimentos não citados nas referências expostas acima, o que acarretou uma busca também no Wikipédia, no intuito de identificar a sinonímia ou a caracterização de tais alimentos desconhecidos.

Vale ressaltar que os alimentos chá e presunto, embora não sejam originários do Brasil, foram incorporados aos hábitos alimentares brasileiros na época da colonização e constam como alimentos característicos de algumas regiões brasileiras nas referências bibliográficas supracitadas. Em tais referências o chá apareceu como de consumo regional nas regiões Centro-oeste e Sul, e o presunto, na região Sul.

O Chimarrão, bebida quente tradicional da região Sul, não foi considerado como chá, pois esse possui formas de consumo diferenciadas. O consumo de chimarrão possui um caráter cultural definido, pois normalmente é consumido em momentos de reuniões com parentes e amigos (OLIVEIRA et al., 2011), não sendo consumido como bebida do $\mathrm{CM}$.

Foram consideradas de consumo nacional as frutas banana e mamão. Somente foram consideradas regionais as bananas-da-terra (também conhecida como banana comprida) e marmelo; as demais, como a banana prata, banana pacovã, banana maçã e banana d'água (banana nanica ou caturra) foram consideradas de consumo nacional. É importante acentuar que, na construção da presente Lista de Alimentos Regionais do CM, foi consultado apenas o livro "Alimentos Regionais Brasileiros", do Ministério da Saúde, publicado em 2002, pois a nova versão de 2015 ainda não tinha sido publicada.

Para a análise dos marcadores de identidade alimentar do CM foram considerados outros grupos de alimentos que constituiu-se em alimentos/preparações comumente consumidos no CM, como: café puro, leite puro, café com leite (ou leite com café), leite com achocolatado, chá, cevada, refresco industrial, refrigerante, pães, bolos e biscoitos, mandioca/batata doce/inhame/cará, cuscuz, tapioca, manteiga, margarina, queijo Prato/Mussarela, queijos (Minas, Canastra, Coalho, Colonial, Manteiga), maionese, mel/melado, embutidos, geleias, frutas, açúcar e adoçante. O grupo dos bolos e biscoitos incluiu os demais produtos de panificação como bolachas, croissant, roscas, broas, biscoitos caseiros, brioches, etc. Foram computados todos os alimentos e preparações consumidos independente de serem considerados saudáveis. 
$\mathrm{Na}$ análise dos recordatórios, foram realizadas algumas padronizações para melhor homogeinização no cômputo de frequência dos alimentos/preparações regionais, a saber: quando do registro de consumo de queijo sem especificação do tipo, foi considerado queijo do tipo Mussarela ou Prato; leite condensado cozido foi considerado como doce de leite; refresco artificial não foi considerado fonte de nenhum nutriente; banana cozida foi considerada como banana-da-terra; doce sem especificação do tipo foi considerado doce de frutas; guaraná somente foi considerado fruta quando escrito "guaraná natural"; 0 registro de "queijo fresco" foi considerado queijo do tipo Minas; registros de pratos com arroz, feijão, carne (exceto charque, jabá, carne de sol e seca), ovo e farinha de mandioca na mesma preparação foram considerados como "quebra torto", preparação típica da região Centro-oeste. Farinha de mandioca consumida sozinha foi considerada de consumo nacional.

Os recordatórios foram digitados no programa Dietwin® (REINSTEIN; REINSTEIN; ZINGANO, 2008), que foi o escolhido para análise dos resultados. Nos casos de alimentos/preparações não contidos no programa Dietwin®, como alguns pães regionais, foi solicitada a Ficha Técnica de Preparação (FTP) aos nutricionistas dos RP que ofereciam CM, e, no caso da inexistência da FTP, foram consultados sites de receitas na internet, selecionando-se três receitas, que foram posteriormente confrontadas para a escolha da receita para a elaboração da FTP, que foi testada no laboratório de Técnica Dietética da UnB para posterior inclusão no programa de análise (Dietwinß).

\subsubsection{Análise qualitativa do café da manhã}

$\mathrm{Na}$ análise qualitativa do recordatório alimentar, considerou-se apenas presença/ausência dos alimentos nas refeições, com base em uma adaptação dos critérios adotados por Alves e Boog (2007). Neste sentido as refeições foram classificadas a partir desses critérios, considerando os alimentos que deveriam estar presentes na alimentação diária. Segue a categorização adotada:

CM Completo: presença de fonte de cálcio, de energia e de alimentos fontes de minerais, vitaminas e fibras;

CM Padrão: presença de fonte de cálcio e de energia; 
CM Incompleto: quaisquer outros alimentos que não contemplem as combinações apresentadas no CM completo ou CM padrão;

CM Ausente ou supressão: nenhum alimento.

Para essa classificação, foram consideradas fontes de cálcio o leite e seus derivados (iogurte, queijos, requeijão, leite condensado e doce de leite). Como fonte de minerais e vitaminas incluíram-se as frutas, e como fonte de energia foram computados os pães, os biscoitos, as bolachas, as farinhas, os bolos e outros produtos de panificação com ou sem acompanhamentos como geleias, mel, margarinas, manteiga, maionese, requeijão, queijos e frios.

Foi utilizada essa classificação qualitativa para avaliar as diferenças de configurações de $\mathrm{CM}$ completo, padrão, incompleto e supressão entre o $\mathrm{CM}$ realizado em casa e o CM realizado no Restaurante Popular. Foi construída para tanto uma escala Likert (LEE et al., 2002) de quatro pontos variando de 0 até 3 , cumprindo os seguintes critérios: 0 $\mathrm{CM}$ completo recebeu nota 3; o CM padrão recebeu nota 2; o $\mathrm{CM}$ incompleto foi representado pela nota 1 , e a supressão obteve nota 0.

\subsubsection{Análise nutricional do café da manhã}

A composição nutricional do $\mathrm{CM}$ foi avaliada pelo software Dietwin® (REINSTEIN; REINSTEIN; ZINGANO, 2008).

Foram considerados válidos para as análises os dados dos recordatórios dos indivíduos selecionados, independente do número de CM realizado por indivíduo, ou seja, o indivíduo que consumiu três, dois ou apenas um CM teve seu recordatório analisado. Para a análise de composição nutricional dessa refeição, foram avaliados o Valor Energético Total (VET), as frações de macronutrientes, os ácidos graxos monoinsaturados, os ácidos graxos saturados, os ácidos graxos trans e as fibras, todos em gramas (g) e percentual de distribuição. Os micronutrientes cálcio e sódio foram avaliados em miligramas $(\mathrm{mg})$ e percentual de distribuição.

O VET da refeição CM foi avaliado de acordo com a Portaria interministerial no 66 (BRASIL, 2006), a qual recomenda que o CM tenha entre 300 e 400 calorias, que 
corresponde de $15 \%$ a $20 \%$ de uma dieta de $2000 \mathrm{Kcal}$, sendo o percentual de $20 \%$ (400 Kcal) adotado para avaliação de consumo energético nessa pesquisa.

Para avaliação do percentual de distribuição das frações de macronutrientes e dos ácidos graxos trans foi considerada a recomendação da Organização Mundial de Saúde (WHO, 2003), que sugere a constribuição energética sobre o VET para os carboidratos (55\% a 75\%), para as proteínas (10\% a 15\%), para os lipídeos (15\% a 30\%) e para os ácidos graxos trans (<1\%). Para a avaliação dos ácidos graxos monoinsaturados (10\% a 15\%) e ácidos graxos saturados (< 10\%) foram também considerados segundo a Organização Mundial de Saúde (WHO, 2007).

Devido ao fato desse estudo avaliar somente o CM não foi avaliado a adequação de consumo, mas o quanto o nutriente consumido no CM contribuiu na recomendação de cada um deles. Entretanto, foram considerados os limites máximos das recomendações dos macronutrientes e dos ácidos graxos monoinsaturados.

A ingestão de fibras foi avaliada segundo o parâmetro proposto pela American Dietetic Association (ADA) (MARLETT et al., 2002), cujo consumo de fibras deve ser de 10 a $14 \mathrm{~g}$ de fibras $/ 1000 \mathrm{kcal}$. Considerando que as fibras foram avaliadas em relação a um $\mathrm{CM}$ de $400 \mathrm{Kcal}$, o que corresponde de 4,0g a 5,6g, foi adotado para essa pesquisa o valor máximo de $5,6 \mathrm{~g}$.

A análise do consumo de cálcio seguiu os parâmetros da Dietary Reference Intakes- DRI (IOM,1997), cuja recomendação para esse mineral é de $1000 \mathrm{mg} / \mathrm{dia}$. Para a avaliação da ingestão do micronutriente sódio foi considerada também a recomendação da Dietary Reference Intakes - DRI (IOM, 2005), que sugere uma ingestão de sódio de até $2300 \mathrm{mg} / \mathrm{dia}$. Entretanto, a análise se processou com referência ao quanto o consumo desses minerais no $\mathrm{CM}$ representou na recomendação do dia, não levando em consideração a contribuição no VET do CM.

\subsection{DELINEAMENTO ESTATÍSTICO}

Após a digitação dos dados constidos nos recordatórios foi realizada uma limpeza excluindo-se os missing e os autliers, pois estes mascaram os resultados a serem encontrados distorcendo seus significados. 
Os dados de natureza quantitativa foram introduzidos em um banco específico para esta pesquisa, elaborado no Programa Statistical Package for Science - SPSS® na versão 20.0, no qual também foram processadas as análises. Após a criação do formulário de entrada dos dados, foi realizada a checagem dos mesmos por meio da análise de distribuição de frequência, comparando-se os valores de cada variável no banco de dados do SPSS® com aqueles possíveis de ocorrência, evitando-se a ocorrência de erros na digitação.

Os dados foram descritos em termos de frequências relativas e medidas resumo como a média e o desvio padrão. Para as análises de associação, o teste estatístico utilizado foi o qui-quadrado de Pearson. Os pressupostos da normalidade foram checados, via teste de Shapiro-Wilk. Os testes estatísticos utilizados foram t de Student e KruskalWallis para apurar a análise de variância, tendo Tukey como Post-hoc. O nível de significância adotado foi de 5\%. 


\section{RESULTADOS}

Neste capítulo, serão apresentados os resultados desta pesquisa, na forma de três artigos independentes. O primeiro artigo intitulado: A regionalidade alimentar no café da manhã: uma revisão integrativa apresenta uma revisão bibliográfica em três bases de dados eletrônicas (MEDLINE, LILACS e SciELO) entre o período de 2003 a 2013. O objetivo deste artigo é o embasamento atualizado da abordagem dos estudos sobre o CM no mundo, com enfoque no consumo de alimentos regionais.

O segundo artigo, com o título: A composição nutricional do café da manhã de usuários de Restaurantes Populares no Brasil, trata da descrição das características sociodemográficas da amostra, da análise da frequência de consumo dos grupos de alimentos e da composição nutricional do CM dos participantes da pesquisa.

O terceiro e último artigo, denominado: Café da manhã: classificação, composição e regionalidade alimentar no Brasil, descreve os resultados referentes à análise da classificação qualitativa do $\mathrm{CM}$; à frequência de consumo de alimentos regionais; à comparação da frequência de consumo de alimentos regionais entre os dias da semana, entre as regiões geográficas e nos Restaurantes Populares que fornecem $\mathrm{CM}$; à comparação entre o $\mathrm{CM}$ realizado em casa e o $\mathrm{CM}$ realizado no Restaurante Popular; e por último a determinação dos marcadores de identidade alimentar do CM dos participantes da pesquisa. 
5.1 CAPÍTULO 1 - A regionalidade alimentar no café da manhã: uma revisão integrativa Food regionality at breakfast: an integrative review 


\section{RESUMO}

O consumo do café da manhã (CM) é um dos indicadores mais importantes de comportamento saudável, apesar disso são poucos os estudos que abordam essa refeição. Por outro lado, também são poucos os registros relacionando essa refeição ao consumo de alimentos regionais. Objetivo: Realizar uma revisão bibliográfica sobre a refeição $\mathrm{CM}$ no mundo, com enfoque no consumo de alimentos regionais nessa refeição. Materiais e Métodos: a revisão integrativa realizada no período de janeiro de 2003 a julho de 2013 consultou as bases de dados eletrônicas MEDLINE, LILACS e SciELO com os seguintes descritores: "desjejum", "desjejum regional", "café da manhã" e "café da manhã regional". Resultados: dos 242 artigos que atendiam aos critérios de inclusão, apenas 8 abordavam de alguma forma o tema regionalidade alimentar no $\mathrm{CM}$. A estrutura familiar e a influência da educação dos pais na manutenção do hábito de consumo do $\mathrm{CM}$ e consumo de alimentos regionais demonstraram ser um dos aspectos mais importantes nesta associação. A região geográfica de residência influencia no perfil de alimentos consumidos no $\mathrm{CM}$ e parece estar pautado também em questões como as tradições e costumes culturais. Além disso, até mesmo fatores como o clima e as condições agrícolas da região podem determinar o perfil de alimentos consumidos em uma comunidade. Conclusão: o tema é pouco estudado e o enfoque no consumo de alimentos regionais é pouco frequente. O CM não é uma refeição freqüente, sendo mais consumido pelas mulheres jovens e de melhor nível social.

Palavras- chave: revisão baseada em evidências; café da manhã; desjejum; alimentos regionais. 


\begin{abstract}
The breakfast $(B)$ consumption is one of the most important indicators of healthy behavior, yet few studies that address this meal. On the other hand, too few records relating to that meal consumption regional food.This paper aims to conduct an evidence based review to determine the prevalence of studies on breakfast consumption with a focus on regional food in the world. The review conducted from January 2003 to July 2013, consulted the electronic databases MEDLINE, LILACS and SCIELO using the following keywords: "breakfast", "breakfast" regional. Of the 242 articles that met the inclusion criteria, only 5 were related somehow the topic regionality food at breakfast. The breakfast is a meal infrequent, more consumed by young women and better social level. The influence of family structure and parental education in maintaining the habit of consumption of breakfast and regional food consumption proved to be one of the most important aspects in this association. The geographic region of residence influences the profile of foods eaten at breakfast and also seems to be ruled on issues such as traditions and cultural customs. Moreover, the factors as climate and agricultural conditions in the region may determine the profile of food consumed in a community.
\end{abstract}

Keysword: evidence based review, breakfast, regional food. 
INTRODUÇÃO

São vários os determinantes da saúde humana, dentre eles a prática de hábitos alimentares saudáveis, que variam de acordo com diferentes áreas geográficas, grupos socioeconômicos e sofrem alterações ao longo do tempo. Hábitos alimentares que envolvem a manutenção de padrões alimentares tradicionais contribuem para maior longevidade, baixa morbidade e mortalidade infantil, assim como para a prevenção de doenças crônicas não transmissíveis (WHO, 1998).

Pesquisadores têm proposto numerosos modelos para identificar e entender os hábitos alimentares nas diferentes culturas. Alguns destes modelos auxiliam na compreensão do papel da alimentação dentro de uma cultura, tais como o conhecimento das formas na qual se prepara uma alimentação tradicional (KITTLER; SUCHER, 2008).

Os termos "alimento regional", "alimento típico" e "alimento tradicional” têm sido comumente utilizados como sinônimos. Para Consoni e Cagliani (2010), por exemplo, o termo "alimento típico" tem sido largamente utilizado como alimento ancorado às tradições locais, com produção local e significados regionais. Entende-se por cozinha regional a resultante da aliança cultural de formação, colonização ou da própria evolução. São cozinhas que perpetuam a influência da cultura gastronômica na vida social e nos costumes. E estão associadas a povos em particular, constituindo aspectos da identidade e sendo a chave simbólica dos costumes (FREITAS, 1997).

O respeito à diversidade e à cultura alimentar é um dos princípios da atual Política Nacional de Alimentação e Nutrição (PNAN) do Brasil. Tal princípio pressupõe o reconhecimento, a preservação, o resgate e a difusão de hábitos e práticas alimentares regionais relacionados ao consumo de alimentos produzidos no local (BRASIL, 2012b).

Corroborando com este pressuposto, o Guia Alimentar para a População Brasileira proposto pelo Ministério da Saúde traz o consenso acerca da importância da cultura alimentar na promoção da alimentação adequada. O mesmo guia destaca ainda, a importância da realização de pelo menos três refeições por dia (café da manhã, almoço e jantar), intercaladas por pequenos lanches (BRASIL, 2014).

Entretanto, pesquisas indicam uma situação distinta do recomendado, mostrando que há uma tendência à substituição de refeições saudáveis por consumo de alimentos industrializados (SHEEHY; ROACHE; SHARMA, 2013). Embora a industrialização de alimentos também deva ser visto, não apenas como um fator maléfico à 
saúde, mas também como um processo importante na conservação dos alimentos, que proporciona o acesso a alguns alimentos que são consumidos longe dos locais de produção ou fora da época de safra. Concomitante a este processo é comum a supressão de refeições, sendo o café da manhã $(C M)$ a refeição mais negligenciada (FREITAS; MENDONÇA; LOPES, 2013; NURUL-FADHILAH et al., 2013). A falta de tempo para preparar os alimentos, dentre outros fatores, tem garantido à população a presença de situações nutricionais de desequilíbrio.

Diversos estudos (AFFINITA et al., 2013; BARR; DIFRANCESCO; FULGONI, 2013; FREITAS; MENDONÇA; LOPES, 2013; MIN et al., 2011; TRANCOSO; CAVALLI; PROENÇA, 2010) têm mostrado que o consumo do CM é importante para a manutenção adequada da saúde. A refeição matinal deveria corresponder a $25 \%$ da ingestão energética diária (FREITAS; MENDONÇA; LOPES, 2013) e proporcionar ingestão adequada de vitaminas, minerais, fibras e ingestão reduzida de gorduras e colesterol (GRIEGER; COBIAC, 2012; NURUL-FADHILAH et al., 2013; SUN et al., 2013). O consumo frequente do CM está associado a diversos benefícios como: melhor controle do peso corporal, redução do risco de síndrome metabólica, melhor funcionamento do sistema gastrintestinal, melhor saúde mental, melhor rendimento escolar e no trabalho (CHAPLIN; SMITH, 2011; FREITAS; MARLATT et al., 2016; MENDONÇA; LOPES, 2013).

Hallstrom et al. (2011) sugerem que o hábito de consumo do CM está relacionado a características sociodemográficas e região de consumo. Por outro lado, são poucos os registros sobre o regionalismo e os alimentos regionais no mundo. Existe uma carência de estudos científicos sobre o consumo do CM (FREITAS; MENDONÇA; LOPES, 2013; TRANCOSO; CAVALLI; PROENÇA; 2010) e estudos envolvendo o consumo de CM em adultos são ainda mais raros (CHAPLIN; SMITH, 2011).

O hábito de consumo de alimentos regionais é pouco frequente no Brasil. Vários alimentos regionais são desconhecidos, o que contribui para a não iserção deste como hábito de consumo habitual (DIMENSTEIN et al., 2010; UGGIONI, 2006). Os alimentos regionais são ricos nutricionalmente e podem ter funções terapêuticas importantes atualmente estudadas (ORSI et al., 2012; CASTRO; BARÓN, 2012; ROESLER et al., 2007) e a oferta de tais alimentos na primeira refeição do dia pode garantir o suporte inicial ao desenvolvimento das atividades diárias do ser humano.

O consumo dos alimentos regionais pode representar uma alternativa para a resolução dos problemas de alimentação e nutrição, através da reorientação de programas governamentais, já que tais alimentos são quase sempre de fácil acesso e baixo custo. 
Podendo e devendo ser analisado sobre diversas perspectivas, sobretudo as nutricionais e culturais.

Considerando a importância do tema, realizou-se uma revisão integrativa com o objetivo de verificar a presença de estudos sobre o café da manhã no mundo, com enfoque no consumo de alimentos regionais nessa refeição.

\section{MATERIAIS E MÉTODOS}

O estudo caracterizou-se como uma revisão integrativa que possibilita a inclusão de estudos experimentais e não-experimentais permitindo uma compreensão completa do fenômeno analisado. A revisão integrativa também combina dados da literatura teórica e empírica, além de agregar propósitos como definição de conceitos, revisão de teorias e evidências, e análise de problemas metodológicos de um tópico em particular (SOUZA; SILVA; CARVALHO, 2010).

A estratégia de busca de artigos desta revisão compreendeu uma pesquisa em bases de dados eletrônicas na Biblioteca Virtual em Saúde (BIREME), utilizando-se as bases MEDLINE (National Library of Medicine, Estados Unidos), LILACS (Literatura Latinoamericana e do Caribe em Ciências da Saúde) e SciELO (Scientific Eletronic Library on Line), no período de janeiro de 2003 a julho de 2013. A busca foi realizada separadamente nos idiomas português, inglês e espanhol utilizando-se os descritores "desjejum", "desjejum regional", "café da manhã" e "café da manhã regional" e os seus equivalentes nas demais línguas.

Após o resultado da busca, foi realizada uma seleção a partir do titulo e foram descartados os artigos que não apresentavam conexão com o tema estudado. O passo seguinte foi a leitura individual do resumo de cada artigo selecionado, verificando-se mais uma vez o atendimento ao tema de interesse. Cabe destacar que cinco artigos não apresentaram resumo e foram descartados. Todos os artigos que abordavam o tema "café da manhã" sob qualquer aspecto foram incluídos. Foram critérios de exclusão para esta seleção os artigos de revisão e editoriais; os artigos em línguas diferentes do português, inglês e espanhol; os artigos incompletos; as monografias, dissertações e teses; e os capítulos de livros. As referências dos artigos incluídos foram vistas com intenção de 
captar mais estudos com o tema de estudo, mas nenhuma se adequou aos critérios de inclusão.

Cada artigo foi analisado de acordo com uma adaptação do sistema de classificação que dispõe os estudos de forma hierárquica, segundo a abordagem metodológica adotada por Souza, Silva e Carvalho (2010). Para este trabalho foi desconsiderado o nível 1 de evidências descrita pelos citados autores, em virtude da exclusão dos artigos de revisão. O objetivo desse sistema de classificação é auxiliar na escolha da melhor evidência possível, propondo uma hierarquia das evidências, segundo o delineamento das pesquisas. Segundo os autores, esse sistema de classificação está inserido na fase de análise crítica dos estudos incluídos, possibilitando uma abordagem organizada para ponderar o rigor e as características de cada estudo. Os níveis de evidências estabelecidos são:

- Nível 1: evidências obtidas em estudos individuais com delineamento experimental;

- Nível 2: evidências de estudos quase-experimentais;

- Nível 3: evidências de estudos descritivos ou com abordagem qualitativa

- Nível 4: evidências provenientes de relatos de caso ou de experiência;

- Nível 5: evidências baseadas em opiniões de especialistas.

\section{RESULTADOS}

Foram identificados 3.475 artigos com os descritores selecionados, sendo que 3.159 foram descartados pelo título, 242 atendiam aos critérios de inclusão e 74 artigos eram repetidos. Entre os selecionados apenas oito artigos abordavam de alguma forma 0 tema regionalidade alimentar no CM. Cinco dos estudos foram conduzidos em países europeus, um no continente asiático e dois nas Américas.

Dos oito artigos selecionados, apenas um abordou especificamente um CM típico: dois artigos tratavam do abandono à dieta tradicional sendo a refeição $\mathrm{CM}$ citada entre as demais refeições; um abordou os alimentos típicos, dentre eles os consumidos no CM; dois enfocaram o padrão dietético em adultos fazendo referência a fatores regionais influenciando o consumo de alimentos nas refeições, entre elas o $\mathrm{CM}$; e três foram descartados por motivos diferentes: um por se tratar de um relatório de curso de imersão cultural de estudantes americanos na cultura alimentar mexicana e outros dois por não 
abordar alimentos típicos, mas apenas a diferença de fazer ou não fazer CM em diferentes países. O quadro 2 apresenta um resumo das características dos cinco estudos incluídos, os quais são apresentados em ordem cronológica de publicação.

Considerando a diversidade de significados nos diferentes países para o descritor "regional" utilizado na busca de artigos da presete pesquisa, fez-se necessário saber quais são os alimentos tradicionais do CM consumidos no país de realização dos estudos incluídos. Para isso verificou-se no Reino Unido que a batata é consumida tradicionalmente em todas as refeições, inclusive no CM (HOBBISS; MAHDAVI, 1995; RILEY, 2010). Já na Coréia o alimento mais tradicionalmente consumido no CM é o arroz e preparações feitas de arroz (CHA; HAN; CHUNG, 2012; KIM; MOON; POPKIM, 2000; SHIM; PAIK; MOON, 2007). Na Colômbia são considerados típicos do CM preparações como caldo de batatas com costela bovina, com ovos e pé bovino; changua com ou sem ovos (sopa de leite, cebolinha e queijo); café com leite; pão; ovo cozido; queijo; bebida de chocolate com ovos cozidos (CASTRO; BARÓN, 2012). Di Giuseppe et al. (2012) consideram como alimentos típicos do $\mathrm{CM}$ na Itália o leite, iogurte, café, chá, torrada, cereais, brioche, biscoito, açúcar, mel e presunto. Na Grécia os alimentos tradicionais do CM são bolos, folhados e tortas. 
Quadro 1. Descrição e avaliação dos artigos incluídos na revisão integrativa.

\begin{tabular}{|c|c|c|c|c|c|c|}
\hline Autor/ano & País & Objetivo & $\begin{array}{l}\text { Delineamento } \\
\text { do estudo }\end{array}$ & $\begin{array}{c}\text { n da } \\
\text { amostra }\end{array}$ & $\begin{array}{l}\text { Alimentos tradicionais } \\
\text { do café da manhã }\end{array}$ & $\begin{array}{l}\text { Nível de } \\
\text { evidência* }\end{array}$ \\
\hline $\begin{array}{l}\text { Mishra et } \\
\text { al., } 2004\end{array}$ & $\begin{array}{l}\text { Inglaterra } \\
\text { Escócia } \\
\text { Gales }\end{array}$ & $\begin{array}{l}\text { Identificar mudanças no padrão } \\
\text { dietético de adultos }\end{array}$ & Longitudinal & $\begin{array}{l}3.187 \\
\text { Adultos }\end{array}$ & Batata & 3 \\
\hline $\begin{array}{l}\text { Song et } \\
\text { al., } 2005\end{array}$ & Coréia & $\begin{array}{l}\text { Identificar a prevalência de } \\
\text { padrão dietético baseado no } \\
\text { consumo de alimentos típicos }\end{array}$ & Transversal & $\begin{array}{l}671 \\
\text { adolescentes }\end{array}$ & Arroz e derivados & 3 \\
\hline $\begin{array}{l}\text { Karlén et } \\
\text { al., } 2008\end{array}$ & $\begin{array}{l}\text { Grécia } \\
\text { Suécia }\end{array}$ & $\begin{array}{l}\text { Avaliar a aderência à dieta } \\
\text { mediterrânea em crianças }\end{array}$ & Transversal & 47 crianças & $\begin{array}{l}\text { Pastéis (bolos), folhados, } \\
\text { tortas }\end{array}$ & 3 \\
\hline $\begin{array}{l}\text { Castro, } \\
\text { Barón, } \\
2012\end{array}$ & Colômbia & $\begin{array}{l}\text { Compilar a memória de algumas } \\
\text { tradições culinárias colombianas }\end{array}$ & Transversal & 37 alimentos & $\begin{array}{l}\text { Caldo de batatas c/ carne ou } \\
\text { ovo, café com leite } \\
\text { +pão+ovo+Queijo, bebida de } \\
\text { chocolate com ovos, } \\
\text { Changua }\end{array}$ & 3 \\
\hline
\end{tabular}

\footnotetext{
*Nível de evidência de acordo com Souza, Silva e Carvalho (2010)
} 
Quanto ao tipo de delineamento de pesquisa dos artigos analisados, evidenciaram-se na amostra selecionada três estudos de cunho transversal e dois de cunho longitudinal. A predominância de estudos do tipo transversal pode representar maior vulnerabilidade a vieses, dificultando a interpretação de resultados pela presença de fatores de confundimento. Com relação à força de evidências obtida nos artigos, constatou-se que todos os estudos apresentaram nível 3, ou seja, não apresentaram fortes evidências para aplicação clínica. Isso demonstra que o tema em questão não é visto atualmente como merecedor de estudos com desenhos controlados, randomizados e com maior rigor científico.

O artigo mais antigo (MISHRA et al., 2004) estudou a influência de classes sociais e regiões de residências nos padrões dietéticos de pessoas adultas. Os dados foram provenientes de um banco de dados de uma pesquisa nacional de saúde e desenvolvimento da Inglaterra que monitora diversas informações de uma coorte de pessoas nascidas em 1946 até a data da publicação do artigo. Foram coletadas as seguintes informações: consumo dietético, nivel socioeconômico e região de residência em dois pontos temporais, aos quatro anos e aos 43 anos de idade.

O perfil dietético considerado na pesquisa acima foi obtido aos 43 anos de idade, sendo este avaliado a partir do registro de alimentos por 48 horas. Foram listados mais de 1000 tipos diferentes de alimentos consumidos que foram categorizados em 44 grupos de alimentos. O nível socioeconômico foi classificado em duas categorias ocupacionais definidas como trabalhos manuais e não manuais, agrupadas para refletir a permanência ou a mudança de classe social dos quatro aos 43 anos de idade. As regiões de residência consideradas para o estudo foram a Escócia, o País de Gales, e o norte e sul da Inglaterra (MISHRA et al., 2004).

A análise de regressão múltipla revelou cinco padrões dietéticos distintos: alimentos saudáveis, alimentos refinados, alimentos tradicionais, sanduiches e alimentos festivos. Dentro da categoria alimentos tradicionais, foram estudados a batata, a cenoura, a carne vermelha, as hortaliças folhosas verdes, e a ervilha. A maioria das pessoas estudadas apresentou nível socioeconômico compatível com a classe de trabalhos não manuais e consumiram significativamente maiores quantidades de alimentos saudáveis (alimentos integrais e frutas) (MISHRA et al., 2004). 
No estudo acima, as pessoas que permaneceram na classe social não manual consumiram significativamente maiores quantidades de itens alimentares correlacionados com a boa saúde, como por exemplo a realização de um CM rico em fibras e micronutrientes (cereais matinais, pães integrais, maçãs e bananas), em relação aos indivíduos que permaneceram na classe social manual. Por outro lado, os indivíduos que se mudaram desde a infância com a família de um trabalhador manual para uma posição não-manual na idade adulta foram consumindo uma dieta melhor, contendo, por exemplo, um CM rico em fibras e micronutrientes.

$\mathrm{Na}$ pesquisa acima, foram identificadas claras diferenças entre as regiões com respeito à ingestão de alimentos tradicionais, sendo estas diferenças mantidas nos poucos casos de mobilidade regional. A mobilidade regional foi fortemente associada com o padrão dietético tradicional e alimentos festivos nos homens, em contraste às mulheres onde a mudança de padrão dietético nao está associada a mobilidade regional. A pesquisa sugere que os hábitos alimentares quando criança influencia o padrão dietético na vida adulta, e este sofre alterações em reflexo da transição regional e social do indivíduo (MISHRA et al., 2004).

O trabalho de Song et al. (2005) realizado na Coréia estudou a ingestão de alimentos tipicamente consumidos por 671 adolescentes de 12 a 14 anos. O padrão dietético foi identificado por meio de três dias de recordatório alimentar que propiciou a categorização dos alimentos em 21 grupos. A análise do padrão dietético indicou a divisão da amostra em dois grupos, ficando o grupo de padrão dietético tradicional com 202 adolescentes e o grupo de padrão dietético modificado com 469. O grupo com alimentação modificada consumiu mais pão, pizza/hamburguer, talharim, cookies e frequentemente não realizavam o $\mathrm{CM}$ quando comparado ao grupo com alimentação tradicional, que consumiu mais arroz, peixes e Kimchi (repolho fermentado), e frequentemente realizam a primeira refeição do dia.

Os resultados da pesquisa de Song et al. (2005) mostram que o grupo com alimentação modificada prefere comer cereais e leite no CM, diferente do grupo tradicional que prefere o $\mathrm{CM}$ com arroz e derivados. Neste estudo foi detectado uma situação interessante no grupo com alimentação modificada, que apresentou maior ingestão de todos os nutrientes, principalmente de cálcio e ferro quando comparado ao 
grupo tradicional. Este achado possivelmente se explica pelo consumo aumentado de alimentos de origem animal e leite. Por outro lado, apresentaram uma maior ingestão de gordura e colesterol como esperado em padrões dietéticos que sofreram processos de transição nutricional.

O tradicional padrão dietético mediterrâneo está sendo abandonado, mesmo sendo positivamente associado à redução da mortalidade nos países que o adotam. Tal situação motivou a pesquisa realizada por Karlén et al. (2008) que investigaram a aderência à dieta mediterrânea de 24 crianças gregas entre um e treze anos de idade ao comparar com os hábitos nutricionais de 23 crianças suecas da mesma idade. $A$ hipótese a ser confirmada era que as crianças gregas escolheriam mais alimentos mediterrâneos que as crianças suecas.

Para a pesquisa realizada por Karlén et al. (2008), os pais das crianças foram convidados a comparecer no centro de saúde em atenção primária, localizado em uma das áreas rurais de Creta (Grécia) e de Kisa (Suécia), para participar da validação do instrumento de origem espanhola denominado KIDMED-index (Índice qualitativo da dieta mediterrânea em crianças e adultos). A análise dos 16 itens do KIDMED-index mostrou que as famílias gregas reportaram significativamente maior uso diário de azeite de oliva, pastéis, massas folhadas e tortas (alimentos assados) para o CM, enquanto que as famílias suecas apresentaram significativamente maiores consumo de cereais, grãos e pães para a primeira refeição do dia. Os resultados confirmaram a hipótese inicial que que na Grécia são consumidos mais alimentos da dieta mediterrânea como hábito alimentar.

Castro e Barón (2012) estudaram os alimentos e preparações regionais consumidas nas refeições de uma região da Colômbia, entre elas o CM. Apresentaram uma mostra de 37 alimentos de maior produção e consumo em Boyacá, situado na parte central da Colômbia, região com uma diversidade gastronômica que se encontra ameaçada por novas influências culturais e ritmos de vida. A comida de Boyacá utiliza como principais ingredientes a batata e o milho, geralmente acompanhados por carne de porco, carne bovina e a galinha. Este artigo relatou não somente os alimentos típicos consumidos em Boyacá, mas também as preparações especificamente consumidas no CM nesta parte da Colômbia, sendo eles: caldo de batatas com costela bovina, com 
ovos e pé bovino; changua com ou sem ovos (sopa de leite, cebolinha e queijo), café com leite, pão, ovo cozido e queijo, bebida de chocolate com ovos.

Em Molise, na Itália, 18.177 indivíduos com mais de 35 anos foram selecionados aleatoriamente para participaram de uma pesquisa cujo objetivo era investigar a influência do consumo de alimentos típicos do CM italiano nas doenças cardiovasculares (DCV). Os participantes responderam a um questionário estruturado para coletar informações pessoais e clínicas, incluindo nível socioeconômico, atividade física, história físico-patológica, fator de risco para DCV e/ou tumor pessoal/familiar e uso de drogas. Quanto à avaliação dietética, os participantes registraram o consumo de alimentos através de um questionário de frequência alimentar referente ao ano anterior e um subgrupo de 100 pessoas teve a sua ingestão alimentar avaliada por registro em recordatórios de 24 horas por um período de um ano. Café, torrada/bolachas e açúcar foram consumidos, respectivamente, por $93,9 \%, 87,9 \%$ e $81,6 \%$ no CM da população estudada, seguido por leite, biscoitos, iogurte, brioches, compotas e chá (respectivamente $67,7 \%, 42,9 \%, 42,8 \%, 38,0 \%, 37,3 \%$ e $33,4 \%$ ), enquanto o cereal e mel foram consumidos, respectivamente, por $17,0 \%$ e $10,4 \%$ de toda a população (DI GIUSEPPE et al., 2012).

A análise multivariada aplicada na pesquisa acima, mostrou que o consumo de um CM tipicamente italiano foi associado a uma menor prevalência de síndrome metabólica e a um risco diminuido de DCV. Assim, o consumo de alimentos típicos da Itália no CM (leite, iogurte, café, chá, torrada, cereais, brioche, biscoito, açúcar, mel, presunto), pode ser considerado um fator protetor contra o início de distúrbios cardiovasculares e da mortalidade relacionada a este evento (DI GIUSEPPE et al., 2012).

\section{DISCUSSÃO}

Esta revisão mostrou que o tema "café da manhã" foi relativamente pouco estudado durante o período de uma década (242 artigos). Entre estes, o percentual de artigos que abordaram de alguma forma o tema da regionalidade alimentar foi ainda 
menor $(3,3 \%)$, sendo que os europeus foram os que mais estudaram esta temática, inexistindo neste percentual qualquer trabalho de origem brasileira.

Parece que a grande preocupação dos pesquisadores em relação ao tema está direcionada ao efeito do CM no rendimento escolar e função cognitiva. No ano de 2012, de 34 artigos provenientes dos 242 selecionados que estudaram o CM, 11 tiveram este enfoque. A associação desta refeição com a obesidade, atividade física e adequação de nutrientes apresentou quantidade semelhante, mas nenhum abordou o consumo de alimentos regionais. Muitos abrangem o aspecto de consumir ou não consumir o CM. Vereecken et al. (2009) demonstraram, inclusive, que existem diferenças regionais no hábito de consumir ou omitir a refeição, mas a abordagem específica no consumo de alimentos tradicionais no $\mathrm{CM}$, ainda não está sendo objeto de foco entre as pesquisas científicas realizadas no mundo.

No geral, o CM não se apresentou como um hábito freqüente entre os pesquisados e varia de acordo com a região, o sexo, fatores socioambientais, e fatores pessoais como fome, sabor e conceito de saúde. Os consumidores de CM mais assíduos são as mulheres mais jovens e de melhor nível social. Apesar disso, as mesmas são as que mais utilizam a supressão desta refeição como fator controlador do peso corporal. As mulheres, quando adolescentes, são as mais influenciadas pelos pais que afetam positivamente o consumo de CM. A estrutura familiar foi um fator muito estudado como variável associada ao consumo da refeição. Adolescentes e adultos provenientes de famílias de estrutura tradicional e com nível educacional diferenciado são mais encorajados a realizarem o CM (DI GIUSEPPE et al., 2012; KARLEN et al., 2008; MISHRA et al.; SONG et al., 2005).

Alguns artigos $(60 \%, n=3)$ destaca a importância do fator sociodemográfico no consumo do CM. A questão social, intimamente conectada ao fator econômico, direciona a prática deste consumo, que tem se demonstrado menos frequente nos níveis sociais mais baixos. O local de residência do comensal influencia a frequência, o quanto e o que se come, mostrando que a escolha de alimentos da primeira refeição do dia está pautada também em questões como as tradições e costumes culturais. Além disso, até mesmo fatores como o clima e as condições agrícolas da região podem 
determinar o perfil alimentar de uma comunidade (KARLEN et al., 2008; MISHRA et al.; SONG et al., 2005).

A globalização tem sido associada ao abandono dos hábitos de consumos de alimentos regionais e a falta de realização do CM. O crescimento econômico do país com a consequente alteração do estilo de vida afeta o comportamento dietético motivado, principalmente, pela conveniência em consumir alimentos prontos, fáceis de comprar e muitas vezes mais baratos, mas quase sempre não saudáveis (MACHADO; SIMÕES, 2008; SHEEHY; ROACHE; SHARMA, 2013). Neste contexto, a mulher é a personagem mais importante, pois tem o papel fundamental de transmitir os costumes tradicionais e hábitos de vida saudável, tanto no casamento como na educação dos filhos.

Poucos estudos $(40 \%, \mathrm{n}=2)$ analisados incluíram na metodologia a avaliação do estado nutricional dos participantes através do Índice de Massa Corpora (DI GIUSEPPE et al., 2012; KARLEN et al., 2008). Dentre estes, um único pesquisou a influência de CM típico na ocorrência de doenças (DI GIUSEPPE et al., 2012), o que sugere que o consumo de alimentos regionais ainda não é considerado como fator importante no hábito de consumo desta refeição e não é visto pelos estudiosos da clínica nutricional como fator alternativo que possa contribuir na resolução de problemas nutricionais do indivíduo, sobretudo em populações mais carentes.

Parte dos estudos (KARLEN et al., 2008; MISHRA et al.; SONG et al., 2005) fazem referência à importância da influência dos pais na manutenção do hábito de consumo do CM pelos filhos, o que indiretamente pressupõe o repasse de uma tradição alimentar de geração para geração.

O único artigo (DI GIUSEPPE et al., 2012) que abordou o CM típico usou o termo "típico" para se referir a alimentos de consumo popular ou de consumo comum no dia a dia das pessoas, não se referindo, desta forma, a alimentos tradicionais, produzidos e consumidos por gerações anteriores. 
CONCLUSÃO

O tema CM é pouco estudado e o enfoque no consumo de alimentos regionais é pouco frequente.

Tendo em vista a existência de desequilíbrios nutricionais no Brasil e no Mundo, torna-se importante o resgate das tradições alimentares e do uso dos alimentos regionais que possuem grande potencial como fonte de nutrientes, melhorando o estado nutricional e, consequentemente, reduzindo as taxas de morbimortalidade.

Considerando a importância da realização da refeição CM na saúde humana e a utilização de alimentos locais, que são mais acessíveis e de baixo custo, sugere-se a realização de mais pesquisas para melhor orientação na elaboração de políticas públicas de alimentação e nutrição.

\section{REFERÊNCIAS BIBLIOGRÁFICAS}

AFFINITA, A. et al. Breakfast: a multidisciplinary approach. Italian journal of pediatrics, v. 39, n. 1, p. 44, 2013. Available in:

<http://www.ijponline.net/content/39/1/44>. Access in: 17 nov. 2013.

BARR, S. I.; DIFRANCESCO, L.; FULGONI, V.L. Consumption of breakfast and the type of breakfast consumed are positively associated with nutrient intakes and adequacy of Canadian adults. Journal of Nutrition, v. 143, n. 1, p. 86-92, 2013.

BRASIL. Ministério da Saúde. Secretaria de Atenção à Saúde. Departamento de Atenção Básica. Guia alimentar para a população brasileira, $2^{\mathrm{a}}$ ed., Brasília: Ministério da Saúde, 2014.156 p.

BRASIL. Ministério da Saúde. Secretaria de Atenção à Saúde. Departamento de Atenção Básica. Política Nacional de Alimentação e Nutrição / Ministério da Saúde. Secretaria de Atenção à Saúde. Departamento de Atenção Básica. - Brasília: Ministério da Saúde, 2012. 84 p. Available in:

<http://189.28.128.100/nutricao/docs/geral/pnan2011.pdf>. Access in: 04 set. 2013. CASTRO, O.A.V.; BARÓN, F.N.L. Alimentos típicos de Boyacá, Colombia.

Perspectivas en Nutricion Humana, Medellín (Colômbia), v. 4, n. 2, p. 21-30, 2012. CHA, H-M.; HAN, G.; CHUNG, H-J.. A study on the trend analysis regarding the rice consumption of Korean adults using Korean National Health and Nutrition Examination Survey data from 1998, 2001 and 2005. Nutrition Research and Practice, v. 6, n. 3, p. 254-262, 2012. 
CHAPLIN, K.; SMITH, A.P. Breakfast and snacks: associations with cognitive failures, minor injuries, accidents and stress. Nutrients, v. 3, p. 515-528, 2011.

CONSONNI, R; CAGLIANI, L.R. Nuclear magnetic resonance and chemometrics to assess geographical origin and quality of traditional food products. Advance and Food Nutrition Research, v. 59, p. 87-165, 2010.

DI GIUSEPPE, R. et al. Typical breakfast food consumption and risk factors for cardiovascular disease in a large sample of Italian adults. Nutrition, Metabolism and Cardiovascular Diseases, v. 22, p. 347-354, 2012.

DIMENSTEIN, R. et al. Alimentos regionais fontes de vitamina A conhecidos por parturientes atendidas em maternidade pública. Extensão e Sociedade, v. 1, n. 2, 2010.

FREITAS, M.C.S. Educação Nutricional: aspectos sócio-culturais. Revista de Nutrição, Campinas, v. 1, n. 10, p. 45-49, 1997.

FREITAS, P.P.; MENDONÇA, R.D.; LOPES, A.C. Factors associated with breakfasting in users of a public health service. Revista de Nutrição, Campinas, v. 26, n. 2, p. 195203, 2013.

GRIEGER, J.A.; COBIAC, L.. Comparison of dietary intakes according to breakfast choice in Australian boys. European Journal of Clinical Nutrition, v. 66, p. 667-672, 2012.

HALLSTRO"M, L. et al. Breakfast habits and factors influencing food choices at breakfast in relation to socio-demographic and family factors among European adolescents. The HELENA Study. Appetite, v. 56, p. 649-657, 2011.

HOBBISS, A.; MAHDAVI, R. Eat a breakfast and eat well. British Food Journal, v. 97, n. 9 , p. $44-45,1995$.

KARLÉN, J. et al. Are children from Crete abandoning a Mediterranean diet? Rural and Remote Health, v. 8, n. 4, p.1034, 2008.

KIM, S.; MOON, S.; POPKIM, B.M. The nutrition transition in South Korea. The American Journal of Clinical Nutrition, v. 71, n. 1, p. 44-53, 2000.

KITTLER, P.G.; SUCHER, K.P. Food and Culture. In: Food and Culture.

Belmonte: Thomson Wadsworth, 2008.

MACHADO, F.M.S.; SIMÕES, A.N. Análise custo-efetividade e índice de qualidade da refeição aplicados à Estratégia Global da OMS. Revista de Saúde Pública, São Paulo, v. 42, n. 1, p. 64-72, 2008.

MIN, C. et al. Skipping breakfast is associated with diet quality and metabolic syndrome risk factors of adults. Nutrition Research and Practice, v. 5, n. 5, p. 455-463, 2011. MISHRA, G.D. et al. The impact of inter-generational social and regional circunstances on dietary intake patterns of British adults: results from the 1946 British Birth Cohort.

Public Health Nutrition, v. 7, n. 6, p. 737-744, 2004.

NURUL-FADHILAH, Abdullah et al. Infrequent Breakfast Consumption Is Associated with Higher Body Adiposity and Abdominal Obesity in Malaysian School-Aged

Adolescents. PLoS One, v. 8, n. 3, e59297, 2013. Avaliable in:

<http://www.ncbi.nlm.nih.gov/pmc/articles/PMC3592841/pdf/pone.0059297.pdf>.

Access in: 04 set. 2013.

ORSI, P.R. et al. Hymenaea stigonocarpa Mart. Ex Hayne: A Brazilian medicinal plant with gastric and duodenal anti-ulcer and antidiarrheal effects inexperimental rodent models. Journal of Ethnopharmacology, v. 143, p. 81-90, 2012. 
RILEY, $\mathrm{H}$. Potato consumption in the UK - why is 'meat and two veg' no longer the traditional British meal? Nutrition Bulletin, v. 35, p. 320-331, 2010.

ROESLER, R. et al. Atividade antioxidante de frutas do cerrado. Revista Ciência e Tecnologia de Alimentos, Campinas, v. 27, n. 1, p. 53-60, 2007.

SHEEHY, T.; ROACHE, C.; SHARMA, S. Eating habits of a population undergoing a rapid dietary transition: portion sizes of traditional and non-traditional foods and beverages consumed by Inuit adults in Nunavut, Canada. Nutrition Journal, 12:70, 2013. Avaliable in: <http://www. nutritionj.com/content/12/1/70>. Access in: 15 ago. 2013.

SHIM, J.E; PAIK, HJ; MOON, HK. Breakfast consumption pattern, diet quality and health outcomes in adults from 2001 National Health and Nutrition Survey. Korean Journal of Nutrition, v. 40, n. 5, p. 451-462, 2007.

SONG, Y. et al. Traditional v. modified dietary patterns and their influence on adolescents' nutritional profile. British Journal of Nutrition, v. 93, p. 943-949, 2005. SOUZA, M.T.; SILVA, M.D.; CARVALHO, R. Revisão integrativa: o que é e como fazer. Einstein, n. 8, p. 102-106, 2010.

SUN, J. et al. Factors associated with skipping breakfast among Inner Mongolia Medical students in China. BMC Public Health, v. 13, n. 42, 2013. Avaliable in:

<http://www.biomedcentral.com/1471-2458/13/42>. Access in: 18 mar. 2014.

TRANCOSO, S.C.; CAVALLI, S.B.; PROENÇA, R.P.C. Café da manhã: caracterização, consumo e importância para a saúde. Revista de Nutrição, Campinas, v. 23, n. 5, p. 856-869, 2010.

UGGIONI, P.L. Valorização do Patrimônio Gastronômico Regional Açoriano:

Gestão de Qualidade em Restaurantes Típicos em Florianópolis - SC. 2006. $265 f$.

Florianópolis, SC, 2006. Dissertação (Mestrado em Nutrição) - Universidade Federal de Santa Catarina.

VEREECKEN, C. et al. Breakfast consumption and its socio-demographic and lifestyle correlates in schoolchildren in 41 countries participating in the HBSC study.

International Journal of Public Health, v. 54, p.180-190, 2009. Supplement 2.

WORLD HEALTH ORGANIZATION. Technical Report Series 880: Preparation and use of food-based dietary guidelines, 1998. 
5.2 CAPÍTULO 2 - A composição nutricional do café da manhã de usuários de Restaurantes Populares no Brasil 


\section{RESUMO}

A alimentação não saudável é um dos principais fatores de risco para as doenças crônicas não transmissíveis e a não realização do café da manhã (CM) é um comportamento alimentar inadequado à promoção da saúde humana, pois o consumo dessa refeição propicia maior ingestão de nutrientes e uma dieta mais saudável. Objetivo: Caracterizar a composição nutricional do CM de população de baixa renda usuária de Restaurantes Populares no Brasil. Materiais e Métodos: Trata-se de um estudo transversal com amostra constituída por 1.547 indivíduos frequentadores de 36 restaurantes vinculados ao Programa Restaurantes Populares. Para análise do consumo alimentar foi utilizado o recordatório de 24 horas por três dias, cujos dados foram analisados por sexo, faixa etária, faixa de renda per capita, escolaridade e região de consumo. Os grupos dos lácteos, cereais, frutas, raízes/tubérculos e carnes/ovos foram analisados pela frequência de consumo, independentemente do tamanho da porção ingerida. O valor energético total, os macronutrientes, as fibras, os ácidos graxos monoinsaturados, saturados e trans foram analisados pelos valores de contribuição na recomendação de cada nutriente. Os micronutrientes cálcio e sódio foram avaliados em relação ao percentual de contribuição no dia de consumo. Resultados: Dos 4.641 CM previstos, 797 (17,2\%) não foram realizados sendo analisados 3.844 CM. A amostra foi predominantemente composta por homens e por indivíduos na faixa etária entre 25 e 34 anos. O nível de escolaridade mais frequente foi o ensino médio completo e a faixa de renda per capita predominante foi a de 0,5 a um Salário Mínimo. Com relação ao estado civil, observou-se um predomínio da união estável para os homens $(41,7 \%, n=377)$ e de solteiro para as mulheres $(37,6 \%, n=242)$. A análise de grupos de alimentos mostrou alto consumo de lácteos e cereais, e baixos consumo de frutas, raízes/tubérculos e carnes/ovos. As frutas foram mais consumidas por homens; por pessoas na faixa de idade entre 35 a 44 anos e pelos participantes com maior faixa de renda. Os nordestinos consumiram mais frutas quando comparados com as demais regiões. Os lácteos e cereais apresentaram tendência contrária de consumo quando a renda foi considerada. Os percentuais nacionais de contribuição 
energética dos macronutrientes no VET do CM realizado pelos participantes da pesquisa foram adequados à uma dieta equilibrada. Os percentuais nacionais de contribuição dos ácidos graxos saturados e ácidos graxos trans se encontraram dentro da recomendação, sendo que a análise regional mostrou níveis de consumo elevados desses mesmos nutrientes na região Centro-oeste. A região Nordeste apresentou percentual de consumo elevado de ácidos graxos saturados, condizente com os altos consumos de carnes/ovos e cereais nestas regiões. A média nacional da ingestão de fibras do CM foi baixa, concordando com o resultado encontrado de baixo consumo de frutas pelos participantes da pesquisa. O consumo nacional de cálcio cobriu $73,49 \%$ do esperado para essa refeição, sendo que o maior consumo aconteceu na região Centrooeste $(93,61 \%)$, sendo essa região uma das que mais consumiu alimentos lácteos. 0 consumo nacional de sódio foi adequado, sendo que as regiões Centro-oeste e Nordeste apresentaram altos consumos, coerente com o maior consumo de carnes/ovos nessas regiões. Conclusão: Os indivíduos pesquisados consumiram um CM equilibrado em relação à composição de nutrientes, exceto em relação ao alto consumo de ácidos graxos saturados e trans na região Centro-oeste e ácidos graxos saturados da região Nordeste. Embora o consumo de lácteos tenha se apresentado como um dos grupos mais consumidos, o consumo de cálcio foi baixo, indicando a necessidade de consumir porções maiores de alimentos fontes desse nutriente. Apesar do consumo de hortaliças não ser um hábito no $\mathrm{CM}$, essas podem ser consumidas sob a forma de sucos puros ou misturados com frutas, o que aumentaria o consumo de minerais, vitaminas e fibras.

Palavras - chave: café da manhã, desjejum, nutricional, grupos alimentares. 


\begin{abstract}
The unhealthy diet is one of the main risk factors for chronic diseases and not performing breakfast $(B)$ is an inappropriate eating behavior promotion of human health because consumption of this meal provides greater nutrient intake and a healthier diet. Objective: To characterize the B of the nutritional composition of the population of lowincome user Popular Restaurants in Brazil. Materials and Methods: This is a crosssectional study sample of 1,547 individuals members of 36 restaurants linked to the Program Popular Restaurants. For analysis of food consumption we used the 24-hour recall for three days, and data were analyzed by gender, age, range of per capita income, education and consumption region. The dairy groups, cereals, fruits, roots/tubers and meat/eggs were analyzed by frequency of use, regardless of the size of the intake portion. The total energy, macronutrients, fiber, monounsaturated fatty acids, saturated and trans were analyzed by contribution amounts on the recommendation of each nutrient. Micronutrients calcium and sodium were assessed in relation to the contribution percentage on consumption. Results: Of 4,641 planned B, 797 (17.2\%) were not carried out and analyzed 3,844 B. The sample was predominantly composed of men and individuals aged between 25 and 34 years. The most common level of education was high school and the prevailing range of per capita income was 0.5 to a minimum wage. Regarding marital status, there was a predominance of stable marriage for men $(41.7 \%, n=377)$ and single women $(37.6 \%, n=242)$. The analysis of food groups showed high consumption of dairy products and cereals, and low consumption of fruits, roots/tubers and meat/eggs. Fruits were more consumed by men; by people in the age group 35 to 44 years and participants with higher income bracket. The Northeast consumed more fruits when compared with other regions. Dairy and cereals showed opposite trend of consumption when income was considered. The national percentage energy contribution of macronutrients in the B total energy performed by the research
\end{abstract}


participants was suitable for a balanced diet. The national contribution percentages of saturated fatty acids and trans fatty acids are found in the recommendation, and the regional analysis showed consumption levels high of those nutrients in the Midwest region. The Northeast region had a high intake of percentage of saturated fatty acids, consistent with the high consumption of meat/eggs and cereals in these regions. The national average intake of $B$ fibers was low, according to the results found low fruit consumption research participants. The National calcium consumption covered $73.49 \%$ of the expected for this meal, while the highest consumption occurred in the Central West region (93.61\%), and this region one of the most consumed dairy foods. The national sodium intake was adequate, and the Mid-West and Northeast had high consumption, consistent with the highest consumption of meat/eggs in these regions. Conclusion: Individuals surveyed consumed a balanced B in relation to the composition of nutrients, except for the high consumption of saturated and trans fatty acids in the Midwest region and saturated fatty acids in the Northeast. Although milk consumption has been presented as one of the most consumed groups, calcium consumption was low, indicating the need to consume larger portions of food sources of this nutrient. Although the vegetable consumption is not a habit in $B$, it can be consumed in the form of pure or mixed juices with fruits, which would increase the consumption of minerals, vitamins and fibers.

Keysword: breakfast, nutritional, foods, food groups. 


\section{INTRODUÇÃO}

A Organização Mundial de Saúde (OMS) possui um plano de ação global para o período de 2013 a 2020 focado em quatro doenças crônicas não transmissíveis - DCNT (doenças cardiovasculares, diabetes, câncer e doenças respiratórias crônicas), que são as principais causas de morbidade e mortalidade no mundo. A alimentação não saudável representa um dos principais fatores de risco para tais doenças (MARTINS, 2014).

O processo de excessiva industrialização alimentar faz com que a população brasileira ainda apresente problemas alimentares e nutricionais marcantes como desnutrição, deficiência de micronutrientes, excesso de peso e outras doenças crônicas não transmissíveis (COUTINHO; GENTIL; TORAL, 2008; LEVY et al., 2012; SOUZA et al., 2013; VASCONCELOS, 2008).

Entre as três principais refeições, o café da manhã (CM) é a refeição mais desfavorecida (NURUL-FADHILAH et al., 2013; FREITAS; MENDONÇA; LOPES, 2013; TRANCOSO; CAVALLI; PROENÇA, 2010). Este comportamento alimentar é inadequado à promoção da saúde humana, pois existem evidências de que o consumo de CM propicia a maior ingestão de nutrientes e uma dieta mais saudável (BARUFALDI, 2014).

Para Trancoso, Cavalli e Proença (2010) "o café da manhã ou desjejum é definido como a primeira refeição consumida pela manhã". Autores (MACHADO; SIMÕES, 2008; MARANGONI et al., 2009) concordam que o seu consumo deve fornecer de 15 a 25\% da ingestão calórica diária. Travé (2013) complementa afirmando que o CM deve incluir pelo menos três grupos básicos: lácteos, cereais e frutas. No Brasil, a composição alimentar mais frequente do CM tem sido café puro ou leite e café, e pão acompanhado de manteiga ou margarina, mas o consumo de frutas é raro (FREITAS; MENDONÇA; LOPES, 2013).

O CM é importante para o alcance das recomendações de nutrientes e da saúde e tem sido associado à ingestão da maioria das vitaminas, minerais (BARUFALDI, 2014; MARCHIONI et al., 2015; SHAFIEE et al., 2013) e fibras e menor 
ingestão de gorduras e colesterol (HOLMES et al., 2012; MIN et al., 2011). Seu consumo regular relaciona-se com benefícios importantes para a saúde, tais como: melhor controle do peso corporal; redução do risco de síndrome metabólica; melhor funcionamento do sistema gastrintestinal; melhor saúde mental; melhor rendimento escolar e no trabalho (BETTS et al., 2011; CHAPLIN; SMITH, 2011; MARCHIONI et al., 2015).

O Programa Restaurantes Populares (PRP) foi instituído com a função de ampliar a oferta de refeições saudáveis a preços acessíveis, reduzindo assim o número de pessoas em situação de insegurança alimentar e vulnerabilidade nutricional (MACHADO et al., 2014).

Os dados provenientes de levantamentos de informações em frequentadores de RP são seguramente muito ricos, pois o PRP é uma política pública específica direcionada à garantia de acesso a uma alimentação de qualidade, nutricionalmente balanceada e segura, promovendo ao mesmo tempo a elevação da qualidade da alimentação realizada fora das residências e disseminando a adoção de hábitos alimentares que resultem na universalização da segurança alimentar e nutricional, considerada como um direito de todos os cidadãos e um dever do Estado (ARAÚJO; ALMEIDA; BASTOS, 2007; BRASIL, 2008).

A presente pesquisa pretende fornecer informações sobre a qualidade nutricional do CM de parte da população brasileira de baixa renda, com a finalidade de contribuir para a elaboração e execução de novas propostas de promoção da saúde, através de ações governamentais em alimentação e nutrição.

Este artigo objetiva caracterizar a composição nutricional do café da manhã de população de baixa renda usuária de Restaurantes Populares no Brasil.

\section{MATERIAIS E MÉTODOS}

Este estudo é do tipo exploratório de delineamento transversal, pois compreende a análise e a descrição dos dados coletados no período entre maio de 
2010 e junho de 2011, referentes ao CM dos usuários de Restaurantes Populares (RP), programa vinculado ao Ministério de Desenvolvimento Social e Combate à Fome (MDS). Esta pesquisa foi aprovada pelo Comitê de Ética e Pesquisa da Faculdade de Saúde da Universidade de Brasília.

Cada restaurante participante recebeu uma carta que correspondeu a um termo de consentimento da instituição, que foi assinado pelo Responsável Técnico da Unidade de Alimentação e Nutrição (UAN). Os participantes da pesquisa receberam uma carta de apresentação do estudo e o Termo de Consentimento Livre e Esclarecido para a devida assinatura.

Para o presente trabalho, foi considerado como unidade amostral o indivíduo frequentador dos Restaurantes Populares na refeição almoço, tendo em vista que nem todas as unidades de restaurantes ofereciam CM. Para a determinação da amostra final, foram considerados os 65 restaurantes vinculados ao Programa Restaurantes Populares do MDS, distribuídos proporcionalmente nas cinco regiões geográficas do país.

Dessa forma, para os participantes, calculou-se uma amostra aleatória simples, com base no total de usuários do Programa Restaurantes Populares no país (55.350). Com o objetivo de garantir a proporcionalidade de usuários para cada região, o levantamento foi feito em pelo menos $20 \%$ dos Restaurantes Populares de cada região, excetuando-se a Região Centro-oeste, onde foi realizado em apenas um restaurante, correspondendo a $25 \%$ da amostra regional. Devido a esse aspecto, ficou caracterizado o comprometimento do erro amostral (erro estimado em 15\%); assim sendo, os dados da região Centro-oeste serão apresentados, mas é necessário acentuar que qualquer generalização dos resultados para o Centro-oeste, pode não ser indicada.

A amostra dos usuários foi calculada conforme Datallo (2008), obtendo-se um tamanho de amostra mínima de 41 usuários por restaurante (36 unidades), ou seja, pelo menos 1.476 usuários no total. A amostra selecionada em cada RP foi de 80 indivíduos, valor superior ao mínimo calculado, pois, como os mesmos indivíduos foram acompanhados durante os três dias consecutivos (domingo, segunda e terça-feira), considerou-se uma margem de segurança durante o processo de coleta para possíveis 
perdas. A amostra final desse estudo constituiu-se de 1.547 indivíduos usuários de 36 restaurantes, com 52 indivíduos em média por restaurante vinculado ao Programa Restaurantes Populares do MDS no ano de 2010, cujo tamanho da amostra final foi obtido com base em parâmetros estatísticos com nível de significância (a) de 5\% e poder de teste de $80 \%$ (COHEN, 1962).

A distribuição das unidades de Restaurantes Populares selecionadas contemplou as cinco regiões geográficas brasileiras e ficou da seguinte forma: Norte, com quatro unidades; Nordeste, com dez unidades; Centro-oeste, com uma unidade; Sudeste, com 15 unidades e Sul com seis unidades. Foram excluídos da pesquisa os indivíduos que não completaram o protocolo (realizar o almoço no Restaurante Popular), as gestantes e os menores de 18 anos. A maioria dos entrevistados fazia o CM em casa, excetuando-se os de seis unidades do Sudeste e uma do Nordeste, cujas unidades de Restaurantes Populares ofereciam durante a semana o CM com cardápios elaborados por nutricionistas.

A seleção da amostra de indivíduos em cada unidade foi realizada de forma sistemática na fila de espera para entrada no Restaurante Popular, selecionando a partir do primeiro indivíduo da fila, o 15ำ e assim sucessivamente a cada 15 indivíduos. Caso não aceitassem participar seriam substituídos na própria fila pelo indivíduo subsequente $\left(16^{\circ}\right)$, sem prejuízo da contagem inicial (30ํㅜㄴ $45^{\circ}$, etc).

Os dados analisados foram extraídos dos recordatórios de 24 horas de três dias aplicados com cada um dos usuários que aceitaram participar. Para detecção da diferença de consumo alimentar entre os dias da semana, foram aplicados recordatórios no domingo, em que todos os participantes realizaram a refeição fora do Restaurante Popular, e também na segunda e terça-feira. As informações de consumo registradas nos recordatórios foram relatadas pelos participantes da pesquisa e anotadas em formulário próprio por membros da equipe de pesquisa devidamente treinados.

A definição de CM para essa pesquisa foi construída a partir da análise preliminar dos próprios recordatórios contendo o relato de consumo diário de alimentos de cada participante. Assim, a refeição CM ficou definida como a primeira refeição do dia (TRANCOSO; CAVALLI; PROENÇA, 2010), realizada a partir de quatro horas da manhã, podendo ser um único alimento/preparação ou vários alimentos/preparações, 
consumidos até as $11 \mathrm{~h} 30 \mathrm{~min}$ da manhã. Esse ponto de corte no horário foi estabelecido também em virtude da análise preliminar dos recordatórios, em que a primeira refeição de alguns participantes aconteceu até as $11 \mathrm{~h} 30 \mathrm{~min}$, com posterior consumo de refeição característica de almoço e em virtude de a maioria dos restaurantes iniciarem a distribuição do almoço a partir das 11h30min.

Por se tratar de um estudo sobre hábitos alimentares regionais brasileiros, e tendo em vista os hábitos característicos de algumas regiões em consumir no $\mathrm{CM}$ preparações mais elaboradas características da refeição almoço, tais refeições também foram consideradas CM desde que essas fossem a primeira refeição do dia. Se a primeira refeição do dia foi o almoço do Restaurante Popular, essa não foi considerada como CM, e, portanto, não consumida.

Os dados sociodemográficos coletados foram sexo, faixa etária, faixa de renda per capita, escolaridade e região geográfica de consumo.

Os grupos de alimentos avaliados foram classificados como consumido e não consumido, independentemente do tamanho da porção ingerida. Foram considerados do grupo de lácteos todos os alimentos/preparações cujo componente principal é o leite, como: iogurtes, queijos, vitaminas, bebidas lácteas, sorvetes e mingaus. Foram considerados cereais: o arroz, milho (incluindo grãos, farinha de milho, canjica de milho, mungunzá, mingaus, pamonha, curau, cuscuz, angu, farofa de milho, bolo de milho, polenta e xerém), trigo (incluindo grãos, farinha, macarrão, pães, tortas, salgadas, tortas doces, bolos, biscoitos), cereal matinal, granola, barra de cereal, aveia e centeio. Foram consideradas raízes e tubérculos: mandioca, farinha de mandioca, batata-inglesa, batata Yacon, batata-doce, batata-baroa, cará e inhame.

Embora o consumo de carnes não seja comum no $\mathrm{CM}$, estas foram avaliadas juntamente com os ovos. Algumas regiões geográficas consomem preparações com carne no café da manhã, como a preparação quebra-torto na região Centro Oeste. Outros exemplos são o cozidão com carne e o caldo de mocotó na região Norte; as carnes, os frangos e as linguiças na região Nordeste (ARAÚJO, 2005; FISBERG; WEHBA; COZZOLINO, 2002).

A composição nutricional do CM foi avaliada através do software Dietwinß (REINSTEIN; REINSTEIN; ZINGANO, 2008) e foi considerada a Necessidade Média 
Estimada (EAR). Foram considerados válidos para as análises os dados de todos os indivíduos selecionados, e que realizaram pelo menos um CM entre os três dias de pesquisa.

Para a análise de composição nutricional desta refeição foram avaliados: o Valor Energético Total (VET), as frações de macronutrientes, a gordura monoinsaturada, as gorduras saturadas e trans, as fibras e os micronutrientes cálcio e sódio. Devido ao fato desse estudo avaliar somente o CM não foi avaliada a adequação de consumo, mas o quanto o nutriente consumido no $\mathrm{CM}$ contribuiu na recomendação de cada um deles.

O VET da refeição CM foi avaliado de acordo com a Portaria interministerial no 66 (BRASIL, 2006), a qual recomenda que o CM tenha entre 300 e 400 calorias, que corresponde de $15 \%$ a $20 \%$ de uma dieta de $2000 \mathrm{Kcal}$, sendo o percentual de $20 \%$ (400 Kcal) adotado para avaliação de consumo energético nessa pesquisa.

A tabela 1 descreve os parâmetros para a análise dos macronutrientes considerados nessa pesquisa.

Tabela 1. Distribuição das recomendações dos macronutrientes sobre o VET de 400 kcal do CM.

\begin{tabular}{|c|c|c|c|}
\hline Nutriente & Recomendações & $\begin{array}{c}\text { Recomendação } \\
\text { em Kcal }\end{array}$ & $\begin{array}{c}\text { Recomendação } \\
\text { em gramas }\end{array}$ \\
\hline Carboidratos & 55 a $75 \%^{a}$ & 220 a 300 & 55 a 75 \\
\hline Proteínas & 10 a $15 \%^{a}$ & 40 a 60 & 10 a 15 \\
\hline Lipídeos & 15 a $30 \%^{a}$ & 60 a 120 & 6,7 a 13,3 \\
\hline Ácidos graxos monoins. & 10 a $15 \%{ }^{b}$ & 40 a 60 & 4,4 a 6,7 \\
\hline Ácidos graxos satur. & $<10 \%{ }^{\mathrm{b}}$ & 40 & $<4,4$ \\
\hline Ácidos graxos trans & $<1 \%^{\mathrm{a}}$ & 4 & $<0,4$ \\
\hline Fibras & 10 a $14 \mathrm{~g} / 1000 \mathrm{Kcal}^{\mathrm{c}}$ & ---- & 4,0 a 5,6 \\
\hline \multicolumn{4}{|c|}{$\begin{array}{l}{ }^{2} \text { World Health Organization (WHO). Diet, nutrition and the prevention of chronic diseases. Geneva: Wor } \\
\text { Health Organization; } 2003 \text {. } \\
\text { b'World Health Organization. Prevention of cardiovascular disease: guidelines for assessment and } \\
\text { management of cardiovascular risk. Geneva: WHO; } 2007 \text {. } \\
\text { cMarlett JA, McBurney MI, Slavin JL; American Dietetic Association. Position of the American Dietetic } \\
\text { Association: health implications of dietary fiber. J Am Diet Assoc. 2002;102:993-1000. }\end{array}$} \\
\hline
\end{tabular}


O cálcio e o sódio foram avaliados segundo as recomendações do Institute of Medicine, sendo avaliados em relação ao dia de consumo, e não em relação ao VET, sendo a Dietary Reference Intakes-DRI de 1000mg/dia para o cálcio (IOM, 1997) e de 2300mg/dia para o sódio (IOM, 2005).

Os dados foram tabulados e analisados no programa Statistical Package for the Social Sciences (SPSS®), versão 20.0. Foram contabilizados o número de entrevistados e o número de recordatórios analisados, considerando-se as refeições realizadas por cada indivíduo.

Os dados foram descritos em termos de frequências relativas e medidas resumo como a média e o desvio padrão. Para as análises de associação, o teste estatístico utilizado foi o qui-quadrado de Pearson. Os pressupostos da normalidade foram checados via teste de Shapiro-Wilk. Os testes estatísticos utilizados foram o quiquadrado, o t de Student e Kruskal-Wallis para apurar a análise de variância, tendo Tukey como Post-hoc. O nível de significância adotado foi de $5 \%$ e o poder de teste foi $80 \%$ (COHEN, 1962).

\section{RESULTADOS E DISCUSSÃO}

Foram coletados três dias de recordatórios alimentares de 1.547 entrevistados nas cinco regiões brasileiras. Das 4.641 refeições previstas, 797 (17,2\%) não foram consumidos (supressão), sendo analisado um total de 3.844 refeições CM.

A distribuição das variáveis sociodemográficas, de acordo com o sexo, encontra-se na tabela 2. Observou-se que a amostra foi predominantemente composta por homens $(58,4 \%, \mathrm{n}=903)$ e por indivíduos na faixa etária entre 25 e 34 anos (homens $20,8 \%$, mulheres $21,3 \%$ ). O nível de escolaridade mais frequente entre os entrevistados foi o ensino médio completo (homens $30,8 \%$, mulheres $35,9 \%$ ) e a faixa média de renda per capita predominante foi a de 0,5 a um Salário Mínimo (SM) (homens 35,9\%, mulheres $36,0 \%$ ). Com relação ao estado civil, observou-se um predomínio da união estável para os homens $(41,7 \%, n=377)$ e de solteiro para as mulheres $(37,6 \%, n=242)$. 
Tabela 2. Distribuição da frequência de dados sociodemográficos do café da manhã de usuários de Restaurantes Populares, 2010/2011.

\begin{tabular}{|c|c|c|c|c|c|c|c|}
\hline & \multirow[t]{2}{*}{ Variáveis } & \multicolumn{2}{|c|}{ Masculino } & \multicolumn{2}{|c|}{ Feminino } & \multicolumn{2}{|c|}{ Total } \\
\hline & & $\mathbf{n}$ & $\%$ & $\mathbf{N}$ & $\%$ & $\mathbf{N}$ & $\%$ \\
\hline Sexo & & 903 & 58,4 & 644 & 41,6 & 1547 & 100 \\
\hline 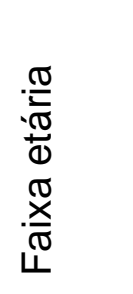 & $\begin{array}{l}18-24 \text { anos } \\
25-34 \\
35-44 \\
45-54 \\
55-64 \\
>65\end{array}$ & $\begin{array}{c}94 \\
188 \\
150 \\
168 \\
131 \\
172\end{array}$ & $\begin{array}{l}10,4 \\
20,8 \\
16,6 \\
18,6 \\
14,5 \\
19,0\end{array}$ & $\begin{array}{c}96 \\
137 \\
109 \\
105 \\
82 \\
15\end{array}$ & $\begin{array}{l}14,9 \\
21,3 \\
16,9 \\
16,3 \\
12,7 \\
17,9\end{array}$ & $\begin{array}{l}190 \\
325 \\
259 \\
273 \\
213 \\
287\end{array}$ & $\begin{array}{l}12,3 \\
21,0 \\
16,7 \\
17,6 \\
13,8 \\
18,6\end{array}$ \\
\hline 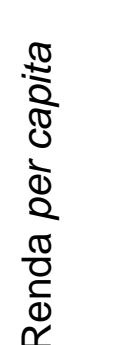 & $\begin{array}{l}\text { Até } 1 / 4 \text { SM } \\
1 / 4 \text { a } 1 / 2 \text { SM } \\
1 / 2 \text { a } 1 \text { SM } \\
1 \text { a } 2 \text { SM } \\
\text { > } 2 \text { SM } \\
\text { Sem } \\
\text { informação }\end{array}$ & $\begin{array}{c}64 \\
170 \\
324 \\
201 \\
85 \\
59\end{array}$ & $\begin{array}{c}7,1 \\
18,8 \\
35,9 \\
22,3 \\
9,4 \\
6,5\end{array}$ & $\begin{array}{c}69 \\
145 \\
232 \\
125 \\
42 \\
31\end{array}$ & $\begin{array}{l}10,7 \\
22,5 \\
36,0 \\
19,4 \\
6,5 \\
4,8\end{array}$ & $\begin{array}{c}133 \\
315 \\
556 \\
326 \\
127 \\
90\end{array}$ & $\begin{array}{c}8,6 \\
20,4 \\
35,9 \\
21,1 \\
8,2 \\
5,8\end{array}$ \\
\hline $\begin{array}{l}\frac{0}{0} \\
\frac{\pi}{0} \\
\frac{0}{\pi} \\
\frac{\pi}{0} \\
\text { d } \\
\text { W }\end{array}$ & $\begin{array}{l}\text { Analfabeto } \\
\text { EFI } \\
\text { EFC } \\
\text { EMI } \\
\text { EMC } \\
\text { ESI } \\
\text { ESC } \\
\text { CT }\end{array}$ & $\begin{array}{c}36 \\
274 \\
129 \\
60 \\
278 \\
54 \\
65 \\
7\end{array}$ & $\begin{array}{c}4,0 \\
30,3 \\
14,3 \\
6,6 \\
30,8 \\
60 \\
7,2 \\
0,8\end{array}$ & $\begin{array}{c}21 \\
182 \\
78 \\
36 \\
231 \\
34 \\
52 \\
10\end{array}$ & $\begin{array}{c}3,3 \\
28,3 \\
12,1 \\
5,6 \\
35,9 \\
5,3 \\
8,1 \\
1,6\end{array}$ & $\begin{array}{c}57 \\
456 \\
207 \\
96 \\
509 \\
88 \\
117 \\
15\end{array}$ & $\begin{array}{c}3,7 \\
29,5 \\
13,4 \\
6,2 \\
32,9 \\
5,7 \\
7,6 \\
1,1\end{array}$ \\
\hline 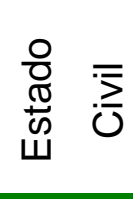 & $\begin{array}{l}\text { Solteiro } \\
\text { União estável } \\
\text { Viúvo } \\
\text { Separado }\end{array}$ & $\begin{array}{c}353 \\
377 \\
51 \\
122\end{array}$ & $\begin{array}{c}39,1 \\
41,7 \\
5,6 \\
13,5\end{array}$ & $\begin{array}{l}242 \\
241 \\
78 \\
83\end{array}$ & $\begin{array}{l}37,6 \\
37,4 \\
12,1 \\
12,9\end{array}$ & $\begin{array}{l}595 \\
618 \\
129 \\
205\end{array}$ & $\begin{array}{c}38,5 \\
39,9 \\
8,3 \\
13,3\end{array}$ \\
\hline
\end{tabular}

EFI- ensino fundamental incompleto; EFC- ensino fundamental completo; EMI- ensino médio incompleto; EMC- ensino médio completo; ESI- ensino superior incompleto; ESC- ensino superior completo; CTcurso técnico; SM- salário mínimo (R\$ 510,00).

Quanto à frequência de consumo da refeição $\mathrm{CM}$ os dados mostram que o percentual médio de supressão (não realização da refeição) dos três dias de refeição CM variou de $15,7 \%(n=243)$ na região Nordeste a $21,6 \%(n=334)$ na região Sul. As 
regiões Sudeste, Norte e Centro-oeste apresentaram percentual médio de supressão do CM de 16,1\% $(n=249), 16,2 \% \quad(n=251), 18,6 \% \quad(n=288)$ respectivamente, e o percentual médio de supressão nacional ficou em 17,2\%.

O percentual de supressão da amostra estudada foi baixo quando comparado a outros estudos brasileiros, como o estudo de MEDEIROS et al. (2007) com indivíduos adultos que encontrou $24,16 \%$ e de MARCHIONI et al. (2015) com adolescentes que encontrou $38 \%$.

Godoy et al. (2014), realizaram um estudo com parte da mesma população dos RP do presente estudo, e estimaram que cerca de $40,6 \%$ desta população encontrava-se em insegurança alimentar, sendo que o maior índice de segurança alimentar se foi o da região Sul (74\%). Considerando que a escala de insegurança alimentar utilizada por estes autores visou identificar o nível de limitação no acesso aos alimentos associados à restrição financeira, e que a região Sul $(21,6 \%, n=334)$ apresentou o maior percentual de supressão, conclui-se que a maior supressão do CM nesta região e nas demais, possivelmente não se deve unicamente ao fator econômico, mas a outros fatores como a falta de tempo e outros aspectos cotidianos (HÖFELMANN; MOMM, 2014; MARANGONI et al., 2009; RIVES et al., 2015 SUGIYAMA et al., 2012; WIJTZES et al., 2016).

Alguns autores (GAMBARDELLA; FRUTUOSO; FRANCHI,1999; O'NEIL et al., 2014; TRAVÉ, 2013) sugerem uma composição padrão para o CM constituída por, pelo menos, três grupos básicos de alimentos: lácteos, cereais e frutas. Por outro lado, diversos autores (GIOVANNINI et al., 2008; JOMORI; PROENÇA; CALVO, 2008; NEUTZLING et al., 2009; STORY; NEUMARK-SZTAINER; FRENCH, 2002) afirmam que fatores socioeconômicos como nível educacional, renda familiar, sexo e região de moradia são importantes determinantes na escolha alimentar.

A tabela 3 descreve a distribuição dos grupos de alimentos por sexo, faixa etária, faixa de renda per capita, escolaridade e região geográfica referente ao CM dos participantes da pesquisa. 
Tabela 3. Distribuição da média de frequência de três dias de consumo de grupos de alimentos por dados sociodemográficos do café da manhã de usuários de Restaurantes Populares, 2010/2011.

\begin{tabular}{|c|c|c|c|c|c|c|c|c|}
\hline \multirow{2}{*}{\multicolumn{2}{|c|}{ Variáveis }} & \multirow{3}{*}{$\begin{array}{c}\mathbf{n} \\
903\end{array}$} & \multirow{3}{*}{$\begin{array}{c}\% \\
58,4\end{array}$} & \multicolumn{5}{|c|}{ Grupos de alimentos (\%) } \\
\hline & & & & \multirow{2}{*}{$\begin{array}{c}\text { Lácteos } \\
54,3\end{array}$} & \multirow{2}{*}{$\begin{array}{c}\text { Cereais } \\
56,5\end{array}$} & \multirow{2}{*}{$\begin{array}{c}\text { Frutas } \\
18,1\end{array}$} & \multirow{3}{*}{$\begin{array}{c}\begin{array}{c}\text { Raízes/ } \\
\text { Tubérculos }\end{array} \\
1,8 \\
2,7\end{array}$} & \multirow{3}{*}{$\begin{array}{c}\begin{array}{c}\text { Carnes/ } \\
\text { Ovos }\end{array} \\
8,4 \\
5,4\end{array}$} \\
\hline & Masculino & & & & & & & \\
\hline ex & Feminino & 644 & 41,6 & 61,9 & 58,3 & 16,9 & & \\
\hline \multirow{6}{*}{ 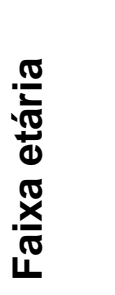 } & 18-24 anos & 190 & 12,3 & 53,1 & 48,4 & 14,2 & 3,1 & 7,1 \\
\hline & $25-34$ & 325 & 21,0 & 55,1 & 56,4 & 16,3 & 1,6 & 8,4 \\
\hline & $35-44$ & 259 & 16,7 & 55,8 & 56,7 & 20,3 & 2,1 & 9,3 \\
\hline & $45-54$ & 273 & 17,6 & 53,8 & 55,1 & 16,1 & 1,6 & 7,5 \\
\hline & $55-64$ & 213 & 13,8 & 57,2 & 57,5 & 19,0 & 2,3 & 4,9 \\
\hline & $>65$ & 287 & 18,6 & 68,3 & 66,2 & 19,1 & 2,6 & 5,1 \\
\hline \multirow{6}{*}{ 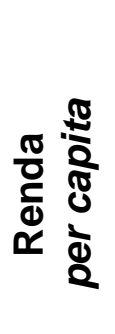 } & Até $1 / 4 \mathrm{SM}$ & 133 & 8,6 & 50,3 & 57,8 & 16,5 & 0,7 & 12,1 \\
\hline & $1 / 4 \mathrm{a}^{1 / 2} \mathrm{SM}$ & 315 & 20,4 & 55,7 & 54,3 & 17,4 & 4,0 & 6,2 \\
\hline & $1 / 2$ a 1 SM & 556 & 35,9 & 57,8 & 59,2 & 15,3 & 1,7 & 7,3 \\
\hline & 1 a 2 SM & 326 & 21,1 & 61,6 & 57,8 & 13,0 & 1,8 & 6,7 \\
\hline & $>2 \mathrm{SM}$ & 127 & 8,2 & 61,0 & 55,9 & 23,6 & 1,9 & 5,5 \\
\hline & $\begin{array}{l}\text { Sem } \\
\text { informação }\end{array}$ & 90 & 5,8 & 52,2 & 53,9 & 18,3 & 2,2 & 6,1 \\
\hline \multirow{8}{*}{$\begin{array}{l}\frac{0}{0} \\
\frac{\pi}{0} \\
\frac{0}{2} \\
\frac{\pi}{0} \\
\frac{0}{0} \\
\text { W }\end{array}$} & $\mathrm{EFI}$ & 456 & 29,5 & 53,1 & 75,9 & 10,1 & 0,2 & 5,3 \\
\hline & EFC & 207 & 13,4 & 54,1 & 82,1 & 10,6 & 2,4 & 4,8 \\
\hline & EMI & 96 & 6,2 & 56,3 & 79,2 & 16,7 & 3,1 & 3,1 \\
\hline & EMC & 509 & 32,9 & 56,6 & 79,6 & 12,0 & 1,2 & 4,1 \\
\hline & ESI & 88 & 5,7 & 50,0 & 78,4 & 17,0 & 0,0 & 3,4 \\
\hline & ESC & 117 & 7,6 & 57,3 & 82,1 & 15,4 & 1,7 & 0,9 \\
\hline & $\mathrm{CT}$ & 17 & 1,1 & 41,2 & 76,5 & 17,6 & 0,0 & 0,0 \\
\hline & Analfabeto & 57 & 3,7 & 54,4 & 70,2 & 3,5 & 0,0 & 3,5 \\
\hline \multirow{6}{*}{ 完 } & Centro-oeste & 43 & 2,8 & 65,1 & 62,8 & 16,3 & 1,1 & 12,8 \\
\hline & Nordeste & 381 & 24,6 & 47,8 & 48,8 & 28,4 & 3,8 & 13,6 \\
\hline & Norte & 175 & 11,3 & 68,8 & 70,6 & 12,0 & 0,2 & 6,8 \\
\hline & Sudeste & 645 & 41,7 & 61,0 & 59,2 & 13,9 & 1,1 & 3,5 \\
\hline & Sul & 303 & 19,6 & 54,6 & 55,3 & 15,0 & 2,5 & 6,2 \\
\hline & Brasil & 1547 & 100 & 59,5 & 59,3 & 17,1 & 1,7 & 8,6 \\
\hline
\end{tabular}

EFI- ensino fundamental incompleto; EFC- ensino fundamental completo; EMI- ensino médio incompleto; EMC- ensino médio completo; ESI- ensino superior incompleto; ESC- ensino superior completo; CTcurso técnico; SM- salário mínimo (R\$ 510,00). 
O grupo dos lácteos foi o mais consumido em ambos os sexos (homens $=54,3 \%$ e mulheres $=61,9 \%$ ). Esse resultado é benéfico à amostra estudada por ser esse grupo fonte de proteína e de cálcio, nutrientes essenciais em diversas funções biológicas (AHMED et al., 2012).

A alta frequência de consumo de lácteos nessa pesquisa é condizente com os resultados de outros estudos. Travé (2013) realizou um estudo para analisar nutricionalmente o consumo do CM e do almoço com 740 estudantes universitários espanhóis, e o resultado mostrou que os grupos de alimentos mais consumidos no CM dos participantes do estudo foram os lácteos $(92,6 \%)$ e os cereais $(58,8 \%)$. Na pesquisa realizada por Marchioni et al. (2015), por exemplo, cujo objetivo foi caracterizar os padrões e a contribuição nutricional do CM de 795 adolescentes paulistas, o grupo do leite e derivados representou o segundo grupo mais frequente. Mattos e Martins (2000), objetivando estimar o consumo médio diário de fibras alimentares nas refeições de 559 indivíduos paulistas maiores de 20 anos, identificaram que o leite foi consumido por $51 \%$ dos participantes.

O grupo de cereais foi o segundo mais consumido nesta pesquisa (homens $=56,5 \%$ e mulheres $=58,3 \%$ ) quando a variável sexo foi avaliada, o que é esperado, pois os cereais são a base da alimentação humana (CLARO; MACHADO; BANDONI, 2007; ENES; SILVA; 2008; VIEIRA et al., 2005).

Enes e Silva (2008) realizaram um estudo cujo objetivo foi analisar a disponibilidade domiciliar de energia, colesterol e fibras, a participação relativa dos macronutrientes no Valor Energético Total e a contribuição dos grupos de alimentos na energia disponível para as famílias residentes na Região Centro-Oeste do País. Utilizando informações obtidas pela Pesquisa de Orçamentos Familiares 2002/2003, encontraram que os alimentos de origem vegetal, reconhecidos como básicos para a alimentação (cereais e derivados, raízes e tubérculos), corresponderam a cerca de $40 \%$ da energia total disponível.

Embora a frequência de consumo de cereais da presente pesquisa tenha sido maior que a frequência encontrada por Enes e Silva (2008), a média de aquisição de cereais tem diminuído nos últimos 40 anos (BEZERRA et al., 2013; CARVALHO, 2008). 
Coelho, Aguiar e Fernandes (2009) investigaram o padrão de consumo de alimentos das famílias brasileiras com base nos dados da Pesquisa de Orçamentos Familiares realizada em 2002/2003. Esses autores encontraram resultados que indicam um maior consumo de proteína animal diário (carnes, leite e queijos) e menor consumo de carboidratos (arroz, farinha de mandioca) com um aumento da renda. Embora o presente estudo represente apenas o $\mathrm{CM}$, a tendência de consumo de lácteos e cereais foi semelhante à encontrada por Coelho, Aguiar e Fernandes (2009). Os lácteos apresentaram menor consumo na faixa de renda de até $1 / 4 \mathrm{SM}(50,3 \%)$ e maior consumo na faixa de renda acima de 2 SM (61\%), em contraposição os cereais que apresentaram maior consumo na faixa de renda de até $1 / 4$ SM e menor consumo $(55,9 \%)$ na faixa acima de $2 \mathrm{SM}$.

Um dos resultados que chama atenção neste estudo é o maior consumo de frutas pelo sexo masculino $(18,1 \%, n=163)$, em relação ao sexo feminino $(16,9 \%$, $\mathrm{n}=109$ ) diferente da maioria dos valores encontrados em pesquisas nacionais. No estudo realizado por Neutzling et al. (2009), por exemplo, cujo objetivo foi descrever a frequência do consumo de frutas e hortaliças por 972 adultos residentes em PelotasRS, encontrou-se que dos $20,9 \%$ entrevistados que relataram o consumo regular desse grupo de alimentos, 26,9\% eram mulheres, consumo bem maior que o dos homens (12,9\%). Mondini et al. (2010) avaliaram o consumo de frutas e hortaliças por 930 adultos da cidade de Ribeirão Preto-SP, e os resultados mostraram que apenas $24 \%$ dos homens e $38 \%$ das mulheres atenderam à recomendação mínima do consumo de frutas e hortaliças.

A participação de frutas e hortaliças na dieta do brasileiro é baixa (LEVY et al., 2012; MARCHIONI et al., 2015). Os dados da Pesquisa de Orçamentos Familiares 2008/2009, por exemplo, mostram que menos de 10\% dos brasileiros atingem as porções recomendadas para as frutas e hortaliças e contribuem com apenas $2,8 \%$ das calorias totais (LOUREIRO et al., 2013, SOUZA et al., 2013). Apesar de, em análise comparativa dos dados das Pesquisas de Orçamentos Familiares (Pesquisa de Orçamentos Familiares) de 2002-2003 e 2008-2009, observou-se que houve aumento na participação de frutas (+28\%) na dieta (JAIME et al., 2015). 
Evidências sugerem que o consumo de frutas e hortaliças desempenha um papel protetor contra as doenças crônicas não transmissiveis devido ao conteúdo em micronutrientes, antioxidante e compostos fitoquímicos e fibras existentes nestes alimentos (FIGUEIREDO; JAIME; MONTEIRO, 2008; GOLDMAN; RADNITZ; MCGRATH, 2012; JAIME; MONTEIRO, 2005; MOURA et al., 2011, NEUTZLING et al., 2009). Por isso, devem ter seus consumos aumentados em ambos os sexos indistintamente a partir da primeira refeição do dia, pois o CM constitui requisito fundamental ao melhor cumprimento da recomendação de cinco a nove porções de frutas e hortaliças ao dia (MACHADO; SIMÕES, 2008).

O consumo de frutas na presente pesquisa apresentou-se mais elevado no maior estrato de renda ( $>2 \mathrm{SM}=23,6 \%$ ). Tal resultado é confirmado na análise da última Pesquisa de Orçamentos Familiares que indica que as frutas são um dos grupos de alimentos em que a participação no consumo diário tende a aumentar de forma uniforme com o nível de rendimentos familiares (BRASIL, 2010).

Além disso, diversos estudos (CLARO; MONTEIRO, 2010; LEVY et al.,2012; NEUTZLING et al., 2009) referem que fatores sociais, culturais e econômicos exercem influência na ingestão de grupos de alimentos na alimentação humana. Dietas com alto teor de frutas e hortaliças são mais caras do que as demais, e a existência de restrições econômicas ao custo da alimentação conduz a dietas com baixa participação de frutas e hortaliças e, portanto, de alta densidade energética (FACHINELO et al., 2011).

Também Mondini et al. (2010), ao avaliarem o consumo de frutas e hortaliças em 930 adultos residentes em Ribeirão Preto-SP, observaram essa mesma associação positiva do consumo de frutas com a renda per capita e a escolaridade. Já na presente pesquisa o maior consumo de frutas aconteceu nos indivíduos que referiram possuir curso técnico como escolaridade.

A região que mais consumiu frutas foi a região Nordeste $(28,4 \%, n=108)$ diferente do encontrado em outras pesquisas (LEVY et al., 2012; NEVES; KOIFMAN; MATTOS, 2006; SOUZA et al., 2013) que descrevem o baixo consumo de frutas pelos nordestinos. Entretanto, é necessário ressaltar que tais pesquisas fazem referência ao consumo diário total, sem distinguir a refeição de consumo. 
Porém, a difusão acentuada de plantio irrigado no Nordeste do Brasil elevou a produção de vegetais nesta região (COSTA et al., 2013), que acrescido a investimentos de programas de governo, como o Programa de Aquisição de Alimentos, prioriza a produção e comercialização de frutas nesta região (LIMA; SAMPAIO; SILVA, 2011), nesse aspecto, justifica o maior consumo de frutas no presente estudo em relação a outros realizados no Brasil.

A frequência de consumo de raízes e tubérculos (homens=1,8\% e mulheres=2,7) no $\mathrm{CM}$ da amostra estudada foi baixa, pois este não é um hábito alimentar comum em todas as regiões do Brasil. Segundo alguns autores (ARAÚJO et al., 2005; BRASIL, 2002; CHAVES et al., 2009; FISBERG, WEHBA, COZZOLINO, 2002; PHILIPPI, 2006), as regiões Nordeste e Norte possuem o hábito de consumir no CM preparações com raízes e tubérculos.

A inserção de maior consumo de raízes e tubérculos em substituição aos panificados no CM seria uma estratégia importante para melhoria da qualidade nutricional da dieta da população brasileira, visto serem fontes de carboidratos e fibras e no caso de algumas variedades, também de minerais e vitaminas, como o potássio e as vitaminas A e C. Em complementação, o Guia Alimentar para a População Brasileira (BRASIL, 2014) recomenda que na alimentação diária devem ser evitados os alimentos processados, pois estes alteram negativamente a composição nutricional dos alimentos. Além disso, a substituição de panificados por raízes e tubérculos propicia a redução do consumo de sódio, tão prejuducial à saúde cardiovascular.

O maior consumo de carnes pelo sexo masculino $(8,4 \%, n=76)$ na presente pesquisa também foi citado por Moura et al. (2011) quando descreveram a prevalência dos fatores de riscos e protetores para doenças crônicas no Brasil, a partir de informações de 54.252 adultos entrevistados na pesquisa Vigilância de Fatores de Risco e Proteção para Doenças Crônicas por Inquérito Telefônico (VIGITEL), em 2007. No estudo de Moura et al. (2011), os homens consumiram 42,7\% e as mulheres $24,3 \%$ de carne.

Para Fischler (1988), os alimentos representam mais que nutrientes, e possuem um valor simbólico distinto que é central para a identificação individual e coletiva, sendo o consumo de carne um excelente exemplo deste fenômeno. $O$ 
consumo de carne constitui no ocidente um modelo de virilidade, que os homens necessitam para a realização adequada dos seus atributos de força (CARNEIRO, 2003; PEREZ, 2012; WOORTMANN, 2013).

Quanto à composição nutricional do $\mathrm{CM}$ dos participantes dessa pesquisa, é possível observar na tabela 4 as médias e desvios padrões da ingestão de energia, macronutrientes, ácidos graxos monoinsaturados, ácidos graxos saturados, ácidos graxos trans, fibras, cálcio e sódio, assim como o percentual de contribuição de cada nutriente sobre o VET, segundo regiões. 
Tabela 4. Média e desvio padrão da ingestão de nutrientes por região geográfica do café da manhã de usuários de Restaurantes Populares, 2010/2011.

\begin{tabular}{lcccccc}
\hline \multicolumn{1}{c}{ Nutriente } & $\begin{array}{c}\text { Brasil } \\
(\mathbf{n = 1 . 4 9 1 )}\end{array}$ & $\begin{array}{c}\text { Centro-oeste } \\
(\mathbf{n}=\mathbf{4 0})\end{array}$ & $\begin{array}{c}\text { Nordeste } \\
(\mathbf{n}=\mathbf{3 7 7})\end{array}$ & $\begin{array}{c}\text { Norte } \\
(\mathbf{n}=\mathbf{1 6 8})\end{array}$ & $\begin{array}{c}\text { Sudeste } \\
(\mathbf{n}=\mathbf{6 2 4})\end{array}$ & $\begin{array}{c}\text { Sul } \\
(\mathbf{n = 2 8 2})\end{array}$ \\
\hline VET (Kcal) & $340,51 \pm 201,77$ & $400,93 \pm 207,16$ & $405,79 \pm 225,52$ & $335,78 \pm 208,14$ & $304,86 \pm 182,21$ & $326,59 \pm 182,45$ \\
Carboidratos (g) & $52,01 \pm 29,82$ & $57,60 \pm 32,55$ & $63,01 \pm 34,88$ & $51,22 \pm 27,86$ & $46,48 \pm 25,88$ & $49,24 \pm 27,43$ \\
Proteínas (g) & $10,06 \pm 7,96$ & $10,83 \pm 6,74$ & $11,76 \pm 8,93$ & $9,33 \pm 10,16$ & $9,24 \pm 6,22$ & $9,99 \pm 8,39$ \\
Lipídeos (g) & $10,33 \pm 8,81$ & $14,40 \pm 8,59$ & $11,83 \pm 9,55$ & $10,30 \pm 8,14$ & $9,32 \pm 8,27$ & $9,99 \pm 8,98$ \\
AG monoinsaturados (g) & $1,99 \pm 2,34$ & $3,00 \pm 2,48$ & $2,12 \pm 2,43$ & $2,02 \pm 2,18$ & $1,79 \pm 2,09$ & $2,09 \pm 2,75$ \\
AG saturados (g) & $3,75 \pm 3,35$ & $5,90 \pm 3,83$ & $4,56 \pm 3,77$ & $3,80 \pm 3,67$ & $3,31 \pm 2,70$ & $3,31 \pm 3,49$ \\
AG trans (g) & $0,24 \pm 0,61$ & $0,50 \pm 0,91$ & $0,32 \pm 0,66$ & $0,27 \pm 0,69$ & $0,20 \pm 0,57$ & $0,17 \pm 0,49$ \\
Fibras (g) & $2,05 \pm 1,68$ & $1,77 \pm 1,07$ & $2,58 \pm 1,67$ & $2,81 \pm 2,23$ & $1,59 \pm 1,46$ & $1,94 \pm 1,49$ \\
Cálcio (mg) & $146,99 \pm 134,50$ & $187,23 \pm 166,14$ & $132,11 \pm 118,71$ & $143,84 \pm 132,24$ & $152,63 \pm 141,49$ & $150,38 \pm 133,42$ \\
Sódio (mg) & $436,50 \pm 375,92$ & $682,23 \pm 477,56$ & $562,23 \pm 495,17$ & $384,71 \pm 306,50$ & $386,03 \pm 312,64$ & $376,56 \pm 277,14$
\end{tabular}

\section{Contribuição (\%)}

\begin{tabular}{|c|c|c|c|c|c|c|c|}
\hline Nutriente & Recomendação & & & & & & \\
\hline VET & $400 \mathrm{Kcal}$ & 85,13 & 100,23 & 101,45 & 83,95 & 76,21 & 81,65 \\
\hline Carboidratos & $75 g^{a^{x}}$ & 69,35 & 76,80 & 84,01 & 68,29 & 61,97 & 65,65 \\
\hline Proteínas & $15 g^{a^{x}}$ & 67,07 & 67,06 & 78,40 & 62,20 & 61,60 & 66,60 \\
\hline Lipídeos & $13,3 \mathrm{~g}^{\mathrm{a}^{\mathrm{x}}}$ & 77,67 & 108,27 & 88,95 & 77,44 & 70,07 & 75,11 \\
\hline AG monoins. & $6,7 \mathrm{~g}^{\mathrm{b}^{*}}$ & 29,70 & 44,78 & 31,64 & 30,15 & 26,72 & 31,19 \\
\hline AG saturados & $<4,4 \mathrm{~g}^{\mathrm{b}}$ & 85,23 & 134,09 & 103,64 & 86,36 & 75,23 & 75,23 \\
\hline AG trans & $<0,4 \mathrm{~g}^{\mathrm{a}}$ & 60,00 & 125,00 & 80,00 & 67,50 & 50,00 & 42,50 \\
\hline Fibras & $5,6 \mathrm{~g}^{\mathrm{c}}$ & 36,61 & 31,61 & 46,07 & 50,18 & 28,39 & 34,64 \\
\hline Cálcio & $1000 \mathrm{mg} / \mathrm{dia}^{\mathrm{d}^{x x}}$ & 14,70 & 18,72 & 13,21 & 14,38 & 15,26 & 15,04 \\
\hline Sódio & $2300 \mathrm{mg} / \mathrm{dia}^{\mathrm{e}^{\mathrm{x} \pi}}$ & 18,98 & 29,66 & 24,44 & 16,73 & 16,78 & 16,37 \\
\hline
\end{tabular}

VET - valor energético total; AG- ácidos graxos; monoins. - monoinsaturado

a'World Health Organization (WHO). Diet, nutrition and the prevention of chronic diseases. Geneva: World Health Organization; 2003.

bWorld Health Organization. Prevention of cardiovascular disease: guidelines for assessment and management of cardiovascular risk. Geneva: WHO; 2007. 
'Marlett JA, McBurney MI, Slavin JL; American Dietetic Association. Position of the American Dietetic Association: health implications of dietary fiber. $J$ Am Diet Assoc. 2002;102:993-1000.

'Institute of Medicine (IOM). Dietary Reference Intakes for calcium, phosphorus, mgnesium, vitamin D, and fluoride. Washington, DC: National Academy Press; 1997.

${ }^{\text {e} I n s t i t u t e ~ o f ~ M e d i c i n e . ~ D i e t a r y ~ R e f e r e n c e ~ I n t a k e s ~ f o r ~ w a t e r, ~ p o t a s s i u m, ~ s o d i u m, ~ c h l o r i d e, ~ a n d ~ s u l f a t e . ~ W a s h i n g t o n, ~ D C: ~ N a t i o n a l ~ A c a d e m y ~ P r e s s, ~} 2005$.

*Foi considerado o limite máximo da recomendação.

** Percentual de contribuição referente à recomendação do dia de consumo 
Analisando a Tabela 4 é possivel observar que os percentuais nacionais de contribuição energética dos macronutrientes no VET do CM realizado pelos participantes da pesquisa, apresentaram-se adequados quanto à recomendação sugerida pela Organização Mundial de Saúde (WHO, 2003). Os percentuais de adequação para os macronutrientes foram: carboidratos $=61,1 \%$; proteínas $=11,8 \%$ e lipídeos $=27,30 \%$. Ao proceder a análise regional observou-se que a região Sudeste (76,21\%) apresentou o menor percentual de contribuição. A análise regional da média VET mostrou que o Norte é diferente do Nordeste $(p=0,000)$; o Nordeste é diferente do Sul $(p=0,000)$ e do Sudeste $(p=0,000)$; e o Centro-oeste é diferente do Sudeste $(p=0,010)$ e do Sul $(p=0,044)$.

Também Carrijo (2013), que avaliou o consumo alimentar do almoço de 1.771 indivíduos provenientes da mesma população do presente estudo, encontrou que os percentuais de energia provenientes dos macronutrientes foram adequados em todas as regiões.

A análise do teste Kruskal-Wallis mostrou a diferença estatística para as médias VET, carboidratos, proteínas e lipídeos. As médias VET e carboidratos foram diferentes significativamente entre as regiões ( $p=0,000$ para ambas), mas as médias proteínas e lipídeos não apresentaram significância estatística $(p=0,076, p=0,163$ respectivamente). Para a média carboidratos, a diferença está entre as regiões Norte e Nordeste $(p=0,000)$, Nordeste em relação ao Sul $(p=0,000)$ e Sudeste $(p=0,000)$, sendo que o Centro-oeste não é diferente estatisticamente.

Considerando a distribuição energética dos macronutrientes do CM dos participantes da presente pesquisa (Tabela 4) e que entre os entrevistados dos 36 Restaurantes Populares a maioria (participantes de 29 restaurantes) realizou o CM em casa, observa-se que os indivíduos dessa amostra realizaram a primeira refeição do dia de forma equilibrada, quanto à distribuição de macronutrientes, independentemente das condições sociodemográficas em que estavam inseridos.

É importante acentuar que para a análise do perfil lipídico da refeição, foram calculadas a média percentual de energia em relação ao VET da refeição proveniente do consumo de gorduras monoinsaturadas, gorduras saturadas e gordura trans (Tabela 4).

O consumo médio nacional de ácidos graxos monoinsaturados foi baixo. Tendo em vista que os alimentos fontes de tais nutrientes são o azeite de oliva, os óleos vegetais (girassol, canola e arroz), a gordura do abacate e das frutas 
oleaginosas (FREITAS et al. 2009) e que, exceto o abacate, tais alimentos não são comumente consumidos no CM brasileiro, tal resultado não é preocupante. Pois, este estudo refere-se apenas à refeição $\mathrm{CM}$, e o indivíduo pode consumir estes nutrientes nas demais refeições do dia.

Os percentuais nacionais de contribuição dos ácidos graxos saturados e ácidos graxos trans se encontram dentro da recomendação, mas quando a análise regional foi realizada, observa-se que os percentuais da região Centro-oeste para esses mesmos nutrientes estavam elevados, sendo que a região Nordeste apresentou percentual elevado de apenas os ácidos graxos saturados.

Estes achados corroboram com os resultados encontrados na análise de grupos de alimentos (Tabela 3 ) em que as regiões Centro-oeste (carnes/ovos12,8\%; cereais-62,8\%) e Nordeste (carnes/ovos-13,6\%; cereais-70,6\%) também apresentaram os dois maiores consumo de carnes/ovos e cereais. Neste caso, citase o consumo de cereais devido à constatação de que o consumo de cereais no CM é normalmente acompanhado por uma das principais fontes de ácidos graxos trans, a margarina (CASTRO et al., 2009).

Marchioni et al. (2015) considera que quase 40\% do consumo diário de gordura trans é realizado no CM. Baseado nessa afirmação pode-se inferir que o baixo consumo desse nutriente na maioria das regiões geográficas estudadas foi um resultado satisfatório no perfil alimentar dos indivíduos entrevistados.

A média de ingestão nacional de fibras foi de 2,05g $\pm 1,68$ (Tabela 4), valor aquém à recomendação de 10 a 14g/1000kcal sugerida pela American Dietetic Association (MARLETT, 2002), sendo que a região Norte apresentou o maior consumo quando comparada às demais regiões. Esse resultado condiz com o baixo consumo de frutas pelos participantes da presente pesquisa (Tabela 3).

O maior consumo de fibras é um fator protetor às doenças cardíacas, cânceres, diabetes e desordens gastrintestinais, atuando especificamente na manutenção de baixos níveis sanguíneos de colesterol, na normalização de níveis de glicose sérica e de insulina, na melhora do trânsito intestinal e em um menor risco para o câncer de cólon (ALVES; BOOG, 2008; BRASIL, 2014; MARLETT, 2002; MARANGONI et al., 2009). Portanto, o aumento do consumo de frutas contribui para a redução de doenças crônicas não transmissíveis, que representam a maior causa de morte no Brasil e no mundo (WHO, 2014). 
Embora a DRI para cálcio seja sobre o consumo diário, no caso da consideração de uma cobertura de $20 \%$ do CM para uma dieta de $2000 \mathrm{kcal}$, se teria uma recomendação de $200 \mathrm{mg}$ para o CM, o que indica que o consumo nacional de cálcio (146,99 mg) pelos participantes da pesquisa cobriu 73,49\% do esperado para essa refeição. No entanto, espera-se que no CM o consumo de cálcio seja maior que nas outras refeições em função dos tipos de alimentos consumidos, sendo que o maior consumo aconteceu na região Centro-oeste (93,61\% de contribuição), corroborado pela análise de grupos de alimentos em que os participantes da região Centro-oeste foram os segundos em maior consumo de lácteos (Tabela 3).

Tendo em vista que o consumo de cálcio previne doenças como a osteoporose, a hipertensão arterial, o câncer de cólon e a obesidade (AHMED et al., 2012; GALAS; AUGUSTYNIAK; SOCHACKA-TATARA, 2013), e que a única fonte de cálcio disponível para o organismo humano é a proveniente da dieta, é essencial garantir uma ingestão mínima do mineral para permitir o crescimento e a manutenção ósseos (BUENO; CZEPIELEWSKI, 2008; LUZ, 2007).

Apesar do grupo de lácteos representar um dos mais consumidos no CM dos participantes dessa pesquisa, as porções ingeridas poderiam ser maiores para maior contribuição do nutriente no consumo diário, dada a importância desse na saúde humana.

Pereira et al. (2009) consideram que o aumento da ingestão de cálcio atenua a sensibilidade ao sal e reduz a pressão sanguínea, principalmente em indivíduos hipertensos. Esse é mais um fator que realça a importância do consumo de alimentos fontes de cálcio no CM.

A DRI para sódio também é considerada sobre o consumo diário, mas a aplicação do raciocínio de $20 \%$ do CM sobre um dia calórico de 2000 Kcal, mostra que seria adequado um limite máximo de $460 \mathrm{mg}$ para o sódio do $\mathrm{CM}$, sendo que o resultado encontrado para o consumo nacional foi de $436,50 \mathrm{mg}$ (Tabeka 4). Mas quando a análise regional foi realizada observou-se consumo elevado nas regiões Centro-oeste e Nordeste, coerente com os maiores consumos de carnes/ovos nessas regiões (Tabela 3 ).

Estatísticamente, o sódio apresentou diferença significativa entre a região Norte e Nordeste $(p=0,000)$, Norte e Centro-oeste $(p=0,001)$, Nordeste em relação ao Norte, ao Sul e ao Sudeste, todos com $p=0,000$. O Centro-oeste foi diferente do Sul $(p=0,000)$ e do Sudeste $(p=0,000)$. 
Sendo o pão um dos principais alimentos consumido no CM dos brasileiros e também um dos principais contribuintes para a ingestão elevada de sódio, merece atenção redobrada no controle da adição de sal pelos fabricantes e no consumo diário pelos indivíduos. O consumo de alimentos como os embutidos e alguns queijos, também influencia a ingestão de sódio e precisam ser monitorados para alcance de uma dieta saudável.

O excesso de sódio, além de estar diretamente relacionado a um fator de risco aumentado para a ocorrência de doenças cardiovasculares, principal causa de mortalidade no mundo (BOLHUIS et al., 2011; BRASIL, 2006; IGNÁCIO et al., 2013; SARNO et al., 2009), também é um fator que pode influenciar a biodisponibilidade do cálcio, uma vez que a ingestão elevada desse nutriente acarreta aumento da excreção renal de cálcio (MORAIS; BURGOS, 2007; PEREIRA et al., 2009).

\section{CONCLUSÃO}

A análise de grupos de alimentos mostrou alto consumo de lácteos e cereais, e baixo consumo de frutas, raízes/tubérculos e carnes/ovos. As frutas foram mais consumidas por homens; por pessoas na faixa de idade entre 35 a 44 anos e pelos participantes com maior faixa de renda. Os nordestinos consumiram mais frutas quando comparados com as demais regiões. Os lácteos e cereais apresentaram tendência contrária de consumo quando a renda foi considerada.

Os percentuais nacionais de contribuição energética dos macronutrientes no VET do CM realizado pelos participantes da pesquisa apresentaram-se adequados, com percentuais de adequação dentro do recomendado.

Os percentuais nacionais de contribuição dos ácidos graxos saturados e ácidos graxos trans se encontravam dentro da recomendação, mas quando a análise regional foi realizada, observou-se que a região Centro-oeste apresentou níveis de consumo elevados para estes dois nutrientes e a região Nordeste apresentou percentual de consumo elevado de ácidos graxos saturados, condizente com os altos consumos de carnes/ovos e cereais nestas regiões. 
A média nacional da ingestão de fibras do CM foi baixa, concordando com o resultado encontrado de baixo consumo de frutas pelos participantes da presente pesquisa.

Embora os lácteos tenha sido um dos grupos de alimentos mais consumidos, o teor de cálcio consumido foi baixo em todas as regiões, demonstrando que a frequência de consumo foi alta, mas a quantidade consumida foi baixa. Tal constatação indica a necessidade de maior ingestão de lácteos e outros alimentos fontes de cálcio no CM.

O consumo nacional de sódio foi dentro do recomendado, sendo que as regiões Centro-oeste e Nordeste apresentaram alto consumo, coerente com o maior consumo de carnes/ovos nessas regiões.

Considerando o perfil de consumo dos grupos de alimentos da amostra estudada, sugere-se que uma forma de melhorar a qualidade nutricional do CM seria consumir no CM maior quantidade de alimentos in natura, como por exemplo, a mandioca, o cará, o inhame e a batata doce em substituição aos panificados; a coalhada e iogurtes caseiros em substituição a queijos e iogurtes industrializados. Além disso, aumentar o consumo de frutas e hortaliças nesta refeição. Embora o consumo de hortaliças não seja hábito no $\mathrm{CM}$, pode ser consumido na forma de sucos puros ou misto com frutas.

\section{REFERÊNCIAS BIBLIOGRÁFICAS}

ALEXANDRE, V. P. et al. Fatores associados às práticas alimentares da população adulta de Goiânia, Goiás, Brasil. Revista Brasileira de Epidemiologia, p. 267-280, 2014.

ALMEIDA, V. M. Ensaio sobre a valorização da culinária tradicional local como estratégia identitária-territorial. 2006. 126f. Dissertação (Mestrado em Geografia) Instituto de Geociências, Universidade Federal Fluminense, 2006.

ALVES, H. J.; BOOG, M.C.F. Comportamento alimentar em moradia estudantil: um espaço para promoção da saúde. Revista de Saúde Pública, São Paulo, v. 41, n. 2 , p. 197-204, 2007.

ARAÚJO, F.A.L.V.; ALMEIDA, M.I; BASTOS, V. C. Aspectos alimentares e nutricionais dos usuários do "Restaurante Popular Mesa do Povo". Saúde e Sociedade, São Paulo, v. 16, n. 1, p. 117-133, 2007.

ARAÚJO, W. M. C. et al. Da alimentação à gastronomia. Brasília: Editora UnB, 2005. $101 p$. 
AZEVEDO, E.C.C. et al. Padrão alimentar de risco para as doenças crônicas não transmissíveis e sua associação com a gordura corporal - uma revisão sistemática. Ciências \& Saúde Coletiva, v. 19, n. 5, p.1447-1458, 2014.

BARUFALDI, L. A. Características de adolescentes de acordo com o consumo de café da manhã em escolas de cinco cidades brasileiras. 2014. 71f. Tese (Doutorado em Saúde Coletiva) - Instituto de Estudos em Saúde Coletiva, Universidade Federal do Rio de Janeiro. 2014.

BETTS, J.A. et al. Bath Breakfast Project (BBP) - Examining the role of extended daily fasting in human energy balance and associated health outcomes: Study protocol for a randomised controlled. Trials, Oxford, v.12, n. 172, 2011. Disponível em: <http://www.trialsjournal.com/content/12/1/172>. Acesso em: 2 mar. 2012. BEZERRA, I.N. et al. Consumo de alimentos fora do domicílio no Brasil. Revista de Saúde Pública, v. 47, p. 200-211, 2013. Suplemento.

BOLHUIS, D.P. et al. A salt reduction of $50 \%$ in bread does not decrease bread consumption or increase sodium intake by the choice of sandwich fillings.

The journal of nutrition, v. 141, n. 12, p. 2249- 2255, 2011.

BRASIL. Ministério da Saúde. Secretaria de Atenção à Saúde. Coordenação-Geral da Política de Alimentação e Nutrição. Guia alimentar para a população brasileira: promovendo a alimentação saudável. Brasília: Ministério da Saúde, 2006. 236p. BRASIL. Ministério da Saúde. Secretaria de Atenção à Saúde. Departamento de Atenção Básica. Guia alimentar para a população brasileira, 2ª ed., Brasília: Ministério da Saúde, 2014.156 p.

BRASIL. Ministério do Desenvolvimento Social e Combate à Fome. Secretaria de Avaliação e Gestão da Informação. Identificação de Perfil e Avaliação dos Usuários de Restaurantes Populares. Brasília, DF, dez. 2008.

BRASIL. Ministério do Planejamento, Orçamento e Gestão. Instituto Brasileiro de Geografia e Estatística. Diretoria de Pesquisas Coordenação de Trabalho e Rendimento. Pesquisa de Orçamentos Familiares 2008-2009: antropometria e estado nutricional de crianças, adolescentes e adultos no Brasil. Brasília. 2010. 130 p.

BRASIL. Portaria interministerial n 66, 25 de agosto de 2006. Altera os parâmetros nutricionais do Programa de Alimentação do Trabalhador - PAT. Brasília, Brasil. Ministério do trabalho e do Emprego. DOU, 2006; (165):153.

BUENO, A.L.; CZEPIELEWSKI, M.A. A importância do consumo dietético de cálcio e vitamina D no crescimento. Jornal de Pediatria, v. 84, n. 5, p. 386-394, 2008.

CARNEIRO, H. Comer animais: carnes, ovos e leites. "In:" ----- (Org.). Comida e Sociedade. Rio de Janeiro: Editora Campus, 2003. p. 63-73.CARRIJO, A.P. Avaliação do consumo alimentar nos Restaurantes Populares do Brasil. 2013. 97f. Dissertação (Mestrado em Nutrição Humana) - Faculdade de Ciências da Saúde, Universidade de Brasília. Brasília, Distrito Federal, 2013.

CARVALHO, M.S. Lugares e paladares: uma contribuição geográfica à diversidade do consumo alimentar no Brasil. Revista RA'E GA, Curitiba: editora UFPR, n. 15, p. 95-111, 2008.

CASTRO, M. A. et al.Trans fatty acid intake among the population of the city of São

Paulo, Brazil. Rev. Saúde Pública, v.43, n.6, p. 991-997, 2009.

CHAPLIN, K.; SMITH, A.P. Breakfast and snacks: associations with cognitive failures, minor injuries, accidents and stress. Nutrients, Switzerland, v. 3, p. 515528, 2011. 
CLARO, R. M.; MACHADO, F. M. S.; BANDONI, D.H. Evolução da disponibilidade domiciliar de alimentos no município de São Paulo no período de 1979 a 1999.

Revista de Nutrição, Campinas, v. 20, n. 5, p. 483-490, 2007.

CLARO, R. M.; MONTEIRO, C. A. Renda familiar, preço de alimentos e aquisição domiciliar de frutas e hortaliças no Brasil. Revista de Saúde Pública, v. 44, n. 6, p. 1014-20, 2010.

COELHO, A. B.; AGUIAR, D. R. D.; FERNANDES, E. A. Padrão de consumo de alimentos no Brasil. RESR, Piracicaba, São Paulo, v. 47, n. 2, p. 335-362, 2009. COHEN, J. The statistical power of abnormal-social psychological research: A review. Journal of Abnormal and Social Psychology, v. 65, p. 145-153, 1962. COSTA, L. C.F.; VASCONCELOS, F.A.G. Prevalence and factors associated with nutritional status among female university students in Florianópolis, SC. Revista Brasileira de Cineantropometria \& Desempenho Humano, Florianópolis, v. 15, n. 3, p. 326-337, 2013.

COUTINHO, J. G.; GENTIL, P. C.; TORAL, N. A desnutrição e obesidade no Brasil: o enfrentamento com base na agenda única da nutrição. Cadernos de Saúde Pública, Rio de Janeiro, v. 24, n. 2, p. 332-340, 2008. Suplemento.

DATALLO, P. Determining sample size balancing power, precision and practicality. Oxford University Press: 2008, chapter 2, p. 27.

ENES, C.C.; SILVA, M.V. A Alimentação das famílias do Centro-Oeste brasileiro: subsídios para ações de Segurança Alimentar e Nutricional. Segurança Alimentar e Nutricional, Campinas, v. 15, n. 2, p. 46-57, 2008.

FACHINELLO, J. C. et al. Situação e perspectivas da fruticultura de clima temperado no Brasil. Revista Brasileira de Fruticultura, Jaboticabal ,SP, volume especial, p. 109-120, 2011.

FIGUEIREDO, I.C.R.; JAIME, P.C.; MONTEIRO, C. A. Fatores associados ao consumo de frutas, legumes e verduras em adultos da cidade de São Paulo. Revista de Saúde Pública, v. 42, n. 5, p. 777-785, 2008.

FISBERG, M.; WEHBA, J.; COZZOLINO, S. M. F. Um, dois, feijão com arroz: a alimentação no Brasil de Norte a Sul. São Paulo: Editora Atheneu, 2002. 418 p. FISCHLER, C. Food, self and identidy. In: Social Sciences Information, v. 27, n. 2, p. $92275,1988$.

FREITAS, M.M. et al. O efeito do consumo de alimentos fonte de ácidos graxos monoinsaturados e poliinsaturados, sobre a composição corporal e perfil lipídico sanguíneo de mulheres sedentárias e fisicamente ativas. Revista Brasileira de Nutrição Esportiva, São Paulo, v. 3, n. 16. p. 356-362, 2009.

FREITAS, P.P.; MENDONÇA, R.D.; LOPES, A.C.S. Factors associated with breakfasting in users of a public health service. Revista de Nutrição, Campinas, v. 26, n. 2, p.195-203, 2013.

GALAS, A.; AUGUSTYNIAK, M.; SOCHACKA-TATARA, E. Does dietary calcium interact with dietary fiberagainst colorectal cancer? A case-control studyin Central Europe. Nutrition Journal, 12:134, 2013. Disponível em:

<http://www.nutritionj.com/content/12/1/134>. Acesso em: 18 mar. 2014. GAMBARDELLA, A.M.D.; FRUTUOSO, M.P.F.; FRANCHI, C. Prática alimentar de adolescentes. Revista de Nutrição, Campinas, v. 12, n. 1, p. 55-63, 1999. GIOVANNINI, M. et al. Breakfast: a good habit, not a repetitive custom. Journal of International Medical Research, v. 36, p. 613-624, 2008.

GODOY, K. C. et al. Perfil e situação de insegurança alimentar dos usuários dos Restaurantes Populares no Brasil. Cadernos de Saúde Pública, Rio de Janeiro, v. 30, n. 6, p. 1239-1249, 2014. 
GOLDMAN, R. L.; RADNITZ, C. L.; McGRATH, R. E. The role of family variables in fruit and vegetable consumption in pre-school children. Journal of Public Health Research, v. 1, n. 22, p. 143,-148, 2012.

GOLLINO, L. et al. Avaliação da ingestão de leite e substitutos e do hábito do desjejum de universitários do curso de nutrição. Segurança Alimentar e

Nutricional, Campinas, v. 20, n. 2, p. 236-244, 2013.

HÖFELMANN, D. A.; MOMM, N. Breakfast: omission and associated factors in school children from Itajaí, Santa Catarina state, Brazil. Nutrire: Rev. Soc. Bras. Alim. Nutr. = J. Brazilian Soc. Food Nutr., São Paulo, v. 39, n. 1, p. 40-55, 2014. HOLMES, B.A. et al. The contribution of breakfast cereals to the nutritional intake of the materially deprived UK population. European Journal of Clinical Nutrition, London, n. 66, p.10-17, 2012.

IGNÁCIO, A. K. F. et al. Efeito da substituição de cloreto de sódio por cloreto de potássio em pão francês. Brazilian Journal of food Technology, Campinas, v. 16, n. 1, p. 1-11, 2013.

INSTITUTE OF MEDICINE (IOM). Dietary Reference Intakes for calcium, phosphorus, mgnesium, vitamin D, and fluoride. Washington, DC: National Academy Press; 1997.

INSTITUTE OF MEDICINE.Dietary reference intakes for water, potassium, sodium, chloride, and sulfate. Washington, DC: National Academy Press, 2005.

JAIME, P. C et al. Prevalência e distribuição sociodemográfica de marcadores de alimentação saudável, Pesquisa Nacional de Saúde, Brasil 2013. Epidemiologia e Serviços de Saúde, v. 24, n. 2, p. 267-276, 2015.

JAIME, P.C.; MONTEIRO, C.A. Fruit and vegetable intake by Brazilian adults, 2003. Cadernos de Saúde Pública, v. 21 n.1, p. 19-24. 2005. Suplemento.

JOMORI, M.M.; PROENÇA, R.P.C.; CALVO, M.C.M. Escolha alimentar: a questão de gênero no contexto da alimentação fora de casa. Caderno Espaço Feminino, v. 19, n. 1, 2008. Disponível em

<http://www.seer.ufu.br/index.php/neguem/article/view/2116>.

LEVY, R.B. et al. Distribuição regional e socioeconômica da disponibilidade domiciliar de alimentos no Brasil em 2008-2009. Revista de Saúde Pública, São Paulo, v. 46, n.1, p. 6-15, 2012.

LOUREIRO, A.S. et al. Diet quality in a sample of adults from Cuiabá (MT), Brazil: association with sociodemographic factors. Revista de Nutrição, v. 26, n. 4, p. 431441, 2013.

LUZ, A.R. Concentrações séricas de cálcio e ferro em jovens consumidores de tereré (ilex paraguarienses), Dourados, MS. Dourados, MS. 2007. $112 f$.

Dissertação (Mestrado em Ciências da Saúde) - Universidade de Brasília, 2007. MACHADO, F.M.S.; SIMÕES, A.N. Análise custo-efetividade e índice de qualidade da refeição aplicados à Estratégia Global da OMS. Revista de Saúde Pública, São Paulo, v. 42, n. 1, p. 64-72, 2008.

MACHADO, I. E. et al. Fatores associados ao excesso de peso em adultos usuários de restaurantes populares em Belo Horizonte, Brasil. Ciências \& Saúde Coletiva, Rio de Janeiro, v.19, n.5, p. 1367-1377, 2014.

MARANGONI, F. A. et al. Consensus document on the role of breakfast in the attainment and maintenance of health and wellness. Acta Biomedica, Italy, n. 80, p.166-171, 2009.

MARCHIONI, D.M.L. et al. Prevalência de omissão do café da manhã e seus fatores associados em adolescentes de São Paulo: estudo ISA-Capital. Nutrire, São Paulo, v. 40 , n. 1 , p. $10-20,2015$. 
MARCONDELLI, P.; COSTA, T. H. M.; SCHMITZ, B. A. S. Nível de atividade física e hábitos alimentares de universitários do $3^{\circ}$ ao $5^{\circ}$ semestres da área da saúde.

Revista de Nutrição, Campinas, v. 21, n. 1, p. 39-47, 2008.

MARLETT, J.A. et al. Position of the American Dietetic Association: health implications of dietary fiber. Journal of American Dietetic Association, v. 102, p. 993-1000, 2002.

MARTINS, A.P.B. (Org.) Redução de sódio em alimentos: uma análise dos acordos voluntários no Brasil. / Instituto Brasileiro de Defesa do Consumidor. Cadernos Idec - Série Alimentos, v. 1. São Paulo: Idec, 2014.

MATTOS, L.L.; MARTINS, I.S. Consumo de fibras alimentares em população adulta. Revista de Saúde Pública, São Paulo, v. 34, n. 1, p. 50-55, 2000.

MEDEIROS, M.A.T. et al. Estado nutricional e práticas alimentares de trabalhadores acidentados. Revista de Nutrição, Campinas, v. 20, n. 6, p. 589-602, 2007.

MIN, C. et al. Skipping breakfast is associated with diet quality and metabolic syndrome risk factors of adults. Nutrition Research and Practice, Korean, v. 5, n. 5, p. 455-463, 2011.

MONDINI, L. et al. Consumo de frutas e hortaliças por adultos em Ribeirão Preto, SP. Revista de Saúde Pública, v. 44, n. 4, p. 686-694, 2010.

MORAIS, G.Q.; BURGOS, M.G.P.A. Impacto dos nutrientes na saúde óssea: novas tendências. Revista Brasileira de Ortopedia, v. 42, n. 7, p. 189-194, 2007.

MOURA, E. C. et al. Fatores de risco e proteção para doenças crônicas: vigilância por meio de inquérito telefônico, VIGITEL, Brasil, 2007. Cadernos de Saúde

Pública, v. 27, n. 3, p. 486-496, 2011.

NEUTZLING, M. B. et al. Fatores associados ao consumo de frutas, legumes e verduras em adultos de uma cidade no Sul do Brasil. Cadernos de Saúde Pública, v. 25, n.11, p. 2365-2374, 2009.

NURUL-FADHILAH, A. et al. Infrequent breakfast consumption is associated with higher body adiposity and abdominal obesity in Malaysian school-aged adolescents.

Plos One, v. 8, n. 3, e59297, mar. 2013. Disponível em:

<http://www.ncbi.nlm.nih.gov/pmc/articles/PMC3592841/pdf/pone.0059297.pdf>.

Acesso em: 04 set. 2013.

O'NEIL, C. E. et al. The role of breakfast in health: definition and criteria for a quality breakfast. Journal of the Academy of Nutrition and Dietetics, v. 114, n. 12, 2014.

Suplemento 3.

PEREIRA, G.A.P. et al. Cálcio dietético - estratégias para otimizar o consumo.

Revista Brasileira de Reumatologia, v. 49, n. 2, p. 164-180, 2009.

PEREZ, R.M. Alimentação e codificação social. Mulheres, cozinha e estatuto.

Cadernos Pagu, v. 39, p. 227-249, 2012.

REINSTEIN, C.S.B.; REINSTEIN, B. B.; ZINGANO, R. Dietwin® profissional 2.0, Software de Análise nutricional. Rio Grande do Sul: 2008. 1 CD-ROM.

RIVES, F.M. et al. Atención farmacéutica en el fomento del desayuno saludable desde la oficina de farmácia. Nutricion Hospitalaria, Madrid, v. 32, n. 3, p.1267$1272,2015$.

SARNO, F. et al. Estimativa de consumo de sódio pela população brasileira, 20022003. Revista de Saúde Pública, v. 43, n. 2, p. 219-225, 2009.

SPSS® for Windows, Rev. 20.0 [programa de computador]. Chicago: SPSS Inc. 1 CD-ROM.

SOUZA, A.M. et al. Alimentos mais consumidos no Brasil: Inquérito Nacional de Alimentação 2008-2009. Revista de Saúde Pública; v.47, n.1, p.190-199, 2013. Suplemento. 
STORY, M.; NEUMARK-SZTAINER, D.; FRENCH, S. Individual and environmental influences on adolescent eating behaviors. American Dietetic Association, v. 102, n. 3, p. 40-51, 2002. Suplemento.

SUGIYAMA, S. et al. Breakfast habits among adolescents and their association with daily energy and fish, vegetable, and fruit intake: a community-based cross-sectional study. Environmental Health and Preventive Medicine, Japan, v. 17, n. 5, p. 408414, 2012.

SUN, Y. et al. Fruit and vegetable consumption and cardiovascular risk factors in older Chinese: The Guangzhou Biobank Cohort Study. Plos One, v. 10, p. 1-15, 2015.

TORRES, C. V.; ALLEN, M.; PÉREZ-NEBRA, A. R. Consumo no Brasil: um teste etic da relação entre valores humanos, significado do produto e preferência de consumo em culturas coletivistas. Revista de Psicologia: Organização e Trabalho, Santa Catarina, v.6, n.1, p.79-105, 2006.

TRANCOSO, S.C.; CAVALLI, S.B.; PROENÇA, R.P.C. Café da manhã: caracterização, consumo e importância para a saúde. Revista de Nutrição, São Paulo, v. 23, n. 5, p. 856-869, 2010.

TRAVÉ, T.D. Análisis nutricional del desayuno y almuerzo en una poblaciónUniversitária. Nutricion Hospitalaria, v. 28, n. 3, p. 1291-1299, 2013. VASCONCELOS, F. A. G. Josué de Castro e a geografia da fome no Brasil. Cadernos de Saúde Pública, Rio de Janeiro, v. 24, n. 11, p. 2710-2717, 2008. VIEIRA, V. C. R. et al. Alterações no padrão alimentar de adolescentes com adequação pôndero-estatural e elevado percentual de gordura corporal. Revista Brasileira de Saúde Materno Infantil, Recife, v. 5, n.1, p. 93-102, 2005. WIJTZES, A.I. et al. Meal-Skipping Behaviors and Body Fat in 6-Year-Old Children. The Journal of Pediatrics, v. 168, p. 118-125, 2016.

WOORTMANN, E.F. A comida como linguagem. Habitus, Goiânia, v. 11, n.1, p. 517, 2013.

WHO. WORLD HEALTH ORGANIZATION (WHO). Diet, nutrition and the prevention of chronic diseases. Geneva: World Health Organization; 2003. WHO. WORLD HEALTH ORGANIZATION. Prevention of cardiovascular disease: guidelines for assessment and management of cardiovascular risk. Geneva: WHO; 2007.

WHO. WORLD HEALTH ORGANIZATION.The impact of chronic diseases in Brazil. Disponível em: <http://www.who.int/chp/chronic_disease_report/en/>. Acesso em 17 jul. 2014.

WHO. WORLD HEALTH ORGANIZATION (WHO). World Health Organization issues new guidance on dietary salt and potassium. Geneva; 2013. 
5.3 CAPITULO 3 - Café da manhã: classificação, composição e regionalidade alimentar no Brasil 


\section{RESUMO}

Diante do estilo de vida inadequado adotado no mundo moderno, o café da manhã (CM) é a refeição mais negligenciada. O hábito de consumo de alimentos regionais nas principais refeições, incluindo o $\mathrm{CM}$, é pouco comum, e isso pode representar uma baixa utilização de recursos alimentares locais em um país que ainda existem desequilíbrios nutricionais marcantes. Objetivos: Descrever qualitativamente o $\mathrm{CM}$ de usuários dos Restaurantes Populares de um programa brasileiro de combate à fome, analisando ainda aspectos culturais, como o hábito de consumo de alimentos regionais e os marcadores de identidade alimentar do $\mathrm{CM}$. Materiais e Métodos: Trata-se de um estudo transversal com amostra constituída por 1.872 indivíduos frequentadores de 36 restaurantes vinculados ao Programa Restaurantes Populares. Para análise do consumo alimentar foi utilizado o recordatório de 24 horas por três dias, cujos dados foram analisados por sexo, faixa etária, faixa de renda per capita, escolaridade, profissão, estado civil, participação em programas de governo e nacionalidade. Para a análise qualitativa do $\mathrm{CM}$ foi adotado um método que classifica a refeição de acordo com a presença/ausência dos alimentos: CM Padrão como a presença de alimentos fontes de cálcio e de energia; CM Completo como a presença de alimentos fontes de cálcio, energia, minerais, vitaminas e fibras; CM Incompleto como quaisquer outros alimentos que não contemplem as combinações do CM padrão ou CM completo; e CM Ausente ou supressão como a ausência total de consumo de alimento. Foi considerada refeição regional aquela que apresentou consumo de pelo menos um alimento/preparação contido em uma lista de alimentos regionais predefinida. Para análise dos marcadores de identidade alimentar do CM foram formados grupos de bebidas, cereais ou substitutos ricos em carboidratos complexos, complementos de cereais, frutas, açúcar e adoçante. Ainda foram analisados os consumos de alimentos/preparações regionais como raízes e tubérculos, cuscuz, tapioca, queijos (Minas, Canastra, Colonial, Coalho e Manteiga), $\mathrm{mel} / \mathrm{melado}$ e geleias. Resultados: Das 5.616 refeições previstas para os três dias de consumo, 17,3\% não foram realizadas, sendo analisados $4.642 \mathrm{CM}$. O percentual de supressão do $\mathrm{CM}$ nessa pesquisa foi relativamente baixo, quando comparado a outros estudos realizados no Brasil e no mundo. O CM do tipo padrão foi predominante em todas as regiões, e o $\mathrm{CM}$ completo foi pouco consumido entre os 
participantes. Os indivíduos que realizaram CM nos Restaurantes Populares consumiram mais alimentos regionais, demonstrando que esses restaurantes estão contribuindo para o maior consumo de alimentos produzidos no local. A região com maior consumo de alimentos regionais foi a Centro-oeste $(46,6 \%)$ e a Sul $(45,9 \%)$, sendo os alimentos regionais mais consumidos em todas as regiões o presunto, 0 cuscuz e a laranja. Houve maior consumo de alimento regional no fim de semana, sendo que a maioria dos entrevistados consumia apenas um alimento regional por refeição. Os alimentos mais consumidos no CM foram o café com leite (ou leite com café), açúcar, pão, margarina, indicando que esses são os marcadores de identidade alimentar do CM na amostra estudada. Conclusão: Considerando que o percentual de CM do tipo padrão foi predominante e que o consumo de embutidos foi acentuado, são necessárias ações de estímulo ao consumo de frutas e de alimentos in natura em todas as refeições, sobretudo na primeira refeição do dia. Há necessidade de novas propostas de ações e de programas cuja finalidade seja a de ampliar o acesso a alimentos regionais saudáveis e adequados, principalmente às famílias de mais baixa renda.

Palavras - chave: café da manhã, desjejum, alimentos regionais, Restaurantes Populares 


\section{ABSTRACT}

With the lifestyle adopted in the modern world, the breakfast $(B)$ is the most neglected meal. The habits of consumption of regional food in the main meals, including the $B$, is unusual, and it may represent a low use of local food resources in a country that still exist striking nutritional imbalances. Objectives: To describe qualitatively the B customers of Popular Restaurants of a Brazilian program to combat hunger, analyzing even cultural aspects, such as the habits of consumption of regional foods and food identity markers of $B$. Materials and Methods: This is a cross-sectional study sample of 1,872 individuals customers of 36 restaurants linked to the Program Popular Restaurants. For analysis of food consumption we used the 24-hour recall for three days, and data were analyzed by gender, age, range of per capita income, education, profession, marital status, participation in governments programs. For the qualitative analysis of the B was adopted a method that classifies the meal according to the presence/absence of food: B Standard as the presence of food sources of calcium and energy; B Complete as the presence of food sources of calcium, energy, minerals, vitamins and fiber; B Incomplete as the any other foods that do not offer the Standard B combinations or complete B; Missing or deletion and $B$ and the total absence of food intake. It was considered that regional meal that showed consumption of at least one food/preparation contained in a predefined list of regional food. For analysis of the food identity markers of $B$ were formed beverage groups, cereals or substitutes rich in complex carbohydrates, cereal supplements, fruit, sugar and sweetener. Even the consumption was analyzed food/regional preparations as roots/tubers, couscous, tapioca, cheeses (Minas, Canastra, Colonial, Rennet and Butter), honey/molasses and marmalade. Results: Of the 5,616 meals planned for the three days of consumption, $17.3 \%$ were not performed and analyzed 4,642 B. The percentage of suppression of $B$ in this study was relatively low compared to other studies conducted in Brazil and in the world. The Standard B was prevalent in all regions, and the complete B was little consumed among the participants. Individuals who underwent B in Popular Restaurants consumed more regional foods, demonstrating that these restaurants are contributing to the increased consumption of food produced on local. The region with greater consumption of regional food was the Midwest (46.6\%) and South $(45.9 \%)$, and regional foods 
consumed in all regions were ham, couscous and orange. There was greater consumption of regional food at the weekend, with the majority of respondents consumed only one regional food per meal. The most consumed foods in B were the latte with coffee (or coffee with milk), sugar, bread, margarine, indicating that these are the $\mathrm{B}$ food identity markers in the sample. Conclusion: Considering that percentage of Standard B was prevalent and that consumption of embedded was pronounced, are necessary actions that encourage consumption of fruits and fresh food at every meal, especially in the first meal of the day. There is need for new proposals for actions and programs whose purpose is to increase access to healthy and appropriate regional food, especially to lower income families.

Keysword: breakfast, regional food, Popular Restaurants 
INTRODUÇÃO

O estilo de vida nas sociedades industrializadas tem promovido modificações desfavoráveis no comportamento alimentar (BOECK et al., 2012; CHAMBERS et al., 2008; CHOI; ZHAO, 2014; MACHADO; SIMÕES, 2008; PROENÇA, 2010; REJMAN; KASPERSKA, 2011). Uma das principais alterações diz respeito à desestruturação das refeições, sendo o café da manhã $(C M)$ a refeição mais prejudicada (NURUL-FADHILAH et al., 2013; FREITAS; MENDONÇA; LOPES, 2013; TRANCOSO; CAVALLI; PROENÇA, 2010).

Para Trancoso, Cavalli e Proença (2010), "o café da manhã ou desjejum é a primeira refeição consumida pela manhã”. Alguns autores (MACHADO; SIMÕES, 2008; MARANGONI et al., 2009) concordam que o seu consumo deve fornecer de 15 a 25\% da ingestão calórica diária. Travé (2013) cita uma definição mais completa ao comentar que o $\mathrm{CM}$ deve fornecer um quarto da necessidade calórica diária e deve incluir pelo menos três grupos básicos: lácteos, cereais e frutas.

O CM é importante para a manutenção adequada do consumo de nutrientes e da saúde e tem sido associado à ingestão da maioria das vitaminas, minerais (SHAFIEE et al., 2013) e fibras e menor ingestão de gorduras e colesterol (HOLMES et al., 2012; MIN et al., 2011). Seu consumo regular relaciona-se com benefícios importantes para a saúde, tais como melhor controle do peso corporal; redução do risco de síndrome metabólica; melhor funcionamento do sistema gastrintestinal; melhor saúde mental; melhor rendimento escolar e no trabalho (BETTS et al., 2011; CHAPLIN; SMITH, 2011).

Em se considerando a grande abrangência do território brasileiro e a enorme diversidade de alimentos disponíveis, principalmente de frutas e hortaliças, em todas as regiões brasileiras, pressupõe-se que a qualidade alimentar das refeições, sobretudo do $\mathrm{CM}$, possa ser expressivamente melhorada com a utilização de alimentos de produção local, também conhecido como regionais ou tradicionais. Os estudos e os inquéritos populacionais (BRASIL, 2004; BRASIL, 2010a) não têm focalizado de maneira mais específica o consumo de alimentos regionais, com exceção dos que compõem a cesta básica brasileira (VEREECKEN et al., 2009). 
Sendo assim, o conhecimento do atual consumo de alimentos/preparações regionais no Brasil ainda é inexistente.

A cultura alimentar brasileira é caracterizada por uma grande miscigenação cultural, resultante das múltiplas influências do processo de colonização (ELOY; REIS, 2012; GARCIA, 2003). Dessa forma, o Brasil não tem uma única cultura alimentar, mas culturas alimentares diversas em cada uma das regiões e até mesmo dentro da mesma região, com pratos típicos que são reconhecidos como marcadores de identidade alimentar (CHEMIN, 2007). O denominador comum encontrado para as grandes refeições no Brasil, como o almoço e o jantar, em todo o país e em todas as classes sociais é o arroz com feijão (CHEMIN, 2007; MACIEL, 2004), mas não há estudos fazendo referência aos marcadores de identidade alimentar do CM.

O Programa Restaurantes Populares (RP) foi instituído em 2003 com a função de ampliar a oferta de refeições saudáveis a preços acessíveis, reduzindo o número de pessoas em situação de insegurança alimentar e vulnerabilidade nutricional (MACHADO et al., 2014). Amostras constituídas com frequentadores de RP podem ser bastante expressivas na reformulação de ações do Governo Federal, em virtude de eles possuírem ampla distribuição de unidades no território nacional e pelo fato de que os indivíduos que os frequentam serem os de maior vulnerabilidade social. Assim, estudar o consumo alimentar dos usuários dos RP permite 0 conhecimento do perfil alimentar regionalizado e proporciona a reflexão de novas ações governamentais no que concerne ao acesso aos alimentos e ao fortalecimento da agricultura familiar e até mesmo na geração de renda.

Este artigo objetiva descrever qualitativamente o $\mathrm{CM}$ de usuários dos Restaurantes Populares do Programa Fome Zero, do Ministério de Desenvolvimento Social e Combate à Fome (MDS), analisando ainda aspectos culturais, como o hábito de consumo de alimentos regionais e os marcadores de identidade alimentar do CM.

\section{MATERIAIS E MÉTODOS}

Este estudo é do tipo exploratório de delineamento transversal, pois compreende a análise e a descrição dos dados coletados no período entre maio de 2010 e junho de 2011, referentes ao CM dos usuários de Restaurantes Populares, 
programa vinculado ao Ministério de Desenvolvimento Social e Combate à FomeMDS. Esta pesquisa foi aprovada pelo Comitê de Ética e Pesquisa da Faculdade de Saúde da Universidade de Brasília ( $n^{\circ}$ 0372/10).

Cada restaurante participante recebeu uma carta que correspondeu a um termo de consentimento da instituição, que foi assinado pelo Responsável Técnico da Unidade de Alimentação e Nutrição (UAN). Os participantes da pesquisa receberam uma carta de apresentação do estudo e o Termo de Consentimento Livre e Esclarecido para a devida assinatura.

Para o presente trabalho, foi considerado como unidade amostral o indivíduo frequentador dos Restaurantes Populares na refeição almoço, tendo em vista que nem todas as unidades de restaurantes ofereciam CM. Para a determinação da amostra final, foram considerados os 65 restaurantes vinculados ao Programa Restaurantes Populares do MDS, distribuídos proporcionalmente nas cinco regiões geográficas do país.

Dessa forma, para os participantes, calculou-se uma amostra aleatória simples, com base no total de usuários do Programa Restaurantes Populares no país (55.350). Com o objetivo de garantir a proporcionalidade de usuários para cada região, o levantamento foi feito em pelo menos $20 \%$ dos Restaurantes Populares de cada região, excetuando-se a Região Centro-oeste, onde foi realizado em apenas um restaurante, correspondendo a $25 \%$ da amostra regional. Devido a esse aspecto, ficou caracterizado o comprometimento do erro amostral (erro estimado em 15\%); assim sendo, os dados da região Centro-oeste serão apresentados, mas é necessário acentuar que qualquer generalização dos resultados para o Centrooeste, pode não ser indicada.

A amostra dos usuários foi calculada conforme Datallo (2008), obtendo-se um tamanho de amostra mínima de 41 usuários por restaurante (36 unidades), ou seja, pelo menos 1.476 usuários no total. A amostra selecionada em cada RP foi de 80 indivíduos, valor superior ao mínimo calculado, pois, como os mesmos indivíduos foram acompanhados durante os três dias consecutivos (domingo, segunda e terçafeira), considerou-se uma margem de segurança durante o processo de coleta para possíveis perdas. A amostra final desse estudo constituiu-se de 1.872 indivíduos usuários de 36 restaurantes, com 52 indivíduos em média por restaurante vinculado ao Programa Restaurantes Populares do MDS no ano de 2010, cujo tamanho da 
amostra final foi obtido com base em parâmetros estatísticos com nível de significância (a) de 5\% e poder de teste de 80\% (COHEN, 1962).

A distribuição das unidades de Restaurantes Populares selecionadas contemplou as cinco regiões geográficas brasileiras e ficou da seguinte forma: Norte, com quatro unidades; Nordeste, com dez unidades; Centro-oeste, com uma unidade; Sudeste com 15 unidades e Sul com seis unidades. Foram excluídos da pesquisa os indivíduos que não completaram o protocolo (realizar o almoço no Restaurante Popular), as gestantes e os menores de 18 anos. A maioria dos entrevistados fazia o CM em casa, excetuando-se os de seis unidades do Sudeste e uma do Nordeste, cujas unidades de Restaurantes Populares ofereciam durante a semana o CM com cardápios elaborados por nutricionistas.

A seleção da amostra de indivíduos em cada unidade foi realizada de forma sistemática na fila de espera para entrada no Restaurante Popular, selecionando a partir do primeiro indivíduo da fila, o 15으, e assim sucessivamente a cada 15 indivíduos. Caso não aceitassem participar seriam substituídos na própria

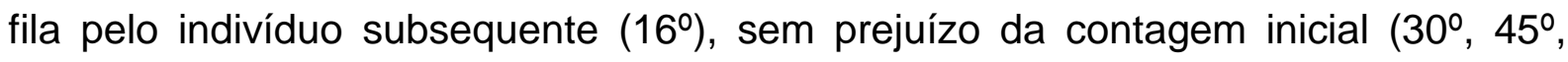
etc).

Os dados sociodemográficos coletados foram sexo, faixa etária, escolaridade, faixa de renda per capita, estado civil, atividade profissional, naturalidade e participação em programa de governo.

Os dados analisados foram extraídos dos recordatórios de 24 horas de três dias, aplicados com cada um dos usuários que aceitaram participar. Para detecção da diferença de consumo alimentar entre os dias da semana, foram aplicados recordatórios no domingo, em que todos os participantes realizaram a refeição fora do Restaurante Popular, e também na segunda e terça-feira. As informações de consumo registradas nos recordatórios foram relatadas pelos participantes da pesquisa e anotadas em formulário próprio por membros da equipe de pesquisa devidamente treinados.

A definição de $\mathrm{CM}$ foi construída a partir da análise preliminar dos próprios questionários contendo o relato de consumo diário de alimentos de cada participante. Assim, a refeição $\mathrm{CM}$ ficou sendo definida como a primeira refeição do dia realizada a partir das quatro horas da manhã, podendo ser um único alimento/preparação ou vários alimentos/preparações, exceto água, consumidos até as $11 \mathrm{~h} 30 \mathrm{~min}$ da manhã. Esse ponto de corte no horário foi estabelecido também em 
virtude da análise preliminar dos questionários, em que a primeira refeição de alguns participantes aconteceu até as $11 \mathrm{~h} 30 \mathrm{~min}$, com posterior consumo de refeição característica de almoço e em virtude de a maioria dos restaurantes iniciarem a distribuição do almoço a partir das 11h30min.

Por se tratar de um estudo sobre hábitos alimentares regionais brasileiros e tendo em vista os hábitos característicos de algumas regiões em consumir no $\mathrm{CM}$ preparações mais elaboradas, características da refeição almoço, tais refeições também foram consideradas CM desde que esta fosse a primeira refeição do dia. Se a primeira refeição do dia foi o almoço do RP, esta não foi considerada como CM.

A informação do local de realização do CM foi obtida pela análise dos questionários contendo o registro de consumo diário de alimentos, uma vez que os entrevistadores foram treinados para registrar o local de realização de cada refeição. Esse procedimento possibilitou a realização da análise comparativa entre o consumo de alimentos regionais no CM realizado em casa e o $\mathrm{CM}$ realizado nas sete unidades de RP que ofereciam essa refeição, levando-se em consideração apenas o consumo de alimentos regionais na segunda e terça-feira, pois aos domingos não havia funcionamento dos Restaurantes Populares. Da mesma forma foi avaliada a diferença de consumo do número de alimentos regionais entre domingo e os dias de meio de semana, assim como os quatros principais alimentos regionais consumidos em cada região.

Foi considerada refeição regional aquela que apresentou consumo de pelo menos um alimento/preparação (independente da região de consumo) contido na Lista de Alimentos Regionais do CM (APÊNDICE D). Essa lista foi elaborada a partir de Ginani (2011), adaptada para o CM, acrescida de outras publicações da área de alimentos (ABRIL COLEÇÕES, 2012; ARAÚJO et al., 2005; BRASIL, 2002a; CHAVES et al., 2009; FISBERG, WEHBA, COZZOLINO, 2002; PHILIPPI, 2006; WIKIPÉDIA, 2013). Como a lista criada por Ginani (2011) refere-se somente à refeição almoço, foi necessária a busca em novas referências para a seleção de alimentos regionais que poderiam ser consumidos nas refeições CM de todas as regiões brasileiras. No exame preliminar dos recordatórios, foram encontrados alguns nomes de alimentos não citados nas referências expostas acima, o que acarretou uma busca também no Wikipédia, no intuito de identificar a sinonímia ou a caracterização de tais alimentos desconhecidos. 
É importante acentuar que, na construção da presente Lista de Alimentos Regionais do CM, foi consultado apenas o livro "Alimentos Regionais Brasileiros", do Ministério da Saúde, publicado em 2002, pois a nova versão de 2015 ainda não tinha sido publicada.

Vale ressaltar que os alimentos chá e presunto, embora não sejam originários do Brasil, foram incorporados aos hábitos alimentares brasileiros na época da colonização e constam como alimentos característicos de algumas regiões brasileiras nas referências bibliográficas supracitadas. Em tais referências o chá apareceu como de consumo regional nas regiões Centro-oeste e Sul, e o presunto, na região Sul.

O Chimarrão, bebida quente tradicional da região Sul, não foi considerado como chá, pois esse possui formas de consumo diferenciadas. O consumo de chimarrão possui um caráter cultural definido, pois normalmente é consumido em momentos de reuniões com parentes e amigos (OLIVEIRA et al., 2011), não sendo consumido como bebida do CM.

Foram consideradas de consumo nacional as frutas banana e mamão. Somente foram consideradas regionais as bananas-da-terra (também conhecida como banana comprida) e marmelo; as demais, como a banana prata, banana pacovã, banana maçã e banana d'água (banana nanica ou caturra) foram consideradas de consumo nacional.

A verificação da composição alimentar proposta neste estudo foi realizada pela classificação do $\mathrm{CM}$ em quatro configurações diferentes: $\mathrm{CM}$ completo, $\mathrm{CM}$ padrão, CM incompleto e supressão. Nessas configurações, considerou-se apenas presença/ausência dos alimentos na refeição, à semelhança do proposto por Alves e Boog (2007) descrita a seguir. Foi construída para tanto uma escala Likert (LEE et al., 2002) de quatro pontos variando de 0 até 3, cumprindo os seguintes critérios: 0 CM completo, como a refeição com a presença de fonte de cálcio, de energia e de alimentos fontes de minerais, vitaminas e fibras, recebeu nota 3; O CM padrão, como a refeição com a presença de fonte de cálcio e de energia, recebeu nota 2; o CM incompleto, como qualquer outra combinação de alimentos não apresentadas no CM completo ou CM padrão, foi representado pela nota 1, e a supressão, como a falta de consumo alimentar no $\mathrm{CM}$, obteve nota 0 .

Em tal configuração, foram considerados fontes de cálcio o leite e seus derivados (iogurte, queijos, requeijão, leite condensado e doce de leite); fonte de 
minerais e vitaminas, as frutas, e como fonte de energia foram computados os pães, os biscoitos, as bolachas, as farinhas, os bolos e outros produtos de panificação com ou sem acompanhamentos como geleias, mel, margarinas, manteiga, maionese, requeijão, queijos e frios.

A informação do local de realização do CM foi obtida pela análise dos questionários contendo o registro de consumo diário de alimentos, uma vez que os entrevistadores foram treinados para registrar o local de realização de cada refeição. Esse procedimento possibilitou a realização da análise comparativa da classificação qualitativa entre o $\mathrm{CM}$ realizado em casa e o CM realizado no Restaurante Popular, quanto as diferenças de configurações de CM completo, padrão, incompleto e supressão.

Para a análise dos marcadores de identidade alimentar do CM foram considerados outros grupos de alimentos que constituiu-se em alimentos/preparações comumente consumidos no CM, como: café puro, leite puro, café com leite (ou leite com café), leite com achocolatado, chá, cevada, refresco industrial, refrigerante, pães, bolos e biscoitos, manteiga, margarina, queijo Prato/Mussarela, maionese, embutidos, frutas, açúcar e adoçante. O grupo dos bolos e biscoitos incluiu os demais produtos de panificação como bolachas, croissant, roscas, broas, biscoitos caseiros, brioches, etc. Foram computados todos os alimentos e preparações consumidos independente de serem considerados saudáveis.

Por se tratar de um estudo sobre o consumo de alimentos regionais brasileiros, foram também registrados os grupos das raízes e tubérculos (mandioca, batata doce, inhame, cará), o cuscuz (de milho e de arroz), a tapioca, os queijos (Minas, Canastra, Colonial, Coalho e Manteiga), o mel/melado e as geleias (de frutas, de amendoim, abóbora, doce de leite em pasta).

$\mathrm{Na}$ análise dos recordatórios, foram realizadas algumas padronizações para melhor homogeinização no cômputo de frequência dos alimentos/preparações regionais, a saber: quando do registro de consumo de queijo sem especificação do tipo, foi considerado queijo do tipo Mussarela ou Prato; leite condensado cozido foi considerado como doce de leite; refresco artificial não foi considerado fonte de nenhum nutriente; banana cozida foi considerada como banana-da-terra; doce sem especificação do tipo foi considerado doce de frutas; guaraná somente foi considerado fruta quando escrito "guaraná natural"; o registro de "queijo fresco" foi 
considerado queijo do tipo Minas; registros de pratos com arroz, feijão, carne (exceto charque, jabá, carne de sol e seca), ovo e farinha de mandioca na mesma preparação foram considerados como "quebra torto", preparação típica da região Centro-oeste. Farinha de mandioca consumida sozinha foi considerada de consumo nacional.

Os recordatórios foram digitados no programa Dietwin® (REINSTEIN; REINSTEIN; ZINGANO, 2008), que foi o escolhido para análise dos resultados. Nos casos de alimentos/preparações não contidos no programa Dietwin®, como alguns pães regionais, foi solicitada a Ficha Técnica de Preparação (FTP) aos nutricionistas dos RP que ofereciam CM, e, no caso da inexistência da FTP, foram consultados sites de receitas na internet, selecionando-se três receitas, que foram posteriormente confrontadas para a escolha da receita para a elaboração da FTP, que foi testada no laboratório de Técnica Dietética da UnB para posterior inclusão no programa de análise (Dietwin®).

Os dados foram tabulados e analisados no programa Statistical Package for the Social Sciences (SPSS®), versão 20.0. Foram contabilizados o número de entrevistados e o número de recordatórios analisados, considerando-se as refeições realizadas por cada indivíduo. A frequência de alimentos/preparações regionais consumidos foi estabelecida por consumo individual, por unidade de restaurante e por região geográfica.

Os dados foram descritos em termos de frequências relativas e medidas resumo como a média e o desvio padrão. Para as análises de associação, o teste estatístico utilizado foi o qui-quadrado de Pearson. Os pressupostos da normalidade foram checados via teste de Shapiro-Wilk. Os testes estatísticos utilizados foram o qui-quadrado, o t de Student e Kruskal-Wallis para apurar a análise de variância, tendo Tukey como Post-hoc. O nível de significância adotado foi de 5\%.

\section{RESULTADOS E DISCUSSÃO}

Foram coletados três dias de recordatório alimentar de 1.872 entrevistados. Dos 5.616 CM previstos, 974 (17,3\%) não foram consumidos (supressão), sendo analisado um total de 4.642 refeições CM. 
Com relação às características sociodemográficas, observou-se que a amostra foi predominantemente composta por homens $(59,1 \%, n=1.108)$ e por indivíduos na faixa etária entre 25 e 34 anos (19,9\%, n=374). A média de idade para os homens foi de 46 anos ( $\pm 17,6$ anos) e para as mulheres de 45 anos $( \pm 17,3$ anos). O nível de escolaridade mais frequente entre os entrevistados foi o ensino médio completo $(31,8 \%, n=597)$. A maior parte dos entrevistados $(61,9 \%, n=1.160)$ relatou trabalhar, sendo a atividade profissional mais frequente a de prestadores de serviço pessoais e à coletividade $(28,6 \%, n=537)$, ou seja, aqueles que trabalhavam na intermediação de vendas de bens e serviços. Com relação ao estado civil, observou-se um predomínio da união estável $(40,8 \%, n=765)$, sendo que a faixa média de renda per capita predominante foi a de 0,5 a um Salário Mínimo (SM) $(41,5 \%, n=777)$, e apenas $10,2 \%$ ( $n=191)$ participavam de algum tipo de programa de governo, além do Programa Restaurante Popular. A maior parte dos entrevistados residia no momento da pesquisa na região Sudeste $(40,8 \%, n=764)$, seguido da região Nordeste com 30,1\% ( $n=563)$. Contudo, a naturalidade mais frequente foi Minas Gerais $(15,1 \%, n=284)$, seguida de São Paulo $(10,3 \%, n=193)$. No total da amostra, existiam apenas oito estrangeiros.

Analisando os três dias de consumo de $\mathrm{CM}$, observou-se que houve diferença significativa entre as regiões geográficas (dia 1, p=0,068; dia 2, $p=0,000 \mathrm{e}$ dia $3, p=0,0536$ ). No segundo dia, os usuários dos Restaurantes Populares da região Norte consumiram mais $\mathrm{CM}$ que os da região Nordeste $(p=0,000)$, Sul $(p=0,000)$ e Sudeste $(p=0,020)$. A região Centro-oeste não foi significativamente diferente das demais em nenhum dos três dias considerados $(p=0,755)$.

$\mathrm{Na}$ tabela 1 é possível verificar a classificação qualitativa do $\mathrm{CM}$ dos participantes da pesquisa por região geográfica. Estes dados descrevem a frequência de indivíduos da amostra que não realizaram o $\mathrm{CM}$, assim como a frequência das demais configurações dessa refeição. $O$ teste qui-quadrado mostrou que houve diferença significativa no perfil de consumo para os três dias $(p=0,000)$. 
Tabela1. Distribuição da frequência da classificação qualitativa do café da manhã dos usuários de Restaurantes Populares por região geográfica do Brasil, 2010/2011.

\begin{tabular}{lccccc}
\hline \multicolumn{1}{c}{$\begin{array}{c}\text { Regiões } \\
\text { Geográficas }\end{array}$} & $\mathbf{N}$ & \multicolumn{4}{c}{ Classificação do CM } \\
\cline { 3 - 6 } & $\begin{array}{c}\text { Supressão } \\
\%\end{array}$ & $\begin{array}{c}\text { Incompleto } \\
\%\end{array}$ & $\begin{array}{c}\text { Padrão } \\
\%\end{array}$ & $\begin{array}{c}\text { Completo } \\
\%\end{array}$ \\
\hline Centro-oeste & 129 & 18,6 & 28,7 & 49,6 & 3,1 \\
Nordeste & 1.692 & 17,1 & 43,9 & 31,4 & 7,6 \\
Norte & 585 & 15,7 & 29,6 & 52,3 & 2,4 \\
Sudeste & 2.289 & 16,2 & 39,6 & 39,3 & 4,9 \\
Sul & 921 & 21,2 & 36,6 & 37,2 & 5,0 \\
Brasil & 5.616 & 17,3 & 35,6 & 41,9 & 4,6 \\
\hline p $<0,05$ & & & & &
\end{tabular}

Os dados da tabela 1 mostram que o percentual médio de supressão nacional ficou em 17,3\%, valor abaixo dos percentuais encontrados em outros estudos sobre o CM no Brasil e no mundo.

Uma pesquisa realizada com estudantes chineses de medicina, por exemplo, apresentou uma prevalência de supressão de CM que variou de 23,5 a 41,7\% (SUN et al., 2013). De 236 adolescentes estudados na Malásia, apenas 50\% consumiam a primeira refeição diária (NURUL-FADHILAH et al., 2013). Ratner et al. (2012) pesquisaram 6.823 estudantes universitários no Chile e encontraram um percentual de $47 \%$ de não realização do CM. Já no Egito, dos 891 adolescentes estudados, apenas 28\% faziam essa refeição (EL-GILANY; ELKHAWAGA, 2012). No Brasil, Costa e Vasconcelos (2013), em uma pesquisa com universitárias de Santa Catarina, encontraram um percentual de supressão do CM de 19,6\%, valor esse próximo ao encontrado na presente pesquisa.

Embora a supressão do $\mathrm{CM}$ seja mais comum em adolescentes de todo o mundo (TRANCOSO; CAVALLI; PROENÇA, 2010), é também bastante comum em pessoas adultas. Alves e Boog (2007) comprovaram essa afirmação ao pesquisar 100 estudantes paulistas com idades entre 19 e 39 anos, cujo percentual de supressão do CM foi de $30 \%$.

Medeiros et al. (2007) estudaram uma amostra de 600 adultos com o objetivo de identificar o estado nutricional e as práticas alimentares de trabalhadores acidentados no trabalho, na cidade de Piracicaba, SP. Entre as práticas alimentares 
rotineiras, observou-se que $24,16 \%$ dos participantes não realizavam o CM com frequência.

Um estudo recente realizado por Marchioni et al. (2015), cujo objetivo foi caracterizar os padrões de CM e verificar a prevalência e os fatores associados à omissão dessa refeição em 795 adolescentes paulistas, encontrou uma prevalência de omissão do CM de $38 \%$, sendo maior entre as meninas.

O declínio no consumo de $\mathrm{CM}$ vem sendo associado às mudanças no estilo de vida contemporâneo da população, tais como o aumento do número de indivíduos que moram sozinhos, a falta de tempo para realizar as refeições e particularidades no consumo de pratos diferentes pelos membros da família (TRANCOSO; CAVALLI; PROENÇA, 2010).

Há evidências de que a supressão do CM está associada aos baixos níveis de escolaridade (FREITAS; MENDONÇA; LOPES, 2013; SUN et al., 2013) e condição socioeconômica (HULSHOF et al., 2003; SUN et al., 2013). Entretanto, na presente pesquisa esse comportamento não foi confirmado em vitrtude de não terem sido encontrado diferenças significativas entre os usuários quando a renda e a escolaridade foram consideradas. Possivelmente esse comportamento das variáveis se deva à predominância de usuários de baixa renda e de baixa escolaridade, fato esperado por se tratar de beneficiários de programa de governo cujo objetivo é atender preferencialmente aqueles usuários. Esses resultados mostram que outros fatores diferentes do nível socioeconômico e de escolaridade estão influenciando o hábito de não realização do $\mathrm{CM}$ na amostra estudada.

De fato, Affinita et al. (2013) realizaram uma revisão bibliográfica com objetivo de analisar o CM sob uma abordagem multidisciplinar. Após a análise de estudos de diversas áreas do conhecimento, os autores consideraram que os motivos que levam as pessoas à não realização do $\mathrm{CM}$ são variados e transitam entre fatores como idade, gênero, profissão, tipo de trabalho, costumes culturais, incluindo-se a falta de apetite matinal e a tentativa de controle do peso corporal.

Dessa forma, observa-se que são muitas as variáveis que influenciam a supressão do CM, mas todas consideram o local, a cultura, e as características sociodemográficas em que o indivíduo está inserido (FREITAS; MENDONÇA; LOPES, 2013; HULSHOF et al., 2003; SUN et al., 2013). Assim, é necessária inclusive a consideração do nível de desenvolvimento econômico da região, que por sua vez é constituído por diferentes taxas de desenvolvimento tecnológico e 
diferentes níveis de desenvolvimento social, cultural e histórico (CASALI; SILVA; CARVALHO, 2010; PEDRAZA, 2004).

A análise inter-regional da presente pesquisa mostrou que o maior percentual de CM incompleto aconteceu na região Nordeste $(43,9 \%, n=743)$, apesar de essa região contar com uma unidade de Restaurante Popular com oferta de CM. O tipo de CM padrão foi muito consumido em todas as regiões, exceto na região Nordeste, apresentando predominância na região Norte $(52,3 \%, n=306)$ e Centrooeste $(49,6 \%, n=64)$. O consumo de CM completo foi baixo em todas as regiões, sendo que a maior frequência aconteceu na região Nordeste $(7,6 \%, n=129)$.

A predominância do $\mathrm{CM}$ padrão também foi demonstrada no estudo realizado por Alves e Boog (2007), que utilizaram os mesmos critérios de classificação do presente estudo. A pesquisa realizada por esses autores, com 100 estudantes universitários de Campinas-SP, demonstrou que 37\% deles realizavam CM padrão. Também Gambardella, Frutuoso e Franch (1999), utilizando a mesma forma de classificação, demonstraram que, de 153 adolescentes paulistas estudados, 45\% realizavam o CM padrão.

$O$ fato de as pesquisas realizadas por alguns autores (ALVES; BOOG, 2007; GAMBARDELLA; FRUTUOSO; FRENCH, 1999) serem constituídas por indivíduos adolescentes e apresentarem a mesma predominância de CM do tipo padrão encontrado na presente pesquisa (amostra de pessoas adultas) parece indicar que, de fato, os hábitos de consumo da infância e da adolescência tendem a se repetir na vida adulta, conforme defendem alguns autores (GRIEGER; COBIAC, 2012; LAZZERI et al., 2013; MARANGONI et al., 2009; SONG et al., 2006).

A análise da escala Likert (LEE et al., 2002) de quatros pontos criada para representar a classificação qualitativa do CM (0 a 0,99=supressão; 1 a 1,99 = CM incompleto; 2 a 2,99 = CM padrão; $3=\mathrm{CM}$ completo), mostrou que a média de consumo do CM realizado nos Restaurantes Populares foi de 1,39, mostrando o predomínio da refeição incompleta. Já a média de consumo do CM realizado em casa foi 1,28, indicando que a maioria dessas pessoas também realiza $\mathrm{CM}$ incompleto. Embora realizar CM no Restaurante Popular e em casa estejam na mesma classificação, esta comparação apresentou diferença significativa $(p=0,000)$, sendo que a refeição em casa apresentou menor consumo de CM incompleto.

O percentual de supressão entre os Restaurantes Populares que serviam o CM e os que não serviam o CM foi analisado nessa pesquisa. Tal análise mostrou 
que a supressão do CM entre os Restaurantes Populares que ofereciam o CM $(16,7 \%, n=182)$ e a supressão dos que não ofereciam a refeição $(17,5 \%, n=792)$ apresentou valores muito próximos, mostrando que servir a refeição nos restaurantes não influenciou na adesão ao hábito de realização do $\mathrm{CM}$.

O percentual de usuários que consumiram CM padrão foi bem próximo tanto nos RP que serviam quanto para aqueles que não serviam $\mathrm{CM}$. Em contrapartida, o percentual de realização de CM completo nas unidades de restaurantes que ofereciam a refeição $(7,4 \%, n=81)$ foi $66 \%$ maior que nas unidades que não ofereciam a refeição $(4,9 \%, n=222)$, mostrando que o acesso aos alimentos melhorou a qualidade da dieta, embora com consumos ainda muito baixos.

A tabela 2 descreve a análise comparativa das configurações do CM por sexo e dias da semana.

Tabela 2. Distribuição da frequência de classificação qualitativa do $\mathrm{CM}$ dos usuários de Restaurantes Populares por sexo e dia da semana, Brasil, 2010/2011.

\begin{tabular}{|c|c|c|c|c|c|}
\hline \multirow{3}{*}{$\begin{array}{c}\text { Configuração } \\
\text { do CM }\end{array}$} & \multirow{3}{*}{$\mathbf{n}$} & \multicolumn{4}{|c|}{ SEXO } \\
\hline & & \multicolumn{2}{|c|}{ Masculino $(n=1.109)$} & \multicolumn{2}{|c|}{ Feminino $(n=763)$} \\
\hline & & $\begin{array}{c}\text { Domingo } \\
(\%)\end{array}$ & $\begin{array}{c}2^{a} \text { e } 3^{a} \text { feira } \\
(\%)\end{array}$ & $\begin{array}{c}\text { Domingo } \\
(\%)\end{array}$ & $\begin{array}{c}2^{a} \text { e } 3^{a} \text { feira } \\
(\%)\end{array}$ \\
\hline Supressão & 974 & 14,1 & 21,2 & 10,7 & 17,4 \\
\hline Incompleto & 1.999 & 43,3 & 38,5 & 37,5 & 37,7 \\
\hline Padrão & 2.359 & 37,7 & 34,7 & 45,3 & 40,0 \\
\hline Completo & 258 & 5,0 & 5,6 & 6,4 & 4,9 \\
\hline Total & 5.616 & 100 & 100 & 100 & 100 \\
\hline
\end{tabular}

$\mathrm{Na}$ tabela 2, é possível observar que a supressão foi menor no fim de semana para ambos os sexos, indicando que, possivelmente, a falta de tempo própria dos dias do meio de semana afeta a possibilidade de realização do $\mathrm{CM}$, conforme argumentam alguns autores (CHO et al., 2003; LEVITSKY; PACANOWSKI, 2013). A tabela 2 também mostra que, independente dos dias da semana, as mulheres suprimem menos a refeição $\mathrm{CM}$, realizam mais $\mathrm{CM}$ padrão durante toda a semana e mais CM completo aos domingos (quando possui mais 
tempo) quando comparadas aos homens, demonstrando uma maior preocupação com a saúde (BERTOLINI; SIMONETTI, 2014; BORGES; SEIDL, 2012).

$\mathrm{O}$ modelo de classificação qualitativa do $\mathrm{CM}$ adotado no presente estudo permitiu agrupar os indivíduos segundo critérios adaptados do modelo usado por outros autores (ALVES, BOOG, 2007; GAMBARDELLA, FRUTUOSO, FRANCH, 1999), mas possue algumas limitações que merecem ser comentadas. O modelo considera como fonte de cálcio apenas os leites e derivados, e desconsideram outras fontes alimentares desse nutriente; o percentual de CM completo poderia ser maior se outras fontes de proteínas forem consideradas; combinações de alimentos classificados como CM completo podem não representar uma refeição saudável, como por exemplo, o consumo na mesma refeição de bolo, doce de leite e banana, que ofertariam ao organismo uma grande quantidade de açúcar, interferindo na adequação dos macronutrientes principalmente.

Ao analisar por região o consumo de refeições dos três dias de consumo contendo alimento/preparação regional no $\mathrm{CM}$, verificou-se que as regiões Centrooeste e Sul apresentaram maior consumo. As regiões Norte e Sudeste apresentaram valores menores (Tabela 3), entretanto essa diferença entre as regiões não foi significativa $(p=0,919)$.

Tabela 3. Distribuição da frequência da supressão e do café da manhã regional, nos três dias de consumo dos usuários de Restaurantes Populares por região geográfica do Brasil, 2010/2011.

\begin{tabular}{lccccc}
\hline \multicolumn{1}{c}{$\begin{array}{c}\text { Regiões } \\
\text { Geográficas }\end{array}$} & $\mathbf{n}$ & \multicolumn{2}{c}{$\begin{array}{c}\text { Café da manhã } \\
\text { Analisado }\end{array}$} & \multicolumn{2}{c}{$\begin{array}{c}\text { Café da manhã } \\
\text { Regional }\end{array}$} \\
\cline { 3 - 6 } & & $\mathbf{n}$ & $\%$ & $\mathbf{N}$ & $\%$ \\
\hline Centro-oeste & 129 & 105 & 81,4 & 49 & 46,6 \\
Nordeste & 1.692 & 1.401 & 82,8 & 529 & 37,7 \\
Norte & 585 & 493 & 84,3 & 116 & 23,5 \\
Sudeste & 2.289 & 1.918 & 83,8 & 671 & 34,9 \\
Sul & 921 & 725 & 78,7 & 333 & 45,9 \\
Brasil & 5.616 & 4.642 & 82,7 & 1.698 & 37,8 \\
\hline
\end{tabular}


Em virtude dos resultados obtidos para os alimentos regionais, o número desses alimentos foi analisado em quartil (mediana=0,000). Os resultados mostraram que o consumo de alimentos regionais foi baixo em todas as regiões geográficas, pois apresentou consumo no terceiro quartil $\left(75^{\circ}\right)$ na maioria das regiões.

Algumas considerações podem ser feitas sobre os resultados encontrados neste estudo quanto ao consumo de alimentos regionais no CM. A região Centro-oeste, por exemplo, tem sido referenciada como região receptora de imigrantes das demais regiões do país, por isso apresenta a segunda maior taxa de urbanização do Brasil (BRASIL, 2012). O Distrito Federal-DF, por ser uma unidade federativa relativamente nova, tem sido responsável por atrair pessoas que migram para essa região em busca de melhoria na qualidade de vida, trazendo seus hábitos e costumes alimentares. Possivelmente, esse processo justifica o maior percentual de $\mathrm{CM}$ regional encontrado na região Centro-oeste no presente estudo. Possivelmente, o estar longe do seu local de nascimento faz com que as pessoas tentem compensar a distância consumindo alimentos que lhes lembrem do seu local de origem.

Culturalmente, a região Sul tem produtos e sabores diferentes das demais regiões brasileiras (BELUZZO, 2004), pois sofreu maior influência de diversos colonizadores europeus (ARAUJO et al., 2005), formando um grupo social e cultural específico no Brasil (CERDAN, 2009). O segundo maior percentual médio de CM regional encontrado no presente estudo pode estar indicando que essa é uma população conservadora de suas tradições, inclusive a alimentar. Ambos os processos identificados no Centro-oeste e no Sul podem ser analisados a partir do conceito de habitus proposto por Bourdieu.

Para Pierre Bourdieu, o gosto é socialmente formado. É a partir de um habitus, princípio gerador de práticas classificáveis (BOURDIEU, 1979), que o indivíduo escolhe práticas e situações cotidianas típicas que costumam estar associadas socialmente. Compreendendo o habitus como um conjunto de predisposições para fazer alguma coisa e não outra, a tendência é que indivíduos que compartilham determinado habitus façam escolhas semelhantes e tenham opiniões semelhantes em relação a gostos (SLOAN, 2005). 
Inevitável seria não comentar a baixa presença de consumo de alimentos regionais no CM da região Sudeste (Tabela 3). São Paulo, a cidade mais populosa e mais rica do país (SILVEIRA NETO; MENEZES, 2010), é considerado o ponto de encontro de várias gastronomias internacionais (portuguesa, italiana, libanesa, árabe e japonesa), e possivelmente por isso seus moradores consomem mais alimentos da gastronomia internacional que alimentos regionais brasileiros. Outra possível justificativa relaciona-se à falta de tempo em preparar pratos regionais logo no início do dia, diante de uma alternativa mais prática e rápida, como consumir o trivial café, leite, pão e manteiga/margarina.

O menor percentual de CM regional encontrado na região Norte $(23,5 \%$, $\mathrm{n}=116$ ) na presente pesquisa (Tabela 3 ) foi também confirmado no estudo conduzido por Chaves et al. (2009). A pesquisa que analisou a utilização de preparações regionais nos cardápios escolares do ensino público brasileiro destacou que, na região Sul do país, $86 \%$ dos cardápios contemplavam pelo menos uma preparação regional por semana, enquanto na região Norte, esse percentual caiu para 38\%.

A quantidade de $\mathrm{CM}$ regional encontrado na região Norte é uma contradição com as características de condições de vida da região, conforme afirmam Santos, Souza e Ferreira (2013). Os autores que pesquisaram os efeitos das transferências sociais e do mercado de trabalho na distribuição de renda nas regiões Sul e Norte do Brasil, no período de 1990 a 2009, comentam que, embora a região Norte tenha apresentado um declínio no nível de extrema pobreza, a população nortista ainda vive em condições precárias em muitas partes da região. Essa situação deveria impulsionar a população à produção de frutas e hortaliças de quintais, à criação de animais comestíveis de pequeno porte ou à busca de alimentos locais de baixo custo. Assim, as refeições, inclusive o CM, seriam melhoradas quanto ao aporte de nutrientes.

O resultado encontrado na presente pesquisa para a região Norte fica ainda mais surpreendente após se considerar que ela tem a menor frequência de consumo de alimentos fora do domicílio entre as regiões brasileiras (BEZERRA; SICHIERI, 2010). Além disso, a compra de alimentos ainda é a maior despesa para as famílias de baixa renda, principalmente no Norte e Nordeste do Brasil (COELHO; AGUIAR; EALES, 2010).

A maioria dos indivíduos participantes da presente pesquisa que consumiu alimentos regionais alimentou-se apenas de um alimento regional em uma 
mesma refeição. As frequências encontradas para o consumo de pelo menos um alimento regional, independentemente do tipo do alimento/preparação, foram $27,1 \%$ $(n=460), 22,3 \%(n=379)$ e $25,2 \%(n=428)$ para o primeiro, o segundo e o terceiro dias, respectivamente. Poucos participantes consumiram dois alimentos regionais em uma mesma refeição: 5,6\% ( $n=95), 3,6 \%(n=61), 4,1 \%(n=70)$ para os três dias, respectivamente. $\mathrm{O}$ consumo de três ou mais alimentos regionais na mesma refeição foi ainda menor nos três dias de consumo. Quando essa análise foi realizada por região, observou-se que o mesmo comportamento se repetiu.

A análise dos três dias de consumo de alimentos regionais mostrou que, para sexo, faixa etária e faixa de renda, não houve diferença significativa. Somente a escolaridade $\left(p=0,005, \quad x^{2}=20,334\right)$ mostrou significância. Os analfabetos consumiram um menor número de alimentos regionais quando comparados aos que têm nível superior incompleto.

Com a finalidade de verificar o consumo do número de alimentos regionais nos Restaurantes Populares, foi realizada uma comparação entre os Restaurantes Populares que ofereciam e os que não ofereciam CM. Essa análise levou em consideração apenas o consumo de alimentos regionais da segunda e terça-feira, pois não havia Restaurantes Populares oferecendo CM nos domingos. A análise nacional e a regional mostrou que há diferença significativa $(p=0,000)$ no consumo de alimentos regionais dos indivíduos que fizeram a refeição CM nos Restaurantes Populares quando comparados aos que fizeram a refeição em casa. Os que se alimentaram nos RPs consumiram mais alimentos regionais $(m=1,32$; $d p=0,52)$. Esse resultado demonstra que os Restaurantes Populares estão contribuindo para um maior incentivo ao consumo de alimentos regionais no Brasil.

Considerando que a nova versão do livro Alimentos Regionais do Ministério da Saúde (BRASIL, 2015) sugere que existem comidas regionais mais consumidas no fim de semana, como é o caso da feijoada servida no almoço, realizou-se uma análise comparativa do consumo de alimentos regionais entre domingo e os dois dias da semana (segunda e terça-feira). Tal análise mostrou que há diferença significativa $(p=0,000)$ no consumo de alimentos regionais entre 0 domingo e os dias úteis. O consumo de alimentos regionais foi maior no dia de domingo em todas as regiões do Brasil. Esse resultado é condizente com outros estudos realizados no Brasil (FERREIRA; PANINI; CORRENTE, 2014; LELIS; TEIXEIRA; SILVA, 2012). 
Em um estudo que objetivou investigar os hábitos alimentares de mulheres na cidade de Viçosa (MG), Lelis, Teixeira e Silva (2012) mostraram que $90,1 \%$ disseram que as refeições de final de semana eram diferentes das refeições de durante a semana. Entre as razões da diferença, estavam comer várias vezes ao dia, maior tempo de preparo das refeições, maior variedade de alimentos preparados, consumo de alimentos diferentes dos consumidos durante a semana e possibilidade de reunir a família (LELIS; TEIXEIRA; SILVA, 2012).

Dentre os trabalhos de consumo alimentar no Brasil, poucos abordam as diferenças alimentares quanto às características regionais. Tais estudos têm focalizado a quantidade de calorias ingeridas e sua associação com os fatores socioeconômicos, além de demonstrarem que a lista de produtos adquiridos pelos brasileiros vem apresentando mudança expressiva (CARVALHO, 2008). Os alimentos saudáveis têm sido substituídos por alimentos industrializados, em detrimento do consumo de alimentos regionais com produção local, como no caso das frutas e hortaliças (LEVY et al., 2012; SOUZA et al., 2013, VASCONCELOS, 2008).

Os quatro alimentos/preparações regionais de maior consumo nos três dias de pesquisa foram contabilizados por indivíduo, por unidade de Restaurante e por região geográfica.

$\mathrm{Na}$ região Centro-oeste, esses alimentos/preparações regionais foram 0 pão de queijo (16,3\%, $n=8)$, o pastel $(12,2 \%, n=6)$, o cuscuz $(10,2 \% n=5)$ e o presunto $(10,2 \%, n=5)$. Entre os alimentos regionais consumidos nessa região as frutas representaram $14,3 \%(n=7)$.

É interessante observar a situação de consumo do pão de queijo que, sendo regional da região Sudeste (ARAÚJO et al., 2005; FHILIPPI, 2006; FISBERG; WEHBA; COZZOLINO, 2002), apresenta maior consumo na região Centro-oeste $(16,3 \%, n=8)$. Esse dado ratifica os dados da Pesquisa de Orçamento Familiar - POF 2008-2009 (BRASIL, 2010a), onde a aquisição alimentar domiciliar per capita anual desse alimento é de $236 \mathrm{~g}$ na região Sudeste e de $488 \mathrm{~g}$ na região Centro-oeste. Esse dado se explica possivelmente pelo fato de o restaurante amostrado estar localizado na periferia de Brasília, onde a migração, como já citada, é acentuada.

Processo semelhante é observado no consumo do pastel, que, sendo originário do Sudeste, apresentou menor consumo na própria região de origem $(1,9 \%, n=13)$ em relação ao percentual de consumo de $12,2 \%(n=6)$ na região 
Centro-oeste. O consumo do pastel no $\mathrm{CM}$ da região Sudeste pode não ter sido tão frequente devido ao fato de ele não ser regularmente utilizado como alimento de CM. Por ser uma preparação muito vendida em feiras livres, é consumido também em outros horários diferentes da realização de CM.

Cabe um comentário especial ao comportamento do consumo de embutidos que, sendo originariamente da região Sul, apareceram como um dos alimentos/preparações mais consumidos em três das cinco regiões geográficas estudadas, demonstrando ser esse alimento cada vez mais consumido no CM do brasileiro. O alto consumo de embutidos em todas as regiões é preocupante, devido ao fato de serem alimentos ricos em sódio e gordura saturada, que por sua vez aumentam o risco de desenvolvimento de doenças cardiovasculares e de alguns tipos de câncer (ASSUNÇÃO et al., 2012; DUTTON; LAITNER; PERRI, 2014; JUNG et al., 2014).

A International Agency for Research on Cancer (IARC), instituição ligada à Organização Mundial de Saúde, publicou um relatório em 2015, em que coloca os embutidos e outras carnes processadas no mesmo grupo de carcinogênicos do tabaco, álcool, amianto e benzeno (SARACCI; WILD, 2015).

O cuscuz, conhecido tradicionalmente como pão de milho (LIMA, 2009), é uma preparação originária de todas as regiões brasileiras, com exceção da região Sul, mas só apresentou maior consumo nas regiões Centro-oeste $(10,2 \% n=5)$ e Nordeste $(27,9 \%, n=148)$. Possivelmente, isso se justifica pela falta de tempo das pessoas em preparar tal prato para o CM.

Além do cuscuz, também foram mais consumidos na região Nordeste 0 queijo coalho $(10,7 \%, n=57)$, a laranja $(6,6 \%, n=35)$ e o maracujá $(6,0 \%, n=32)$. Entre os alimentos regionais consumidos nessa região, as frutas representaram $43,8 \%(n=232)$, demonstrando que a população nordestina tem consumido um CM mais equilibrado, no que diz respeito às recomendações do Guia Alimentar para a População Brasileira (BRASIL, 2014), quanto ao maior consumo de vitaminas, sais minerais e fibras.

O queijo coalho é um produto elaborado a partir de leite cru, sendo um dos mais tradicionais queijos produzidos no Nordeste brasileiro. Tem sua origem ligada à fabricação artesanal em numerosas unidades de produção caseira e propriedades rurais de pequeno porte (MENESES et al., 2012; FREITAS et al., 2009). Segundo Almeida, Paiva Junior e Guerra (2010), o queijo coalho é uma 
representação legítima da tradição e da cultura do estado de Pernambuco, onde está sendo desenvolvido o processo de certificação desse queijo, visando a uma identidade própria, que irá diferenciá-lo dos demais queijos produzidos na região Nordeste.

A mandioca é um alimento muito presente na história da alimentação brasileira. É o ingrediente básico de diversas preparações brasileiras, dentre elas a tapioca, ou beiju, preparação regional mais consumida entre os entrevistados da região Norte $(19,8 \%, n=23)$ na presente pesquisa. Os outros três alimentos/preparações mais consumidos na região Norte foram o chá $(10,3 \%, n=12)$, o bolo de milho $(5,1 \%, n=6)$ e a banana-da-terra $(5,1 \%, n=6)$. Entre os alimentos regionais consumidos nessa região, as frutas representaram 42,2\% $(n=49)$, demonstrando que, embora a região Norte tenha apresentado o menor percentual de $\mathrm{CM}$ regional $(23,5 \%, \mathrm{n}=116)$, seu consumo de frutas é semelhante à região Nordeste $(43,8 \%, n=232)$.

Mesmo não sendo tradicional da região Norte, o chá foi consumido de forma frequente, apesar do clima quente característico da região. Possivelmente, a justificativa para esse alto consumo está nas consequências do processo migratório para o Norte do Brasil, estimulado pelo Governo Federal na década de 80 . As instituições públicas federais criaram na época um sistema orientado no sentido de assentar migrantes com "knowhow" agrícola, com pequenos capitais, oriundos principalmente de estados sulinos (MOURA; MOREIRA, 2001). Dessa forma, o hábito de consumo de chá foi migrado da região Sul para o Norte do Brasil.

A migração do consumo de chá para regiões diversas da sua origem pode também estar relacionada ao papel funcional assumido por esse alimento, por conferir inúmeros benefícios à saúde humana, principalmente o chá verde e o chá preto (LIMA et al., 2009; SENGER; SCHWANKE; GOTTLIEB, 2010).

$\mathrm{Na}$ região Centro-oeste, especificamente em Mato Grosso, os trabalhadores do campo realizam como primeira refeição do dia uma preparação denominada de quebra torto, acompanhada por algum tipo de chá quente. $\mathrm{O}$ hábito dessa refeição, que pode ser constituída de banana-da-terra cozida, mandioca cozida, cuscuz, pamonha e bolos diversos, pode ter influenciado na determinação desse alimento como regional do Centro-oeste (FISBERG; WEHBA; COZZOLINO, 2002). 
Os entrevistados da região Sudeste relataram consumir como alimento regional no CM principalmente o presunto $(8,8 \%, n=59)$, o queijo Minas $(8,8 \%$, $n=59)$, o chá $(7,1 \%, n=48)$ e a laranja $(6,2 \%, n=42)$. Entre os alimentos regionais consumidos nessa região, as frutas representaram 22,3\%, $(n=150)$.

Embora o queijo Minas, popularmente chamado de "queijo branco", seja muito utilizado em dietas para redução de calorias, parece não ser consumido de forma regular no CM dos usuários dos Restaurantes Populares brasileiros, sendo hábito marcante somente na sua região de origem (Sudeste). O baixo consumo de queijo Minas registrado nas demais regiões geográficas pode estar relacionado ao preço de mercado, uma vez que os queijos possuem o maior valor de mercado dentre os derivados do leite (FERNANDES; SANTOS, 2009), sendo a população estudada de baixa renda.

O presunto $(13,8 \%, n=46)$, a geleia de frutas $(12,6 \%, n=42)$, a mortadela $(9,6 \%, n=32)$ e o doce de leite $(8,4 \%, n=28)$ foram os alimentos regionais mais consumidos na região Sul. Os dados dessa pesquisa confirmam que a região Sul é a maior consumidora de embutidos entre as demais regiões brasileiras. Os valores encontrados para o consumo de presunto nesta pesquisa são corroborados pela POF 2008-2009, onde a prevalência de consumo para esse alimento na região Sul é de 7,4 \%, na região Centro-oeste de 4,4\% e no Sudeste de 4,2\% (BRASIL, 2010a). Entre os alimentos regionais consumidos na região Sul, as frutas representaram $16,8 \%,(n=56)$.

Um estudo realizado no Rio Grande do Sul por Assunção et al. (2012) demonstrou que, dos 4.325 adolescentes pesquisados, 48,5\% consumiam embutidos por mais de quatro vezes por semana, e que esse hábito é maior entre os adolescentes de melhor nível socioeconômico e filhos de mãe com maior escolaridade, supostamente devido ao fato de os embutidos quase sempre apresentarem preços elevados em relação a outros complementos do CM.

Cristofoletti et al. (2013) realizaram uma pesquisa com 772 nipobrasileiros, residentes em São Paulo, e concluíram que a ingestão elevada de alimentos embutidos associou-se à ocorrência de obesidade generalizada com adiposidade abdominal em homens, mas não em mulheres. As mulheres possuem maior interesse por questões relacionadas à alimentação saudável, ao consumo de alimentos com baixo conteúdo calórico e cuidados com a saúde e com o corpo, o 
que acaba por influenciar mais seus hábitos e seu estilo de vida (MUNIZ et al., 2012).

Como a região Sul foi a que mais recebeu influência dos imigrantes europeus, com seus históricos de guerra e sujeitos aos fatores climáticos, isso fez com que os sulistas desenvolvessem receitas como as geleias e os picles, para se adequarem aos períodos alternados de excesso e de escassez na produção de alimentos (SONATI; VILARTA; SILVA, 2009). A geléia de frutas (12,6\%, $n=42)$, conhecida regionalmente como chimia, foi o segundo alimento/preparação regional mais consumido na região Sul.

O Guia Alimentar para a População Brasileira (BRASIL, 2014) considera que alimentos e preparações culinárias, que resultam de modos de comer particulares, constituem parte importante da cultura de uma sociedade e estão fortemente relacionados com a identidade e o sentimento de pertencimento social das pessoas. Hofelmann e Momm (2014) corroboram com esta afirmação ao referirem que os alimentos que compõem o CM também variam de acordo com a cultura, a exemplo do que ocorrem nas demais refeições. Essas afirmativas são confirmadas pelos achados do presente estudo, que encontrou diferença significativa entre as regiões geográficas no que se refere ao consumo, apesar da não interferência da variável renda per capita nesse quesito.

Para alguns autores, a composição alimentar mais frequente do CM no Brasil é café puro ou leite com café (ou café com leite), e pão acompanhado de manteiga ou margarina (ALVES; BOOG, 2007; FREITAS; MENDONÇA; LOPES, 2013; MONTEIRO; MENDONÇA, 2004; OLIVEIRA; HÉBAUD-MONY, 1998). Cabe notar que poucos estudos contabilizam a frequência que cada alimento é consumido na refeição, como no caso de café ou leite puros e/ou leite com café (ou café com leite). Além disso, há uma diferença nutricional substancial em alimentar-se com leite com café, café com leite ou café puro. Destaca-se que todos esses alimentos são passíveis de representar um marcador de identidade alimentar do CM brasileiro.

Para Counihan e Van Esterik (2008), a alimentação é um poderoso marcador de identidade cultural, pois a escolha dos alimentos representa um caminho para expressar preferências, identidades e significados culturais (SOBAL et al., 2006).

Segundo Maciel (2001), a comida pode marcar um território ou um lugar, servindo como marcador de identidade ligado a uma rede de significados associados 
a uma nação, território ou região. Sendo assim, o alimento/preparação marcador de identidade é um emblema unificador que representa o que é típico (MACIEL, 2004).

Para Hernandez (2005), os marcadores de identidade alimentar são as formas de alimentação, os produtos consumidos e as formas pelas quais são preparados, relacionando-se com a produção, os conhecimentos e as práticas culinárias inseridas em todo o contexto socioeconômico em que o grupo está inserido.

Os autores citados nos parágrafos anteriores (COUNIHAN; VAN ESTERIK, 2008; HERNANDEZ, 2005; MACIEL, 2004; SOBAL et al., 2006), não delimitam qual é o ponto de corte para se considerar um marcador de identidade. $\mathrm{Na}$ área de alimentação, esse ponto de corte pode ser definido pela frequência com que o alimento é consumido por um grupo.

Considerando a historiografia da alimentação brasileira, que apresenta a mandioca como cotidianamente consumida na primeira refeição do dia (CASCUDO, 2004; MACIEL, 2005), é possível inferir que ela possa ser citada como o primeiro marcador de identidade alimentar do CM brasileiro. Mas, como afirmam Affinita et al. (2013), essa refeição mudou ao longo do tempo, sendo largamente dependente da cultura e da disponibilidade de alimentos tradicionais em diferentes regiões. O Guia Alimentar para a População Brasileira ratifica esta informação ao considerar que a mandioca, a batata doce, o cará e o inhame são alimentos próprios de CM regional, não sendo atualmente consumidos pela grande maioria dos brasileiros (BRASIL, 2014).

A tabela 4 descreve a frequência de consumo dos alimentos presentes no $\mathrm{CM}$ dos participantes da pesquisa que foram agrupados da seguinte forma: bebidas, cereais ou substitutos ricos em carboidratos complexos, complemento dos cereais/substitutos, frutas, açúcar/adoçante. Houve diferença significativa pelo teste de Kruskal-wallis com Tukey como pos hoc nos três dias de consumo dos alimentos/preparações, entre as regiões geográficas, conforme pode ser observado na Tabela 4.

Alguns alimentos tiveram a média de consumo nacional muito baixa, portanto não foram apresentados na Tabela 4. São eles: chá $(1,5 \%)$, cevada $(0,4 \%)$, refresco $(1,9 \%)$, refrigerante $(0,6 \%)$, queijo Canastra $(0,2 \%)$, queijo Coalho $(0,9 \%)$, queijo Colonial $(0,1 \%)$, queijo Manteiga $(0,1 \%)$, maionese $(0,6 \%)$, mel/melado $(0,6 \%)$. 
Tabela 4. Distribuição da frequência dos principais alimentos consumidos no café da manhã dos usuários de Restaurantes Populares por região geográfica, 2010/2011.

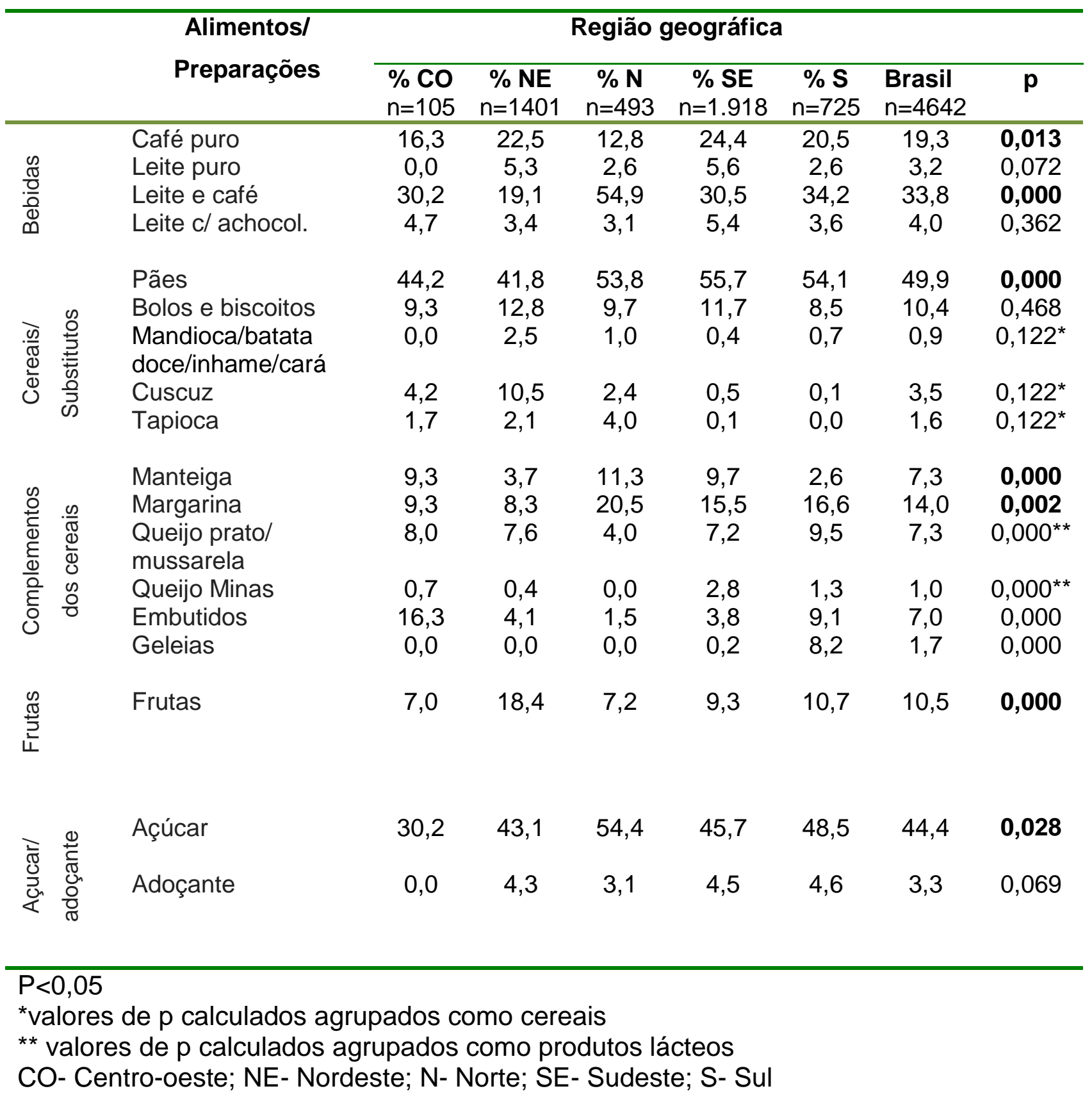

A significância estatística do consumo de alimentos/preparações contidos na tabela 4 foi analisada quanto à faixa de renda e quanto à escolaridade. Em relação à faixa de renda, houve diferença significativa apenas no consumo de embutidos e de bolos/biscoitos; quando comparados, os que percebem $\geq 2 \mathrm{SM}$ consomem significativamente diferente de quem ganha de até $1 / 4 \mathrm{SM}$ até quem 
ganha até $1 \mathrm{SM}(\mathrm{p}=0,041)$. Os usuários de maior faixa de renda ( $\geq 2 \mathrm{SM})$ consomem mais embutidos e bolos/biscoitos.

Em relação à escolaridade, houve diferença significativa no consumo de embutidos e de leite com achocolatado. Quando comparados, os frequentadores com Ensino Fundamental Completo (EFC) consumiram menos embutidos do que aqueles que declararam ter cursado o Ensino Médio Completo (EMC) ( $p=0,032)$.

Ainda quanto à escolaridade, os frequentadores referiram que o consumo do leite com achocolatado foi maior entre os que cursaram o EMC do que os que cursaram o Ensino Fundamental Incompleto $(p=0,004)$.

O consumo da mistura leite com café ou café com leite foi maior do que o café puro em todas as regiões geográficas, exceto na região Nordeste. A análise de significância estatística entre as regiões mostrou que houve diferença significativa do consumo de leite com café ou café com leite da região Norte em relação a todas as outras (todas com $\mathrm{p}=0,000)$ e Centro-oeste $(0,020)$; houve diferença significativa também da região Nordeste quando comparada ao Sul e ao Sudeste $(p=0,000)$. Em relação ao consumo de café puro houve diferença significativa somente do Norte em relação ao Sudeste $(p=0,005)$.

A combinação de leite com café teve origem na Alemanha (ORMOND; PAULA; FAVERET FILHO, 1999) e foi se espalhando pelo mundo à semelhança do consumo de café puro, que é atualmente uma das bebidas mais consumidas no mundo (ARRUDA et al., 2009). Apesar da ausência de recomendação nos guias nacionais quanto ao consumo de café, é comum a presença da combinação "leite com café" ou "café com leite" em particular no desjejum e no lanche da tarde de crianças, como sugere ANTUNES; SCHIERI; SALLES-COSTA (2010), e entre adolescentes, adultos e idosos conforme dados apresenados nesse trabalho.

A última versão do Guia Alimentar para a População Brasileira (BRASIL, 2014) apresentou exemplos de refeições CM realizadas por brasileiros das cinco regiões geográficas e de todas as classes de renda, de todas as faixas etárias e provenientes dos meios urbano e rural. Em todos os exemplos de refeições descritos pelo documento, o café com leite é presença constante na primeira refeição do dia. Vale ressaltar que essa mistura de café com leite considera a importância do valor proteico existente no leite e do valor cultural do café na alimentação brasileira, além do seu valor como estimulante. 
Alguns autores (FERRREIRA; MAGALHAES, 2011; GARCIA, 1997) acreditam que o café puro representa o $\mathrm{CM}$ de muitos brasileiros. Além de possíveis justificativas socioeconômicas para esse hábito alimentar na população brasileira, o café estabeleceu-se no Brasil e no mundo como um componente cultural muito forte, por fazer parte do cotidiano das pessoas, constituindo-se em um alimento insubstituível (ARRUDA et al., 2009).

De fato, em alguns estudos, o consumo de café puro é maior que o consumo de leite. Mattos e Martins (2000), por exemplo, realizaram uma pesquisa com o objetivo de estimar o consumo médio diário de fibras nas refeições de indivíduos adultos do Estado de São Paulo. Dos 559 participantes adultos, 87,5\% tomaram café, e apenas 51,3\% consumiram o leite na refeição CM. Cabe notar que, nesse caso, os usuários relataram o consumo de mais de uma bebida simultaneamente. Embora os autores não tenham especificado a frequência de consumo da mistura leite com café (ou café com leite) no $\mathrm{CM}$, ressaltam que boa parte da população brasileira adota um CM à base de café, nem sempre associado ao leite.

A problemática nesse tipo de análise é que poucos estudos pesquisam o consumo isolado de café puro e de leite com café (ou café com leite), a exemplo do que fizeram Conceição et al., (2010) em um estudo sobre consumo alimentar de escolares da rede privada e pública. Nessa pesquisa, a frequência de café puro, leite puro e café com leite foi calculada separadamente. Mas a maioria dos estudos contabiliza o consumo de café em uma categoria única, independente da forma de ingestão, se puro ou combinado com o leite, e sem considerar que a mistura leite com café é nutricionalmente diferente de café com leite.

A aceitação do café no Brasil é bem clara e pode ser observada no estudo realizado por Arruda et al., (2009). A pesquisa, que objetivou identificar os consumidores em 250 mineiros abaixo de 30 anos, mostrou que o leite $(31,0 \%$, $\mathrm{n}=250$ ) é o segundo na lista de substituição do café feita pelos entrevistados, perdendo apenas para o suco $(33,3 \%, n=250)$. O resultado desse estudo reforça a preocupação quanto à determinação e ao valor nutricional do CM dos brasileiros, que substituem alimentos importantes por outros de diferentes grupos alimentares de qualidade nutricional inferior (embutidos, refrigerantes, açúcar, adoçante), como é o caso da baixa predileção pelo leite no CM. 
Embora a mandioca ainda seja citada como substituto do pão em algumas regiões do país (SILVA, 2008), os dados do presente estudo mostram que, de fato, a mandioca deixou de ser o marcador de identidade alimentar entre os brasileiros, cedendo lugar ao pão, que apresentou maior consumo que as raízes e tubérculos, e as preparações cuscuz e tapioca, em todas as regiões na população frequentadora dos Restaurantes Populares.

A região que mais consumiu raízes e tubérculos foi o Nordeste $(2,5 \%$, $\mathrm{n}=35$ ); mesmo assim é um percentual muito baixo quando comparado ao pão (49,9\%, n=699). O consumo de cuscuz foi maior no Nordeste $(10,5 \%, n=147)$ quando comparado às demais regiões, e a tapioca foi mais consumida na região Norte $(4,3 \%, n=5)$.

Mesmo com maior consumo de cuscuz e tapioca no Nordeste e no Norte, respectivamente, o pão é, hoje, um dos marcadores de identidade alimentar mais importantes do CM, não só por sua frequência, mas também por sua amplitude.

Entre os complementos do pão (manteiga, margarina, maionese, mel/melado, queijos, embutidos, requeijão e geléias), a margarina foi a mais consumida, com diferença significativa da região Nordeste em relação ao Sul $(p=0,002)$, e o Sudeste em relação ao Sul $(p=0,017)$.

A manteiga apresentou diferença significativa no seu consumo no Sul em relação ao Nordeste $(p=0,009)$ e em relação ao Sudeste $(p=0,013)$.

Para alguns autores (LIMA, 2014; MACIEL, 2005), certas frutas possuem status de marcador cultural por serem amplamente consumidas, e são reconhecidas, juntamente com as hortaliças, o feijão e o peixe, como marcadores de um padrão saudável de alimentação (JAIME et al., 2015). Considerando que o Brasil é o terceiro maior produtor mundial de frutas, com uma produção de 40 milhões de toneladas ao ano (FACHINELLO et al., 2011), não deveria haver obstáculos para que as frutas representassem um marcador de identidade cultural no Brasil. Entretanto, o consumo de frutas e de sucos naturais foi semelhante ao de bolos e de biscoitos (10,5\%; 10,4\% respectivamente).

$\mathrm{Na}$ presente pesquisa, houve diferença significativa quanto ao consumo de frutas da região Nordeste com as regiões Norte $(p=0,000)$, Sul $(p=0,018)$ e Sudeste $(p=0,000)$. A região Nordeste consumiu quase o dobro das regiões Sudeste e Sul e mais do que duas vezes a quantidade consumida no Norte do país. 
O maior consumo de frutas no $\mathrm{CM}$ dos nordestinos na presente pesquisa foi um fato surpreendente, visto que vários estudos (LEVY et al., 2012; NEVES; KOIFMAN; MATTOS, 2006; SOUZA et al., 2013) descrevem o baixo consumo de frutas por essa população. Entretanto, é necessário ressaltar que tais pesquisas fazem referência ao consumo diário total, sem distinguir a refeição de consumo.

Para Faller e Fialho (2010), o maior consumo de frutas pelos nordestinos pode ser um indicativo de que, além do fator econômico, outras variáveis podem estar contribuindo para esse resultado, como o maior acesso a estabelecimentos fornecedores de frutas e de hortaliças nessa região. Para esses autores, até mesmo o tamanho da seção nos mercados destinada aos hortifrutigranjeiros, assim como a diversidade de produtos ofertados, influenciam na maior aquisição desses alimentos.

Por outro lado, a difusão de plantio irrigado tem sido muito intensa no nordeste do Brasil, o que elevou a produção de vegetais na região (COSTA et al., 2013). Este manejo, que propiciou o aumento da produtividade de frutas, deve estar também associado ao Programa de Aquisição de Alimentos (PAA), que tem as frutas como um dos principais produtos a serem produzidos e comercializados (LIMA; SAMPAIO; SILVA, 2011). Esse programa, criado em 2003 pelo Governo Federal, destinou mais da metade de seus recursos para a região Nordeste (51\%), entre os anos de 2003 a 2009, período este que antecedeu imediatamente a presente pesquisa (BRASIL, 2010a).

Para Leonardo (2009), as frutas e as hortaliças não representam a cultura alimentar brasileira, visto que o prazer alimentar no país está centrado na mistura de massas, gorduras, doces e carnes. Daí a necessidade da formação de um novo conceito alimentar, com a inserção de novos valores na cultura alimentar, para o estabelecimento de marcadores de identidade alimentar mais saudável.

Sichieri (2013) questiona qual seria o papel das políticas públicas no enfrentamento da inadequação da alimentação de grande parte da população. $O$ que fazer quando menos de $10 \%$ da população atinge as recomendações de consumo de frutas e hortaliças? Para Azevedo (2014), a alta prevalência de excesso de peso e o baixo consumo de frutas e de hortaliças pela população brasileira indicam a necessidade de intervenções, visando à implementação de estratégias de prevenção e de promoção da saúde, incentivando maior consumo de frutas e de hortaliças. Jaime et al., (2009) consideram que iniciativas de promoção do consumo de frutas e de hortaliças devem atender à população como um todo, principalmente 
aos estratos populacionais com baixa renda e escolaridade como é o caso da população deste estudo.

No momento em que as frutas representarem um marcador de identidade alimentar no CM dos brasileiros, visto ser essa refeição a mais comumente realizada em casa, onde as frutas estão mais disponíveis, será um indicativo de que a nação terá baixa prevalência de patologias relacionadas à alimentação, o que representa uma economia significativa em relação aos gastos destinados à promoção e à manutenção da saúde.

Com relação à utilização de açúcar ou adoçante na bebida do CM dos entrevistados desta pesquisa, o maior consumo ficou para o açúcar $(44,4 \%)$, e ele apresentou diferença significativa entre as regiões Norte e Nordeste $(p=0,031)$ e Centro-oeste $(p=0,047)$. A região Norte apresentou o maior consumo de açúcar (54,4\%, $n=195)$, já as regiões Nordeste $(43,1 \%, n=564)$ e Centro-oeste $(30,2 \%$, $n=43$ ) os dois menores consumos entre todas as regiões brasileiras.

A referência a esses dois últimos alimentos nas pesquisas brasileiras é bastante esquecida nas abordagens sobre o $\mathrm{CM}$, e isso sugere que os estudos que enfocam a primeira refeição do dia precisam ser mais detalhados, para que a precisão dos resultados seja garantida. Afinal, a utilização do açúcar e do adoçante dietético contribui no valor nutricional da dieta e pode constituir-se em hábito alimentar cultural, além de ter implicâncias nutricionais importantes.

A análise dos dados descritos na tabela 4 mostrou que os marcadores de identidade alimentar no CM da população estudada é o café com leite (ou leite com café), pão, margarina e açúcar. Os dados também mostram que é necessário incrementar ações de estímulo ao consumo de frutas e de alimentos in natura ou minimamente processados no $\mathrm{CM}$, como a mandioca, a batata doce, o cará e o inhame, ao ponto de eles serem considerados novos marcadores de identidade alimentar no país, o que representaria uma população mais saudável.

\section{CONCLUSÃO}

O percentual de supressão do CM nesta pesquisa foi relativamente baixo, sobretudo nos fins de semana, quando comparado a outros estudos realizados no 
Brasil e no mundo, sendo esse percentual menor no sexo feminino que no sexo masculino.

Os resultados mostraram um predomínio da refeição padrão em todas as regiões geográficas e um baixo percentual de realização de CM completo, o que aconteceu também nos Restaurantes Populares que ofereciam o CM.

O consumo de alimentos regionais na refeição CM mostrou-se baixo, sendo maior nas regiões Centro-oeste e Sul, e maior no fim de semana. Esse comportamento pode estar se repetindo nas demais refeições do dia, demonstrando que o aproveitamento dos recursos alimentícios locais está acontecendo de forma inexpressiva nas regiões brasileiras. Embora a região Centro-oeste tenha apresentado um dos maiores percentuais de consumo de alimentos regionais, é importante lembrar que os dados provenientes dessa região possuem limitações de inferências estatísticas devido ao tamanho limitado da amostra.

Os usuários que realizaram CM nos Restaurantes Populares consumiram mais alimentos regionais, demonstrando que esses restaurantes estão contribuindo para um maior consumo de alimentos regionais.

Tendo em vista o percentual de consumo dos alimentos/preparações regionais dos participantes da pesquisa, é possível considerar que os marcadores de identidade alimentar da refeição CM são o leite com café (ou café com leite), açúcar, e pão com margarina.

As frutas apresentaram baixo percentual de consumo, e os embutidos foram mais prevalentes entre os alimentos regionais. Das cinco regiões geográficas, três apresentaram o presunto como um dos principais alimentos regionais consumidos, demonstrando o maior consumo de produtos industrializados em detrimento dos in natura.

É necessário incrementar ações de estímulo ao consumo de frutas e de outros alimentos in natura no CM, como a mandioca, a batata doce, o cará e o inhame, ao ponto de eles representarem novos marcadores de identidade alimentar no país, o que formaria uma população mais saudável.

Ações de estímulo à realização do $\mathrm{CM}$ e ao consumo de alimentos regionais podem ser estratégias importantes para o cumprimento da Política Nacional de Segurança Alimentar e Nutricional. O consumo de alimentos cultivados na própria região, além de contribuir para a geração de empregos e para uma 
melhor distribuição de renda, reduziria custos e traria uma melhor qualidade nutricional aos alimentos consumidos pela população.

REFERÊNCIAS BIBLIOGRÁFICAS

ABRIL COLEÇÕES. Coleção Cozinha Regional Brasileira. São Paulo: Editora Abril, 2012.

AFFINITA, A. et al. Breakfast: a multidisciplinary approach. Italian Journal of

Pediatrics, v. 39, n. 1, p. 44, 2013. Disponível em:

<http://www.ijponline.net/content/39/1/44>. Acesso em: 17 nov. 2013.

ALMEIDA, S.L.; PAIVA JUNIOR, F.G.; GUERRA, J.R.F. A estratégia de internacionalização de negócios na perspectiva da tradução cultural: o caso da indicação geográfica no agronegócio. Revista Ibero-Americana de Estratégia RIAE, São Paulo, v. 9, n. 2, p. 75-98, mai./ago. 2010.

ALVES, H. J.; BOOG, M. C. F. Comportamento alimentar em moradia estudantil: um espaço para promoção da saúde. Revista de Saúde Pública, v. 41, n. 2, p.197-204, abr. 2007.

ANDRADE, S.S. Põe tapioca, põe farinha d'água? Gastronomia do açaí e identidade socioespacial e cultural ma grande Belém. 2014. 259 f. Tese (doutorado em Ciências) - Universidade Federal do Pará, Núcleo de Altos Estudos Amazônicos, Pará. 2014.

ANTUNES, M.M.L.; SICHIERI, R.; SALLES-COSTA, R. Consumo alimentar de crianças menores de três anos residentes em área de alta prevalência de insegurança alimentar domiciliar. Cadernos de Saúde Pública, Rio de Janeiro, v. 26, n. 8, p. 1642-1650, 2010.

ARAUJO, W.M.C. et al. Região Sudeste; Região Sul. In: Da alimentação à gastronomia. Brasília: Editora Universidade de Brasília, 2005. p. 55-65.

ARRUDA, A.C. et al. Justificativas e motivações do consumo e não consumo de café. Ciência e Tecnologia de Alimentos, Campinas, v. 29, n. 4, p. 754-763, 2009. ASSUNCAO, M. C. F. et al.Consumo de carnes por adolescentes do Sul do Brasil. Revista de Nutrição, Campinas, SP, v. 25, n.4, p. 463-472, 2012.

AZEVEDO, E.C.C. et al. Padrão alimentar de risco para as doenças crônicas não transmissíveis e sua associação com a gordura corporal - uma revisão sistemática.

Ciências \& Saúde Coletiva, v. 19, n. 5, p.1447-1458, 2014.

BELUZZO, R. A valorização da cozinha regional. In: 1'aCONGRESSO BRASILEIRO DE GASTRONOMIA E SEGURANÇA ALIMENTAR, 1., 2004,Brasília-DF. Anais ... Brasília: UnB, 2004.

BERTOLINI, D.N.P.; SIMONETTI, J.P. O gênero masculino e os cuidados de saúde: a experiência de homens de um centro de saúde. Escola Anna Nery Revista de Enfermagem, v. 18, n. 4, p. 722 - 727, 2014.

BETTS, J.A. et al. Bath Breakfast Project (BBP) - Examining the role of extended daily fasting in human energy balance and associated health outcomes: Study protocol for a randomised controlled. Trials, Oxford, v.12, n. 172, 2011. Disponível em: <http://www.trialsjournal.com/content/12/1/172>. Acesso em: 2 mar. 2012. 
BEZERRA, I.N.; SICHIERI, R. Características e gastos com alimentação fora do domicílio no Brasil. Revista de Saúde Pública, São Paulo, v. 44, n. 2, p. 221-229, 2010.

BOECK, S. et al. Gender and Race are significant determinants of students' food choices on a college campus. Journal of Nutrition Education and Behavior, Indianápolis, EUA, v. 44, n. 4, p. 372-8, 2012.

BORGES,L.M.; SEIDL, E.M.F. Percepções e comportamentos de cuidados com a saúde entre homens idosos. Psicologia: Ciência e Profissão, v. 32, n.1, p. 66 81, 2012.

BOURDIEU, P. O habitus e o espaço dos estilos de vida. In: A distinção: crítica social do julgamento. 2. ed. Rio Grande do Sul: Zouk, 1979, p.162-211. BRASIL. Ministério da Saúde. Secretaria de Atenção à Saúde. Departamento de Atenção Básica. Alimentos regionais brasileiros. 2. ed. Brasília: Ministério da Saúde, 2015.482 p.

BRASIL. Ministério da Saúde. Secretaria de Políticas de Saúde. Coordenação Geral da Política de Alimentação e Nutrição. Alimentos regionais brasileiros. 1. ed. Brasília: Ministério da Saúde, 2002. 140 p.

BRASIL. Ministério da Saúde. Secretaria de Atenção à Saúde. Departamento de Atenção Básica. Guia alimentar para a população brasileira, 2. ed., Brasília: Ministério da Saúde, 2014.156 p.

BRASIL. Ministério do Planejamento, Orçamento e Gestão. Instituto Brasileiro de Geografia e Estatística. Censo demográfico 2010: Nupcialidade, fecundidade, migração. 2010b. Disponível em:

<ftp://ftp.ibge.gov.br/Censos/Censo_Demografico_2010/Nupcialidade_Fecundidade_ Migracao/tab1_3.pdf>. Acesso em: 20 set. 2014.

BRASIL. Ministério do Planejamento, Orçamento e Gestão. Instituto Brasileiro de Geografia e Estatística. Pesquisa de orçamentos familiares 2002-2003: Análise da disponibilidade domiciliar de alimentos e do estado nutricional no Brasil. Rio de Janeiro. 2004. 266 p.

BRASIL. Ministério do Planejamento, Orçamento e Gestão. Instituto Brasileiro de Geografia e Estatística. Pesquisa de orçamentos familiares 2008-2009:

antropometria e estado nutricional de crianças, adolescentes e adultos no Brasil. Brasília. 2010a. 130 p.

BRASIL. Ministério do Planejamento, Orçamento e Gestão. Instituto Brasileiro de Geografia e Estatística. Síntese de indicadores sociais. Aspectos demográficos. Disponível em:

<http://www.ibge.gov.br/home/estatistica/populacao/condicaodevida/indicadoresmini mos/sinteseindicsociais2015/default_tab_xls.shtm>. Acesso em: 16 nov. 2013.

CARVALHO, M.S. Lugares e paladares: uma contribuição geográfica à diversidade do consumo alimentar no Brasil. Revista RA'E GA, Curitiba: editora UFPR, n. 15, p. 95-111, 2008.

CASALI, G. F. R.; SILVA, O. M.; CARVALHO, F. M. A. Sistema regional de inovação: estudo das regiões brasileiras. Revista de Economia Contemporânea, v. 14 , n. 3, p. 515-550. 2010.

CASCUDO, C. Instalação da cozinha portuguesa no Brasil. In: História da

Alimentação no Brasil. 3. ed. São Paulo: Global, 2004. p. 229-258.

CERDAN, C. Valorizaçâo dos produtos de origem e do patrimônio dos territórios rurais no sul do Brasil: contribuição para o desenvolvimento territorial sustentável. Política \&Sociedade, n.14, p. 277-299, abr. 2009. 
CHAMBERS, S. et al. The influence of age and gender on food choice: a focus group exploration. International Journal of Consumer Studies, v. 32, n. 4, p. 356-65, 2008.

CHAPLIN, K.; SMITH, A.P. Breakfast and snacks: associations with cognitive failures, minor injuries, accidents and stress. Nutrients, Switzerland, v. 3, p. 515528, 2011.

CHAVES, L.G. et al.The national school food program as a promoter of regional food habits. Revista de Nutrição, Campinas, São Paulo, v. 22, n. 6, p. 857-866, 2009.

CHEMIN, S.M. Padrões alimentares brasileiros: o respeito à diversidade culinária. In: MIRANDA, D.S.; CORNELLI,G. (org.). Cultura e Alimentação: saberes alimentares e sabores culturais. São Paulo: SESC, 2007. p. 159-164.

$\mathrm{CHOI}, \mathrm{J} . ; \mathrm{ZHAO}$, J. Consumers' behaviors when eating out: does eating out change consumers' intention to eat healthily? British Food Journal, v. 116, n. 3, p. 494-509, 2014.

COELHO, A.B.; AGUIAR, D.R.D.; EALES, J.S. Food Demand in Brazil: An Application of Shonkwiler\& Yen Two-Step Estimation Method. Estudos

Econômicos, São Paulo, v. 40, n. 1, p. 185-211, janeiro-março. 2010.

COHEN, J. The statistical power of abnormal-social psychological research: A review. Journal of Abnormal and Social Psychology, v. 65, p. 145-153, 1962. COSTA, L.C.F.; VASCONCELOS, F.A.G. Prevalence and factors associated with nutritional status among female university students in Florianópolis, SC. Revista

Brasileira de Cineantropometria \& Desempenho Humano, Florianópolis, v. 15, n. 3, p. 326-337, 2013.

COSTA, L.V. et al. Produtividade Agrícola e Segurança Alimentar dos Domicílios das Regiões Metropolitanas Brasileiras. RESR, Piracicaba, SP, v. 51, n. 4, p. 661-680, 2013.

COUNIHAN, C.; VAN ESTERIK, P. (Eds.). Food and culture: A reader (2nd ed.). London; New York: Routledge, 2008.

CRISTOFOLETTI, M. F. et al. Associação entre consumo de alimentos embutidos e obesidade em um estudo de base populacional de nipo-brasileiros. Arquivos

Brasileiro de Endocrinologia e Metabologia, v. 57, n. 6, p. 464-472, 2013.

DUTTON, G.R.; LAITNER, M.H.; PERRI, M.G. Lifestyle interventions for cardiovascular disease risk reduction: a systematic review of the effects of diet composition, food provision, and treatment modality on weight loss. Current

Atherosclerosis Reports, v. 16, n. 10, p.442, 2014.

EL-GILANY, A.H.; ELKHAWAGA, G. Socioeconomic determinants of eating pattern of adolescent students in Mansoura, Egypt. Pan African Medical Journal, v.13, n. 22, 2012.

ELOY, A.L.S.; REIS, R.R.V .A comida de rua como ferramenta na preservação dos alimentos tradicionais.In: SEMINÁRIO SOBRE ALIMENTOS E MANIFESTAÇÕES CULTURAIS TRADICIONAIS. GT01 - A Produção de Alimentos Tradicionais nos Territórios Rurais e Urbanos, 1., 2012, Sergipe. Anais eletrônicos... Sergipe: Universidade Federal de Sergipe, 2012. Disponível em:

$<$ http://www.grupam.net/anais-do-i-seminario-sobre-alimentos-emanifesta\%C3\%A7\%C3\%B5es-culturais-tradicionais/>. Acessoem: 10 out. 2014. FACHINELLO, J. C. et al. Situação e perspectivas da fruticultura de clima temperado no Brasil. Revista Brasileira de Fruticultura, v. 33, n. especial 1, p. 109-120, 2011. FALLER, A. L. K.; FIALHO, E. Disponibilidade de polifenóisem frutas e hortaliças consumidas no Brasil.Revista de Saúde Pública, v. 43, n. 2, p. 211-218, 2009. 
FERNANDES, R.A.S.; SANTOS, C.M. Evolução das margens de comercialização de leites e queijos no Estado de São Paulo no período de 2000 a 2008. Informações Econômicas, SP, v. 39, n. 8, p. 16-26, 2009.

FERREIRA, V. A.; MAGALHÃES, R. Práticas alimentares cotidianas de mulheres obesas moradoras da Favela da Rocinha (Rio de Janeiro, RJ, Brasil). Ciência \& Saúde Coletiva, Rio de Janeiro, v.16, n.6, p. 2983-299, 2011.

FERREIRA, P.M.; PANINI, S.J.; CORRENTE, J.E. Diversity of eating patterns in older adults: A new scenario?. Revista de Nutrição, Campinas, v. 27, n. 1, p. 67-79, 2014.

FIGUEIREDO, R.V. “Açaí passado: Abordagem transdisciplinar de caracterização da bebida açaí (Euterpe oleracea Mart.) post fermentação espontânea. 2014. $141 \mathrm{f}$. Dissertação (Mestrado em Ciências e Tecnologia de Alimentos) - Universidade Federal de Viçosa, 2014.

FISBERG, M.; WEHBA, J.; COZZOLINO, S. M. F. Um, dois, feijão com arroz: a alimentação no Brasil de Norte a Sul. São Paulo: Editora Atheneu, 2002. 418 p. FREITAS, M. F. L. et al. Detecção de genes toxigênicos em amostras de Staphylococcus spp. isoladas de queijos de coalho. Ciência e Tecnologia de Alimentos, v. 29, n. 2, p. 375-379, 2009.

FREITAS, P. P.; MENDONÇA, R. D.; LOPES, A. C. S. Factors associated with breakfasting in users of a public health service. Revista de Nutrição, Campinas, São Paulo, v. 26, n. 2, p. 195-203, mar./apr. 2013.

GAMBARDELLA, A.M.D.; FRUTUOSO, M.P.F.; FRANCHI, C. Prática alimentar de adolescentes. Revista de Nutrição, Campinas, v. 12, n. 1, p. 55-63, 1999.

GARCIA, R. W. D. Representações sociais da alimentação e saúde e suas repercussões no comportamento alimentar. Revista de Saúde Coletiva, Rio de Janeiro, v. 7, n. 2, p. 51-68,1997.

GARCIA, R. W. D. Reflexos da globalização na cultura alimentar: considerações sobre as mudanças na alimentação urbana. Revista de Nutrição, Campinas, São Paulo, v. 16, n. 4, p. 483-492, 2003.

GINANI, V.C. Avaliação da qualidade nutricional, sensorial e cultural de cardápios populares. 2011. 131 f. Tese (Doutorado em Nutrição Humana) Universidade de Brasília, Brasília - DF.

GRIEGER, J.A.; COBIAC, L. Comparison of dietary intakes according to breakfast choice in Australian boys. European Journal of Clinical Nutrition, v. 66, p. 667672, 2012.

GUIMARÃES, L.A.C. O açaí já "parou" o carioca? estudo qualitativo do consumo da polpa de açaí na cidade do Rio de Janeiro. Novos Cadernos NAEA, Pará, v. 2, n. 1, p. 95-112, 1999.

HERNANDEZ, J.C. Patrimônio e globalização: o caso das culturas alimentares. In: CANESQUI, A.M.; GARCIA, R.W.D. (Org). Antropologia e Nutrição: um diálogo possível. Rio de Janeiro: Editora FIOCRUZ, 2005, p.129-145.

HÖFELMANN, D. A.; MOMM, N. Breakfast: omission and associated factors in schoolchildren from Itajaí, Santa Catarina state, Brazil. Nutrire: Rev. Soc. Bras. Alim. Nutr. = J. Brazilian Soc. Food Nutr., São Paulo, v. 39, n. 1, p. 40-55, 2014.

HOLMES, B.A. et al. The contribution of breakfast cereals to thenutritional intake of the materially deprived UK population. European Journal of Clinical Nutrition, London, n. 66, p. 10-17, 2012.

HULSHOF, K.F.A.M. et al. Socio-economic status, dietary intake and 10 y trends: the Dutch National Food Consumption Survey. European Journal of Clinical Nutrition, London, n. 57, p.128-137, 2003. 
JAIME, P.C. et al. Fatores associados ao consumo de frutas e hortaliças no Brasil, 2006. Revista de Saúde Pública, v. 43, n. 2, p.57-64, 2009. Suplemento.

JAIME, P.C et al. Prevalência e distribuição sociodemográfica de marcadores de alimentação saudável, Pesquisa Nacional de Saúde, Brasil 2013. Epidemiologia e Serviços de Saúde, v. 24, n. 2, p. 267-276, 2015.

JUNG, S.J. et al. Beneficial effects of Korean traditional diets in hypertensive and type 2 diabetic patients. Journal of Medical Food, v. 17, n. 1, p. 161-171, 2014. LAZZERI, G. et al. Association between fruits and vegetables intake and frequency of breakfast and snacks consumption: a cross-sectional study. Nutrition Journal, Londres, v. 12, p.123, 2013. Disponível em:

<http://www.nutritionj.com/content/12/1/123>. Acesso em: 30 mar. 2014.

LEE, J.W. et al. Cultural differences in responses to a Likert Scale. Research in Nursing \& Health, v. 25, p. 295-306, 2002.

LELIS, C.T.; TEIXEIRA, K.M.D.; SILVA, N.M.S. A inserção feminina no mercado de trabalho e suas implicações para os hábitos alimentares da mulher e de sua família.

Saúde em Debate, Rio de Janeiro, v. 36, n. 95, p. 523-532, 2012.

LEONARDO, M. Antropologia da alimentação. Revista Antropos, Barcelona, v. 3, ano 2, p. 1-6, 2009. Disponível em:

$<$ http://revista.antropos.com.br/downloads/dez2009/Artigo\%201\%20-

\%20Anntropologia\%20da\%20Alimenta\%E7\%E30\%20-\%20Maria\%20Leonardo.pdf>.

Acesso em: 4 fev. 2015.

LEVY, R.B. et al. Distribuição regional e socioeconômica da disponibilidade domiciliar de alimentos no Brasil em 2008-2009. Revista de Saúde Pública, São Paulo, v. 46, n.1, p. 6-15, 2012.

LIMA, A.C.B. Flavors of the city: access to regional fruit and fruit consumption in the State of Acre, Brazil. Boletim do Museu Paraense Emílio Goeldi. Ciências Humanas, v. 9, n. 1, p. 79-92, 2014.

LIMA, A.E.F.; SAMPAIO, J.L.F.; SILVA, D.R. Políticas locais de segurança alimentar e agricultura familiar no maciço de Baturitè - CE- BRA. Revista Geográfica da

América Central, Costa Rica, n. especial, p. 1-13, 2011.

LIMA, C. Vocabulários. In: _ . Tachos e panelas: historiografia da alimentação brasileira. 3. ed. Recife: Raízes Brasileiras, 2009. cap. IX.

LIMA, J.D. et al. Chá: aspectos relacionados à qualidade e perspectivas. Ciência Rural, Santa Maria, v. 39, n. 4, 2009.

MACHADO, F.M.S.; SIMÕES, A.N. Análise custo-efetividade e índice de qualidade da refeição aplicados à Estratégia Global da OMS. Revista de Saúde Pública, São Paulo, v. 42, n. 1, p. 64-72, 2008.

MACHADO, I. E. et al. Fatores associados ao excesso de peso em adultos usuários de restaurantes populares em Belo Horizonte, Brasil. Ciências \& Saúde Coletiva,

Rio de Janeiro, v.19, n.5, p. 1367-1377, 2014.

MACIEL, M.E. Cultura e alimentação ou o que têm a ver os macaquinhos de Koshima com Brillat-Savarin? Horizontes Antropológicos, v. 7, n. 16, p. 145-46, 2001.

MACIEL, M.E. Identidade cultural e alimentação. In: CANESQUI, A.M.; GARCIA, R.W.D. (orgs). Antropologia e Nutrição: um diálogo possível. Rio de Janeiro: editora FIOCRUZ, 2005. p. 49-55.

MACIEL, M.E. Uma cozinha à brasileira. Estudos Históricos, n. 33, p. 25-29, 2004. MARANGONI, F. A. et al. Consensus document on the role of breakfast in the attainment and maintenance of health and wellness. Acta Biomedica, Italy, n. 80, p. 166-171, 2009. 
MARCHIONI, D.M.L. et al. Prevalência de omissão do café da manhã e seus fatores associados em adolescentes de São Paulo: estudo ISA-Capital. Nutrire, São Paulo, v. 40, n. 1 , p. 10-20, 2015.

MATTOS, L.L.; MARTINS, I.S. Consumo de fibras alimentares em população adulta. Revista de Saúde Pública, São Paulo, v. 34, n. 1, p. 50-55, 2000.

MEDEIROS, M.A.T. et al. Estado nutricional e práticas alimentares de trabalhadores acidentados. Revista de Nutrição, Campinas, v. 20, n. 6, p. 589-602, 2007.

MENESES, R. B. et al.O comércio de queijo de coalho na orla de Salvador, Bahia: trabalho infantil e segurança de alimentos. Revista de Nutrição, Campinas, São Paulo, v. 25, n. 3, p. 381-392, 2012.

MIN, C. et al. Skipping breakfast is associated with diet quality and metabolic syndrome risk factors of adults. Nutrition Research and Practice, Korean,v. 5, n. 5, p. 455-463, 2011.

MONTEIRO, D.; MENDONÇA, M.M. Quintais na cidade: a experiência de moradores da periferia do Rio de Janeiro. Agriculturas, v. 1, n. 0, p. 29-31, 2004.

MORATOYA, E.E. et al. Mudanças no padrão de consumo alimentar no Brasil e no mundo. Revista de Política Agrícola, Brasília, v. 22, n. 1, p. 72-84, 2013.

MOURA, H.A.; MOREIRA, M.M. A População da Região Norte: processos de ocupação e de urbanização recentes. Parcerias estratégicas, n.b12, p. 214-238, 2001.

MUNIZ, L.C. et al. Fatores de risco comportamentais acumulados para doenças cardiovasculares no sul do Brasil. Revista de Saúde Pública, São Paulo, v. 46, n. 3, p. 534-42, 2012.

NEVES, F.J.; KOIFMAN, R.J.; MATTOS, I.E. Mortalidade por câncer de cólon e reto e consumo alimentar em capitais brasileiras selecionadas. Revista Brasileira de Epidemiologia, São Paulo, v. 9, n. 1, p. 112-20, 2006.

NURUL-FADHILAH, A. et al. Infrequent breakfast consumption is associated with higher body adiposity and abdominal obesity in Malaysian school-aged Adolescents.

PLoS One, v. 8, n. 3, e59297, march. 2013. Disponível em:

<http://www.ncbi.nlm.nih.gov/pmc/articles/PMC3592841/pdf/pone.0059297.pdf>. Acesso em: 04 set. 2013.

OLIVEIRA, A.K.M. et al. Ethnobotany and traditional medicine of the inhabitants of the Pantanal Negro sub-region and the raizeiros of Miranda and Aquidauna, Mato Grosso do Sul, Brazil. Brazilian Journal of Biology, v. 71, n. 1, p. 283-289, 2011. Suplemento.

OLIVEIRA, S.P.; THÉBAUD-MONY, A. Hábitos e práticas alimentares em três localidades da cidade de São Paulo (Brasil). Revista de Nutrição, v. 11, n.1, p. 3750, 1998.

ORMOND, J.G.P.; PAULA, S.R.L.; FAVERET FILHO, P. Café: (re)conquista dos mercados. BNDES Setorial, Rio de Janeiro, n. 10, p. 3-56, set. 1999.

PEDRAZA, D.F. Padrões Alimentares: da teoria à prática - o caso do Brasil. Mneme - Revista Virtual de Humanidades, n. 9, v. 3, jan./mar.2004. Disponível

em:<http://www.seol.com.br/mneme>. Acesso em: 16 nov. 2013.

PHILIPPI, S.T. Nutrição e Técnica Dietética. $2^{\underline{a}}$ edição. Editora Manole, 2006. p. 239-52.

PROENÇA, R.P.C. Alimentação e globalização: algumas reflexões. Ciência e Cultura, São Paulo, v. 62, n. 4, p. 43-47, 2010.

RATNER, R.G. et al. Calidad de la alimentación y estado nutricional em estudiantes universitarios de 11 regiones del Chile. Revista de Medicina Chilena, v. 140, n. 12, p. 1571-1579, dec. 2012. 
REJMAN, K.; KASPERSKA, A. Nutritional and health benefits as the determinants of food choice in Polish consumers. Perspectives in Public Health, v. 131, n. 6, p. 262-266, 2011.

SANTOS, H.M.; SOUZA, S.C.I.; FERREIRA, C.R. Distribuição de renda, trabalho e transferências de renda nas regiões sul e norte do Brasil. Revista Faz Ciência, v. 15, n. 1, p. 205-238, 2013. Disponível em:

<http://erevista.unioeste.br/index.php/fazciencia/article/view/8993>. Acesso em 1 set. 2015.

SARACCI,R.; WILD, C.P. Nutrition, Metabolism and cancer . In: Agency for Research on Cancer: the first 50 years, 1965-2015. World Health . International Organization, Lions,p. 160 - 179, 2015.

SENGER, A.E.V.; SCHWANKE, C.H.A.; GOTTLIEB, M.G.V. Chá verde

(Camelliasinensis) e suas propriedades funcionais nas doenças crônicas não transmissíveis. Scientia Medica, Porto Alegre, v. 20, n. 4, p. 292-300, 2010.

SHAFIEE, Gita et al. Associação de consumo de café da manhã com fatores de risco cardiometabólico. Jornal de Pediatria, Rio de Janeiro, v. 89, n. 6, p. 575-582, 2013.

SICHIERI, R. Consumo alimentar no Brasil e o desafio da alimentação saudável. Com Ciência. 2013, n.145, pp. 0-0. Disponível em:

<http://www.comciencia.br/comciencia/?section=8\&edicao=85\&id=1042>. Acesso em: 10 jan. 2015.

SILVA, H.A. Mandioca, a rainha do Brasil? Ascensão e queda da Manihot esculenta em São Paulo. 2008. 168f. Dissertação (Mestrado em História) Faculdade de Filosofia, Letras e Ciencias Humanas. Universidade de São Paulo. 2008.

SILVEIRA NETO, R.M.; MENEZES, T. A. Nível e evolução da desigualdade dos gastos familiares no Brasil: uma análise para as regiões metropolitanas no período 1996 a 2003. Estudos Econômicos, São Paulo, v. 40, n. 2, p. 341-372, 2010. SLOAN, D. Gastronomia, restaurantes e comportamento do consumidor. Tradução Sonia Bidutte. Barueri: Manole, 2005. Cap.1.

SOBAL, J. et al. A conceptual model of the food choice process over the life course. In: SHEPHERD, R., RAATS, M. (Eds.), The Psychology of Food Choice. CAB International, Oxfordshire, p. 1-18, 2006.

SONATI, J.G.; VILARTA, R.; SILVA, C.C. Influências culinárias e diversidade cultural da identidade brasileira: imigração, regionalização e suas comidas. In: MENDES, T.; VILARTA, R.; GUTIERREZ, G.L. (org). Qualidade de vida e cultura alimentar. Campinas: Ipês Editorial, p.137-147. 2009.

SONG, W.O. et al. Ready-to-eat breakfast cereal consumption enhances milk and calcium intake in the US population. Journal of the American Diet Association, Ohio, United States, v. 106, p.1783 - 1789, 2006.

SOUZA, A. M. et al. Alimentos mais consumidos no Brasil: Inquérito Nacional de Alimentação 2008-2009. Revista de Saúde Pública, v. 47, n. 1, p. 190-199, 2013. Suplemento.

SPSS® for Windows, Rev. 20.0. [programa de computador]. Chicago: SPSS Inc. 1 CD-ROM.

SUN, J. et al. Factors associated with skipping breakfast among Inner Mongolia Medical students in China. BMC Public Health, London,13:42, 2013. Disponível em: <http://www.biomedcentral.com/1471-2458/13/42>. Acesso em: 18 mar. 2014. 
TRANCOSO, S. C.; CAVALI, S. B.; PROENÇA, R. P.C. Café da manhã: caracterização, consumo e importância para a saúde. Revista de Nutrição, Campinas, São Paulo, v. 23, n. 5, p. 856-869, set./out. 2010.

TRAVÉ, T.D. Análisis nutricional Del desayuno y almuerzo en una población universitária. Nutricion Hospitalaria, v. 28, n. 3, p. 1291-1299, 2013.

VEREECKEN, C. et al. Breakfast consumption and its socio-demographic and lifestyle correlates in schoolchildren in 41 countries participating in the HBSC study. International Journal of Public Health, v. 54, p.180-190, sept. 2009. Suplemento 2. 


\section{CONCLUSÃO}

- $\quad$ O tema CM é pouco estudado no Brasil e no mundo e o enfoque no consumo de alimentos regionais é pouco frequente.

- A amostra foi predominantemente composta por homens e por indivíduos na faixa etária entre 25 e 34 anos. O nível de escolaridade mais frequente foi o ensino médio completo e a maior parte dos entrevistados eram trabalhadores. Em relação ao estado civil, observou-se um predomínio da união estável, sendo que a faixa média de renda per capita predominante foi a de 0,5 a 1 Salário Mínimo e apenas 10,2\% participavam de algum tipo de programa de governo. A maior parte dos entrevistados residia no momento da pesquisa na região Sudeste $(40,8 \%)$, sendo que, a naturalidade mais frequente foi Minas Gerais.

- A análise de grupos de alimentos mostrou alto consumo de lácteos e cereais, e baixo consumo de frutas, raízes/tubérculos e carnes/ovos. As frutas foram mais consumidas por homens; por pessoas na faixa de idade entre 35 a 44 anos e pelos participantes com maior faixa de renda. Os nordestinos consumiram mais frutas quando comparados com as demais regiões.

- Os percentuais nacionais de contribuição energética dos macronutrientes no VET do CM realizado pelos participantes da pesquisa apresentaram-se adequados, com percentuais de adequação dentro do recomendado.

- Os percentuais nacionais de contribuição dos ácidos graxos saturados e ácidos graxos trans se encontravam dentro da recomendação, mas quando a análise regional foi realizada, observou-se que a região Centro-oeste apresentou níveis de consumo elevados para estes dois nutrientes e a região Nordeste apresentou percentual de consumo elevado de ácidos graxos saturados.

- A média nacional da ingestão de fibras do CM foi baixa, concordando com o resultado encontrado de baixo consumo de frutas pelos participantes da presente pesquisa.

- Embora os lácteos tenha sido um dos grupos de alimentos mais consumidos, o teor de cálcio consumido foi baixo em todas as regiões, demonstrando que a frequência de consumo foi alta, mas a quantidade consumida foi baixa. Tal 
constatação indica a necessidade de maior ingestão de lácteos e outros alimentos fontes de cálcio no CM.

- O consumo nacional de sódio foi dentro do recomendado, sendo que as regiões Centro-oeste e Nordeste apresentaram alto consumo, coerente com o maior consumo de carnes/ovos nessas regiões.

- O consumo de alimentos regionais na refeição CM mostrou-se baixo na presente pesquisa, sendo maior nas regiões Centro-oeste e Sul, e maior no fim de semana. A maioria dos indivíduos que consumiu alimentos regionais alimentou-se apenas de um alimento regional em uma mesma refeição. Somente a escolaridade mostrou influenciar o número de alimentos regionais consumidos ao nível nacional: os analfabetos consumiram um menor número de alimentos regionais quando comparados aos que tem nível superior incompleto, sendo que nem o sexo nem a faixa etária influenciaram o consumo de alimentos regionais entre os participantes.

- As frutas apresentaram baixo percentual de consumo, e os embutidos foram os mais prevalentes entre os alimentos regionais. Das cinco regiões geográficas, três apresentaram o presunto como um dos principais alimentos regionais consumidos, demonstrando o maior consumo de produtos industrializados em detrimento aos in natura.

- A análise nacional e regional mostrou que há diferença significativa no consumo de alimentos regionais dos indivíduos que fizeram a refeição CM nos Restaurantes Populares, ou seja, os Restaurantes Populares estão contribuindo para um maior incentivo ao consumo de alimentos regionais no Brasil.

- Os resultados mostraram um predomínio da refeição padrão em todas as regiões geográficas, exceto no Nordeste, e um baixo percentual de realização de CM completo, o que aconteceu também nos Restaurantes Populares que ofereciam o CM.

- A análise comparativa da avaliação qualitativa entre o CM realizado em casa com o CM realizado no Restaurante Popular mostrou que em ambos os casos houve predomínio de consumo de refeição incompleta.

- Os percentuais de supressão do CM entre os Restaurantes Populares que ofereciam e que não ofereciam a refeição foram muito próximos, mostrando 
que servir a refeição nos restaurantes não influenciou na adesão ao hábito de realização do $\mathrm{CM}$. O CM incompleto somente foi maior para o sexo masculino nos dias da semana.

- $\quad$ O percentual de CM incompleto foi ligeiramente maior nas unidades que serviam a refeição, que nas unidades que não serviam $\mathrm{CM}$. Sugerindo que muitos dos usuários das unidades que ofereciam a refeição, dispensaram alguns tipos de alimentos oferecidos, optando por não realizar a refeição completa.

- O percentual médio nacional de supressão do CM ficou em 17,8\%, relativamente baixo, sobretudo nos fins de semana, quando comparado a outros estudos realizados no Brasil e no mundo. Este percentual foi menor no sexo feminino, sendo que e a região Sul apresentou o maior e a região Norte o menor percentual de supressão.

- Tendo em vista os tipos de alimentos consumidos pelos participantes da pesquisa, é possível considerar que os marcadores de identidade alimentar da refeição CM são o leite com café (ou café com leite), açúcar e pão com margarina.

- Considerando o perfil de consumo dos grupos de alimentos da amostra estudada, sugere-se que uma forma de melhorar a qualidade nutricional do $\mathrm{CM}$ seria consumir no CM maior quantidade de alimentos in natura, como por exemplo, a mandioca, o cará, o inhame e a batata doce em substituição aos panificados; a coalhada e iogurtes caseiros em substituição a queijos e iogurtes industrializados. Além disso, aumentar o consumo de frutas e hortaliças nesta refeição. Embora o consumo de hortaliças não seja hábito no $\mathrm{CM}$, pode ser consumido na forma de sucos puros ou misto com frutas. 


\section{CONSIDERAÇÕES FINAIS}

Tendo em vista a importância da realização da refeição CM na saúde humana é necessário que o governo federal promova mais ações de estímulo à realização do $\mathrm{CM}$, assim como de incentivo ao consumo de alimentos regionais, pois podem ser estratégias importantes para o cumprimento da Política Nacional de Segurança Alimentar e Nutricional. O consumo de alimentos cultivados na região, além de contribuir para a geração de empregos, melhor distribuição de renda, é de baixo custo e de melhor qualidade nutricional.

A oferta de CM em Restaurantes Populares é ação importante para a população de baixa renda para que possam ter acesso a grupos variados de alimentos. Além disso, a presença do nutricionista auxilia na oferta de refeições mais saudáveis. No entanto, são importantes campanhas educativas nas unidades para que haja consumo dos alimentos ofertados e não somente a oferta dos mesmos. É imprescindível também que o nutricionista entenda seu papel de liderança na escolha alimentar por parte dos usuários. O planejamento de cardápios guia as escolhas e a presença de alimentos regionais é que possibilitará seu consumo. $\mathrm{O}$ profissional deve compreender sua função como promotor da manutenção do patrimônio imaterial.

É imprescindível incrementar ações de estímulo ao consumo de frutas e de alimentos in natura no $\mathrm{CM}$, como a mandioca, a batata doce, o cará e o inhame, ao ponto de estes representarem novos marcadores de identidade alimentar do $\mathrm{CM}$ no país, o que conduziriam uma população mais saudável. Além disso, diminuiríamos o consumo de alimentos fontes de sódio e gorduras saturadas.

Poderiam ser implementadas ações mais específicas, e de maior abrangência no território nacional, como o incentivo aos estados e municípios para maior oferta de $\mathrm{CM}$ às populações carentes, assim como de incentivo fiscal às pequenas, médias e grandes empresas para a oferta de $\mathrm{CM}$ para aqueles que não conseguem realizar a refeição em casa.

A realização de campanhas educativas enfocando a importância da realização da primeira refeição do dia e do melhor aproveitamento de alimentos locais podem auxiliar na redução dos desequilíbrios nutricionais ainda presentes no Brasil. 
Diante da importância da formação do hábito alimentar, seria proveitosa a maior abordagem do hábito de realização dessa refeição nas escolas, sobretudo no ensino fundamental, visto que a criança dessa etapa escolar será o futuro adulto a repassar para as crianças vindouras, a importância do hábito de consumo do CM e do uso dos alimentos regionais, que possuem grande potencial como fonte de nutrientes, melhorando o estado nutricional e, consequentemente, reduzindo as taxas de morbimortalidade. 


\section{REFERÊNCIAS BIBLIOGRÁFICAS}

ABRIL COLEÇÕES. Editora Abril. Coleção Cozinha regional brasileira. São Paulo, v. 1-19. 2012.

AÇÃO BRASILEIRA PELA NUTRIÇÃO E DIREITOS HUMANOS - ABRANDH. Direito Humano à Alimentação Adequada no Contexto da Segurança Alimentar e Nutricional. Brasília: ABRANDH, 2010. 204p.

AÇÃO BRASILEIRA PELA NUTRIÇÃO E DIREITOS HUMANOS - ABRANDH. O direito humano à alimentação adequada e o sistema nacional de segurança alimentar e nutricional. Brasília: ABRANDH, 2013. 263p.

ADOLPHUS, K.; LAWTON, C.L.; DYE,L. The relationship between habitual breakfast consumption frequency and academic performance in British adolescents. Front Public Health, v. 3, n. 68, p. 1-10, 2015.

AFFINITA, A. et al. Breakfast: a multidisciplinary approach. Italian Journal of Pediatrics, v. 39, n. 1, p. 44, 2013. Disponível em:

<http://www.ijponline.net/content/39/1/44>. Acesso em: 17 nov. 2013.

AFFENITO, S.G. Breakfast: a missed opportunity. Journal of the American Dietetic Association, v. 107, n. 4, p. 565-9, 2007.

AGUIAR, A.L.O. et al. Avaliação clínica e evolutiva de crianças em programa de atendimento ao uso de fórmulas para alergia à proteína do leite de vaca. Revista Paulista de Pediatria, v. 31, n. 2, p. 152-158, 2013.

AHMED, A. et al. Effect of multiple fortification on the bioavailability of minerals in wheat meal bread. Journal of Food Science and Technology, v. 49, n. 6, p. 737744, 2012.

AIRES, J.S. Efetividade no processo de capacitação dos enfermeiros para utilização do álbum seriado - alimentos regionais promovendo a segurança alimentar. 2012. 139f. Dissertação (Mestrado em Enfermagem) - Universidade Federal do Ceará, 2012.

ALEXANDER, K.E. et al. Association of breakfast skipping with visceral fat and insulin indices in overweight Latino youth. Obesity, v. 17, n. 8, p. 1528-33, 2009. ALFENAS, R.C.G.; BRESSAN, J.; PAIVA, A.C. Effects of protein quality on appetite and energy metabolism in normal weight subjects. Arquivo Brasileiro de Endocrinologia e Metabologia, v. 54, n. 1, p. 45-51, 2010.

ALMEIDA, V. M. Ensaio sobre a valorização da culinária tradicional local como estratégia identitária-territorial. 2006. 126f. Dissertação (Mestrado em Geografia) Instituto de Geociências, Universidade Federal Fluminense, 2006.

ALVES, H. J.; BOOG, M.C.F. Comportamento alimentar em moradia estudantil: um espaço para promoção da saúde. Revista de Saúde Pública, v. 41, n. 2, p. 197204, 2007.

ANSORENA, D. et al. 2012: No trans fatty acids in Spanish bakery products. Food Chemistry, v. 138, p. 422-429, 2013.

ARAÚJO, F.R.; SANTOS, D.F.; ARAÚJO, M.A.D. O direito humano à alimentação adequada promovido por políticas de acesso a alimentos: o caso da unidade NatalRN do Projeto Café do Trabalhador. Revista de Políticas Públicas, São Luís, v. 15, n. 2, p. 267-276, 2011.

ARAÚJO, W. M. C. et al. Da alimentação à gastronomia. Brasília: Editora UnB, 2005. $101 \mathrm{p}$. 
AUED-PIMENTEL, S. et al. Ácidos graxos trans em óleos vegetais refinados poliinsaturados comercializados no estado de São Paulo, Brasil. Ciências e Tecnologia de Alimentos, v. 29, n. 3, p. 646-651, 2009.

AVELAR, P.S.; PINHEIRO-SANT'ANA, H.M.; LIBERATO, S.C. Alimentos enriquecidos com vitaminas comercializados em Belo Horizonte - MG. In: CONGRESSO INTERNACIONAL DE NUTRIÇÃO, LONGEVIDADE E QUALIDADE DE VIDA/Alimentos Fortificados, 2., 2001, São Paulo. Anais ... São Paulo: Núcleo, 2001.

AZADBAKHT, L. et al. Breakfast eating pattern and its association with dietary quality indices and anthropometric measurements in young women in Isfahan. Nutrition, New York, v. 29, p. 420-425, 2013.

BARBOSA, L. Feijão com arroz e arroz com feijão: o Brasil no prato dos brasileiros. Horizontes Antropológicos, Rio Grande do Sul, v. 13, n. 28, p. 87-116, 2007.

BARTON, B. A. et al. The relationship of breakfast and cereal consumption to nutrient intake and Body Mass Index: The National Heart, Lung, and Blood Institute Growth and Health Study. Journal of the American Dietetic Association, n. 105, p. 1383-1389, 2005.

BARUFALDI, L. A. Características de adolescentes de acordo com o consumo de café da manhã em escolas de cinco cidades brasileiras. 2014. 71f. Tese (Doutorado em Saúde Coletiva) - Instituto de Estudos em Saúde Coletiva, Universidade Federal do Rio de Janeiro. 2014.

BEDANI, R.; ROSSI E.A. O consumo de cálcio e a osteoporose. Semina: Ciências Biológicas e da Saúde, Londrina, v. 26, n. 1, p. 3-14, 2005.

BENATAR, J.R.; STEWART, R.A.H.The effects of changing dairy intake on trans and saturated fatty acid levels- results from a randomized controlled study. Nutrition Journal, v. 13, p. 32, 2014.

BENTO, I.C. Perfil sociodemográfico, nutricional e psicossocial dos usuários de restaurantes e refeitórios populares de Belo Horizonte - MG: fundamento para a elaboração de uma intervenção educativa alimentar e nutricional. 2012. $118 \mathrm{f}$. Dissertação (Mestrado em Saúde e Enfermagem) - Escola de Enfermagem, Universidade Federal de Minas Gerais, Belo Horizonte, Minas Gerais.

BENTON, D.; BROCK, H. Mood and the macro-nutrient composition of breakfast and the

mid-day meal. Appetite, v. 55, p. 436-440, 2010.

BERTA, E. E. et al. Estado nutricional de escolares y su relación con el hábito y calidad del desayuno. Revista Chilena de Nutrición, v. 42, n. 1, p. 45-52, 2015. BERTIN, R.L. et al. Estado nutricional, hábitos alimentares e conhecimentos de nutrição em escolares. Revista Paulista de Pediatria, São Paulo, v. 28, n. 3, p. 3038, 2010.

BERTOLINO, C.N. et al. Influência do consumo alimentar de ácidos graxos trans no perfil de lipídios séricos em nipo-brasileiros de Bauru, São Paulo, Brasil. Cadernos de Saúde Pública, Rio de Janeiro, v. 22, n. 2, p. 357-364, 2006.

BESSIÈRE, J. Terroir, gastronomie et tourisme: manger ailleurs, manger local. Espace, n. 242, p. 34-36, 2006.

BEZERRA, A. C. D.; MANCUSO, A. M. C.; HEITZ, S. J. J. Alimento de rua na agenda nacional de segurança alimentar e nutricional: um ensaio para a qualificação sanitária no Brasil. Ciências e Saúde Coletiva, v. 19, n. 5, p. 1489-1494, 2014. 
BISPO, J.S. Perfil alimentar referente ao desjejum dos professores da Universidade de Brasília. 2006. 144 f. Dissertação (Mestrado em Nutrição Humana) - Departamento de Nutrição, Universidade de Brasília, 2006. BLOM, W.A.M et al. Effect of a high-protein breakfast on the postprandial ghrelin response. American Jounal Clinical Nutrition, v. 83, p. 211-20, 2006. BOLHUIS, D.P. et al. A salt reduction of $50 \%$ in bread does not decrease bread consumption or increase sodium intake by the choice of sandwich fillings.

The journal of nutrition, v. 141, n. 12, p. 2249- 2255, 2011.

BONJOUR, J.-P. et al. Dairy in adulthood: from foods to nutrient interactions on bone and skeletal muscle health. Journal of the American College of Nutrition, v. 32, n. 4, p. 251-263, 2013.

BOTELHO, R.B.A. Culinária Regional: O nordeste e a alimentação saudável. 2006.192f. Tese (Doutorado em Ciências da Saúde) - Faculdade de Ciências da Saúde, Universidade de Brasília, Brasília, Distrito Federal, 2006.

BOURDIEU, P. A distinção: crítica social do julgamento. Rio Grande do Sul: Zouk, 1979, p.162-211.

BRANCO, I. G. et al. Avaliação sensorial e estabilidade físico-química de

um blend de laranja e cenoura. Ciência eTecnologia de Alimentos, v. 27, n. 1, p. 712, 2007.

BRASIL. Conselho Nacional de Segurança Alimentar e Nutricional - Consea. II Conferência Nacional de Segurança Alimentar e Nutricional. Brasília, DF, 2004. BRASIL. Lei $\mathbf{n}^{\circ} \mathbf{1 1 . 3 4 6}$, de 15 de setembro de 2006. Cria o Sistema Nacional de Segurança Alimentar e Nutricional - Sisan com vistas em assegurar o direito humano à alimentação adequada e dá outras providências. Diário Oficial da União, set. 2006a.

BRASIL. Ministério da Cultura. Instituto do Patrimônio Histórico e Artístico Nacional. Patrimônio Cultural. Disponível em:

$<$ http://portal.iphan.gov.br/portal/montarPaginalnicial.do>. Acesso em: 10 out. 2015b. BRASIL. Ministério da Saúde. Agência Nacional de Vigilância Sanitária - Guia de Boas Práticas Nutricionais para Pão Francês. Brasília: ANVISA, 2012a. BRASIL. Ministério da Saúde. Agência Nacional de Vigilância Sanitária. Resolução RDC no 359, de 23 de dezembro de 2003. Aprova o Regulamento Técnico de Porções de Alimentos Embalados para Fins de Rotulagem Nutricional. Brasília, DF, 2003b.

BRASIL. Ministério da Saúde. Agência Nacional de Vigilância Sanitária. Resolução RDC no 360, de 23 de dezembro de 2003. Dispõe sobre o Regulamento Técnico sobre rotulagem nutricional de alimentos embalados. Brasília, DF, 2003a.

BRASIL. Ministério da Saúde. Secretaria de Atenção à Saúde. Coordenação-Geral da Política de Alimentação e Nutrição. Guia alimentar para a população brasileira: promovendo a alimentação saudável. Brasília: Ministério da Saúde, 2006b. 236p. BRASIL. Ministério da Saúde. Secretaria de Atenção à Saúde. Departamento de Atenção Básica. Política Nacional de Alimentação e Nutrição / Ministério da Saúde. Secretaria de Atenção à Saúde. Departamento de Atenção Básica, Brasília: Ministério da Saúde, 2012b. 84 p. Disponível em: <http://189.28.128.100/nutricao/docs/geral/pnan2011.pdf>. Acesso em: 04 set. 2013. BRASIL. Ministério da Saúde. Coordenação Geral de Políticas Públicas. Receitas Regionais para crianças de 6 a 24 meses. Brasília [s.n], 2010b. 28p. BRASIL. Ministério da Saúde. Secretaria de Atenção à Saúde. Departamento de Atenção Básica. Guia alimentar para a população brasileira, $2^{\mathrm{a}}$ ed., Brasília: Ministério da Saúde, 2014a.156 p. 
BRASIL. Ministério da Saúde. Secretaria de Políticas de Saúde. Coordenação Geral da Política de Alimentação e Nutrição. Alimentos regionais brasileiros. $1^{\underline{a}}$ ed., Brasília: Ministério da Saúde, 2002a.

BRASIL. Ministério da Saúde. Secretaria de Atenção à Saúde. Departamento de Atenção Básica. Alimentos regionais brasileiros. 2. ed., Brasília : Ministério da Saúde, 2015a.

BRASIL. Ministério da Saúde. Secretaria de Vigilância em Saúde. Departamento de Análise de Situação de Saúde. Plano de ações estratégicas para o enfrentamento das doenças crônicas não transmissíveis (DCNT) no Brasil 2011-2022. Brasília, 2011c.160 p. : il. - (Série B. Textos Básicos de Saúde). BRASIL. Ministério da Saúde. Secretaria-Executiva. Secretaria de Atenção Básica. Glossário temático: alimentação e nutrição. Brasília: Editora do Ministério da Saúde, 2007a. 60 p. - (Série A. Normas e Manuais Técnicos).

BRASIL. Ministério do Desenvolvimento Social e Combate à Fome. Câmara Interministerial de Segurança Alimentar e Nutricional. Plano Nacional de Segurança Alimentar e Nutricional: 2012/2015. Brasília, DF: CAISAN, 2011b. BRASIL. Ministério do Desenvolvimento Social e Combate à Fome. Roteiro de implantação para restaurantes populares. Brasília: MDS, 2007b. Disponível em: $<$ http://www.mds.gov.br/segurancaalimentar/equipamentos/restaurantespopulares/ar quivos/roteiro-de-implantacao-restaurantes-populares-versao-para-

visualizacao.pdf/view>. Acesso em: 24 fev. 2014.

BRASIL. Ministério do Desenvolvimento Social e Combate à Fome. Restaurantes populares. Disponível em:

<http://www.mds.gov.br/segurancaalimentar/equipamentos/restaurantespopulares>. Acesso em: 12 jan. 2011 a.

BRASIL. Ministério do Planejamento, Orçamento e Gestão. Instituto Brasileiro de Geografia e Estatística. Diretoria de Pesquisas Coordenação de Trabalho e Rendimento. Pesquisa de Orçamentos Familiares 2008-2009: antropometria e estado nutricional de crianças, adolescentes e adultos no Brasil. Brasília. 2010a. 130 p.

BRASIL. Ministério do Planejamento, Orçamento e Gestão. Instituto Brasileiro de Geografia e Estatística. Pesquisa Nacional de Saude do Escolar. 2009. Disponivel em: <http://www.ibge.gov.br/home/estatistica/populacao/pense/default.shtm>.

Acesso em 12 fev. 2012.

BUENO, A.L.; CZEPIELEWSKI, M.A. A importância do consumo dietético de cálcio e vitamina D no crescimento. Jornal de Pediatria, v. 84, n. 5, p. 386-394, 2008.

BUNOMO, J.R. A culinária mineira como signo e patrimônio cultural imaterial. In: Congresso Internacional Interdisciplinar em Sociais e Humanidades, 2., 2013, Belo Horizonte. Anais eletrônicos... Belo Horizonte, 2013. Disponível em: <www.2coninter.com.br/artigos/pdf/34.pdf >. Acesso em 15 out. 2014.

BURLANDY, L. Seguranca alimentar e nutricional e o setor saúde. In: Brasil.

Ministério da Saúde. Textos de opinião: temas estratégicos para a Política Nacional de Alimentação e Nutricao (PNAN) / Ação Brasileira pela Nutrição e Direitos Humanos (ABRANDH). Ministério da Saúde - Brasilia: Organização Pan Americana de Saúde (OPAS), 2011.

p. 119-154.

CABRAL, C.S. et al. Segurança alimentar, renda e Programa Bolsa Família: estudo de coorte em municípios do interior da Paraíba, Brasil, 2005-2011. Cadernos de Saúde Pública, Rio de Janeiro, v. 30, n. 2, p. 393-402, 2014. 
CAPATTI, A. Slow Food et tourisme: Des interest gastronomiques lies. Espace, $n$. 242, p. 34-36, 2006.

CARDOSO, L.O. et al. Fatores socioeconômicos, demográficos, ambientais e comportamentais associados ao excessode peso em adolescentes: uma revisão sistemática da literatura. Revista Brasileira de Epidemiologia, São Paulo, v. 12, n. 3, p. 378-403, 2009.

CARDOSO, L.O.; MONTEIRO, C.A. Situação nutricional da populacao brasileira cenário atual e futuros desafios. In: Brasil. Ministério da Saúde. Textos de opinião: temas estratégicos para a Política Nacional de Alimentação e Nutricao (PNAN) / Ação Brasileira pela Nutrição e Direitos Humanos (ABRANDH). Ministério da Saúde - Brasilia: Organizacao Pan Americana de Saúde (OPAS), 2011. p. 89-118.

CARRIJO, A.P. Avaliação do consumo alimentar nos Restaurantes Populares do Brasil. 2013. 97f. Dissertação (Mestrado em Nutrição Humana) - Faculdade de Ciências da Saúde, Universidade de Brasília. Brasília, Distrito Federal, 2013. CARUS, J.P.; FRANCA, G.V.A.; BARROS, A.J.D. Local e tipo das refeições realizadas por adultos em cidade de médio porte. Revista de Saúde Pública, São Paulo, v. 48, n. 1, p. 68-74, 2014.

CARVALHO, E.N. et al. Avaliação da qualidade nutricional das refeições servidas aos idosos em instituição asilar. Estudos interdisciplinares sobre 0 envelhecimento, Porto Alegre, v. 5, p. 119-136, 2003.

CARVALHO, M. O alimento: do espaço privado à mercadoria. In: MIRANDA, D.S.; CORNELLI, G. (orgs). Cultura e Alimentação: saberes alimentares e sabores culturais. São Paulo: SESC, 2007. p. 86-96.

CARVALHO, M.S. Lugares e paladares: uma contribuição geográfica à diversidade do consumo alimentar no Brasil. Revista RA'E GA, Curitiba: editora UFPR, n. 15, p. 95-111, 2008.

CASCUDO, C. História da Alimentação no Brasil. 3a edição, São Paulo: Global, 2004. 946p.

CASTRO, I.R.R. Desafios e perspectivas para a promoção da alimentação adequada e saudável no Brasil. Cadernos de Saúde Pública, Rio de Janeiro, v. 31, n. 1, p. 7-9, 2015.

CASTRO, J.M. The time of day and the proportions of macronutrients eaten are related to total daily food intake. British Journal of Nutrition, v. 98, p.1077-1083, 2007.

CASTRO, J.M. The time of day of food intake influences overall intake in humans. Journal of Nutrition, v. 134, p. 104-111, 2004.

CASTRO, M.A. et al. Trans fatty acid intake among the population of the city of São Paulo, Brazil. Revista de Saúde Pública, v. 43, n. 6, p. 991-997, 2009.

CAVICCHIOLI, M.R. O terroir e a identidade cultural. Revista Adega, ed. 10, 2006. Disponível em:<http://revistaadega.uol.com.br/artigo/o-terroir-e-a-identidadecultural_6122.html>. Acesso em: 26 ago. 2014.

CAVIGNAC, J. A.; OLIVEIRA, L. A. História e etnografia nativas da alimentação no Brasil: notas biográficas a respeito de um antropólogo provinciano. ImburanaRevista do Núcleo Câmara Cascudo de Estudos Norte-Rio-Grandenses/UFRN, n. 2, 2010.

CAYRES, S. U. Breakfast frequency, adiposity, and cardiovascular risk factors as markers in adolescents. Cardiology in the Young, v. 26, p. 244-249, 2016.

CECATO, D. O consumo do café da manhã na manutenção e redução de peso: uma revisão da literatura. Revista de Atenção à Saúde, v. 13, n. 44, p. 80-84, 2015. 
CERDAN, C. Valorizaçâo dos produtos de origem e do patrimônio dos territórios rurais no sul do Brasil: Contribuição para o desenvolvimento territorial sustentável.

Política \& Sociedade, n. 14, p. 277-299, 2009.

CHAPLIN, K.; SMITH, A.P. Breakfast and snacks: associations with cognitive failures, minor injuries, accidents and stress. Nutrients, Switzerland, v. 3, p. 515528, 2011.

CHAVES, L.G. et al.The national school food program as a promoter of regional food habits. Revista de Nutrição, Campinas, São Paulo, v. 22. n. 6, p. 857-866, 2009. CHEIN, F.; LEMOS, M.B.; ASSUNÇÃO, J.J.Desenvolvimento desigual: evidências para o Brasil. Revista Brasileira de Economia, Rio de Janeiro, v. 61, n. 3, p. 301330, 2007.

CHEMIN, S.M. Padrões alimentares brasileiros: o respeito à diversidade culinária. In: MIRANDA, D.S.; CORNELLI, G. (orgs). Cultura e Alimentação: saberes alimentares e sabores culturais. São Paulo: SESC, 2007. p. 159-164. $\mathrm{CHO}, \mathrm{S}$. et al. The effect of breakfast type on total daily energy intake and Body Mass Index: Results from the Third National Health and Nutrition Examination Survey (NHANES III). Journal of the American College of Nutrition, Italy, v. 22, p. 296302, 2003.

CHOWDHURY, E.A. et al. Effect of extended morning fasting upon ad libitum lunch intake and associated metabolic and hormonal responses in obese adults.

International Journal of Obesity, p. 1-7, 2015.

CHUNG, S. et al. Breakfast skipping and breakfast type are associated with daily nutrient intakes and metabolic syndrome in Korean adults. Nutrition Research and Practice, v. 9, n. 3, p. 288-295, 2015.

CIMADON, H.M.S.; GEREMIA, R.; PELLANDA, L.C. Hábitos alimentares e fatores de risco para aterosclerose em estudantes de Bento Gonçalves (RS). Arquivos Brasileiro de Cardiologia, v. 95, n. 2, p.166-172, 2010.

CIRINO, A.C.L. Consumo de alimentos com fortificação voluntária de vitaminas e minerais: estudo de base populacional. 2013. 209f. Dissertação (Mestrado em Epidemiologia) - Faculdade de Medicina, Universidade Federal de Pelotas. 2013. CLEGG, M.; SHAFAT, A. Energy and macronutrient composition of breakfast affect gastric emptying of lunch and subsequent food intake, satiety and satiation.

Appetite, 7p. 2010. Disponível em: <www.elsevier.com/locate/appet>. Acesso em: 10 mar. 2014.

COHEN, J. The statistical power of abnormal-social psychological research: A review. Journal of Abnormal and Social Psychology, v. 65, p. 145-153, 1962. CONSONNI, R.; CAGLIANI, L.R. Nuclear magnetic resonance and chemometrics to assess geographical origin and quality of traditional food products. Advances in Food and Nutrition Research, v. 59, p. 87-165. 2010.

CORDER, K. Breakfast consumption and physical activity in adolescents: daily associations and hourly patterns. American Journal of Clinical Nutrition, United States, n. 99, p. 361-368, 2014.

CORREIA, A. et al. Ethnic aspects of vitamin D deficiency. Arquivos Brasileiro de Endocrinologia e Metabologia v. 58, n. 5, p. 540-544, 2014.

CORREIA, P. et al. Pão São, uma alternativa ao pão tradicional. In: ENCONTRO DE QUIMICA DOS ALIMENTOS, 11., 2012, Bragança. Anais eletrônicos... Bragança: Escola Superior Agrária de Viseu, 2012. Disponível em: <http://repositorio.ipv.pt/handle/10400.19/1178>. Acesso em: 18 dez.2014. CORTÉS, E. et al. Ácidos grasos trans en la nutrición de niños con trastornos neurológicos. Nutrición Hospitalaria, v. 28, n. 3, p. 1140-1144, 2013. 
COSTA, A. E. Nem só de pão [de queijo] vive o homem. 2009. 81f. Monografia (Especialização em Turismo) - Centro de Excelência em Turismo. Universidade de Brasília. Brasília, 2009.

COSTA, E.A.C.; SCHOR, T. Redes urbanas, abastecimento e o café da manhã de idosas na cidade de Tefé, Amazonas: elementos para a análise da geografia da alimentação no

Brasil. Hygeia, v. 9, n. 17, p. 52 - 73, 2013. Disponível em:

http://www.seer.ufu.br/index.php/hygeia. Acesso em: 12 fev. 2015.

COSTA, L. C.F.; VASCONCELOS, F.A.G. Prevalence and factors associated with nutritional status among female university students in Florianópolis, SC. Revista

Brasileira de Cineantropometria \& Desempenho Humano, v. 15, n. 3, p. 326-337, 2013.

COTTON, J.R.; BURLEY, V.J.; BLUNDELL, J.E. Fat and satiety: effect of fat in combination with either protein or carbohydrate. Obesity in Europe, v. 93, 1993.

COTTON, J.R.; BURLEY, V.J.; BLUNDELL, J.E. Fat and satiety: no additional intensification of satiety following a fat supplemented breakfast. International Journal of Obesity, v. 16, n.1, p. 11, 1992. Suplemento.

COUTINHO, A.L.D. Farinhada e comensalidade no semi-árido baiano: hábitos alimentares e identidade sertaneja. In: SEMINÁRIO SOBRE ALIMENTOS E MANIFESTAÇÕES CULTURAIS TRADICIONAIS. GT01 - A Produção de Alimentos Tradicionais nos Territórios Rurais e Urbanos, 1, 2012, Sergipe. Anais eletrônicos... Sergipe: Universidade Federal de Sergipe, 2012. Disponível em: $<$ http://www.grupam.net/anais-do-i-seminario-sobre-alimentos-emanifesta\%C3\%A7\%C3\%B5es-culturais-tradicionais/>. Acesso em: 10 out. 2014. COUTINHO, J. G.; GENTIL, P. C.; TORAL, N. A desnutrição e obesidade no Brasil: o enfrentamento com base na agenda única da nutrição. Cadernos de Saúde Pública, Rio de Janeiro, v. 24, n. 2, p. 332-340, 2008. Suplemento.

CRUZ, F.T.; SCHNEIDER, S. Qualidade dos alimentos, escalas de produção e valorização de produtos tradicionais. Revista Brasileira de Agroecologia, v. 5, n. 2, p. 22-38, 2010.

CUNHA, D.T. et al. Regional food dishes in the Brazilian National School Food Program: acceptability and nutritional composition. Revista de Nutrição, São Paulo, v. 27, n. 4, p. 423-434, 2014.

DaMATTA, R. Sobre comidas e mulheres. In: DaMATTA, R. O que faz do brasil, Brasil? Rio de Janeiro: Editora Rocco, 1986, p. 29 - 39.

DATALLO, P. Determining sample size balancing power, precision and practicality. Oxford University Press: 2008, chapter 2, p. 27.

DESHMUKH-TASKAR, P.R. National patterns of breakfast consumption:

nutritional and health implications. 2010. $229 \mathrm{f}$. Dissertation (Doctor of philosophy) - Texas woman's university - USA. 2010a.

DESHMUKH-TASKAR, P.R. et al. Do breakfast skipping and breakfast type affect energy intake, nutrient intake, nutrient adequacy, and diet quality in young adults? NHANES 1999-2002. Journal American of College Nutrition, v. 29, n. 4, p. 407418, 2010b.

Di GIUSEPPE, R. et al.Typical breakfast food consumption and risk factors for cardiovascular disease in a large sample of Italian adults. Nutrition, Metabolism and Cardiovascular Diseases, Italy, v. 22, p. 347-354, 2012.

DIMENSTEIN, R. et al. Alimentos regionais fontes de vitamina A conhecidos por parturientes atendidas em maternidade pública. Extensão e Sociedade, v. 1, n. 2 , 2010. 
DOLADER, M.A.M. A alimentação judia na idade média. In: FLANDRIN, J-L.; MONTANARI, M.; [tradução de Machado,L.V.; Teixeira, G.J.F]. História da alimentação. São Paulo: Estação Liberdade, 1998. p. 359-379.

DÓRIA, C.A. Quando a política se interessa pela cozinha. In: A culinária materialista: construção racional do alimento e do prazer gastronômico. São Paulo: editora Senac, 2009, p. 65-121.

DOVE, E.R. et al. Skim milk compared with a fruit drink acutely reduces appetite and energy intake in overweight men and women. American Journal of Clinical

Nutrition, n. 90, p. 70-5, 2009.

DUNCAN, B.B. et al. Doenças crônicas não transmissíveis no Brasil: prioridade para enfrentamento e investigação. Revista de Saúde Pública, São Paulo, v. 46, n. 1, p. 126-134, 2012. Suplemento.

DUPONT, F. Gramática da alimentação e das refeições romanas. In: FLANDRIN, JL.; MONTANARI, M.; [tradução de Machado,L.V.; Teixeira, G.J.F]. História da alimentação. São Paulo: Estação Liberdade, 1998. p.199- 216.

ELOY, A.L.S.; REIS, R.R.V. A comida de rua como ferramenta na preservação dos alimentos tradicionais. In: SEMINÁRIO SOBRE ALIMENTOS E MANIFESTAÇÕES CULTURAIS TRADICIONAIS. GT01 - A Produção de Alimentos Tradicionais nos Territórios Rurais e Urbanos, 1., 2012, Sergipe. Anais eletrônicos... Sergipe: Universidade Federal de Sergipe, 2012. Disponivel em:

$<$ http://www.grupam.net/anais-do-i-seminario-sobre-alimentos-emanifesta\%C3\%A7\%C3\%B5es-culturais-tradicionais/>. Acesso em: 10 out. 2014. ENES, C.C.; SLATER, B. Obesidade na adolescência e seus principais fatores determinantes. Revista Brasileira de Epidemiologia, Sao Paulo, v. 13, n. 1, p.16371, 2010.

ERLICH, R. Cultural and historical trends and influences of food, nutrition and cuisine on health and development. Asia Pacific Journal Clinical Nutrition, v. 13, n. 2, p. 125-130, 2004.

ESCOLA NACIONAL DE SAUDE PÚBLICA - ENSP. Ministério da Saúde renova acordo com indústria para melhorar alimentação dos brasileiros. 26/11/2010. Disponivel em:

<http://www.ensp.fiocruz.br/portalensp/informe/site/materia/detalhe/23666>. Acesso em 05 jan. 2015.

ESTIMA, C.C.P. et al. Meal consumption patterns and anthropometric measurements in adolescents from a low socioeconomic neighborhood in the metropolitan area of Rio de Janeiro, Brazil. Appetite, v. 52, p. 735-739, 2009.

FABRI, R.K. Uso de alimentos regionais da agricultura familiar na alimentação escolar: um estudo de caso em Santa Catarina. 2013. 291f. Dissertação (Mestrado em Nutrição) - Universidade Federal de Santa Catarina, Florianópolis, 2013. FEDERAÇÃO DAS INDÚSTRIAS DO ESTADO DE SÃO PAULO - FIESP; INSTITUTO DE TECNOLOGIA DE ALIMENTOS - ITAL. Brasil Food Trends 2020. São Paulo, 2010. Disponível em: <www.brasilfoodtrends.com.br/>. Acesso em: 16 dez. 2014.

INSTITUTE OF MEDICINE (IOM). Dietary Reference Intakes for calcium, phosphorus, mgnesium, vitamin D, and fluoride. Washington, DC: National ACADEMY PRESS; 1997.

INSTITUTE OF MEDICINE (IOM). Dietary Reference Intakes for water, potassium, sodium, chloride, and sulfate. Washington, DC: National Academy Press, 2005. 
FEIJÓ, R.B. ET AL. ESTUDO DE HÁBITOS ALIMENTARES EM UMA AMOSTRA DE ESTUDANTES secundaristas de Porto Alegre. Pediatria, n. 19, p. 257-262, 1997.

FISBERG, M.; WEHBA, J. COZZOLINO, S. M. F. Um, dois, feijão com arroz: a alimentação no Brasil de Norte a Sul. São Paulo: Editora Atheneu, 2002. 418 p. FONSECA, V.M.; SICHIERI, R.; VEIGA, G.V. Fatores associados à obesidade em adolescentes. Revista de Saúde Pública, São Paulo, n. 32, p. 541-549, 1998. FOUILLÉ, D. Desenvolvendo o gosto por alimentos saudáveis. In: SLOAN, D.(Org.). Gastronomia, restaurantes e comportamento do consumidor. Barueri, São Paulo: Manole, 2005. p.175- 190.

FREITAS, P.P.; MENDONÇA, R.D.; LOPES, A.C.S. Factors associated with breakfasting in users of a public health service. Revista de Nutrição, v. 26, n. 2, p.195-203, 2013.

GABRIEL, C. G. et al. Planejamento de cardápios para escolas públicas municipais: reflexão e ilustração desse processo em duas capitais brasileiras. Revista de Nutrição, v. 25, n. 3, p. 363-372, 2012.

GALAS, A.; AUGUSTYNIAK, M.; SOCHACKA-TATARA, E.Does dietary calcium interact with dietary fiberagainst colorectal cancer? A case-control studyin Central Europe. Nutrition Journal, 12:134, 2013. Disponível em: <http://www.nutritionj.com/content/12/1/134>. Acesso em: 18 mar. 2014. GAMBARDELLA, A.M.D.; FRUTUOSO, M.P.F.; FRANCHI, C. Prática alimentar de adolescentes. Revista de Nutrição, Campinas, v. 12, n. 1, p. 55-63, 1999. GARCIA, R. W. D. Reflexos da globalização na cultura alimentar: considerações sobre as mudanças na alimentação urbana. Revista de Nutrição, Campinas, São Paulo, v. 16, n. 4, p. 483-492, 2003.

GARCIA, R. W. D. Representações sociais da alimentação e saúde e suas repercussões no comportamento alimentar. Revista de Saúde Coletiva, Rio de Janeiro, v. 7, n. 2, p. 51-68.1997.

GIBSON, S.; ASHWELL, M. Dietary patterns among British adults: compatibility with dietary guidelines for salt/sodium, fat, saturated fat and sugars. Public Health of Nutrition, v. 14, n. 8, p. 1323-1336, 2011.

GIMENES, M.H.S.G. Cozinhando a tradição: festa, cultura e história no litoral paranaense. 2008. 393 f. Tese (Doutorado em História) - Universidade Federal do Paraná, 2008.

GINANI, V.C. Avaliação da qualidade nutricional, sensorial e cultural de cardápios populares. 2011. 131 f. Tese (Doutorado em Nutrição Humana) Universidade de Brasília, Brasília, Distrito Federal, 2011.

GIOVANNINI, M. et al. Breakfast: a good habit, not a repetitive custom. Journal of International Medical Research, v. 36, p. 613-624, 2008.

GODOY, K.C. et al. Perfil e situação de insegurança alimentar dos usuários dos Restaurantes Populares no Brasil. Cadernos de Saúde Pública, Rio de Janeiro, v. 30, n. 6, p. 1239-1249, 2014.

GRIEGER, J.A.; COBIAC, L. Comparison of dietary intakes according to breakfast choice in Australian boys. European Journal of Clinical Nutrition, London, v. 66, p. 667-672,2012.

HALLSTRO"M, L. et al. Breakfast habits and factors influencing food choices at breakfast in relation to socio-demographic and family factors among European adolescents. The HELENA Study. Appetite, London, v. 56, p. 649-657, 2011. 
HARTER, D.L. et al. Association between low bone mass and calcium and caffeine intake among perimenopausal women in southern Brazil: cross-sectional study. São Paulo Medical Journal, v. 131, n. 5, p. 315-322, 2013.

HERNANDEZ, J.C. Patrimônio e globalização: o caso das culturas alimentares. In: CANESQUI, A.M.; GARCIA, R.W.D. (Orgs). Antropologia e Nutrição: um diálogo possível. Rio de Janeiro: Editora FIOCRUZ, 2005, p.129-145.

HERNANDEZ, J.C; ARNAIZ, M.G. Aproximaciones teóricas. In: HERNANDEZ, J.C; ARNAIZ, M.G. Alimentación y cultura. Barcelona: Ed. Ariel, 2005, p. 93-165. HERRERA, G.L. Caraccterización del consumo deficitário de lós grupos básicos de alimentos en el estudiante de cuarto año en la escuela de medicina "Dr Witremundo Torrealba". Maracay, Venezuela. Comunidade y Salud, v. 5, n. 2, p. 13-22, 2007. HIGDON, J.V.; FREI, B. Coffee and health: a review of recent human research. Critical Reviews in Food Science Nutrition, v. 46, n. 2, p.101-23, 2006. HISSANAGA, V. M.; PROENCA, R.P.C.; BLOCK, J. M. Ácidos graxos trans em produtos alimentícios brasileiros: uma revisão sobre aspectos relacionados à saúde e à rotulagem nutricional. Revista de Nutricão, São Paulo, v. 25, n. 4, p. 517-530, 2012.

HOERTEL, H.A.; WILL, M.J.; LEIDY, H.J. A randomized crossover, pilot study examining the effects of a normal protein vs. high protein breakfast on food cravings and reward signals in overweight/obese "breakfast skipping", late-adolescent girls.

Nutrition Journal 2014, 13:80. Disponível em:<http://www.nutritionj.com/content/13/1/80>. Acesso em: 20 set. 2015. HÖFELMANN, D. A.; MOMM, N. Breakfast: omission and associated factors in school children from Itajaí, Santa Catarina state, Brazil. Nutrire: Rev. Soc. Bras. Alim. Nutr. = J. Brazilian Soc. Food Nutr., São Paulo, v. 39, n. 1, p. 40-55, 2014. HOLMES, B.A. et al.The contribution of breakfast cereals to the nutritional intake of the materially deprived UK population. European Journal of Clinical Nutrition, London, n. 66, p.10-17, 2012.

HUANG, C. et al. Breakfast consumption frequency is associated with grip strength in a population of healthy Japanese adults. Nutrition, Metabolism and

Cardiovascular Diseases, 2014. Disponível em: <http://dx.doi.org/10.1016/j.numecd.2013.12.013>. Acesso em: 12 out. 2014. HULSHOF, K.F.A.M. et al. Socio-economic status, dietary intake and $10 \mathrm{y}$ trends: the Dutch National Food Consumption Survey. European Journal of Clinical Nutrition, London, n. 57, p.128-137, 2003.

IGNÁCIO, A.K.F. et al. Efeito da substituição de cloreto de sódio por cloreto de potássio em pão francês. Brazilian Journal of food Technology, Campinas, v. 16, n. 1, p. 1-11, 2013.

JAKUBOWICZ, D. et al. High caloric intake at breakfast vs. dinner differentially influences weight loss of overweight and obese women. Obesity, v. 21, n. 12, p. 2504-2512, 2013.

KAHLEOVA, $\mathrm{H}$. et al. Eating two larger meals a day (breakfast and lunch) is more effective than six smaller meals in a reduced-energy regimen for patients with type 2 diabetes: a randomised crossover study. Diabetologia, v. 57, p.1552-1560, 2014. KANT, A.K. et al. Association of breakfast energy density with diet quality and body mass index in American adults: National Health and Nutrition Examination Surveys, 1999-2004. American Journal of Clinical Nutrition, n. 88, p.1396-1404, 2008. KANT, A.K.; GRAUBARD, B.I. Within-person comparison of eating behaviors, time of eating, and dietary intake on days with and without breakfast: NHANES 2005-2010.

American Journal of Clinical Nutrition, p.102:661-70, 2015. 
KENNEDY, E.; DAVIS, C. Departament of Agriculture School Breakfast Program. American Journal of Clinical Nutrition, v. 67, p. 798-803, 1998. Suplemento. KEPPLE, A.W.; SEGALL-CORRÊA, A.M. Conceituando e medindo segurança alimentar e nutricional. Ciência \& Saúde Coletiva, Rio de Janeiro, v. 16, n. 1, p.187199, 2011.

KURODA, T. et al. Relationship between skipping breakfast and bone mineral density in young Japanese women. Asia Pacific Journal of Clinical Nutrition, China, v. 22, n. 4, p. 583-589, 2013.

KUTSUMA, A.; NAKAJIMA, K.; SUWA, K. Potential association between breakfast skipping and concomitant late-night-dinner eating with metabolic syndrome and proteinuria in the japanese population. Scientifica, v. 2014, article ID 253581, 9 pages. Disponível em:

<http://www.ncbi.nlm.nih.gov/pmc/articles/PMC3984843/pdf/SCIENTIFICA2014253581.pdf $>$. Acesso em: 12 jan. 2015.

LAZZERI, G. et al. Association between fruits and vegetables intake and frequency of breakfast and snacks consumption: a cross-sectional study. Nutrition Journal, Londres, v. 12, p.123, 2013. Disponível em:

<http://www.nutritionj.com/content/12/1/123>. Acesso em: 30 mar. 2014.

LEAL, G.V.S. et al. Food intake and meal patterns of adolescents, São Paulo, Brazil

Revista Brasileira de Epidemiologia, São Paulo, v. 13, n. 3, p. 1-10, 2010.

LEE, J.W. et al. Cultural differences in responses to a Likert Scale. Research in Nursing \& Health, v. 25, p. 295-306, 2002.

LEONARDO, M. Antropologia da alimentação. Revista Antropos, Barcelona, v. 3, ano 2, p. 1-6, 2009. Disponível em:

$<$ http://revista.antropos.com.br/downloads/dez2009/Artigo\%201\%20-

\%20Anntropologia\%20da\%20Alimenta\%E7\%E30\%20-\%20Maria\%20Leonardo.pdf>. Acesso em: 4 fev. 2015.

LEVITSKY, D.A; PACANOWSKI, C.R. Effect of skipping breakfast on subsequent energy intake. Physiology and Behavior, Zurich, v. 119, p. 9-16, 2013.

LIMA, M.F.F. O ceará e a emergência de uma cozinha regional. In: SEMINÁRIO SOBRE ALIMENTOS E MANIFESTAÇÕES CULTURAIS TRADICIONAIS. GT04 - O Alimento como memória e identidade nos territórios, 1., 2012, Sergipe. Anais eletrônicos... Sergipe: Universidade Federal de Sergipe, 2012. Disponivel em: $<$ http://www.grupam.net/anais-do-i-seminario-sobre-alimentos-emanifesta\%C3\%A7\%C3\%B5es-culturais-tradicionais/>. Acesso em: 10 out. 2014. LONGO-SILVA, G. et al. Avaliação do consumo alimentar em creches públicas em São Paulo, Brasil. Revista Paulista de Pediatria, São Paulo, v. 30, n. 1, p. 35-41, 2012.

LUZ, A.R. Concentrações séricas de cálcio e ferro em jovens consumidores de tereré (ilex paraguarienses), Dourados, MS. Dourados, MS. 2007. $112 f$.

Dissertação (Mestrado em Ciências da Saúde) - Universidade de Brasília, 2007. MACHADO, F.M.S.; SIMÕES, A.N. Análise custo-efetividade e índice de qualidade da refeição aplicados à Estratégia Global da OMS. Revista de Saúde Pública, São Paulo, v. 42, n. 1, p. 64-72, 2008.

MACHADO, I. E. et al. Fatores associados ao excesso de peso em adultos usuários de restaurantes populares em Belo Horizonte, Brasil. Ciências \& Saúde Coletiva, Rio de Janeiro, v. 19, n. 5, p. 1367-1377, 2014.

MACIEL, M.E. Uma cozinha à brasileira. Estudos Históricos, n. 33, p. 25-29, 2004. 
MACIEL, M.E. Identidade cultural e alimentação. In: CANESQUI, A.M.; GARCIA, R.W.D. (orgs). Antropologia e Nutrição: um diálogo possível. Rio de Janeiro: editora FIOCRUZ, 2005. p. 49-55.

MADER, H. O movimento slow food no Brasil. In: MIRANDA, D.S.; CORNELLI, G. (orgs). Cultura e Alimentação: saberes alimentares e sabores culturais. São Paulo: SESC, 2007. p. 165- 169.

MAEDA, S.S. et al. Recomendações da Sociedade Brasileira de Endocrinologia e Metabologia (SBEM) para o diagnóstico e tratamento da hipovitaminose

D. Arquivos Brasileiro de Endocrinologia e Metabologia, v. 58, n. 5, p. 411-433, 2014.

MAGALHÃES, R. Avaliação de políticas e iniciativas públicas de segurança alimentar e nutricional: dilemas e perspectivas metodológicas. Ciências \& Saúde

Coletiva, Rio de Janeiro, v. 19, n. 5, p. 1339-1346, 2014.

MAINARD, N. A ingestão de alimentos e a orientação da escola sobre alimentação, sob o ponto de vista do aluno concluinte do ensino fundamental. 2005.151f. Dissertação (Mestrado em Ciências). Universidade de São Paulo.

Piracicaba, 2005.

MALTA, D.C. et al. Doenças crônicas não transmissíveis e o suporte das ações intersetoriais no seu enfrentamento. Ciências \& Saúde Coletiva, Rio de Janeiro, v. 19, n. 11, p. 4341-4350, 2014.

MALUF, R. Segurança alimentar e nutricional com valorização da cultura alimentar. In: MIRANDA, D.S.; CORNELLI, G. (orgs). Cultura e Alimentação. Saberes alimentares e sabores culturais. São Paulo: SESC, 2007, p. 143-50.

MARANGONI, F. A. et al. Consensus document on the role of breakfast in the attainment and maintenance of health and wellness. Acta Biomedica, Italy, n. 80, p.166-171, 2009.

MARCHIONI, D.M.L. et al. Prevalência de omissão do café da manhã e seus fatores associados em adolescentes de São Paulo: estudo ISA-Capital. Nutrire, São Paulo, v. 40 , n. 1, p. 10-20, 2015.

MARLATT, K.L. et al. Breakfast and fast food consumption are associated with selected biomarkers in adolescents. Preventive Medicine Reports, v. 3, p. 49-52, 2016.

MARLETT, J.A. et al. Position of the American Dietetic Association: health implications of dietary fiber. Journal of American Dietetic Association, v. 102, p. 993-1000, 2002.

MARTINS, A.P.B. (Org.) Redução de sódio em alimentos: uma análise dos acordos voluntários no Brasil. / Instituto Brasileiro de Defesa do Consumidor. Cadernos Idec - Série Alimentos - Volume 1. São Paulo: Idec, 2014.

MARTINS, M.C. et al. Segurança alimentar e uso de alimentos regionais: validação de um álbum seriado. Revista da Escola de Enfermagem da USP, São Paulo, v. 46, n. 6, p.1354-1361, 2012.

MARTINS, M.C. Intervenção educativa para utilização de alimentos regionais por famílias de pré-escolares. 2010. 162 f. Tese (Doutorado em Enfermagem) Universidade Federal do Ceará, Fortaleza. 2010.

MASTROROSA, L. É do Brasil. In:

Pingado e pão na chapa: histórias e receitas de café da manhã. Rio de Janeiro: Memória Visual, 2010. p. 33- 49. MATTOS, L.L.; MARTINS, I.S. Consumo de fibras alimentares em população adulta. Revista de Saúde Pública, São Paulo, v. 34, n. 1, p. 50-55, 2000. 
MAZZILI, R.N. Algumas considerações sobre o consumo de alimentos em lcapara e Pontal de Ribeira, São Paulo, Brasil. Revista de Saúde Pública, São Paulo, v. 9, p. 49-55, 1975.

MEDEIROS, M.A.T. et al. Estado nutricional e práticas alimentares de trabalhadores acidentados. Revista de Nutrição, Campinas, v. 20, n. 6, p. 589-602, 2007.

MELBY, M.K.; TAKEDA, W. Lifestyle constraints, not inadequate nutrition education, cause gap between breakfast ideals and realities among Japanese in Tokyo.

Appetite, United kingdom, v. 72, p. 37-49, 2014.

MENETON, P. et al. Dietary sources and correlates of sodium and potassium intakes in the French general population. European Journal of Clinical Nutrition, v. 63, p. 1169-1175, 2009.

MENEZES, E.W. et al. Impact of dietary fiber energy on the calculation of food total energy value in the Brazilian Food Composition Database. Food Chemistry, v. 193, p. 128-133, 2016.

MENEZES, F.A.F.; BRAIT-POPLAWSKI, L.; ROVERSI, M.M.S. Elementos do sistema não

contributivo de seguridade social no Brasil: Do plano Fome Zero ao plano Brasil Sem Miséria. IBASE/ BROT FÜR DIE WELT. Versão portuguesa, Stuttgart, Alemanha, Julho 2012. Disponível em: <http://www.brot-fuer-die-

welt.de/fileadmin/mediapool/2_Downloads/Fachinformationen/Analyse/analyse_33_p ortugiesisch_Elementos_da_Seguridade_Social_no_Brasil.pdf>. Acesso em: 30 jul. 2014.

MILLA; P.G.; JOHNS, P. C.; AGUERO, S.D. Asociación del consumo del desayuno y la calidad de vida en adultos mayores autonomos chilenos. Nutrition Hospitalaria, Madrid, v. 30, n. 4, p. 845-850, 2014.

MIN, C. et al. Breakfast patterns are associated with metabolic syndrome in Korean adults. Nutrition Research and Practice, Korea, v. 6, n. 1, p. 61-67, 2012.

MIN, C. et al. Skipping breakfast is associated with diet quality and metabolic

syndrome risk factors of adults. Nutrition Research and Practice, Korean, v. 5, n. 5, p. 455-463, 2011.

MINTZ, S.W. Comida e antropologia: Uma breve revisão. Revista Brasileira de

Ciências Sociais, v. 16, n. 47, p. 31-41, 2001.

MIRZAEI, A. et al. The study of primary schoolchildren eating breakfast status in Ilam: A pilot study. Journal of Basic Research in Medical Science, v. 3, n. 1, p. 39, 2016.

MONTEAGUDO, C. et al. Proposal for a Breakfast Quality Index (BQI) for children and adolescents. Public Health Nutrition, Cambridge, v. 16, n. 4, p. 639-644, 2012. MONTEIRO, C.A. Segurança alimentar e nutrição no Brasil. In: Brasil. Ministério da Saúde. Saúde no Brasil - Contribuições para a Agenda de Prioridades de Pesquisa/Ministério da Saúde. Brasília: Ministério da Saúde, 2004. 306 p.

MONTEIRO, C.A. et al. A new classification of foods based on the extent and purpose of their processing. Cadernos de Saúde Pública, Rio de Janeiro, v. 26, n. 11, p. 2039-2049, 2010.

MONTEIRO, D.; MENDONÇA, M.M. Quintais na cidade: a experiência de moradores da periferia do Rio de Janeiro. Agriculturas, v. 1, n. 0, p. 29-31, 2004.

MORAIS, D.C. et al. Insegurança alimentar e indicadores antropométricos, dietéticos e sociais em estudos brasileiros: uma revisão sistemática. Ciências \& Saúde

Coletiva, Rio de Janeiro, v. 19, n. 5, p. 1475-1488, 2014.

MORAIS, G.Q.; BURGOS, M.G.P.A. Impacto dos nutrientes na saúde óssea: novas tendências. Revista Brasileira de Ortopedia, v. 42, n. 7, p. 189-194, 2007. 
MORALES, I.F. et a. Breakfast quality and its relationship to the prevalence of overweight and obesity in adolescents in Guadalajara (Spain). Nutrición

Hospitalaria, Madrid, v. 26, n. 5, p. 952-958, 2011.

MORILLAS-RUIZ, J.M. et al.The type of fat ingested at breakfast influences the plasma

lipid profile of postmenopausal women. BioMed Research International, v. 2014. Disponivel em: <http://www.hindawi.com/journals/bmri/2014/815915/abs/>. Acesso em 15 set. 2014.

MULLAN, B. A.; SINGH, M. A systematic review of the quality, content, and context of breakfast consumption. Nutrition and Food Science, v. 40, n. 1, p. 81-114, 2010. MUR DE FRENNE, L.; FLETA, J.; MORENO, L. Ingesta de alimentos a lo largo de todo el dia em niños zaragozanos. Nutrition Clinical, v. 2, p.19-30, 1994.

NESTEL, P. Trans Fatty Acids: Are Its Cardiovascular Risks Fully Appreciated?

Clinical Therapeutics, v. 36, n. 3, 2014.

NICKLAS, T.A. et al. Impact of breakfast consumption on nutritional adequacy of the diets of young adults in Bogalusa, Louisiana: ethnic and gender contrasts. Journal American Dietetic Association, v. 98, p.1432-1438, 1998.

NICKLAS, T.A. et al. Children's meal patterns have changed over a 21-year period: the

Bogalusa heart study. Journal American Dietetic Association, v. 104, n. 5, p. 75361, 2004.

NICKLAS, T.A. et al. Eating patterns, dietary quality and obesity. Journal ofthe American College Nutrition, v. 6, p. 599-608, 2001.

NILSON, E.A.F.; JAIME, P.C.; RESENDE, D.O. Iniciativas desenvolvidas no Brasil para a redução do teor de sódio em alimentos processados. Revista Panamericana de Salud Publica, Washington, v. 32, n. 4, p. 287-92, 2012.

NURUL-FADHILAH, A. et al. Infrequent breakfast consumption is associated with higher body adiposity and abdominal obesity in Malaysian school-aged adolescents.

PLoS One, v. 8, n. 3, e59297, mar. 2013. Disponível em:

<http://www.ncbi.nlm.nih.gov/pmc/articles/PMC3592841/pdf/pone.0059297.pdf>.

Acesso em: 04 set. 2013.

NUZZO, L. Avaliação do estado nutricional de adolescentes de uma instituição particular de ensino. 1998. 76f. Dissertação (Mestrado) - São Paulo: Faculdade de Saúde Pública, Universidade de São Paulo; 1998.

OLIVEIRA, A.K.M. et al. Ethnobotany and traditional medicine of the inhabitants of the Pantanal Negro sub-region and the raizeiros of Miranda and Aquidauna, Mato Grosso do Sul, Brazil. Brazilian Journal of Biology, v. 71, n. 1, p. 283-289, 2011. Suplemento.

OLIVEIRA, S.P.; THÉBAUD-MONY, A. Hábitos e práticas alimentares em três localidades da cidade de São Paulo (Brasil). Revista de Nutrição, Campinas, v. 11, n. 1, p. 37-50, 1998.

O'NEIL, C.E. et al. The role of breakfast in health: definition and criteria for a quality breakfast. Journal of the Academy of Nutrition and Dietetics, v. 114, n. 12, 2014. Suplemento 3.

ORTEGA, R.M. et al. Associations between obesity, breakfast-time food habits and intake of energy and nutrients in a group of elderly Madrid residents. Journal of the American College of Nutrition, v. 15, n. 1, 1996.

ORTIZ, R. Mundialização e cultura. 2.ed. São Paulo: Brasiliense, 1994. 234p. PEDERSEN, T.P. et al. Fruit and vegetable intake is associated withfrequency of breakfast, lunch and evening meal: cross-sectional study of 11-, 13-, and 15-year- 
olds. International Journal of Behavioral Nutrition and Physical Activity, 9:9, 2012. Disponível em: <http://www.ijbnpa.org/content/9/1/9>. Acesso em 10 mar. 2012.

PEREIRA, G.A.P. et al. Cálcio dietético - estratégias para otimizar o consumo. Revista Brasileira de Reumatologia, v. 49, n. 2, p. 164-180, 2009.

PEREIRA, M.A. et al. Breakfast frequency and quality may affect glycemia and appetite in adults and children. The Journal of Nutrition, United States, v. 141, n. 1, p. 163-168, 2011.

PEREIRA, M.G. Epidemiologia: teoria e prática. 3ª̣ed. Rio de Janeiro: Guanabara Koogan. 2001. 596 p.

PHILIPPI, S.T. Nutrição e Técnica Dietética. 2ª edição. Editora Manole, 2006. p. 239-52.

PINEYRUA, D.G.F. Regionalismo alimentar: identificação de grupos de consumidores que valorizam o prazer e as tradições alimentares. 2006. 117f. Dissertação (Mestrado em Agronegócios) - Departamento de Economia e Administração. Universidade Federal do Mato Grosso do Sul. 2006.

PINHEIRO, C.T. et al. Hábitos e preferências alimentares de funcionários de um hospital de pelotas, RS. In: XIX CIC, XII ENPOS, II MOSTRA CIENTÍFICA, 2010. Pelotas. Anais eletrônicos... Pelotas: Universidade Federal de Pelotas, 2010. Disponível em:<http://www.antropologiasocial.com.br/xix-cic-xii-enpos-ii-mostracientifica-2010/>. Acesso em: 18 dez. 2014.

PINHEIRO, K. A.P.N. Perfil de consumo de desjejum de estudantes da área de saúde da Universidade de Brasília, DF. 2006. 143 f. Dissertação (Mestrado em Nutrição Humana) - Departamento de Nutrição, Universidade de Brasília. 2006. PONS, S.C. Pontos de partida teórico-metodológicos para o estudo sociocultural da alimentação em um contexto de transformação. In: CANESQUI, A.M.; GARCIA, R.V.D. (org.). Antropologia e Nutrição: um diálogo possível. Rio de Janeiro: Editora FIOCRUZ, 2005. p. 101- 126.

POPKIN, B.M. Global nutrition dynamics: the world is shifting rapidly toward a diet linked with noncommunicable diseases. American Journal Clinical Nutrition, n. 84, p. 289-98, 2006. Disponível em:

<http://ajcn.nutrition.org/content/84/2/289.full.pdf+html>. Acesso em: 12 dez 2014. PORCINO, D.C. et al. Comensalidade e memória alimentar: um estudo em um mercado popular da cidade de salvador-bahia. .In: SEMINÁRIO SOBRE

ALIMENTOS E MANIFESTAÇÕES CULTURAIS TRADICIONAIS. GT04- O Alimento como Memória e Identidade nos Territórios, 1., 2012, Sergipe. Anais eletrônicos... Sergipe: Universidade Federal de Sergipe, 2012. Disponivel em: $<$ http://www.grupam.net/anais-do-i-seminario-sobre-alimentos-emanifesta\%C3\%A7\%C3\%B5es-culturais-tradicionais/>. Acesso em: 10 out. 2014. POT, G.K.; HARDY, R.; STEPHEN, A.M. Irregularity of energy intake at meals: prospective associations with the metabolic syndrome in adults of the 1946 British birth cohort. British Journal of Nutrition, v. 115, p. 315-323, 2016.

POULAIN, J-P. Apresentação. In: POULAIN, J-P. Sociologias da Alimentação: os comedores e o espaço social alimentar. Florianópolis: Ed. Da UFSC, 2004, p.19-22. POULAIN, J-P.; PROENÇA, R. P.C. O espaço social alimentar: um instrumento para o estudo dos modelos alimentares. Revista de Nutrição, São Paulo, v. 16, n. 3, p. 245-256, 2003.

PRADO, S.D. et al. A pesquisa sobre segurança alimentar e nutricional no Brasil de 2000 a 2005: tendências e desafios. Ciência \& Saúde Coletiva, Rio de Janeiro, v. 15 , n. 1, p. 7-18, 2010. 
PROENÇA, R.P.C. Alimentação e globalização: algumas reflexões. Ciência e Cultura, São Paulo, v. 62, n. 4, p. 43-47, 2010.

PROENÇA, R. P. da C. et al. Qualidade nutricional e sensorial na produção de refeições. Florianópolis: Ed. da UFSC, 2005. p. 221.

PROENÇA, R.P.C.; SILVEIRA, B.M. Recomendações de ingestão e rotulagem de gordura trans em alimentos industrializados brasileiros: análise de documentos oficiais. Revista de Saúde Pública, v. 46, n. 5, p. 923-28, 2012.

PURSLOW, L.R. et al.Energy intake at breakfast and weight change: prospective study of 6,764 middle-aged men and women. American Journal of Epidemiology, Estados Unidos, v. 167, n. 2, p. 188-92, 2008.

RAINS, T.M. et al. A randomized, controlled, crossover trial to assess the acute appetitive and metabolic effects of sausage and egg-based convenience breakfast meals in overweight premenopausal women. Nutrition Journal, v. 14, n. 17, p. 1-10, 2015.

RAMPERSAUD, G.C. Benefits of breakfast for children and adolescents: update and recommendations for practitioners. American Journal of Lifestyle Medicine, v. 3, n. 2, p. 86-103, 2009.

RAMPERSAUD, G. C. et al. Breakfast habits, nutritional status, body weight, and academic performance in children and adolescents. Journal of the American Dietetic Association, v. 105, n. 5, p. 743-760, 2005.

RECH, R.R. et al. Prevalência de obesidade em escolares de 7 a 12 anos de uma cidade Serrana do RS, Brasil. Revista Brasileira de Cineantropometria e

Desempenho Humano, v. 12, n. 2, p. 90-97, 2010.

REEVES, S. et al. Breakfast habits, beliefs and measures of health and well being in a nationally representative UK sample. Appetite, United Kingdom, v. 60, p. 51-57, 2013.

REINSTEIN, C.S.B.; REINSTEIN, B. B.; ZINGANO,R. Dietwin® profissional 2.0, Software de Análise nutricional. Rio Grande do Sul: 2008. 1 CD-ROM.

REJMAN, K.; KASPERSKA, A. Nutritional and health benefits as the determinants of food choice in Polish consumers. Perspectives in Public Health, v. 131, p. 262266v, 2011.

RIERA-MELIS, A. Sociedade feudal e alimentação (séculos XII-XIII). In: FLANDRIN, J-L.; MONTANARI, M.; [tradução de Machado,L.V.; Teixeira, G.J.F]. História da Alimentação. São Paulo: Estação Liberdade, 1998. p. 387- 408.

RIVES, F.M. et al. Atención farmacéutica en el fomento del desayuno saludable desde la oficina de farmácia. Nutricion Hospitalaria, Madrid, v. 32, n. 3, p.12671272, 2015.

RUEDA, J.M.; KHOSLA, P. Impact of breakfasts (with or without eggs) on body weight regulation and blood lipids in university students over a 14-week semester.

Nutrients,v. 5, p. 5097-113, 2013.

SANTOS, J. S. et al. Perfil antropométrico e consumo alimentar de adolescentes de Teixeira de Freitas - Bahia. Revista de Nutrição, Campinas, São Paulo, v. 18, n. 5, p. 623-632, 2005.

SANTOS, L.A.S. Da dieta à reeducação alimentar: algumas notas sobre o comer contemporâneo a partir dos programas de emagrecimento na internet. Physis

Revista de Saúde Coletiva, Rio de Janeiro, v. 20, n. 2, p. 459-474, 2010.

SANTOS, R.O. Caracterização da população adulta e idosa do município de

São Paulo segundo padrões de refeições - Estudo de base populacional, ISA Capital 2008. 2014. 107f. Dissertação (Mestrado) - São Paulo: Faculdade de Saúde Pública da Universidade de São Paulo, 2014. 
SANTOS, R.O. et al. Dietary patterns for meals of Brazilian adults. British Journal of Nutrition, v.114, p. 822-828, 2015.

SANTOS, V. F. N.; PASCOAL, G.B. Aspectos gerais da cultura alimentar paraense. Revista da Associação Brasileira de Nutrição, São Paulo, ano 5, n. 1, p. 73-80, 2013.

SARNO, F. et al. Estimativa de consumo de sódio pela população brasileira, 20022003. Revista de Saúde Pública, v. 43, n. 2, p. 219-225, 2009.

SCHEMBRE, S.M. et al. Eating breakfast more frequently is cross-sectionally associated with greater physical activity and lower levels of adiposity in overweight latina and african american girls. American Journal Clinical Nutrition, v. 98, p. 275-81, 2013.

SCHUSDZIARRA, V. et al. Impact of breakfast on daily energy intake - an analysis of absolute versus relative breakfast calories. Nutrition Journal, 10:5, 2011.

Dísponível em: <http://www.nutritionj.com/content/10/1/5>. Acesso em: 05 mar. 2014.

SHAFIEE, G. et al. Association of breakfast intake with cardiometabolic risk factors. Jornal de Pediatria, Rio de Janeiro, v. 89, n. 6, p. 575-582, 2013.

SHEEHY, T.; ROACHE, C.; SHARMA,S. Eating habits of a population undergoing a rapid dietary transition: portion sizes of traditional and non-traditional foods and

beverages consumed by Inuit adults in Nunavut, Canada. Nutrition Journal, 12:70, 2013. Disponível em: <http://www.nutritionj.com/content/12/1/70>. Acesso em: 15 ago. 2013.

SILVA, A.B. Perfil nutricional da clientela atendida nos restaurantes comunitários do Distrito Federal. 2010. 109 f. Dissertação (Mestrado em Nutrição Humana) - Universidade de Brasília, Brasília, Distrito Federal, 2010.

SILVA, A.C. De Vargas a Itamar: políticas e programas de alimentação e nutrição.

Estudos avançados, São Paulo, v. 9, n. 23, p. 87-107, 1995.

SILVA, C.C.S. et al. Associação entre consumo alimentar e (in)segurança alimentar e nutricional em São José dos Ramos - PB. Brazilian Journal of Food Technology, São Paulo, v. 15, n. especial, p. 23-30, 2012.

SILVA, D.O.; FREITAS, M.C.S.; SOUSA, J.R. Significados e representações do conceito de comida na persperctiva da promoção da alimentação saudável. In: FREITAS, M.C.S; SILVA, D.O. (orgs). Narrativas sobre o Comer no Mundo da Vida. Salvador: EDUFBA, 2014, p. 79- 94.

SILVA, H.A. Mandioca, a rainha do Brasil? Ascensão e queda da Manihot esculenta em São Paulo. 2008. 168f. Dissertação (Mestrado em História) Faculdade de Filosofia, Letras e Ciências Humanas. Universidade de São Paulo. 2008.

SILVA, H.H.C. Consumo alimentar de desjejum de adolescentes em escolas particulares de Brasília. 2006. 80f. Dissertação (Mestrado em Ciências da Saúde) - Faculdade de Ciências da Saúde, Universidade de Brasília. 2006.

SILVA, J. G. Segurança alimentar: uma construção comunitária. 2003. Disponível em: <http://www.presidencia.gov.br/artigosdomesa> Acesso em: 20 dez. 2014.

SILVA, M. S. et al. Risco de doenças crônicas não transmissíveis na população atendida em Programa de Educação Nutricional em Goiânia (GO), Brasil. Ciências e Saúde Coletiva, v. 19, n. 5, p. 1409-1418, 2014.

SILVA, M.V. Avaliação da adequação nutricional dos alimentos consumidos em um Centro Integrado de Educação Pública (CIEP). Cadernos de Saúde Pública, Rio de Janeiro, v. 11, n. 4, p. 552-559, 1995. 
SILVEIRA, M.L. et al. Conhecimento, atitude e prática sobre alimentos regionais entre famílias de pré-escolares. Revista da Rede de Enfermagem do Nordeste, Fortaleza, v. 15, n. 1, p. 37-44, 2014.

SIVARAMAKRISHNAN, M.; KAMATH, V. A typical working-day breakfast among children, adolescents and adults belonging to the middle and upper socio-economic classes in Mumbai, India - challenges and implications for dietary change. Public Health Nutrition, v. 15, n. 11, p. 2040-2046, 2012.

SMITH, K.J. et al. Skipping breakfast: longitudinal associations with cardiometabolic risk factors in the childhood determinants of adult health study. American Journal of Clinical Nutrition, v. 92, p. 1316-25, 2010.

SOARES, M.J.; PING-DELFOS, W.C.S. Second meal effects of dietary calcium and vitamin D. European Journal of Clinical Nutrition, n. 62, p. 872-878, 2008.

SOBRINHO, F.M. et al.Fatores determinantes da insegurança alimentar e nutricional: estudo realizado em Restaurantes Populares de Belo Horizonte, Minas Gerais, Brasil. Ciências \&Saúde Coletiva, Rio de Janeiro, v. 19, n. 5, p. 1601-1611, 2014. SONATI, J.G.; VILARTA, R.; SILVA, C.C. Influências culinárias e diversidade cultural da identidade brasileira: imigração, regionalização e suas comidas. In: MENDES, T.; VILARTA, R.; GUTIERREZ, G.L. (orgs). Qualidade de vida e cultura alimentar. Campinas: Ipês Editorial. 2009. p. 137-147.

SONG, W.O. et al. Ready-to-eat breakfast cereal consumption enhances milk and calcium intake in the US population. Journal of the American Diet Association, Ohio, United States, v. 106, p. 1783 - 1789, 2006.

SONG, Y.J. et al. Traditional v. modified dietary patterns and their influence on adolescents' nutritional profile. British Journal of Nutrition, v. 93, p. 943-949, 2005. SOUZA, A.M. et al. Alimentos mais consumidos no Brasil: Inquérito Nacional de Alimentação 2008-2009. Revista de Saúde Pública, São Paulo, v. 47, n. 1, p. 190199, 2013. Suplemento.

SOUZA, B.F.N.J.; MARIN-LEON, L. Food insecurity among the elderly: crosssectional study with soup kitchen users. Revista de Nutrição, Campinas, São Paulo, v. 26, n. 6, p. 679-91, 2013.

SOUZA, F.C.; ALMEIDA, M.G. Por uma leitura geográfica do fazer e do comer, no campo e na cidade, em Goiás. Revista Formação, São Paulo, v. 2, n. 14, p.

104-118, 2011. Disponivel

em:<http://revista.fct.unesp.br/index.php/formacao/article/view/649/665>. Acesso em: 20 out. 2014.

SOUZA, M.T.; SILVA, M.D; CARVALHO, R. Revisão integrativa: o que é e como fazer. Einstein, n. 8, p. 102-106, 2010.

SOUZA, S.M. et al. Relação entre o Indice de Massa Corporal e o tipo de desjejum de pacientes de um consultório de nutrição. Revista Brasileira de Obesidade, Nutrição e Emagrecimento, v. 1, n. 3, p. 79-84, 2007.

SPSS® for Windows, Rev. 20.0 [programa de computador]. Chicago: SPSS Inc. 1 CD-ROM.

STRAZZULLO, P. et al. Population based strategy for dietary salt intake reduction: Italian initiatives in the EuropeanFramework. Nutrition, Metabolism \&

Cardiovascular Diseases, v. 22, p. 161-166, 2012.

SUGIYAMA, S. et al. Breakfast habits among adolescents and their association with daily energy and fish, vegetable, and fruit intake: a community-based crosssectional study. Environmental Health and Preventive Medicine, Japan, v. 17, n. 5, p. 408-414, 2012. 
SUN, J. et al. Factors associated with skipping breakfast among Inner Mongolia medical students in China. BMC Public Health, London,13:42, 2013. Disponível em: <http://www.biomedcentral.com/1471-2458/13/42>. Acesso em: 18 mar. 2014. SZWARCWALD, C.L. et al. Pesquisa Nacional de Saúde no Brasil: concepção e metodologia de aplicação. Ciência \& Saúde Coletiva, Rio de Janeiro, v. 19, n. 2, p. 333-342, 2014.

TACO - Tabela Brasileira de Composição de Alimentos - Núcleo de Estudos e Pesquisas em Alimentação - NEPA-UNICAMP, versão II, 2.ed., Campinas, São Paulo, 2006.

TINOCO, l. et al. Teores de sódio descritos na informação nutricional de produtos alimentícios de sabor doce. Corpus et Scientia, Rio de Janeiro, v. 9, n. 2, p. 56-68, 2013.janeiro | v. 9, n. 2 | p. 56-68 | jul./dez. 2013 rio de janeiro | v. 9, n. 2 | p. 56-68 | jul./dez. 2013

TONIETTO, J. Afinal, o que é Terroir? Bon Vivant, Flores da Cunha, v. 8, n. 98, p. 08 , abr.

2007. Disponível em: <http://www.cnpuv.embrapa.br/publica/artigos>. Acesso em: 18 ago. 2014.

TRANCOSO, S.C.; CAVALLI, S.B.; PROENÇA, R.P.C. Café da manhã: caracterização, consumo e importância para a saúde. Revista de Nutrição, São Paulo, v. 23, n. 5, p. 856-869, 2010.

TRAVÉ, T.D. Análisis nutricional del desayuno y almuerzo en una poblaciónUniversitária. Nutricion Hospitalaria, v. 28, n. 3, p. 1291-1299, 2013.

TRICHES, R.M.; GIUGLIANI, E.R.J. Obesidade, práticas alimentares e conhecimentos de nutrição em escolares. Revista de Saúde Pública, v. 39, n. 4, 541-7, 2005.

TRICHOPOULOU, A. et al. Traditional foods: why and how tosustain them. Trends in Food Science \& Technology, n. 17, p. 498-504, 2006.

UEMURA, M. et al. Breakfast skipping is positively associated with incidence of type 2 Diabetes Mellitus: evidence from the aichi workers' cohort study. Journal of Epidemiology, v. 25, n. 5, p. 351-358, 2015.

UGGIONI, P.L. Valorização do Patrimônio Gastronômico Regional Açoriano: Gestão de Qualidade em Restaurantes Típicos em Florianópolis-SC. 2006. 265 f. Dissertação (Mestrado em Nutrição) - Universidade Federal de Santa Catarina, Santa Catarina. 2006.

UGGIONI, P.L; PROENÇA, R.P.C.; ZENI, L.A.Z.R. Assessment of gastronomic heritage quality in traditional restaurants. Revista de Nutrição, São Paulo, v. 23, n. 1, p. 7-16, 2010.

UNIVERSIDADE DE BRASILIA. Faculdade de Ciências da Saúde. Departamento de Nutrição. Projeto de pesquisa: Diagnóstico da Qualidade e Atenção Dietética nos Restaurantes Populares do Brasil. Brasília, 2010. 99 p.

VALENGA, L.R. Hábitos alimentares dos alunos da $7^{\text {a }}$ série "A" do Colégio Estadual Altair Mongruel do município de Ortigueira - Paraná. 2011. 39f. Monografia (especialização). Universidade Tecnológica Federal do Paraná - UTFPR - Campus Medianeira. 2011. Disponível em:

<http://repositorio.roca.utfpr.edu.br/jspui/handle/1/2402>. Acesso em 12 jan. 2015. VAN DEN BOOM, A. et al. The contribution of ready-to-eat cereals to daily nutrient intake and breakfast quality in a Mediterranean setting. Journal of American College Nutrition, v. 25, p. 135-143, 2006.

VASCONCELOS, F. A. G. Josué de Castro e a geografia da fome no Brasil. Cadernos de Saúde Pública, Rio de Janeiro, v. 24, n. 11, p. 2710-2717, 2008. 
VIEIRA, M.V.; DEL CIAMPO, I.R.L.; DEL CIAMPO, L.A. Hábitos e consumo alimentar entre adolescentes eutróficos e com excesso de peso. Journal of Human Growth and Development, v. 24, n. 2, p. 157-162, 2014.

VIEIRA, V.C.R. et al. Alterações no padrão alimentar de adolescentes com adequação pôndero-estatural e elevado percentual de gordura corporal. Revista Brasileira de Saúde Materno Infantil, Recife, n. 5, p. 93-102, 2005.

VIEIRA, V.L. et al. Ações de alimentação e nutrição e sua interface com segurança alimentar e nutricional: uma comparação entre Brasil e Portugal. Saúde e

Sociedade, São Paulo, v. 22, n. 2, p. 603-617, 2013.

VILLAS BÔAS, G.F.M. Alimentos regionais: avaliação das mudanças da oferta no programa de restaurantes populares brasileiros. 2013. 93 f. Dissertação (Mestrado em Nutrição Humana) - Faculdade de Ciências da Saúde, Universidade de Brasília, Brasília, Distrito Federal, 2013.

WANG, Y.; PROCTOR, S.D. Current issues surrounding the definition of trans-fatty acids:

implications for health, industry and food labels. British Journal of Nutrition, v. 110, p. 1369-1383, 2013.

WEAVER, C.M.; HEANEY, R.P. Food sources, supplements, and bioavailability. In: . Calcium in Human Health. Totowa: Human Press Inc, 2006. p.129-42.

WIJTZES, A.I. et al. Meal-Skipping Behaviors and Body Fat in 6-Year-Old Children.

The Journal of Pediatrics, v. 168, p. 118-125, 2016.

WIKIPÉDIA. A enciclopédia livre. Disponível em:<https://pt.wikipedia.org>. Acesso em: 10 fev. 2013.

WHO. WORLD HEALTH ORGANIZATION (WHO). Diet, nutrition and the prevention of chronic diseases. Geneva: World Health Organization; 2003.

WHO. WORLD HEALTH ORGANIZATION. Global Strategy for food safety: Safer Food For Better Health. Switzerland, 2004, 20p.

WHO. WORLD HEALTH ORGANIZATION. Prevention of cardiovascular disease: guidelines for assessment and management of cardiovascular risk. Geneva: WHO; 2007.

WHO. WORLD HEALTH ORGANIZATION. Review and updating of current WHO recommendations on salt/sodium and potassium consumption. Geneva: WHO, 2011.

WHO. WORLD HEALTH ORGANIZATION.The impact of chronic diseases in Brazil. Disponível em: <http://www.who.int/chp/chronic_disease_report/en/>. Acesso em 17 jul. 2014.

YOO, K-B. et al. Breakfast eating patterns and the metabolic syndrome: the Korea National Health and Nutrition Examination Survey (KNHANES) 2007-2009. Asia Pacific Journal of Clinical Nutrition, China, v. 23, n. 1, p. 128-137, 2014. ZUIN, P.B.; ZUIN, L.F.S. Tradição e Alimentação. Aparecida, SP: Idéias \& Letras, 2009.148p. 


\section{APÊNDICES}

APÊNDICE A - Termo de consentimento da empresa

\section{TERMO DE COMPROMISSO}

Projeto: Avaliação dos Restaurantes Populares

Coordenadoras do projeto: Prof. ${ }^{a}$ Dr. ${ }^{a}$ Raquel B. A. Botelho e Prof ${ }^{a}$ Dr $^{a}$ Rita de C. Akutsu

Da: Universidade de Brasília - UnB

Para: Empresa

AC: RESPONSÁVEL TÉCNICO

O Sr. (a) está sendo convidado a participar do projeto "Avaliação de Restaurantes Populares" da Universidade de Brasília. A sua unidade foi escolhida por sorteio dentre as unidades que compõem os Restaurantes Populares.

Para esta pesquisa serão coletados dados sobre a clientela externa (usuários) referente ao consumo alimentar do café da manhã e almoço. Todos os dados serão coletados na própria unidade através de um questionário pré-elaborado e aplicado por pesquisadores devidamente treinados e preparados para tal atividade.

As empresas interessadas em participar da pesquisa deverão assinar um termo de consentimento livre e esclarecido autorizando a coleta de dados, que inclui, por parte dos pesquisadores, a garantia de sigilo da identidade da empresa participante e dos entrevistados quanto aos resultados obtidos. O termo de consentimento livre e esclarecido possui duas vias (uma para o participante e outra para o pesquisador). Os resultados serão compilados e estruturados.

Para que os objetivos da pesquisa sejam atingidos, e sua unidade possa compor a amostra da pesquisa, é necessário o seu consentimento.

Desde já agradecemos a sua atenção e lembramos que a participação da empresa contribuirá para a produção de conhecimento sobre a segurança alimentar, segurança de alimentos e impacto ambiental em Restaurantes Populares.

Endereço: Depto de Nutrição - UnB , Brasília-DF - CEP:

Telefone: (61) Celular: (61) (telefone do responsavel pelo projeto)
Atenciosamente,
Brasília,

Dräita Akutsu/Dra Raquel Botelho

COORDENADORAS DO PROJETO 
APÊNDICE B- Termo de Consentimento Livre e Esclarecido

\section{UNIVERSIDADE DE BRASÍLIA - UnB FACULDADE DE CIÊNCIAS DA SAÚDE DEPARTAMENTO DE NUTRIÇÃO}

Projeto: Avaliação dos Restaurantes Populares

Coordenadoras do projeto: Prof. ${ }^{a}$ Dr. ${ }^{a}$ Raquel B. A. Botelho e Prof ${ }^{a} \operatorname{Dr}^{a}$ Rita de C.Akutsu

\section{TERMO DE CONSENTIMENTO LIVRE E ESCLARECIDO}

O Sr. (a) está sendo convidado a participar da pesquisa "Avaliação do Serviço de Alimentação Coletiva prestado pelos Restaurantes Populares: Diagnóstico da qualidade e atenção dietética das refeições servidas". Este projeto é de grande importância para aprofundar os conhecimentos acerca do perfil nutricional de todos os consumidores e possibilitar ações que os beneficiem. Esta pesquisa tem como objetivo principalmente avaliar a qualidade da refeição servida e estabelecer o perfil nutricional, analisando: peso, altura, hábitos alimentares e consumo.

Assine abaixo se você aceita participar de livre e espontânea vontade, no que diz respeito ao fornecimento de informações para o preenchimento dos questionários da pesquisa relacionados aos dados sociodemográficos, consumo alimentar e qualidade da refeição.

Local de de 
APÊNDICE C - Formulário de pesquisa - Dados sociodemográficos

\section{UNIVERSIDADE DE BRASÍLIA - UnB \\ FACULDADE DE CIÊNCIAS DA SAÚDE \\ DEPARTAMENTO DE NUTRIÇÃO}

Projeto: Avaliação dos Restaurantes Populares

Coordenadoras do projeto: Prof. ${ }^{a}$ Dr. ${ }^{a}$ Raquel B. A. Botelho e Prof ${ }^{a}$ Dr$^{a}$ Rita de C.Akutsu

IDENTIFICAÇÃO DA UNIDADE:

DATA:

Nome:

Sexo: ( ) Feminino ( ) Masculino

Data de nascimento:

Idade em anos:

Escolaridade:

Naturalidade:

Estado civil:

Número de pessoas da família:

Renda familiar:

Exerce alguma atividade profissional? ( ) Sim Não Se sim, qual?

Participa de algum programa de Governo: （ ) Sim Não 


\section{APÊNDICE D - LISTA DE ALIMENTOS/PREPARAÇÕES REGIONAIS DO CAFÉ DA MANHÃ}

\section{REGIÃO CENTRO-OESTE}

\section{Alimentos/Preparações}

Biscoito de polvilho

Bolinhos de polvilho

Bolo de arroz

Bolo de mandioca (Mané Pelado)

Bolo de queijo

Caldo de cana

Canjica(milho branco, leite, coco, açúcar)

Carne de sol

Carne seca

Chás

Coalhada

Cuscuz

Erva mate (Mato Grosso)

Farinha de milho

Mandioca cozida

Mel

Pamonha

Quebra-torto (sobras do jantar: arroz, feijão, carne, ovo, farinha, etc - Mato Grosso)

\section{Frutas}

Abacaxi

Abacaxi do cerrado

Abiu

Araçá

Araticum ou marolo

Ata de cobra

Banana-da-terra frita/cozida/assada

Banana verde

Baru

Bocaiúva

Buriti

Cagaita

Cajá

Caju

Cajuí

Cana de açúcar 
Caraguatá

Catolé

Coco - babão

Coco - cabeçudo

Coco-indaiá

Coroa-de-frade

Curriola

Goiaba

Grão-de-galo

Guapeva

Guariroba

Jabuticaba

Jaracatiá

Jatobá

Jenipapo

Jurubeba

Laranja

Limão

Lobeira

Maça

Macaúba

Mama-cadela

Mamãozinho-do-mato

Manga

Mangaba

Marmelada-de-cachorro

Marmelada-olho-de-boi

Melancia

Murici

Pera-do-cerrado

Pinha-de-guará

Siputá

Tarumã

Xixá

\section{REGIÃO NORDESTE}

\section{Alimentos/Preparações}

Aluá(bebida refrigerante de farinha de arroz ou de milho ou de casca de fruta)

Biscoito de cera

Biscoitos caseiros

Bolacha comum (feitas em padarias: sete capas, rainha)

Bolacha ou biscoito sorda (farinha de trigo, rapadura, cravo, canela, gengibre)

Bolinho de estudante (bolo de coco frito)

Bolinho frito

Bolo de batata doce

Bolo de carimã

Bolo de fubá 
Bolo de mandioca

Bolo de milho

Bolo de rolo

Bolo Manuê (bolo de mandioca)

Bolo tapioca (bolo de goma, bolo de puba)

Bolos salgados

Cabeça de galo (pirão de ovos pouchet, carne desfiada)

Caldo de mocotó

Canjica (milho branco, leite, coco, açúcar)

Carne com farinha

Carne de sol

Carne seca (jabá ou carne de charque)

Castanha de caju

Cuscuz de arroz ou de milho

Doce de banana

Farinha de banana

Farinha de milho

Lingüiça frita

Manteiga de garrafa

Mel

Mingau de carimã

Mingau de farinha de banana verde

Mingau de milho

Mungunzá (milho branco, leite, coco, açúcar)

Nata

Pamonha

Pão baiano

Pão bolachão

Pão carteira

Pão criolo

Pão de coco

Passaporte (pão hot dog, carne moída, salsicha, molho de tomate)

Peixe assado/frito

Peta

Pirão

Queijo coalho

Queijo manteiga

Rapadura

Requeijão do sertão (em barra)

Rosca

Tapioca

Xerém

\section{Frutas}

Abacate

Abacaxi

Abricó

Açaí(Juçara) 
Acerola

Araçá

Araticum

Azeitona roxa (sabor doce)

Babolho

Bacaba

Bacupari

Bacuri

Banana-da-terra

Banana verde

Buriti

Cacau

Cagaita

Cainito

Cajá

Cajarana

Caju

Carambola

Carnaúba

Chichiu (família do melão - Pernanbuco)

Coco

Cupuaçu

Fruta pão

Gergelim

Goiaba

Graviola

Guabiraba

Guajiru

Jabuticaba

Jaca

Jambo

Jamelão (Jambolão)

Jatobá

Jenipapo

Juá

Juçara (açai)

Laranja

Limão

Maçarambuda

Manga

Mangaba

Mangostão

Maracujá

Melancia

Melão

Murici

Noz pile

Palma

Pinha (ata, fruta conde)

Pitanga 
Pitomba

Romã

Sapotá

Sapoti

Siriguela

Taioba

Tamarindo

Tangerina

Uampi

Umbu

Uva de mesa

\section{Raízes e tubérculos}

Batata doce cozida/ frita/ assada

Cará cozido

Inhame cozido

Mandioca cozida/frita

\section{REGIÃO NORTE}

\section{Alimentos/Preparações}

Aluá(bebida refrigerante de farinha de arroz ou de milho ou de casca de fruta)

Banana frita/cozida

Bolo de mandioca

Bolo de milho/fubá

Bolo podre (tapioca, ovo, leite, manteiga, coco)

Broa de polvilho

Caldo de caridade (pirão de farinha de mandioca)

Caldo de mocotó

Canjica (curau de milho verde)

Castanha de caju

Castanha do Brasil

Cuscuz

Farinha de milho

Milho cozido

Mingau de arroz

Mingau de banana verde

Mingau de caribe

Mingau de crueira com açaí (crueira: parte grosseira da mandioca que não passa na peneira)

Mingau de fubá

Mingau de tapioca

Mungunzá (milho branco, leite, coco, açúcar)

Pamonha 
Queijo coalho

Sanduiche de Tucumã

Sopas

Tacacá

Tapioca

Frutas

Abacaxi

Abiu

Abricó

Açaí

Acerola

Ajuru

Araçá

Bacaba

Bacuri

Biribá

Buriti

Cacau

Caju

Camapu

Camu-camu

Camutin

Carambola

Castanha do Brasil

Coco

Cubiu

Cupuaçu

Cupuaí

Cupuí

Cutite

Cutitiribá

Ginja

Graviola

Grumixana

Guaraná

Inajá

Ingá-cipó

Jaca

Jambo

Jenipapo

Maçaramduba

Manga

Mangaba

Mapati

Maracujá

Marajá

Melancia 
Mucajá

Murici

Murta

Patau

Piquiá

Pitanga

Pitomba

Pupunha crua/cozida

Sapota-dos-Solimões

Sapoti

Sorvinha ou sorva

Taperebá (cajá)

Tucumã

Umari

Uxi

\section{Raízes e Tubercúlos}

Batata doce cozida/ frita/ assada

Cará roxo cozido

Inhame cozido

Mandioca cozida/frita

\section{REGIÃO SUDESTE}

\section{Alimentos/Preparações}

Banana frita com açúcar e canela (opcional: farinha de mandioca)

Biscoito cabeça de macaco (ovos e fubá)

Biscoito de angu

Biscoito de polvilho assado (Pêta)

Biscoito de polvilho frito

Biscoito de queijo assado

Biscoito escaldado

Bolacha de nata

Bolinho de farinha de arroz (loirinhas)

Bolinhos com ovos e fubá (cabeça de macaco)

Bolo de arroz

Bolo de fubá

Bolo de mandioca

Bolo de Milharina

Brevidade

Broa de amendoim

Broa de fubá/milho

Broa de inhame

Broa de melado

Caldo de cana 
Canjica(milho branco, leite, coco, açúcar)

Cubu (broa de amendoim ou de fubá)

Curau de milho verde

Cuscuz paulista

Doce de leite

Farinha de mandioca com açúcar

Farinha de milho

Geleia de frutas

Leite com farinha de milho ou farinha de mandioca e açúcar

Lingüiça calabresa

Lingüiça frita

Mexido (sobras do jantar - Minas Gerais)

Mingau de fubá

Ovo frito com farinha de milho, com ou sem açúcar

Pamonha

Pão de mandioca

Pão de queijo

Pão dourado com coco

Pão na chapa

Pastel (diversos sabores)

Pastel de angu

Queijo Canastra

Queijo de Minas Frescal

Rapadura

Requeijão em barra

Rosca

Sanduiche Bauru (pão francês, carne, tomate, queijo. Variação: presunto ou calabresa)

Sanduiche de atum

Sanduiche de frango

Sequilho

Sonho

Tapioca

\section{Frutas}

Abacate

Abacaxi

Abiu

Açaí

Amora do mato

Araçá

Araticum

Banana-da-terra

Brejaúva

Buriti

Cagaita

Cajá

Caju 
Caqui

Carambola

Cidra

Coco

Figo

Gabiroba

Goiaba

Jabuticaba

Jaca

Jambolão

Jatobá

Jenipapo

Laranja

Limão

Maça

Manga

Mangaba

Maracujá

Marmelada de cachorro ou de bezerro

Marmelo

Melancia

Morango

Pêssego

Pinha

Pinhão

Pitanga

Sapucaia

Saputi

Tamoia

Uva

\section{REGIÃO SUL}

\section{Alimentos/Preparações}

Bolo de mel

Broa de centeio

Broa de fubá

Broa de mel

Broa de trigo

Brote (pão de milho)

Canjica (milho branco, leite, coco, açúcar)

Carne de charque

Chá

Chimia

Coalhada

Copa

Cuca de amêndoas 
Cuca de frutas

Cuca de mel

Doces

Erva mate (chimarão)

Farinha de milho

Lingüiça frita

Mel

Morcilha ou morcela (embutido de sangue coagulado e arroz)

Mortadela

Nata

Pão de centeio

Pão de milho

Pé de moleque

Presunto

Requeijão (barra e cremoso)

Sagu

Salame

Salsicha

Salsichão (vermelho ou branco)

Strudel de maça

Tortas

Frutas

Ameixa

Amora

Bergamota (Tangerina)

Damasco

Feijoa

Framboesa

Jabuticaba

Laranja

Limão

Maça

Marmelo

Morango

Nectarina

Pera

Pêssego

Pinha

Pinhão

Uva

ARAÚJO, W. M. C; BOTELHO, R.B.A.; ZANDONADI, R.P.; ARAÚJO, H. M. C; GINANI, V.C. Da alimentação à gastronomia. Brasília: Editora UnB, 2005. 101p. 
BRASIL. Ministério da Saúde. Secretaria de Políticas de Saúde. Coordenação Geral da Política de Alimentação e Nutrição. Alimentos regionais brasileiros. 1. ed. Brasília: Ministério da Saúde, 2002.

CHAVES, L.G.; MENDES, P.N.R.; de BRITO, R.B.; BOTELHO, R.A.B. The national school food program as a promoter of regional food habits. Revista de Nutrição, $v$. 22. n. 6, p. 857-866, 2009.

EDITORA ABRIL. Coleção Cozinha Regional Brasileira. São Paulo, v. 1-19, 2012.

FISBERG, M.; WEHBA, J. COZZOLINO, S. M. F. Um, dois, feijão com arroz: a alimentação no Brasil de norte a sul. São Paulo: Editora Atheneu, 2002. 418 p.

GINANI, V.C. Avaliação da qualidade nutricional, sensorial e cultural de cardápios populares. 2011. 131 f. Tese (Doutorado em Nutrição Humana) Universidade de Brasília, Brasília - DF.

MASTROROSA, L. É do Brasil. In:

Pingado e pão na chapa: histórias e receitas de café da manhã. Rio de Janeiro: Memória Visual, 2010. p. 33- 49.

PHILIPPI, S.T. Nutrição e Técnica Dietética. 2aㅡㄹ edição. Editora Manole, p. 239-52, 2006.

WIKIPÉDIA. A enciclopédia livre. Disponível em: <https://pt.wikipedia.org>. Acesso em 10 fev 2012. 